\author{
UNIVERSIDADE DE SÃO PAULO \\ ESCOLA DE ENGENHARIA DE SÃO CARLOS \\ DEPARTAMENTO DE ENGENHARIA ELÉTRICA
}

AFONSO CELSO TURCATO

Desenvolvimento de uma metodologia baseada em redes neurais artificiais para identificação de anomalias em redes de comunicação Profinet 



\section{Desenvolvimento de uma metodologia baseada em redes neurais artificiais para identificação de anomalias em redes de comunicação Profinet}

Dissertação apresentada à Escola de Engenharia de São Carlos da Universidade de São Paulo, como parte dos requisitos para obtenção do título de Mestre em Ciências pelo Programa de Engenharia Elétrica.

Área de Concentração: Sistemas Dinâmicos

Orientador: Prof. Dr. Rogério Andrade Flauzino

\section{São Carlos \\ 2015}

Trata-se da versão corrigida da dissertação. A versão original se encontra disponível na EESC/USP que aloja o Programa de Pós Graduação de Engenharia Elétrica. 


\section{AUTORIZO A REPRODUÇÃO TOTAL OU PARCIAL DESTE TRABALHO, POR QUALQUER MEIO CONVENCIONAL OU ELETRÔNICO, PARA FINS DE ESTUDO E PESQUISA, DESDE QUE CITADA A FONTE.}

Turcato, Afonso Celso

Desenvolvimento de uma metodologia baseada em redes neurais artificiais para identificaçăo de anomalias em redes de comunicação Profinet / Afonso Celso Turcato; orientador Rogério Andrade Flauzino. Săo Carlos, 2015.

Dissertação (Mestrado) - Programa de Pós-Graduaçăo em Engenharía Elétrica e Área de Concentraçăo em Sistemas Dinâmicos -- Escola de Engenharia de São Carlos da Universidade de Săo Paulo, 2015.

1. Identificaçăo de faltas de anomalias. 2 . Intrusão em redes de comunicação. 3. Redes neurais artificiais. 4. Profinet. 5. Redes de automaçăo. 6 . Segurança em redes de dados. I. Título. 


\section{FOLHA DE JULGAMENTO}

Candidato: Engenheiro AFONSO CELSO TURCATO.

Título da dissertação: "Desenvolvimento de uma metodologia baseada em redes neurais artificiais para a identificação de anomalias em redes de comunicação Profinet".

Data da defesa: 25/06/2015

Comissão Julgadora:

Resultado:

Prof. Associado Rogério Andrade Flauzino (Orientador)

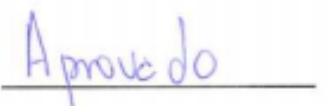

(Escola de Engenharia de São Carlos/EESC)

Prof. Dr. Karl Heinz Kienitz

APBVASD

(Instituto Tecnológico de Aeronáutica/ITA)

Prof. Dr. Josué Silva de Morais

(Universidade Federal de Uberlândia/UFU)

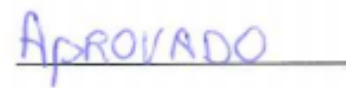

Coordenador do Programa de Pós-Graduação em Engenharia Elétrica:

Prof. Associado Luis Fernando Costa Alberto

Presidente da Comissão de Pós-Graduação:

Prof. Associado Paulo César Lima Segantine 



\section{Dedicatória}

Dedico este trabalho aos meus pais, Antônio e Inês, pelo exemplo de persistência e garra frente às adversidades da vida. Dedico também, com carinho e estima à minha esposa Cintia pelo constante incentivo e compreensão da importância deste trabalho e, em especial, ao meu filho João Henrique, presente de Deus e minha maior alegria. 



\section{Agradecimentos}

Agradeço primeiramente a Deus por me dar forças para a realização deste trabalho.

Agradeço a toda a minha família em especial aos meus pais e irmãos Daniel e Andréia, a minha esposa Cintia, por todo apoio necessário para que eu alcançasse meus objetivos.

Ao meu orientador Prof. Dr. Rogério Andrade Flauzino pela confiança, apoio e orientação por toda a jornada de estudos na confecção deste trabalho.

Ao professor Dr. Dennis Brandão pelo incentivo, recomendações e por permitir o desenvolvimento deste trabalho nas instalações do Laboratório de Automação Industrial.

Ao professor Dr. Ivan Nunes Silva pelos valiosos ensinamentos transmitidos.

À Universidade de São Paulo por disponibilizar os recursos necessários para o desenvolvimento deste trabalho.

Ao Programa de Pós-Graduação em Engenharia Elétrica da EESC, pela minha aceitação como pesquisador.

Aos antigos companheiros de trabalho da empresa Smar Equipamentos Industriais, mais especificamente ao pessoal da Engenharia de Projetos e Sistemas, em especial ao amigo Josué Morais pelo incessante incentivo aos meus estudos.

Aos amigos Luis Ferracini, Renato Fernandes e Renato Veiga pelas inúmeras conversas, experiências e aprendizado adquiridos juntos.

Ao amigo Guilherme Sestito pela enorme contribuição para a conclusão deste trabalho, pelo esforço dedicado aos artigos científicos, pela amizade e pelas longas conversas.

Aos professores da área de Automação do Instituto Federal de Educação, Ciência e Tecnologia de São Paulo campus Sertãozinho pelo incentivo a pós-graduação. 

Tu te tornas eternamente responsável por aquilo que cativas.

Antoine de Saint-Exupéry 



\section{Resumo}

TURCATO, A. C. (2015). Desenvolvimento de uma metodologia baseada em redes neurais artificiais para identificação de anomalias em redes de comunicação Profinet. Dissertação (Mestrado) - Escola de Engenharia de São Carlos, Universidade de São Paulo, São Carlos, 2015.

Este trabalho propôs o desenvolvimento e a avaliação de uma metodologia com o propósito de identificar anomalias em redes de comunicação Profinet, muito utilizadas na automação de plantas industriais. A metodologia desenvolvida está fundamentada na análise das características de comunicação do protocolo Profinet e na identificação e classificação de padrões, sendo esta, uma das principais aplicações do uso de Redes Neurais Artificiais (RNA). As anomalias são identificadas por meio da análise do tráfego de rede Profinet em sua fase de operação. Tais anomalias podem ser desde defeitos comuns apresentados pelos equipamentos da rede e/ou tentativas de ataques a esta, que por sua vez, podem gerar instabilidade e mau funcionamento da unidade industrial que fazem parte. Para o desenvolvimento deste trabalho foram apresentados: $o$ detalhamento do protocolo Profinet, os mecanismos de segurança mais utilizados atualmente, os tipos de sistemas de detecção de anomalias existentes e os principais tipos de ataques em redes de comunicação conhecidos na literatura. Alguns ensaios para a validação da metodologia foram realizados, utilizando-se uma infraestrutura de rede instalada em laboratório. Ensaios com diferentes tipos de equipamentos interligados em rede foram realizados e os resultados apresentados. Como resultado final, demonstrouse que a metodologia utilizada obteve êxito na identificação da presença ou ausência de anomalias na rede, sendo que os resultados obtidos podem ser considerados satisfatórios e condizentes às expectativas desta dissertação. Concluiu-se então que a metodologia apresentada é factível e aplicável no meio industrial, podendo ser incorporada a uma ferramenta mais abrangente, como os analisadores de redes Profinet.

Palavras chaves: Identificação de faltas e anomalias, Intrusão em redes de comunicação, Redes neurais artificiais, Profinet, Redes de automação, Segurança de redes de dados. 



\section{Abstract}

TURCATO, A. C. (2015). Development of a methodology based on artificial neural networks to identify abnormalities in Profinet communication networks. Dissertação (Mestrado) - Escola de Engenharia de São Carlos, Universidade de São Paulo, São Carlos, 2015.

This work proposed the development and evaluation of a methodology in order to identify anomalies in Profinet communication networks, widely used in the automation of industrial plants. The methodology is based on an analysis of the communication features of the Profinet protocol and identifying and pattern classification, which is one of the main applications of the use of Artificial Neural Networks (ANN). The anomalies are identified by analyzing the Profinet network traffic in its operation phase. Such anomalies can be provided by common defects in equipment in the network and / or attempted attacks to this, which in turn can cause instability and malfunction of the plant forming part. In development of this work were presented: the details of the Profinet protocol, the security mechanisms most widely used, the types of anomalies detection systems and the main types of attacks on communication networks known in the literature. Some assays to validate the method were performed, using a network infrastructure installed in the laboratory. Tests with different types of networked equipment were performed and the results presented. The final result showed that the methodology was successful in identifying the presence or absence of anomalies in the network, and the obtained results can be considered satisfactory and consistent with expectations of this paper. It was therefore concluded that this methodology is feasible and applicable in industrial environment and can be incorporated into a more comprehensive tool, such as analyzers Profinet networks.

Keywords: Faults and anomalies identification, Intrusion in communication networks, Artificial neural networks, Profinet, Automation networks, Data network security. 



\section{Lista de Figuras}

Figura 1: Produção científica nas últimas décadas...................................................................... 7

Figura 2: Número de nós por protocolo baseado em RTE no mundo......................................... 14

Figura 3: Representação da versão CBA do protocolo Profinet.................................................. 15

Figura 4: Interações entre IO-Controller, IO-Device e IO-Supervisor. ....................................... 16

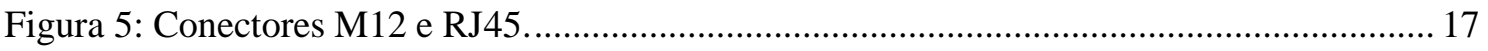

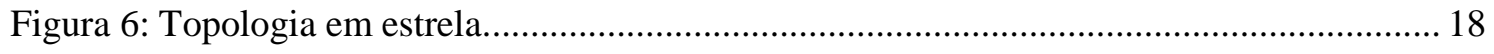

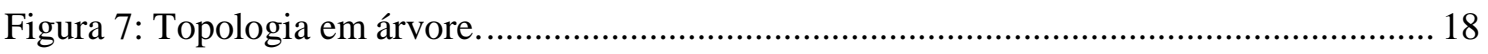

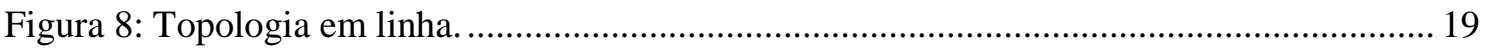

Figura 9: Modelo do funcionamento do swtich "Store \& Forward" ............................................. 20

Figura 10: Modelo de funcionamento do switch "Cut-Through" ............................................... 20

Figura 11: Exemplo de espelhamento de porta em uma rede Profinet........................................ 21

Figura 12: Pilha de comunicação Profinet baseado no modelo OSI. ......................................... 22

Figura 13: Dinâmica de troca de dados na comunicação RT...................................................... 24

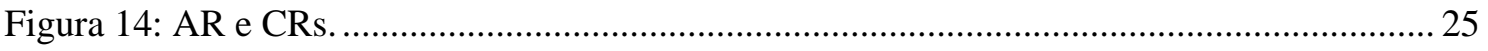

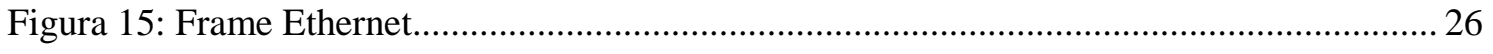

Figura 16: Princípio de funcionamento do Black Channel ........................................................... 39

Figura 17: Ciclo do modelo de procedimento......................................................................... 41

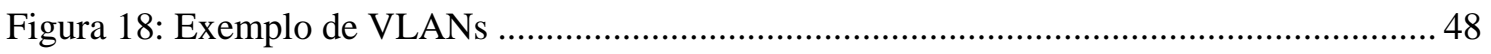

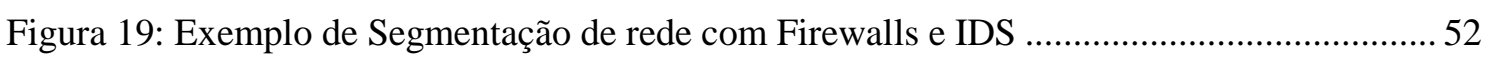

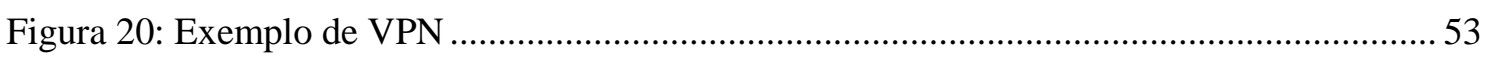

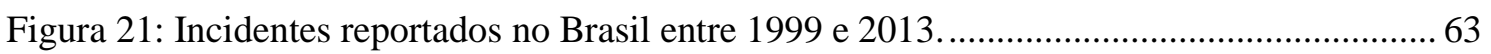

Figura 22: Ataques reportados no Brasil entre Janeiro e Dezembro de 2013 .............................. 68

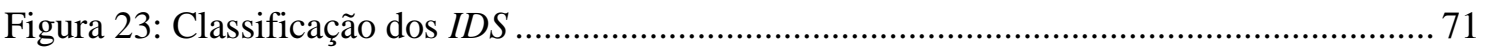

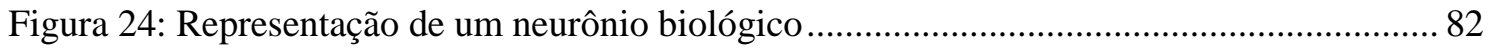

Figura 25: Representação de um neurônio artificial ................................................................... 83

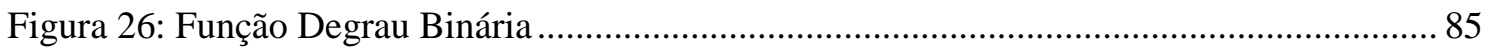

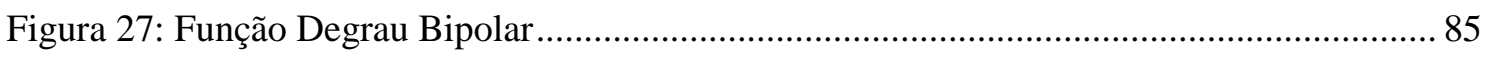

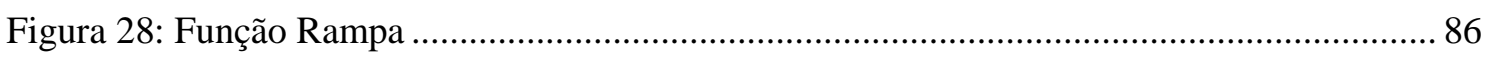

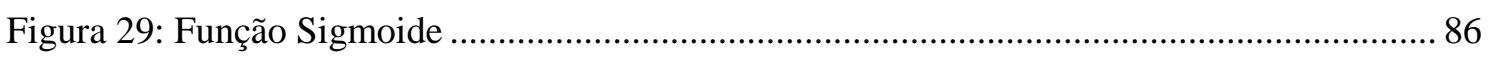

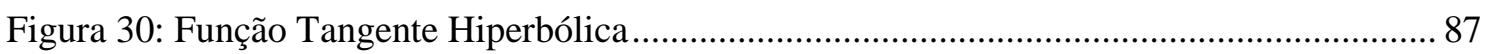

Figura 31: Representação das camadas de uma rede neural artificial.......................................... 88

Figura 32: Representação de uma rede FeedForward (camada única)....................................... 89

Figura 33: Representação de uma rede FeedForward (multicamadas)......................................... 89

Figura 34: Representação de uma rede recorrente. ……............................................................ 90

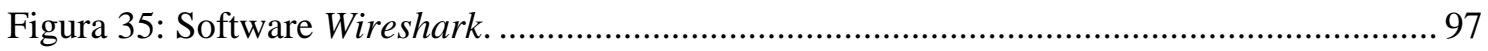


Figura 36: Configuração da rede Profinet no software TIA Portal. 99

Figura 37: Exemplo de captura de pacotes com espelhamento de porta no switch. 100

Figura 38: Interligação dos equipamentos para a captura. 100

Figura 39: Interligação dos equipamentos no Cenário 1. 102

Figura 40: Interligação dos equipamentos no Cenário 2. 103

Figura 41: Interligação dos equipamentos no Cenário 3. 103

Figura 42: Interligação dos equipamentos no Cenário 4. 104

Figura 43: Processo de extração de atributos por meio da Janela Deslizante (estado j). 107

Figura 44: Processo de extração de atributos por meio da Janela Deslizante (estado j+1)....... 107

Figura 45: Coeficiente de Correlação (em módulo) do atributo A01 para cada $\beta$. .................... 116

Figura 46: Coeficiente de Correlação (em módulo) do atributo A02 para cada $\beta$. .................... 116

Figura 47: Coeficiente de Correlação (em módulo) do atributo A03 para cada $\beta$. .................... 117

Figura 48: Coeficiente de Correlação (em módulo) do atributo A04 para cada $\beta$. .................... 117

Figura 49: Coeficiente de Correlação (em módulo) do atributo A05 para cada $\beta$. .................... 117

Figura 50: Coeficiente de Correlação (em módulo) do atributo A06 para cada $\beta$. .................... 118

Figura 51: Coeficiente de Correlação (em módulo) do atributo A07 para cada $\beta$. .................... 118

Figura 52: Coeficiente de Correlação (em módulo) do atributo A08 para cada $\beta$.................... 118

Figura 53: Coeficiente de Correlação (em módulo) do atributo A09 para cada $\beta$. .................... 119

Figura 54: Coeficiente de Correlação (em módulo) do atributo A10 para cada $\beta$. .................... 119

Figura 55: Coeficiente de Correlação (em módulo) do atributo A11 para cada $\beta$.................... 119

Figura 56: Coeficiente de Correlação (em módulo) do atributo A12 para cada $\beta$. ................... 120

Figura 57: Coeficiente de Correlação (em módulo) do atributo A13 para cada $\beta$. .................... 120

Figura 58: Coeficiente de Correlação (em módulo) do atributo A14 para cada $\beta$..................... 120

Figura 59: Coeficiente de Correlação (em módulo) do atributo A15 para cada $\beta$. ................... 121

Figura 60: Coeficiente de Correlação (em módulo) do atributo A16 para cada $\beta$. .................... 121

Figura 61: Coeficiente de Correlação (em módulo) do atributo A17 para cada $\beta$. ................... 121

Figura 62: Coeficiente de Correlação (em módulo) do atributo A18 para cada $\beta$. .................... 122

Figura 63: Coeficiente de Correlação (em módulo) do atributo A19 para cada $\beta$. ..................... 122

Figura 64: Coeficiente de Correlação (em módulo) do atributo A20 para cada $\beta$. ................... 122

Figura 65: Valor médio dos módulos dos Coeficientes de Correlação com a saída para cada $\beta$.

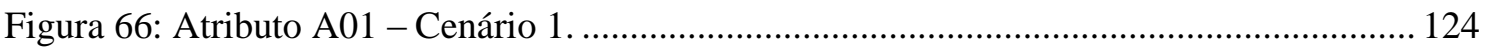

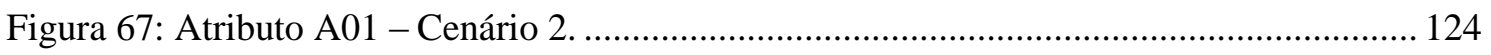

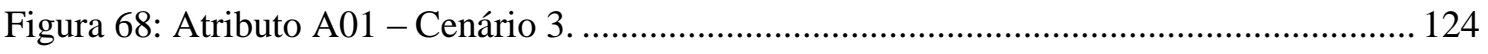

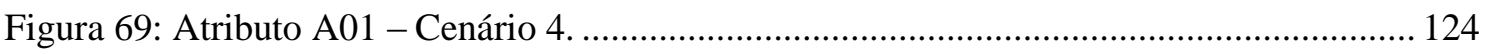




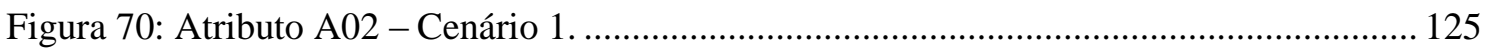

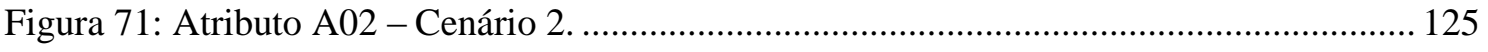

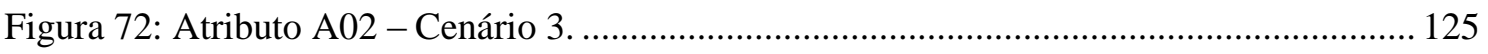

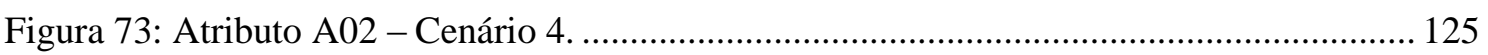

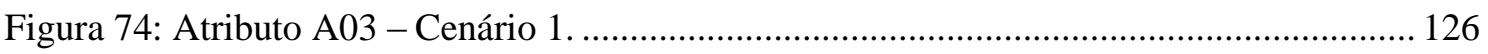

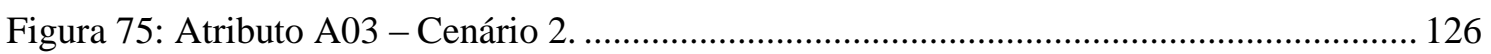

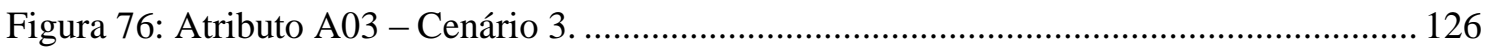

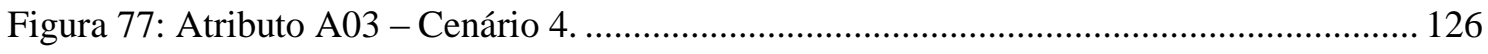

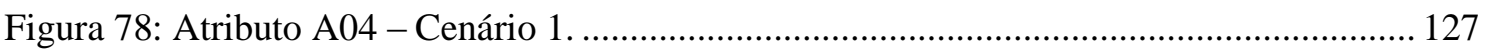

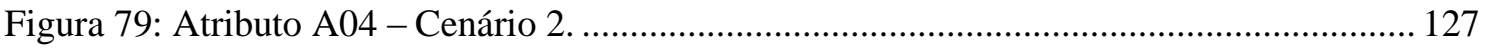

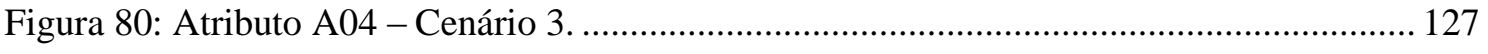

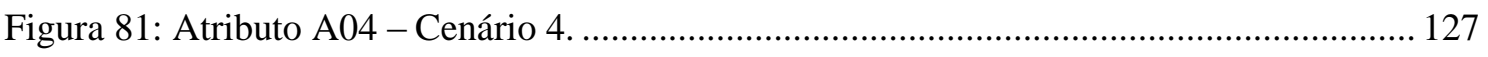

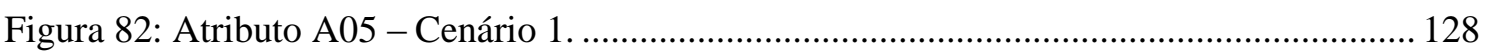

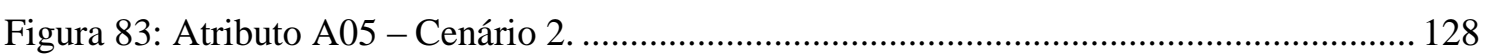

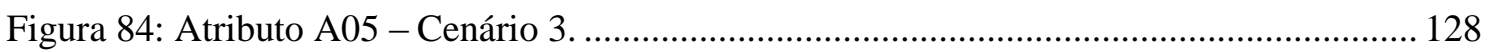

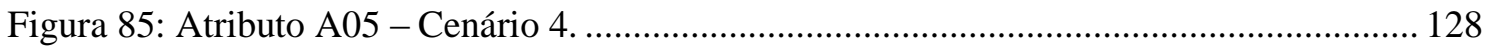

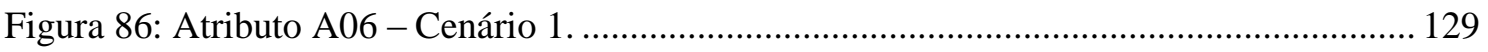

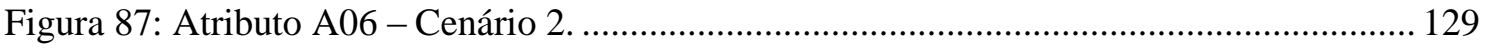

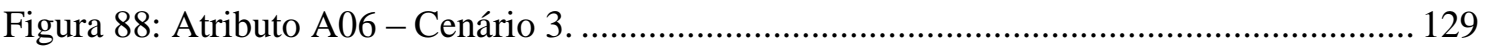

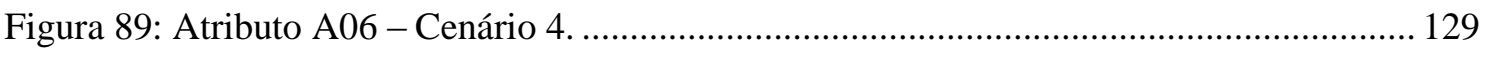

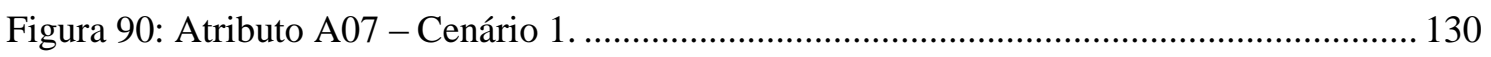

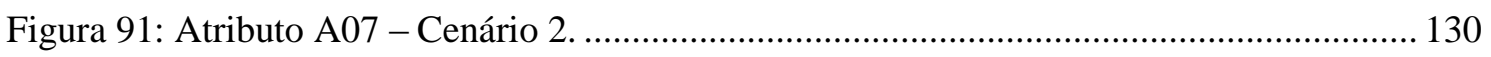

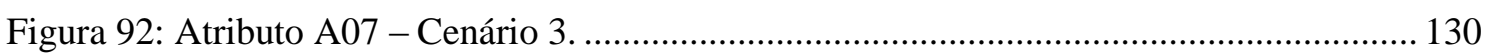

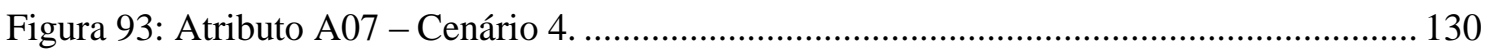

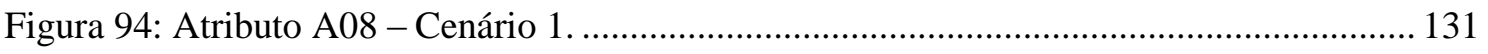

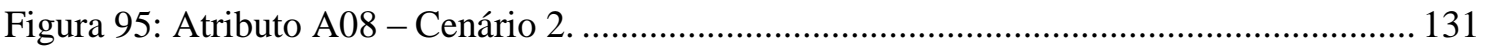

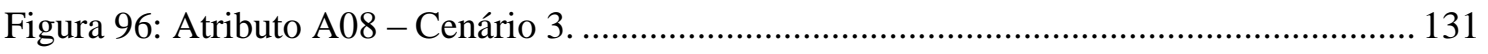

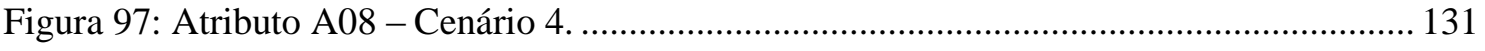

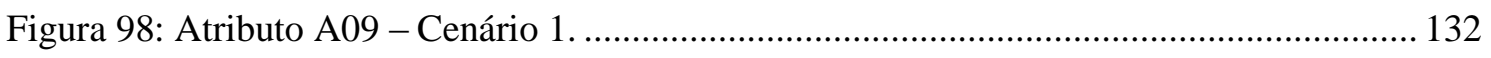

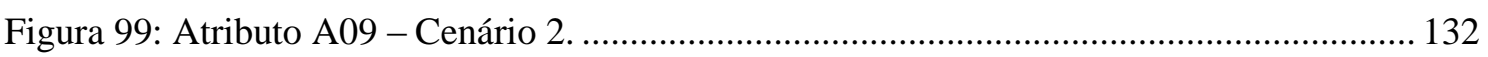

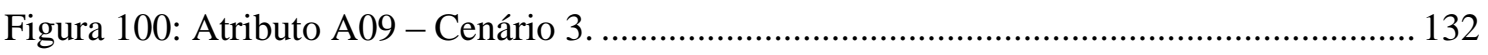

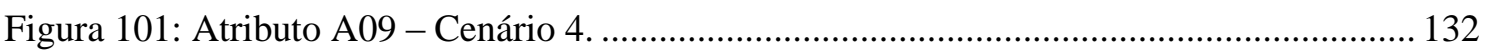

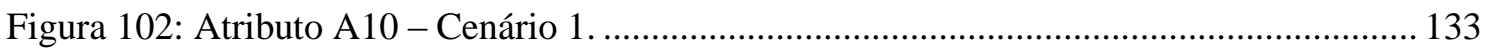

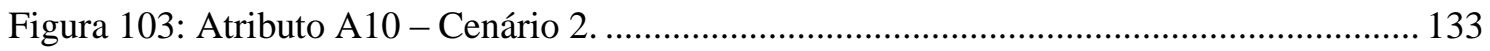

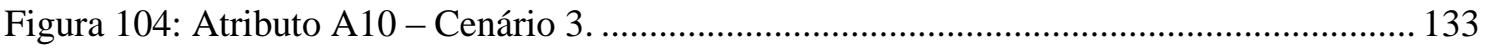

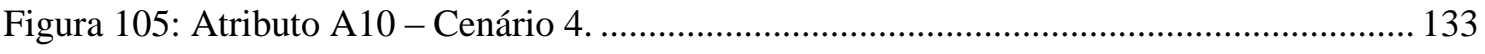

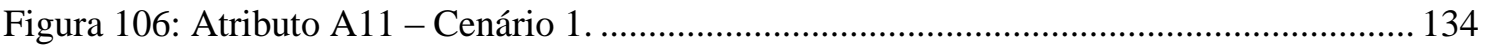


Figura 107: Atributo A11 - Cenário 2. 134

Figura 108: Atributo A11 - Cenário 3. 134

Figura 109: Atributo A11 - Cenário 4. 134

Figura 110: Atributo A12 - Cenário 1. 135

Figura 111: Atributo A12 - Cenário 2. 135

Figura 112: Atributo A12 - Cenário 3. 135

Figura 113: Atributo A12 - Cenário 4. 135

Figura 114: Atributo A13 - Cenário 1. 136

Figura 115: Atributo A13 - Cenário 2. 136

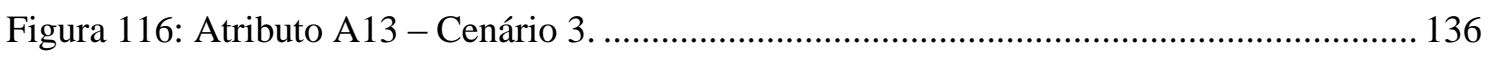

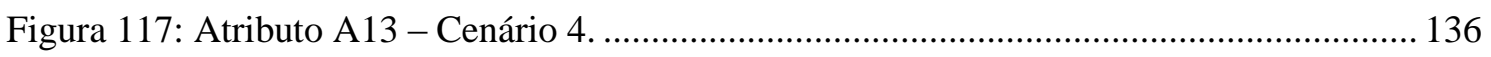

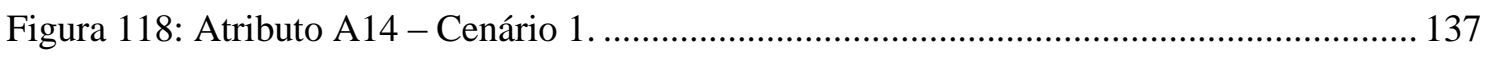

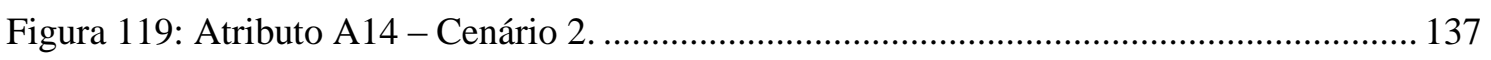

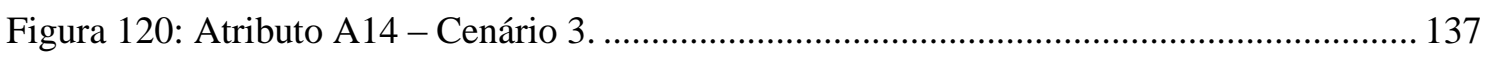

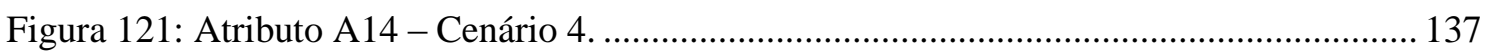

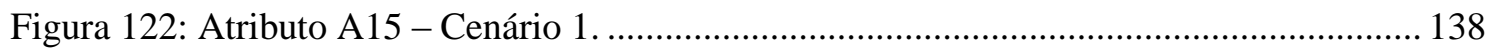

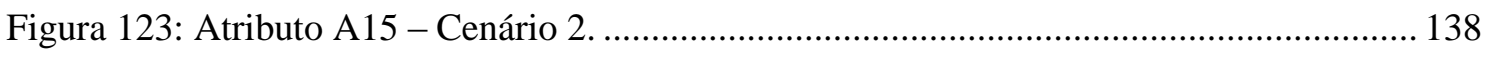

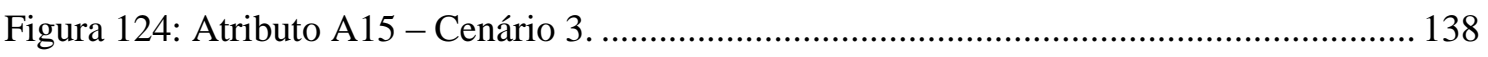

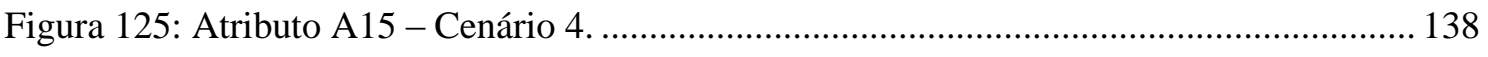

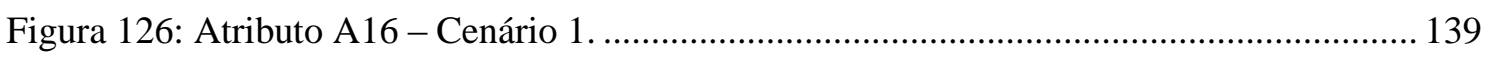

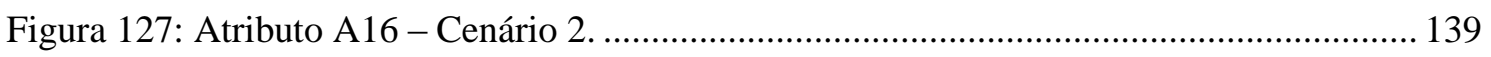

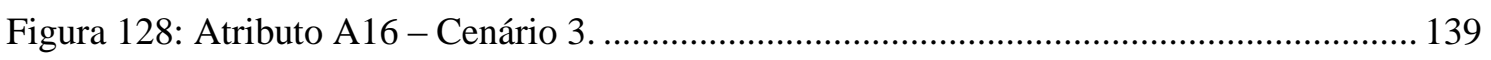

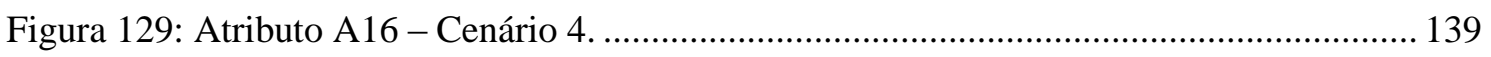

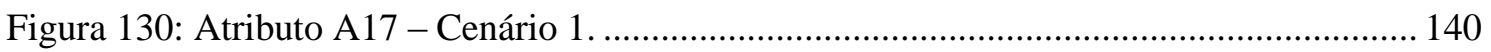

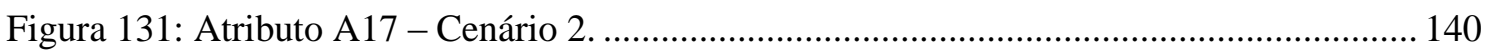

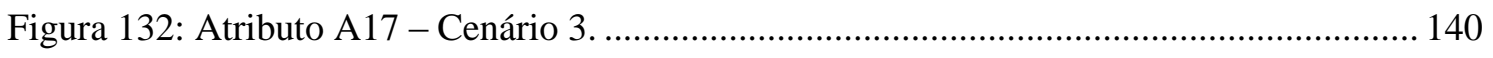

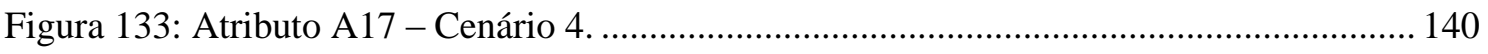

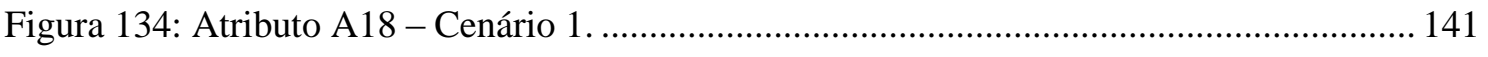

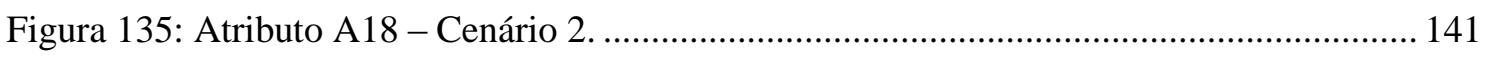

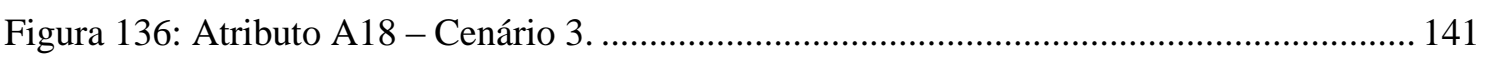

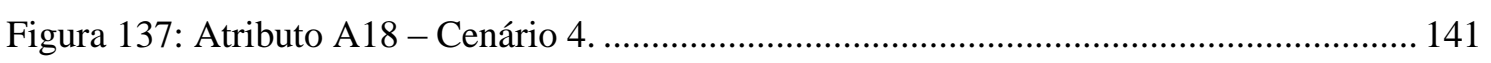

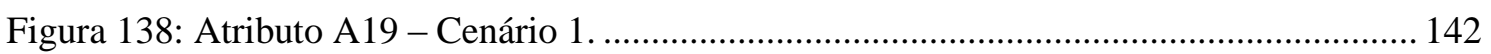

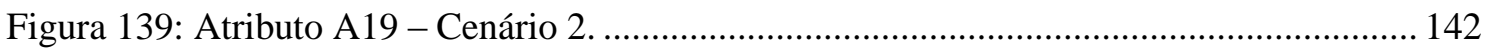

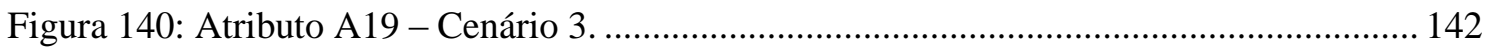

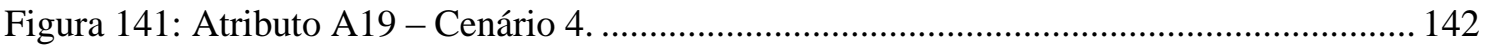

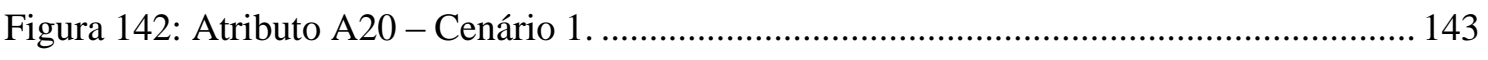

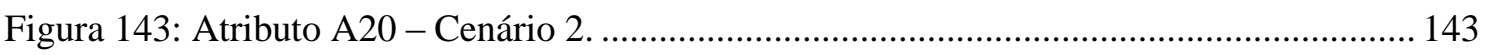


Figura 144: Atributo A20 - Cenário 3.

Figura 145: Atributo A20-Cenário 4.

Figura 146: Coeficiente de correlação de cada atributo com a saída (A01 - A10) .................... 146

Figura 147: Coeficiente de correlação de cada atributo com a saída (A11 - A20) .................... 146

Figura 148: Valor dos Coeficientes de Correlação para todos os cenários. ............................... 147

Figura 149: Coeficiente de Correlação Cruzada do atributo A01 .............................................. 148

Figura 150: Coeficiente de Correlação Cruzada do atributo A02 ............................................. 149

Figura 151: Coeficiente de Correlação Cruzada do atributo A04 ................................................ 149

Figura 152: Coeficiente de Correlação Cruzada do atributo A05.............................................. 149

Figura 153: Coeficiente de Correlação Cruzada do atributo A06............................................ 150

Figura 154: Coeficiente de Correlação Cruzada do atributo A08. .............................................. 150

Figura 155: Coeficiente de Correlação Cruzada do atributo A14 ............................................ 150

Figura 156: Coeficiente de Correlação Cruzada do atributo A17 ............................................... 151

Figura 157: Coeficiente de Correlação Cruzada do atributo A19 .............................................. 151

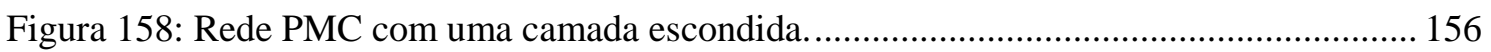

Figura 159: Rede PMC com duas camadas escondidas. ............................................................ 157

Figura 160: Rede PMC com 20 neurônios na camada escondida............................................... 159 



\section{Lista de Tabelas}

Tabela 1: Produção científica (critério Deteç̧ão de Ataques em Redes)....................................... 5

Tabela 2: Produção científica (critério Detecção de Ataques em Redes Industriais)..................... 5

Tabela 3: Produção científica (critério Ataques em Redes) ........................................................ 6

Tabela 4: Produção científica (critério Ataques em Redes Industriais) .......................................... 6

Tabela 5: Produção científica (critério Segurança em Redes Industriais) ....................................... 6

Tabela 6: Produção científica nas últimas décadas (sumário)...................................................... 8

Tabela 7: Comparação entre os canais de comunicação Profinet................................................... 25

Tabela 8: Protocolos típicos em uma rede Profinet...................................................................... 27

Tabela 9: Faixas de valores do Frame ID e os protocolos correspondentes.................................. 28

Tabela 10: Equipamentos utilizados durante os testes em laboratório......................................... 98

Tabela 11: Softwares utilizados durante os testes em laboratório............................................... 98

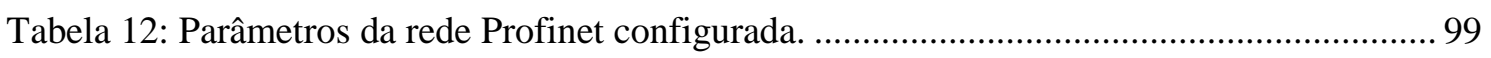

Tabela 13: Parâmetros de rede dos equipamentos envolvidos na captura................................... 101

Tabela 14: Exemplo de informações extraídas de cada pacote .................................................. 105

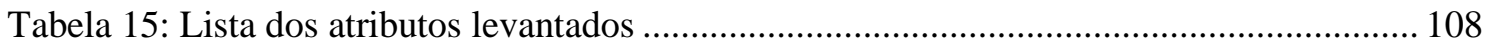

Tabela 16: Coeficiente de Correlação (em módulo) dos atributos A01 a A10 com a saída para cada $\beta$.

Tabela 17: Coeficiente de Correlação (em módulo) dos atributos A11 a A20 com a saída para cada $\beta$.

Tabela 18: Valor médio dos módulos dos Coeficientes de Correlação com a saída para cada $\beta$.

Tabela 19: Coeficiente de correlação de cada atributo com a saída.......................................... 145

Tabela 20: Valor dos Coeficientes de Correlação para todos os cenários.................................. 147

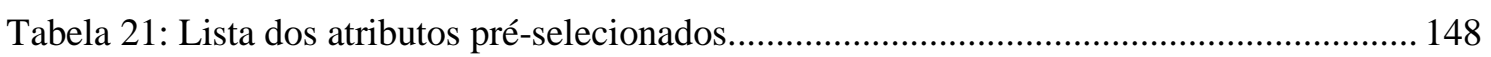

Tabela 22: Correlação Cruzada dos atributos pré-selecionados para todos os cenários. ........... 148

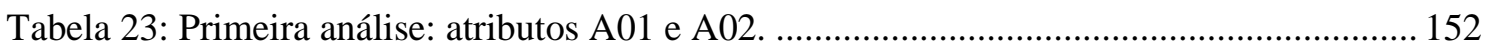

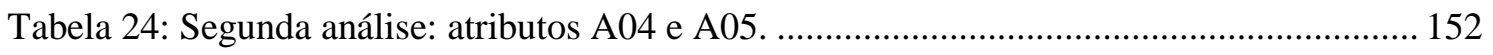

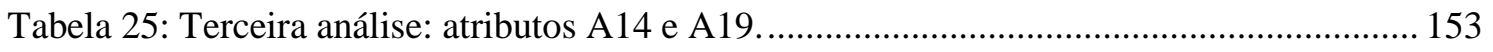

Tabela 26: Resultado final: atributos restantes A02, A05, A06, A08, A17 e A19.................... 153

Tabela 27: Relação dos atributos eleitos como parâmetros no processo de identificação de

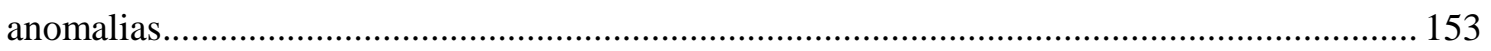

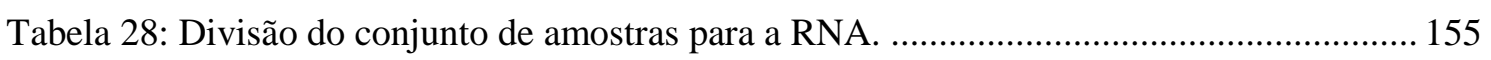

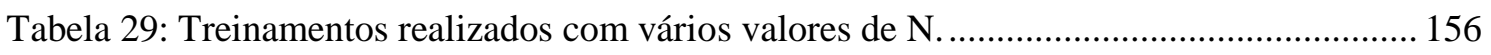

Tabela 30: Treinamentos realizados com vários valores de N.................................................. 157

Tabela 31: Valores Médios de EP para diversas redes considerando os três treinamentos........ 158 


\section{Sumário}

\section{Capítulo 1}

Introdução à Dissertação de Mestrado ............................................................. 1

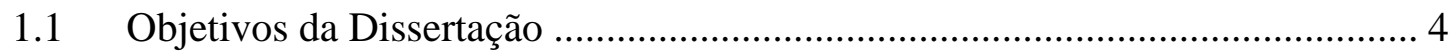

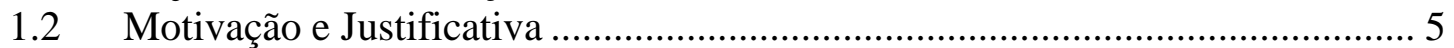

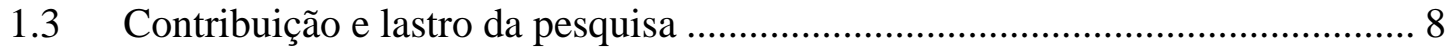

1.4 Organização da Dissertação de Mestrado ......................................................... 9

\section{Capítulo 2}

Protocolos Real Time Ethernet e estrutura do protocolo Profinet.........11

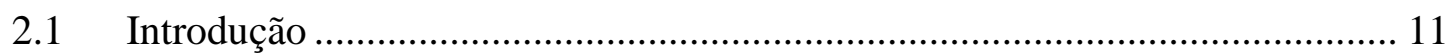

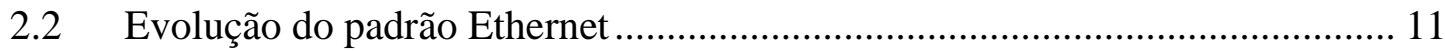

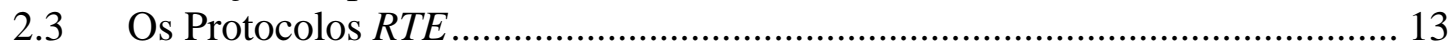

2.4 Principais aspectos do protocolo Profinet...................................................... 14

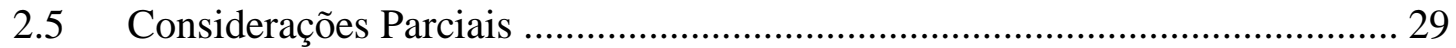

\section{Capítulo 3}

Segurança em redes Profinet.............................................................................31

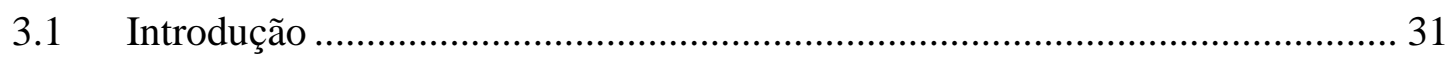

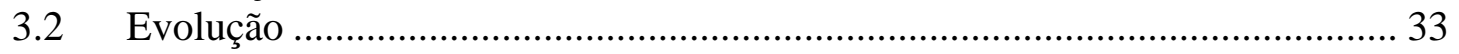

3.3 Desafios no mundo da Automação …….................................................... 35

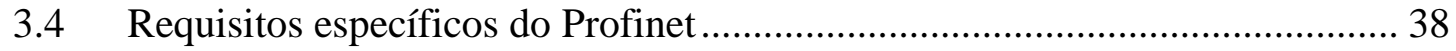

3.5 Processo de gestão de Segurança ............................................................... 41

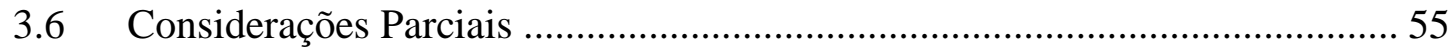

\section{Capítulo 4}

Ataques em redes Ethernet ......................................................................57

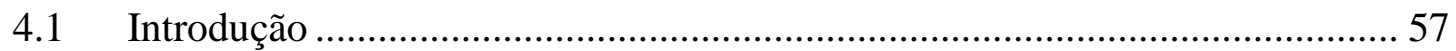

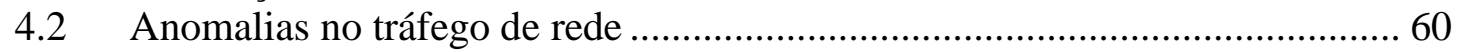

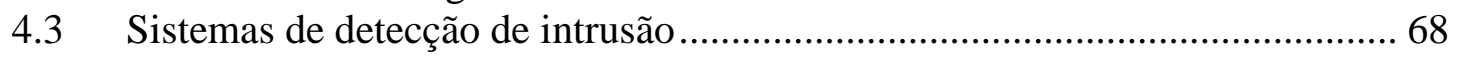

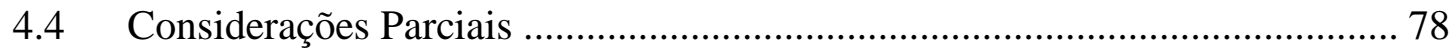

\section{Capítulo 5}

Fundamentos de Redes Neurais Artificiais....................................................79

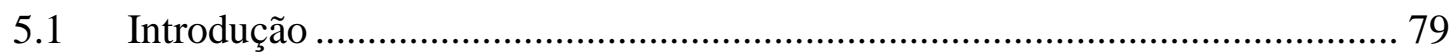

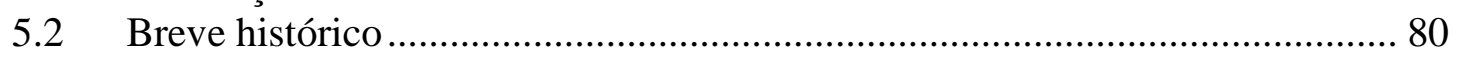

5.3 Relação entre neurônio biológico e neurônio artificial.................................. 81

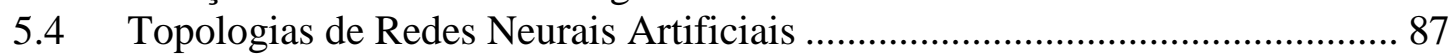

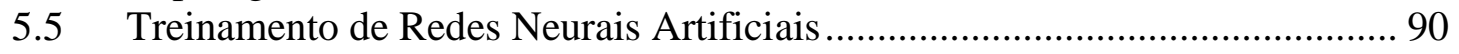

5.6 Redes Perceptron Multicamadas (PMC) .................................................... 92

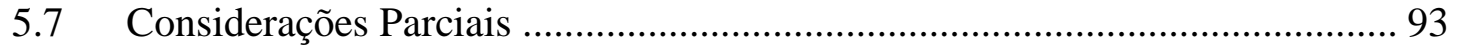




\section{Capítulo 6}

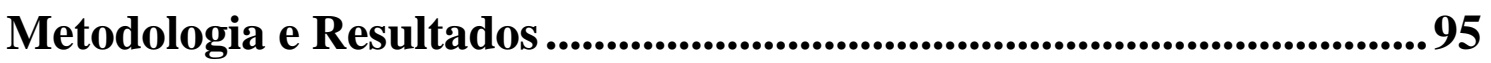

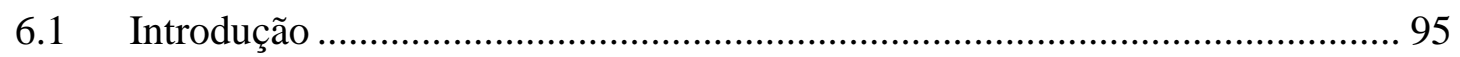

6.2 Coleta de dados do tráfego da rede ............................................................... 95

6.3 Extração dos atributos pertinentes do tráfego da rede ...................................... 105

6.4 Análise e seleção dos principais atributos .................................................... 144

6.5 Preparação dos dados para o treinamento das RNAs...................................... 153

6.6 Treinamento das RNAs........................................................................ 155

6.7 Análise dos resultados ......................................................................... 158

\section{Capítulo 7}

Conclusões Gerais e Trabalhos Futuros ..............................................161

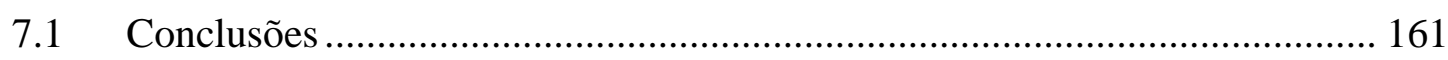

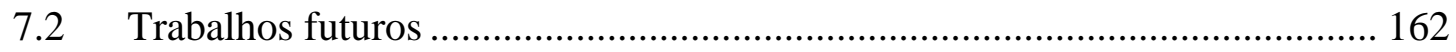

Referências Bibliográficas ..................................................................165

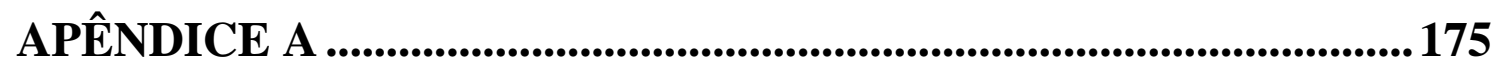




\section{Capítulo 1}

\section{Introdução à Dissertação de Mestrado}

O protocolo de comunicação Ethernet é dominante em ambientes de escritórios por ter a instalação fácil e manutenção relativamente barata, além de possuir alta taxa de transmissão de dados quando comparado a outros protocolos existentes. Ele surgiu em 1970, mas somente em 1983 que o primeiro padrão IEEE 802.3 foi publicado (MOYNE; TILBURY, 2007).

Diversos fabricantes de equipamentos industriais tentaram utilizar o padrão Ethernet original em plantas industriais. Porém, por não possuir imunidade a ruídos, conectores adequados e redundância na transmissão de dados, na época ele foi considerado inapropriado para o meio industrial (KLEINES et al., 2007).

Uma das principais características desejadas nos protocolos para uso no meio industrial é o determinismo, o qual consiste em existir um tempo máximo em que se garante que a informação chegue íntegra ao seu destino. No protocolo Ethernet original, todas as estações compartilham o mesmo meio físico. Quando uma estação vai iniciar uma transmissão, é necessário que ela verifique previamente se o meio (cabo) está livre. Caso ocorram transmissões simultâneas, haverá colisões de dados que então, serão tratadas pelo mecanismo de controle de acesso ao meio CSMA/CD (Carrier Sense Multiple Access with Collision Detection) que acarreta na inexistência de qualquer nível de determinismo (TANENBAUM, 2003).

Com isso, o protocolo Ethernet sofreu modificações em hardware e software para cumprir as exigências feitas pelas indústrias, tais como determinismo, comunicação em tempo real, confiabilidade e robustez. Assim, a partir destas modificações, começaram a surgir os chamados Real Time Ethernet (RTE) (DECOTIGNIE, 2005).

Atualmente, as redes Ethernet também podem ser utilizadas nos níveis mais baixos de automação de fábricas, no chamado chão-de-fábrica (FERRARI; FLAMMINI; VITTURI, 2005). Vários fabricantes desenvolveram suas próprias soluções baseadas no RTE, por exemplo: o protocolo Ethernet/IP foi desenvolvido pela empresa norte-americana Allen Bradley, o Modbus TCP/IP pela francesa Schneider Electric, o EtherCAT pela alemã Beckhoff e o Profinet pela também empresa alemã Siemens (KLEINES et al., 2007). Muitas dessas soluções foram incluídas nas normas 
IEC 61784 (INTERNATIONAL ELECTROTECHNICAL COMISSION, 2010) e IEC 61158 (INTERNATIONAL ELECTROTECHNICAL COMISSION, 2014). Nestas normas estão definidos alguns protocolos especificamente projetados para substituirem as tecnologias de redes de campo tradicionais (fieldbus).

A existência de várias soluções gera uma segmentação no mercado e como consequência, poucos protocolos acabam se destacando, sendo que, a grande maioria mantém-se como soluções proprietárias restritas aos seus próprios fabricantes (KLEINES et al., 2007). Algumas pesquisas de mercado realizadas no âmbito mundial, e apresentadas nesta dissertação (Seção 2.3), mostram que o protocolo Profinet possui posição de destaque no mercado mundial.

Contudo, conforme mencionado anteriormente, as redes Ethernet têm se tornado parte crítica da infraestrutura nos sistemas de controle de processos onde ocorrem trocas de informações cruciais via rede de dados (LINDA; VOLLMER; MANIC, 2009). Essa infraestrutura crítica, que cada vez mais está focada em segurança, pode ser encontrada em sistemas tipo SCADA (Supervisory Control And Data Acquisition) e em plantas nucleares (YANG; USYNIN; HINES, 2006) (KIM et al., 2000). O comprometimento destes sistemas pode não somente levar a grandes perdas financeiras, mas também, colocar em perigo a segurança pública. Desta forma, fica evidente a necessidade de proteção destas infraestruturas críticas frente a possíveis anomalias.

Uma anomalia, no contexto de redes de comunicação, pode ser definida como qualquer desvio ocorrido em relação ao comportamento normal e que, na maioria dos casos, foi criada com a intenção de comprometer ou causar o mau funcionamento do sistema. Algumas anomalias podem ser tentativas de invasão por parte de entidades não autorizadas (e.g. hackers) para terem acesso a informações confidenciais ou então, para comprometer o funcionamento do sistema.

Já os Sistemas de Detecção de Intrusão (IDS - Intrusion Detection System) têm como objetivo rastrear e identificar alguma atividade imprópria, ilegal ou anômala na rede (DENNING, 1987). Esses sistemas existem desde que o primeiro modelo foi proposto nos anos 80 (ANDERSON, 1980).

As tecnologias de detecção de intrusão são utilizadas para viabilizar a observação de conjuntos de dados de rede, em busca de ameaças potenciais ou conhecidas no tráfego de rede (Network Intrusion Detection System - NIDS) e/ou nos dados de 
auditoria registrados nos hosts ${ }^{l}$ (Host Intrusion Detection System - HIDS) (NORTHCUTT; NOVAK, 2002).

Em termos gerais, existem dois tipos de $I D S$, os baseados em assinaturas e os baseados em anomalias (ZHONG; KHOSHGOFTAAR; SELIYA, 2007).

Para que os sistemas baseados em assinatura funcionem, é necessária uma base de dados que contenha todas as assinaturas dos casos de intrusões já conhecidas e identificadas. Assim, cada situação pode ser identificada como uma intrusão ou não. Este tipo de sistema é muito eficiente no reconhecimento de ataques que já tenham suas assinaturas identificadas anteriormente, porém, tem como principal desvantagem a sua impossibilidade em identificar ataques inéditos, gerando assim, um elevado número de falsos negativos. Além disso, utilizam assinaturas catalogadas, em geral, em bases extensas que requerem muito trabalho e conhecimento de especialistas para serem estabelecidas e revisadas. O conhecimento sobre novos ataques só é obtido por meio da análise posterior de dados do tráfego de rede.

Em contrapartida, os sistemas baseados em anomalias buscam por desvios ocorridos em relação ao comportamento normal assimilado em sua etapa de aprendizado (RYAN; LIN; MIIKKULAINEN, 1998) (GHOSH; SCHWARTZBARD; SCHATZ, 1999). Assim, este tipo de sistema de detecção constrói um modelo representativo baseado exclusivamente em casos anteriores de comportamento normal e não assimila informações sobre as características de intrusões futuras. Desta forma, o sistema se torna capaz de identificar tipos de ataques novos que causam alguma modificação dinâmica na rede, pois estes, por sua vez, serão distintos do modelo de comportamento normal aprendido previamente. Contudo, qualquer outro comportamento normal não incluído no conjunto de treinamento gerará um falso positivo.

Neste trabalho, a abordagem de detecção baseada em anomalia foi adotada para 0 desenvolvimento de um NIDS. Utiliza-se técnicas de extração de atributos do tráfego da rede, baseada em janela deslizante que é usada para a análise off-line dos dados reais oriundos dos campos de controle (header) dos pacotes capturados de uma rede Profinet. Esta técnica permite capturar precisamente a natureza comportamental e tendências do fluxo de pacotes da rede (LINDA; VOLLMER; MANIC, 2009). Para tanto, é utilizada

\footnotetext{
${ }^{1}$ Host: é qualquer computador ou máquina conectado a uma rede. O termo geralmente se refere a um computador que utiliza as redes TCP/IP (incluindo a Internet) (Host Definition, 2005).
} 
uma RNA do tipo PMC (Perceptron Multicamadas) responsável por identificar e classificar o fluxo entre as classes 'normal' e 'anômala' (WERBOS, 1994) e (HAGAN; MENHAJ, 1994).

Além disso, é demonstrado neste trabalho que o conjunto de treinamento que, por sua vez, é formado por uma combinação entre casos normais, capturados de um fluxo real, e casos de intrusão gerados artificialmente, possibilita, com sucesso, que a rede neural tenha distinção entre os casos normais e os casos anômalos quando em fase de operação.

O desempenho do sistema é então testado apresentando-se dados inéditos à rede (dados não utilizados durante a fase de treinamento), tanto para os casos 'normais' quanto para os casos 'anômalos'.

\subsection{Objetivos da Dissertação}

Este trabalho tem como principal objetivo desenvolver e avaliar uma metodologia com o propósito de identificar anomalias no tráfego de redes Profinet. Metodologia esta baseada na aplicação de redes neurais artificiais como classificador de padrões.

Consequentemente, são apresentados estudos de casos que demonstram a possibilidade e a eficácia em se utilizar uma RNA para análise e classificação off-line do tráfego de dados de uma rede Profinet, a fim de identificar possíveis anomalias existentes. Essas anomalias podem ser desde defeitos comuns apresentados pelos equipamentos da rede ou tentativas de ataques a esta que, por sua vez, podem gerar instabilidade e mau funcionamento da unidade industrial a que pertence. Para identificar as anomalias é utilizada uma metodologia similar à utilizada no trabalho realizado em Linda et al. (2009), porém para uma rede Profinet.

Como objetivo secundário tem-se a apresentação dos principais tópicos relacionados à segurança no contexto de redes Ethernet, do protocolo Profinet, dos métodos e abordagens de segurança indicados pela Profibus International (PI) e de uma descrição acerca dos principais tipos de ataques em redes Ethernet. 


\subsection{Motivação e Justificativa}

Nos últimos anos foi possível observar um grande aumento de ataques cibernéticos a unidades fabris em todo o mundo (LYDON, 2012). Assim, são de essencial importância as pesquisas que visam contribuir para o desenvolvimento de ferramentas que vão de encontro a esses ataques a fim de identificá-los prematuramente e com isso, tornar possível a tomada de ações corretivas mais eficazes com o objetivo de eliminá-los em um menor tempo possível.

Em uma pesquisa de revisão bibliográfica, realizada em Janeiro de 2015, selecionando-se todas as bases de dados disponíveis pelo mecanismo de busca e configurando como critério de filtro as keywords: 'intrusion detection system' ou 'anomaly detection system' e 'network', foram encontrados 6086 resultados entre Artigos, Jornais, Revistas, Atas de Conferências, entre outros, no período compreendido entre 1977 e 2015 . Os resultados estão descritos na Tabela 1.

Tabela 1: Produção científica (critério Detecção de Ataques em Redes) FONTE: Adaptado de (IEEE Xplore Digital Library, 2015).

\begin{tabular}{crr} 
ANO & \multicolumn{2}{c}{ RESULTADOS } \\
\hline Até 1985 & 2 & $0,03 \%$ \\
\hline $1986-1995$ & 66 & $1,08 \%$ \\
\hline $1996-2005$ & 1185 & $19,47 \%$ \\
\hline $2006-2015$ & 4833 & $79,41 \%$ \\
\hline
\end{tabular}

Alterou-se o critério de busca com as keywords: 'intrusion detection system' ou 'anomaly detection system' e 'industrial network', foram encontrados 153 resultados no período entre 1994 e 2015. Os resultados estão descritos na Tabela 2.

Tabela 2: Produção científica (critério Detecção de Ataques em Redes Industriais) FONTE: Adaptado de (IEEE Xplore Digital Library, 2015).

\begin{tabular}{crr} 
ANO & \multicolumn{2}{c}{ RESULTADOS } \\
\hline Até 1985 & 0 & $0 \%$ \\
\hline $1986-1995$ & 5 & $3,27 \%$ \\
\hline $1996-2005$ & 21 & $13,73 \%$ \\
\hline $2006-2015$ & 127 & $83,01 \%$ \\
\hline
\end{tabular}


Alterando-se a busca com as keywords: 'intrusion' ou 'cyber attack' e 'network', foram encontrados 7841 resultados no período entre 1977 e 2015 . Os resultados estão descritos na Tabela 3.

Tabela 3: Produção científica (critério Ataques em Redes) FONTE: Adaptado de (IEEE Xplore Digital Library, 2015).

\begin{tabular}{crr} 
ANO & \multicolumn{2}{c}{ RESULTADOS } \\
\hline Até 1985 & 3 & $0,04 \%$ \\
\hline $1986-1995$ & 69 & $0,88 \%$ \\
\hline $1996-2005$ & 1480 & $18,88 \%$ \\
\hline $2006-2015$ & 6289 & $80,21 \%$ \\
\hline
\end{tabular}

Adicionalmente, quando a busca foi realizada com as keywords: 'intrusion' ou 'cyber attack' e 'industrial network', foram encontrados apenas 212 resultados no período entre 1992 e 2015. Os resultados estão descritos na Tabela 4.

Tabela 4: Produção científica (critério Ataques em Redes Industriais) FONTE: Adaptado de (IEEE Xplore Digital Library, 2015).

\begin{tabular}{crr} 
ANO & \multicolumn{2}{c}{ RESULTADOS } \\
\hline Até 1985 & 0 & $0 \%$ \\
\hline $1986-1995$ & 4 & $1,90 \%$ \\
\hline $1996-2005$ & 21 & $9,95 \%$ \\
\hline $2006-2015$ & 187 & $88,15 \%$ \\
\hline
\end{tabular}

Quando as keywords foram alteradas para: 'security' e 'industrial network', foram encontrados 1687 trabalhos publicados entre os anos 1967 e 2015. Os resultados estão descritos na Tabela 5 .

Tabela 5: Produção científica (critério Segurança em Redes Industriais) FONTE: Adaptado de (IEEE Xplore Digital Library, 2015).

\begin{tabular}{crr} 
ANO & \multicolumn{2}{c}{ RESULTADOS } \\
\hline Até 1985 & 3 & $0,18 \%$ \\
\hline $1986-1995$ & 21 & $1,24 \%$ \\
\hline $1996-2005$ & 244 & $14,46 \%$ \\
\hline $2006-2015$ & 1419 & $84,11 \%$ \\
\hline
\end{tabular}

Detalhe que merece atenção nos resultados dessas buscas é que em torno de $85 \%$ (em média) da produção científica, para cada caso supracitado, ocorreu na última década, evidenciando o aumento das atividades de pesquisas desses temas. A Figura 1 ilustra esses resultados. 
Produção Científica nas Últimas Décadas

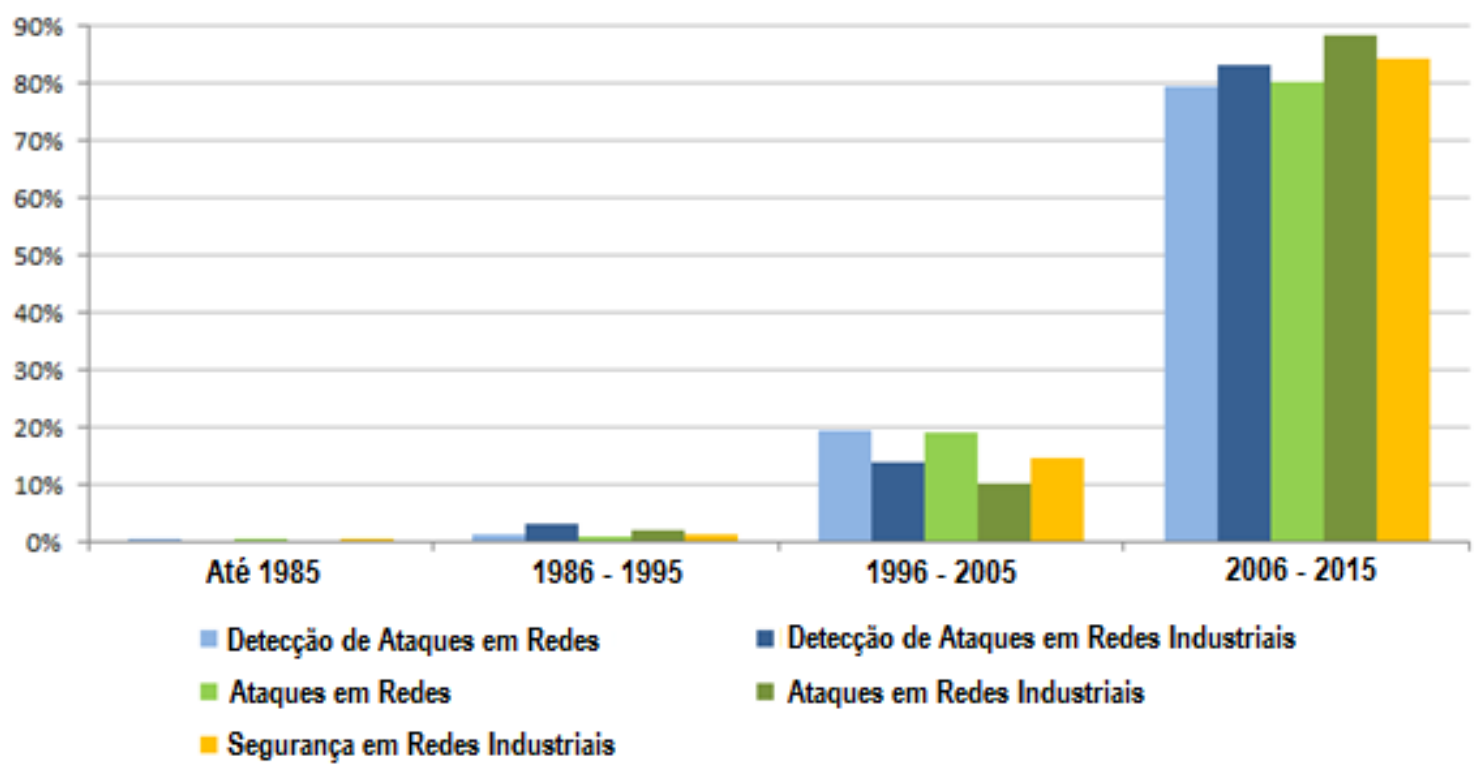

Figura 1: Produção científica nas últimas décadas.

FONTE: Baseado nos dados de (IEEE Xplore Digital Library, 2015).

Em contrapartida, quando a busca foi realizada com as keywords: 'security' e 'profinet', apenas 07 resultados foram encontrados no período compreendido entre 2006 e 2015. São eles: (RUNDE; TEBBE; NIEMANN, 2013); (SITA, 2012); (DUERKOP et al., 2012); (AKERBERG et al., 2010); (AKERBERG; BJORKMAN, 2009b), (AKERBERG; BJORKMAN, 2009c); (BAUD; FELSER, 2006).

Complementando a análise, refazendo-se a busca configurando como critério de filtro as palavras-chaves 'intrusion detection system' ou 'anomaly detection system' e 'profinet', nenhum resultado foi retornado. Alterando-se as palavras-chaves para: 'intrusion' ou 'cyber attack' e 'profinet', também nenhum resultado foi obtido.

A Tabela 6 sumariza essas informações coletadas por meio das buscas realizadas. A avaliação desses resultados indica que, nos últimos anos, tem ocorrido um aumento significativo na produção científica relacionada à segurança em redes de comunicação, inclusive em redes industriais, e no desenvolvimento de mecanismo de detecção de intrusão/anomalias nessas redes. Contudo, especificamente para redes Profinet pouco tem sido produzido. Esse fato foi aspecto de motivação para o desenvolvimento desta Dissertação. 
Tabela 6: Produção científica nas últimas décadas (sumário). FONTE: Adaptado de (IEEE Xplore Digital Library, 2015).

KEYWORDS

RESULTADOS

\begin{tabular}{lc}
\hline 'intrusion detection system' OU 'anomaly detection system' E 'network' & 6086 \\
\hline 'intrusion detection system' OU 'anomaly detection system' E 'industrial network' & 153 \\
\hline 'intrusion' OU 'cyber attack' E 'network' & 7841 \\
\hline 'intrusion' OU 'cyber attack' E 'industrial network' & 212 \\
\hline 'security' E 'industrial network' & 1687 \\
\hline 'security' E 'profinet' & 7 \\
\hline 'intrusion' OU 'cyber attack' E 'profinet' & 0 \\
\hline 'intrusion detection system' OU 'anomaly detection system' E' 'profinet' & 0 \\
\hline
\end{tabular}

\subsection{Contribuição e lastro da pesquisa}

A principal contribuição desta dissertação é o desenvolvimento de técnicas e métodos de detecção de anomalias no tráfego de redes Profinet, por meio da aplicação de redes neurais artificiais. Técnicas estas que podem, futuramente, serem utilizadas como base para o desenvolvimento de ferramentas de diagnóstico avançado em redes de automação.

Ao longo do período de realização do Mestrado a atividade de divulgação científica foi conduzida por meio das seguintes publicações:

- TURCATO, A. C.. Diagnóstico de redes Profinet IO utilizando o software Wireshark. Revista Saber Eletrônica, v. 48, p. 34-40, 2012.

- DiAS, A. L.; SESTITO, G. S.; TURCATO, A. C.; SOUZA, P. H. T. O. E.; BRANDAO, D. Um Estudo sobre a Tecnologia Profinet. Em: $1^{\circ}$ Congresso de Automação e Inovação Tecnológica Sucroenergética, 2013, Sertãozinho.

- SEStito, G. S.; DiAS, A. L.; TURCATO, A. C.; SOUZA, P. H. T. O. E.; BRANDAO, D. Análise Comparativa de Redes Profibus e Profinet. Em: 17 Congresso Internacional e Exposição de Automação, Sistemas e Instrumentação, 2013, São Paulo. Brazil Automation - ISA, 2013.

- TURCAto, A. C.; FlauZINO, R. A.; SESTITO, G. S.; DiAS, A. L.; BRANDÃO, D. Ataque Denial-Of-Service em Redes Profinet IO: Estudo de Caso. Em: XII Simpósio Brasileiro de Automação Inteligente, 2015, Natal-RN (artigo submetido, aguardando aprovação). 


\subsection{Organização da Dissertação de Mestrado}

A organização desta Dissertação é feita da seguinte forma:

- Capítulo 2: Apresenta as características necessárias para o embasamento teórico sobre os protocolos de redes baseado na Ethernet focando principalmente nas características do protocolo Profinet, com ênfase na estrutura de comunicação, topologias de redes e no formato dos frames.

- Capítulo 3: São apresentados os conceitos e mecanismos de segurança oficiais recomendados pela PI para utilização em redes Profinet. Serão apontados os aspectos fundamentais para o estabelecimento de um conceito de segurança abrangente no que tange as redes industriais, mais especificamente, para a tecnologia Profinet.

- Capítulo 4: São discutidos os principais tipos de ataques em redes Ethernet e como muitos desses ataques são ou podem ser detectados. Neste capítulo são descritos também os dois principais tipos de IDS existentes atualmente, suas vantagens e desvantagens além de suas aplicações. Pesquisas correlatas são apresentadas, a fim de embasar todo o estudo e metodologia utilizados.

- Capítulo 5: Os principais aspectos sobre as RNA e sua aplicação no reconhecimento e classificação de padrões são apresentados.

- Capítulo 6: Fundamentalmente expõe a metodologia desenvolvida e aplicada nos testes realizados, e apresenta e discute os resultados obtidos.

- Capítulo 7: Apresenta as conclusões finais e os trabalhos futuros. 


\section{Capítulo 2}

\section{Protocolos Real Time Ethernet e estrutura do protocolo Profinet}

\subsection{Introdução}

Este capítulo é destinado à descrição do protocolo de comunicação industrial Profinet para o entendimento da proposta desta dissertação. Serão expostas, de forma sucinta, as modificações que o padrão Ethernet sofreu no decorrer dos anos para suportar comunicação em tempo real. Assim, alguns tópicos do protocolo Profinet serão apresentados com foco à estrutura da comunicação do protocolo.

\subsection{Evolução do padrão Ethernet}

O Profinet é um padrão aberto de Ethernet Industrial para automação criado em 2002 cujo suas capacidades foram aprimoradas para satisfazer as condições mais severas encontradas nas aplicações industriais. Permite o estabelecimento de comunicação em tempo real, sendo regido pelas normas IEC 61158 e IEC 61784 e tem o suporte de uma associação internacional de empresas do segmento de automação industrial denominada PI (Profibus International) (POPP; WEBER, 2004).

Inicialmente o Profinet possuía duas versões: Profinet $I O$ e Profinet $C B A$. O Profinet $C B A$ era suportado pela empresa Siemens, porém atualmente essa versão do Profinet foi descontinuada pela PI e praticamente deixou de existir (POPP; WEBER, 2004).

A versão Profinet IO é a versão que atingiu maior abrangência no meio industrial e no meio acadêmico. Essa versão é focada na comunicação de equipamentos de campo e, portanto, foi a escolhida para a realização desse trabalho.

No restante do texto, todas as ocorrências do termo 'Profinet' se referem exclusivamente à versão Profinet $I O$.

Desde 1985, o padrão Ethernet sofreu várias modificações para se adequar ao ambiente industrial. Em 1987, foi padronizada a arquitetura 1Mbps 1base5 com par trançado e uso de hubs interligando as estações ponto a ponto que além de regenerarem 
o sinal, eram também capazes de detectar colisões de pacotes notificando todas as entidades envolvidas na comunicação. Um avanço da mesma arquitetura para $10 \mathrm{Mbps}$ foi feito em 1990, para 100 Mbps em 1995 e em 1998, para 1 Gbps. Em 1997, o padrão IEEE 802.3x estabeleceu a comunicação full-duplex e assim, os hubs foram então substituídos por switches.

Assim, seguindo o padrão IEEE 802.3D, o switch passa a regenerar o sinal e transmitir os frames Ethernet somente entre as entidades envolvidas na comunicação. Além disso, os frames que chegam até o switch são armazenados em um buffer, enfileirados e transmitidos posteriormente quando o meio físico tornar-se disponível.

Consequentemente, todas as conexões podem então ser consideradas como pontoa-ponto de uma estação para um switch (e vice-versa) e entre switches. Assim, toda a comunicação se torna full-duplex e sem colisões. A eliminação das colisões foi um grande avanço para a previsibilidade do comportamento do protocolo em busca do determinismo.

Além de hardware, houve diversas alterações em software. Considerando o modelo de referência OSI (Open System Interconnection), na camada 4, de Transporte, uma série de protocolos dedicados à comunicação em tempo real foi proposta. Os já bem estabelecidos protocolos TCP - Transmission Control Protocol e UDP - User Datagram Protocol são os mais usados e muitos esforços foram concentrados em busca de uma melhoria deles em conjunto com o protocolo IP - Internet Protocol da camada subsequente.

Na camada 3, a de Rede, o protocolo mais utilizado é o IP - Internet Protocol. O uso de roteadores tem um impacto considerável nas garantias de tempo real, em particular, sem o uso de uma política de roteamento especial, mensagens urgentes podem não chegar em tempo hábil ao seu destino devido ao excesso de mensagens de baixa prioridade passando pelo roteador, que por sua vez, torna-se o gargalo da transmissão (DECOTIGNIE, 2005).

Por fim, na camada de Enlace ou Data Link Layer (2), o mecanismo de acesso ao meio (MAC - Media Access Control) foi fundamental para obtenção das características de real-time. Uma série de soluções foi proposta, sendo que o mecanismo CSMA/CD (Carrier Sense Multiple Access with Collision Detection) destacou-se quando utilizado em conjunto com os switches (TANENBAUM, 2003). 
Considerando-se as mudanças realizadas no padrão Ethernet sucintamente descritas acima, tornou-se então possível, utilizando este padrão, a comunicação em tempo real e assim, esse passou a ser conhecido como Real Time Ethernet (RTE).

\subsection{Os Protocolos RTE}

Com o passar dos anos, diversos fabricantes desenvolveram seus próprios protocolos baseados em RTE. Segundo (INTERNATIONAL ELECTROTECHNICAL COMISSION, 2010) são definidos 14 padrões de comunicação baseados em RTE, são eles:

1. CIP

2. Profinet

3. P-Net

4. Interbus

5. Vnet/IP

6. TCnet

7. EtherCat

8. Ethernet IP

9. Powerlink

10. EPA

11. Modbus RTPS

12. Sercos

13. RAPIEnet

14. SafetyNet

Dentre esses protocolos $R T E$, o protocolo Profinet é o que apresenta um maior volume de vendas, considerando um intervalo de cinco anos, começando em 2010 e com projeção para 2015, segundo relatório emitido pelo IMS Research (IMS RESEARCH, 2011). Os resultados podem ser vistos na Figura 2. 


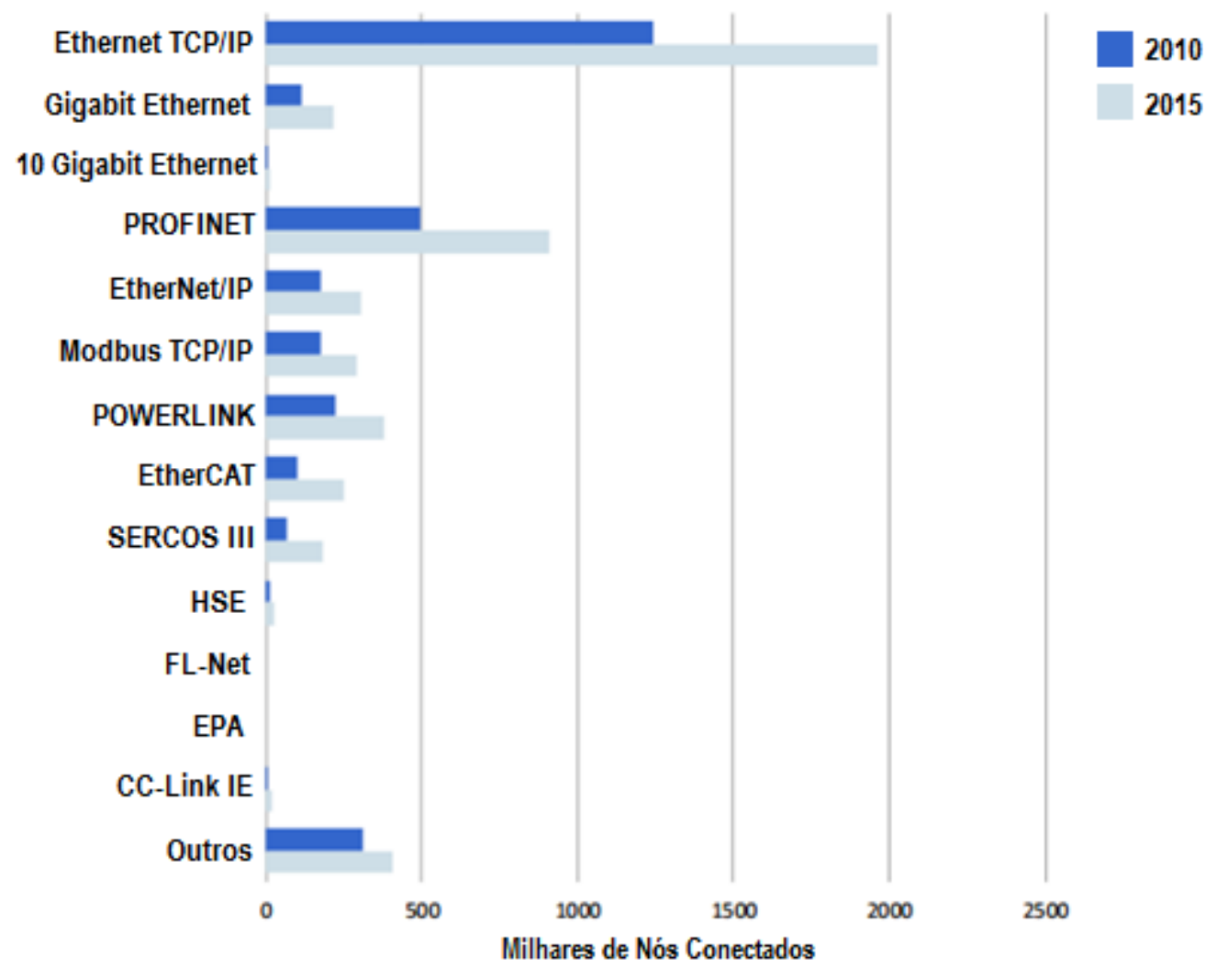

Figura 2: Número de nós por protocolo baseado em RTE no mundo. FONTE: Adaptado de (IMS RESEARCH, 2011).

\subsection{Principais aspectos do protocolo Profinet}

Nesta seção, são abordados os conceitos teóricos do protocolo pertinentes para essa dissertação. Mais informações sobre o protocolo Profinet podem ser encontradas nas normas da PI (PROFIBUS INTERNATIONAL, 2010), (PROFIBUS INTERNATIONAL, 2011) e (PROFIBUS INTERNATIONAL, 2012).

O protocolo Profinet é um padrão de comunicação aberto definido pelas IEC 61158 (INTERNATIONAL ELECTROTECHNICAL COMISSION, 2014) e IEC 61784 (INTERNATIONAL ELECTROTECHNICAL COMISSION, 2010). Inicialmente, o Profinet possuía duas versões: Profinet $C B A$ e Profinet $I O$.

A versão CBA (Component Based Automation) foi projetada para ser responsável pela comunicação em tempo real entre áreas de uma mesma planta industrial e também, comunicação dita máquina a máquina. Por exemplo, a área "Logística de Entrega" pode-se comunicar com a área "Montagem de Peças" através da rede Profinet. A Figura 3 ilustra esse comportamento. 


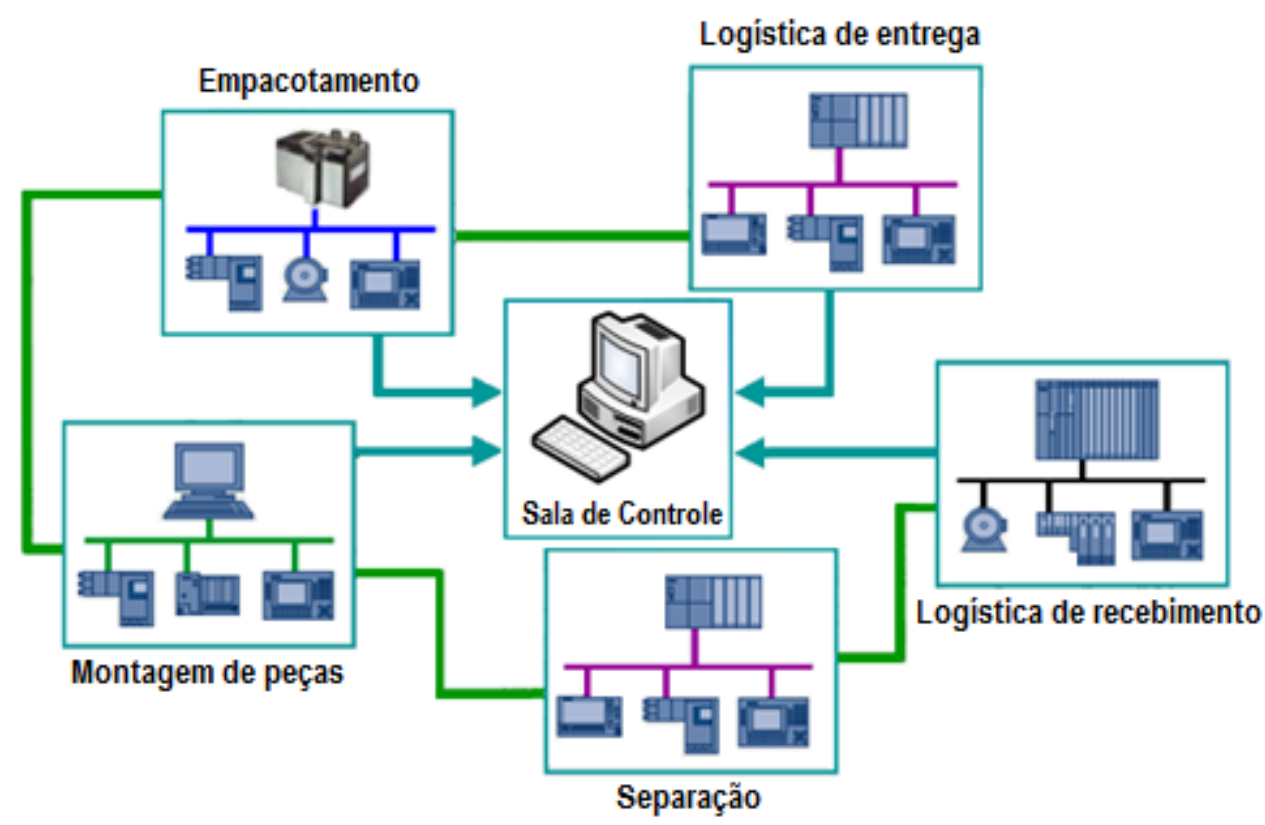

Figura 3: Representação da versão CBA do protocolo Profinet. FONTE: Adaptado de (PROFIBUS INTERNATIONAL, 2012)

No entanto, a versão $C B A$ foi descontinuada e apenas está mantido o apoio técnico aos produtos que ainda estão no mercado (POPP; WEBER, 2004). Assim, como essa versão foi descontinuada, o escopo desta pesquisa não abrange essa versão.

Em contrapartida, a versão Profinet IO(Input/Output) obteve grande abrangência tanto no mercado de automação quanto no meio acadêmico e, portanto, decidiu-se focar o trabalho desta dissertação nesta versão.

O Profinet IO é responsável pela comunicação com os dispositivos de campo. É por meio dessa versão que os dados de processo, oriundos das entradas e saídas dos equipamentos, são tratados. É importante destacar que, apesar das versões $C B A$ e $I O$ abrangerem escopos diferentes, ambas podem trabalhar em conjunto ou isoladamente.

No Profinet $I O$ são definidos três tipos de dispositivos (PROFIBUS INTERNATIONAL, 2010):

- IO-Controller: Desempenha o papel de gerenciamento da rede. Fazendo-se uma analogia ao protocolo Profibus, o IO-Controller (controlador) seria o mestre da rede. No controlador é que estão contidas as lógicas de processo sendo este, o elemento que endereça, configura e parametriza os IO-Devices. É geralmente representado por um CLP - Controlador Lógico Programável. 
- IO-Device: É o dispositivo de campo responsável por informar ao IO-Controller os dados de processo e/ou executar alguma função dada por ele. Em sua maioria, podem gerar também dados de alarmes e de diagnóstico.

- IO-Supervisor: Podem ser computadores, IHMs (Interface Homem-Máquina) com a finalidade de enviar/receber parâmetros dos equipamentos da rede, sejam eles um IO-Device ou um IO-Controller. Também podem ser utilizados na identificação de falhas nesses dispositivos e/ou na rede (diagnóstico da rede).

Uma característica importante desses três tipos de equipamentos é a ausência de hierarquia entre eles, ou seja, todos estão no mesmo patamar de importância. A Figura 4 ilustra as interações entre os equipamentos descritos acima.

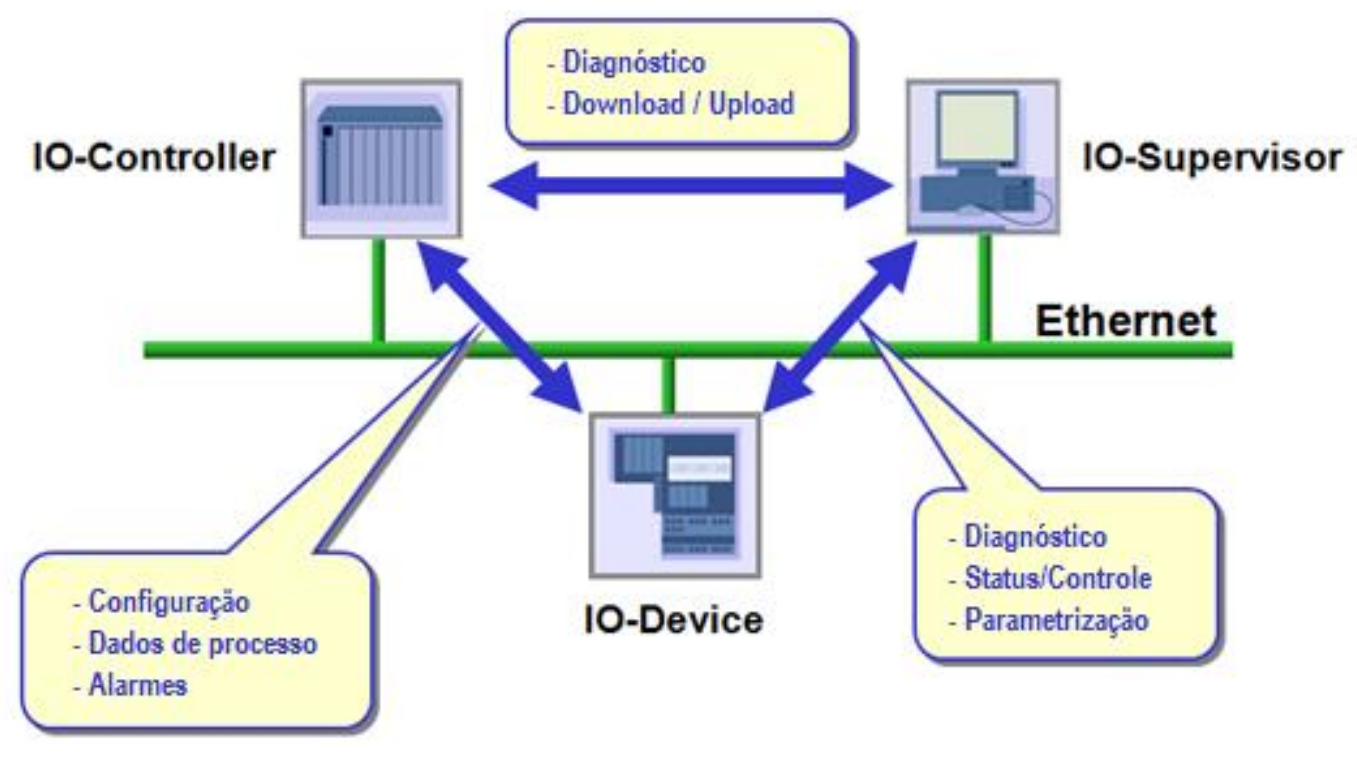

Figura 4: Interações entre IO-Controller, IO-Device e IO-Supervisor. FONTE: Adaptado de (PROFIBUS INTERNATIONAL, 2010)

O sinal é transmitido no padrão 100BASE-TX, cabo blindado, par trançado, dois pares de cabo Categoria CAT 5e FTP (Foiled Twisted Pair). A cor característica é verde e internamente há pares branco e azul, amarelo e laranja. A velocidade de transmissão utilizada é de 100 Mbits/s. Os conectores podem ser RJ45 ou M12 (Figura 5) sendo que o comprimento máximo do cabo é de $100 \mathrm{~m}$. 


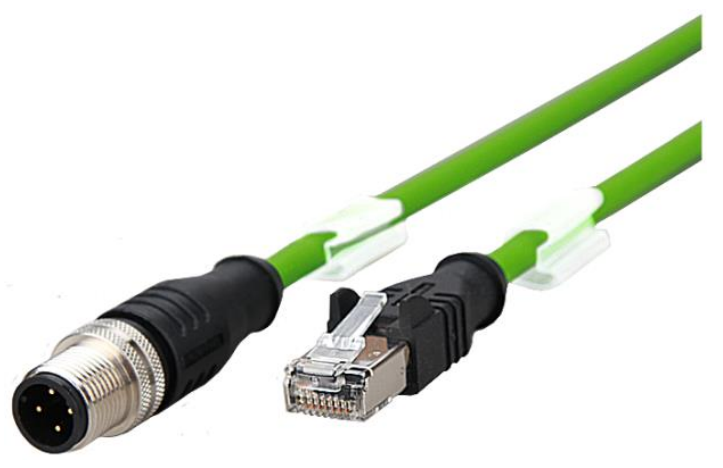

Figura 5: Conectores M12 e RJ45.

FONTE: (METZ CONNECT, 2015)

Uma integração ampla e versátil com outros protocolos é possível. Um estudo, realizado em 2005 (JASPERNEITE; FELD, 2005), analisou a integração do protocolo Profinet com o protocolo Profibus e com o protocolo Interbus. Neste estudo, os autores concluíram que é possível mapear todas as propriedades dos protocolos Profibus e Interbus em um único dispositivo Profinet, por meio da utilização de gateways e destaca inclusive que, o Profinet é uma plataforma indicada para plantas industriais com protocolos de comunicação heterogêneos.

\subsubsection{Topologias de rede empregadas em redes de automação}

Durante a fase de projeto de uma rede de automação, muitos fatores devem ser considerados: interferência eletromagnética, o correto aterramento, as distâncias entre dispositivos, o volume de dados transmitidos na rede e muitos outros fatores regidos pelas normas. Contudo, mesmo levando-se em consideração todos esses aspectos, restrições físicas das instalações são fatores que exigem habilidade do projetista. Um protocolo que permite a utilização simultânea de várias topologias de rede facilita ao projetista atender os requisitos do projeto. Neste quesito, o Profinet é bem flexível e, diferentes topologias podem ser usadas em conjunto (PROFIBUS INTERNATIONAL, 2010).

A topologia estrela (star) é muito comum em redes Profinet devido ao intenso uso de switches. Consiste geralmente em muitos IO-Devices conectados em um único switch. Se um único nó Profinet falhar ou for removido, os outros nós Profinet continuam a operar normalmente. Contudo, se o switch falhar, a comunicação de todos os nós conectados será comprometida. A Figura 6 ilustra essa topologia. 


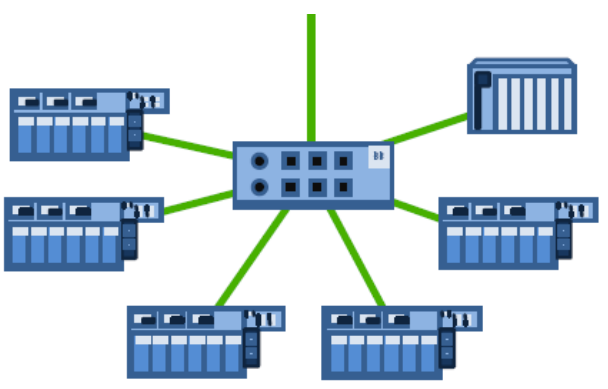

Figura 6: Topologia em estrela.

FONTE: Adaptado de (PROFIBUS INTERNATIONAL, 2010)

Já a topologia árvore (tree) é formada pela junção de topologias em estrela em um único switch que trabalha como distribuidor de sinal. O switch funciona como um distribuidor de sinal para as extremidades em estrela. Dessa forma, o sinal de uma topologia estrela não é visto pela topologia estrela vizinha, a menos que esta esteja em troca de dados com a primeira. A topologia em árvore é um típico exemplo de uma planta de automação sendo agrupada de diferentes ilhas industriais conforme a Figura 7.

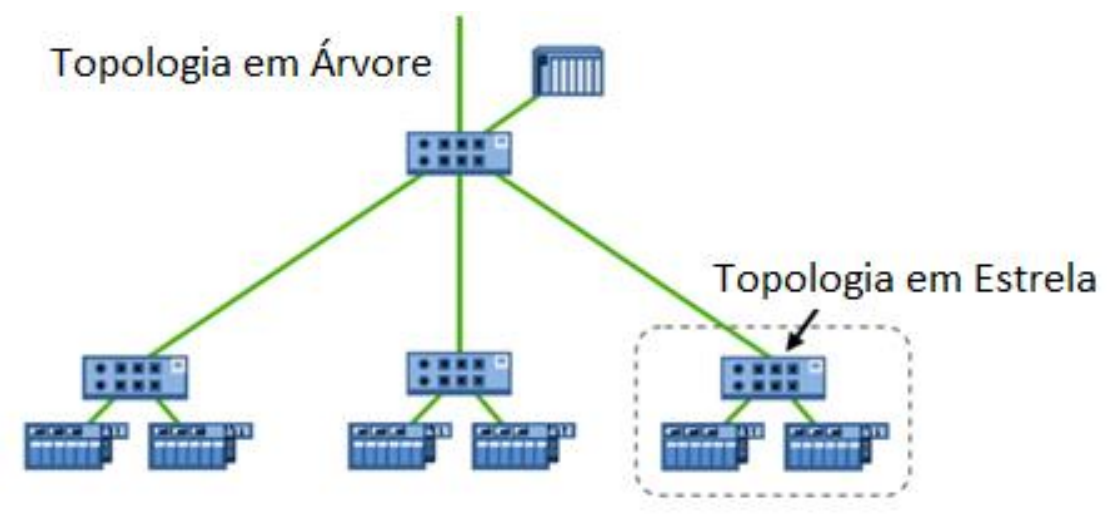

Figura 7: Topologia em árvore.

FONTE: Adaptado de (PROFIBUS INTERNATIONAL, 2010)

A topologia barramento (bus) é a mais conhecida na área de automação industrial. A maioria dos IO-Devices possui um switch interno que facilita a implantação dessa topologia. Como pode ser observado pela Figura 8, elimina-se assim, a necessidade de um switch central. 


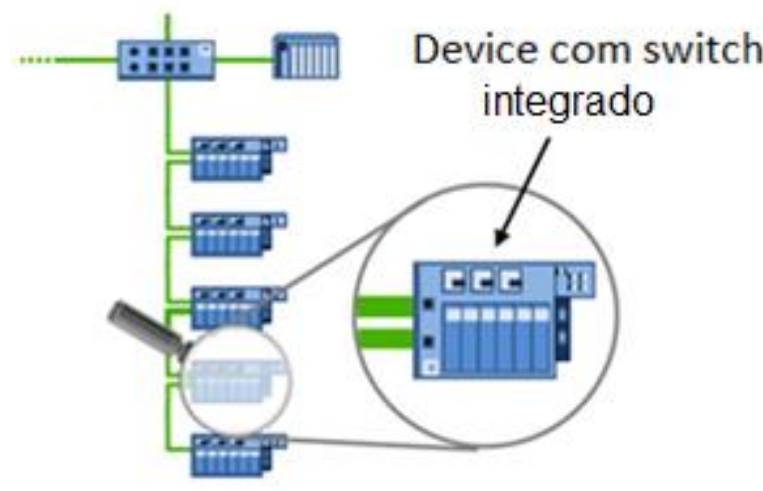

Figura 8: Topologia em linha.

FONTE: Adaptado de (PROFIBUS INTERNATIONAL, 2010)

No uso desse tipo de topologia deve-se atentar para o fato de que caso haja a interrupção da linha por falha de algum dispositivo, todos os dispositivos, que estão conectados após o ponto de falha, terão sua comunicação comprometida.

A topologia anel (ring) consiste basicamente na interligação da topologia em barramento (bus) com as extremidades do cabo conectadas em um mesmo ponto. Essa forma de conexão cria um caminho alternativo para o tráfego de dados, caso a rota principal seja interrompida.

Atualmente, existe uma nova topologia, ainda não muito bem documentada, mas que está sendo muito utilizada em ambiente industriais, que é denominada topologia butterfly. Essa topologia consiste na interligação de duas ou mais topologias em anel criando pontos de conexão distribuídos entre os anéis da rede.

\subsubsection{Utilização de switches}

O switch possui papel fundamental no desempenho das redes Profinet. Existem basicamente dois tipos de switch: o tipo "Store \& Forward" e o tipo "Cut - Throught" (CISCO, 2008).

Quando um pacote de dados chega ao switch que trabalha no modo "Store \& Forward", o mesmo encaminha este pacote para o destino somente depois de tê-lo recebido por completo e ter com isso, checado sua integridade. Caso seja detectado algum erro no pacote, o switch descarta-o. Em consequência disso, um atraso proporcional ao comprimento da informação é adicionado na comunicação. Contudo, existe a vantagem de que somente os pacotes íntegros passam a trafegar na rede. A Figura 9 ilustra o atraso interno gerado por este tipo de switch. Considerando que o 
tamanho dos pacotes transmitidos seja variado, tem-se que os atrasos gerados por estes switches também sejam variados.

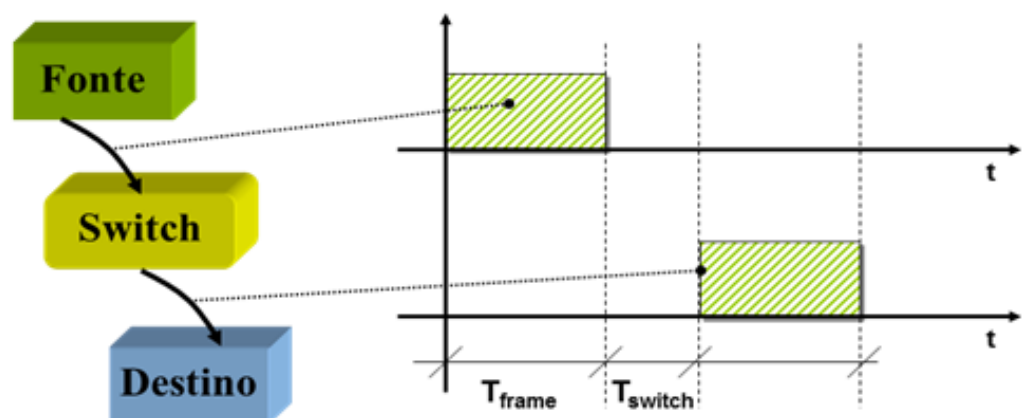

Figura 9: Modelo do funcionamento do swtich "Store \& Forward". FONTE: Adaptado de (PROFIBUS INTERNATIONAL, 2010).

Já o switch "Cut-Throught" checa apenas os seis primeiros bytes do pacote recebido, correspondentes ao MAC Address de destino e, imediatamente, encaminha-o para o destino. Apesar desse tipo de switch não descartar pacotes inválidos ou mal formados, este tipo insere um atraso menor na transmissão e com uma vantagem extra, o pequeno atraso adicionado pela verificação de apenas os seis primeiros bytes é praticamente constante. A Figura 10 ilustra o atraso interno gerado por este tipo de switch. A função de verificação da integridade do pacote fica exclusivamente para o receptor final da comunicação. Este é o tipo de switch mais usado em automação industrial (PROFIBUS INTERNATIONAL, 2010).

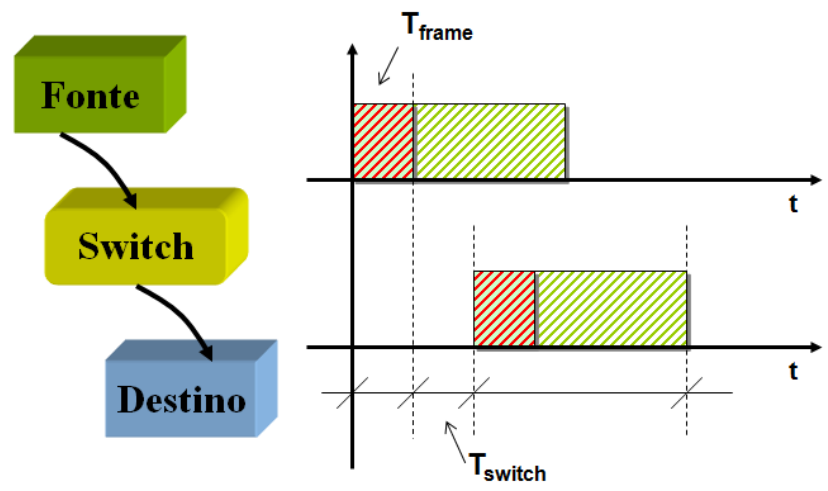

Figura 10: Modelo de funcionamento do switch "Cut-Through". FONTE: Adaptado de (PROFIBUS INTERNATIONAL, 2010).

O espelhamento de porta é uma função utilizada por switches gerenciáveis para propósitos de monitoramento do tráfego da rede. Com essa função ativa, o switch envia cópias de pacotes de rede que trafegam por uma porta (ou mais portas) para outra porta 
em que uma ferramenta de análise de rede pode estar conectada. Um exemplo é ilustrado na Figura 11.

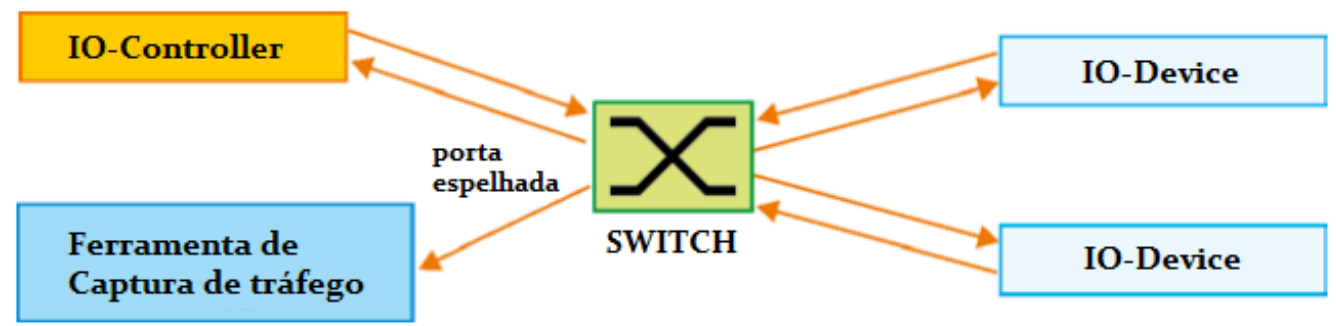

Figura 11: Exemplo de espelhamento de porta em uma rede Profinet. FONTE: Adaptado de (TURCATO, 2012).

Através dessa funcionalidade, a ferramenta de análise de rede recebe todos os pacotes que trafegam pela rede, não interferindo diretamente no funcionamento natural desta.

\subsubsection{Tipos de comunicação}

O padrão Profinet define três diferentes níveis de performance para cobrir os diversos requerimentos das inúmeras aplicações a que se destinam. O primeiro nível se refere ao Profinet NRT (Non Real Time) que utiliza a pilha de protocolos TCP/IP para transmissão com tempo de ciclo maior que $100 \mathrm{~ms}$, tendo como finalidade principal, as aplicações em automação de processos. Para aplicações com requerimentos de tempo de ciclo menores, utiliza-se então o segundo nível, o Profinet RT (Real Time). Nesse nível de performance, os dados de $I / O$ são transmitidos utilizando-se apenas o protocolo Ethernet (camadas 1 e 2 do modelo $O S I$ ), enquanto que os dados de diagnósticos e configuração permanecem utilizando o padrão TCP/IP. Desta forma, o Profinet RT possibilita tempos de ciclo menores, em torno de $10 \mathrm{~ms}$.

Para as aplicações em que o tempo de ciclo é crítico um terceiro nível de performance pode ser utilizado. Nessas aplicações, utiliza-se o Profinet IRT (Isochronous Real Time) que trabalha com tempo de ciclo menor que 1 ms e jitter ${ }^{2}$ menor que $1 \mu$ s. Para utilização deste nível, é necessária a utilização de hardware específico.

A Figura 12 ilustra as camadas de comunicação utilizadas no Profinet comparando-as com o modelo de referência OSI.

\footnotetext{
2 Jitter: variações de pequena duração, não acumulativas nos instantes significativos de um sinal digital da sua posição ideal no tempo.
} 


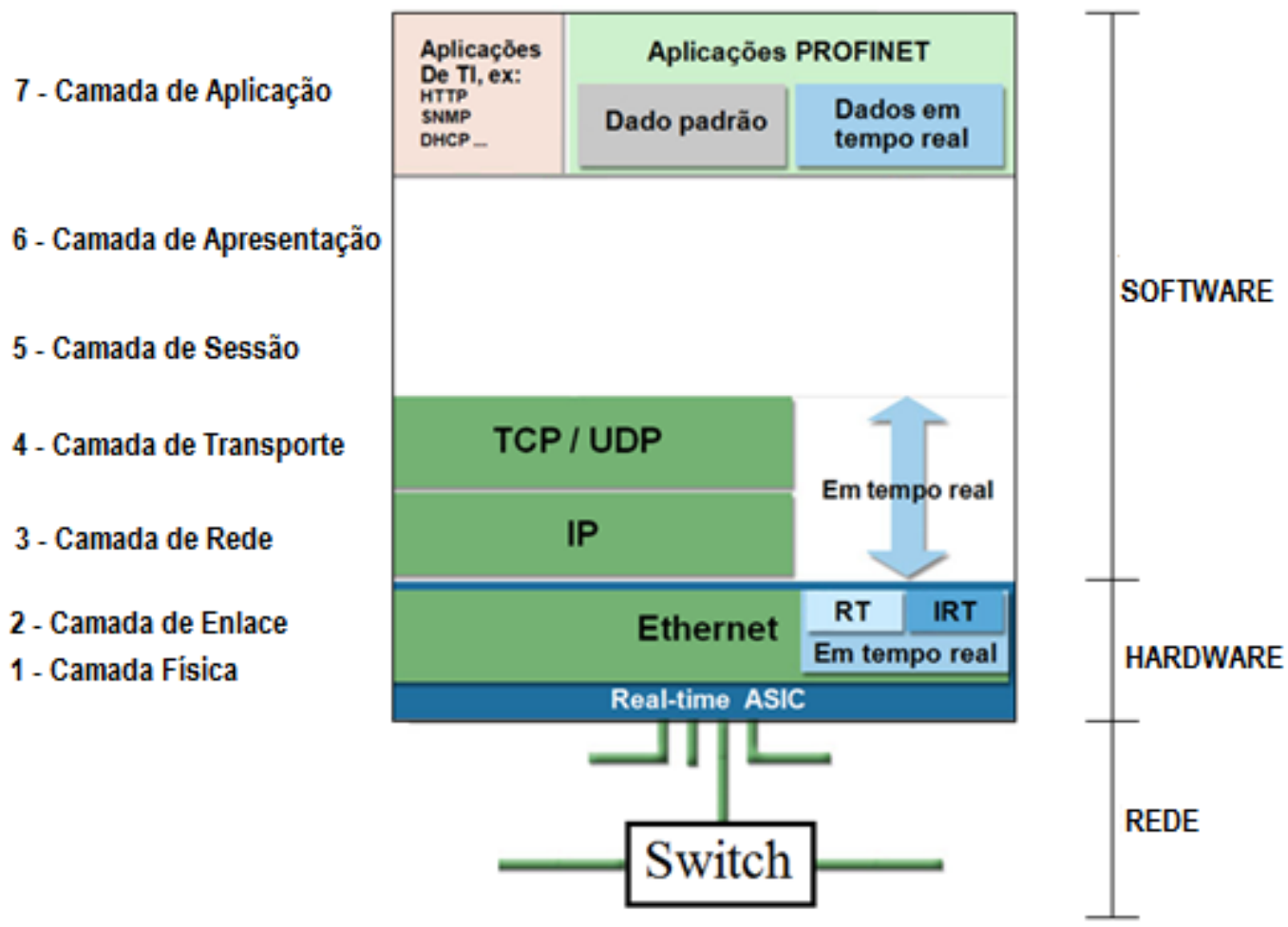

Figura 12: Pilha de comunicação Profinet baseado no modelo OSI. FONTE: Adaptado de (PROFIBUS INTERNATIONAL, 2012).

\subsubsection{Comunicação $N R T$}

Essa forma de comunicação, mais lenta, é realizada com a utilização dos protocolos UDP, TCP e IP. Basicamente, por este canal são configurados e lidos parâmetros dentro dos IO-Devices, são coletados os dados de diagnóstico e são inicializadas as $A R s^{3}$.

Devido à utilização dessa pilha de protocolos, cada dispositivo da rede Profinet deve obrigatoriamente possuir um endereço IP distinto. É comum também, cada dispositivo conter um servidor Web integrado que por sua vez, pode ser acessado para obtenção de diagnósticos e até mesmo configuração de parâmetros.

Esta comunicação é dita “Non Real time (NRT)” e acíclica. Nota-se ainda o uso de filas neste tipo de comunicação: quando se torna necessário o envio/recebimento de parâmetros, os pedidos são enfileirados dentro de um buffer no dispositivo. Assim, temse a garantia de que nenhum pedido será perdido e que um dado novo não sobrescreverá o dado anterior.

\footnotetext{
${ }^{3}$ AR (Application Relationship): e uma conexão lógica formada entre o IO-Controller e o IO-Device.
} 


\subsubsection{Comunicação $R T$}

No canal de tempo real $(R T)$ são transmitidos os dados cíclicos e alarmes. Denominam-se dados cíclicos, os dados de processo que são enviados pelos dispositivos, de tempos em tempos em uma taxa configurável. Em contrapartida, os alarmes são ditos não cíclicos porque são enviados no momento é que são gerados. No entanto, ambos os tipos de dados são $R T$.

É dita comunicação não sincronizada porque não apresenta mecanismos de sincronização entre os elementos da rede como visto na comunicação IRT que será explicada adiante. Este canal de alto desempenho representa a maior parte do tráfego das aplicações do Profinet.

A troca de dados é baseada no modelo Consumer-Provider (PROFIBUS INTERNATIONAL, 2012). Isto significa que o Consumer registra o Provider por meio da $A R$ e recebe o dado do Provider. A comunicação é unicast, ou seja, o dado é mandado diretamente para o Consumer. Este mecanismo difere-se do sistema Publisher-Subscriber, pois neste último, um dispositivo manda um dado via broadcast/multicast e tal informação é recebida por vários dispositivos da rede. Sendo que, apenas os dispositivos que necessitam do dado irão utilizá-lo.

Durante a troca de dados, estes são enviados sem confirmação de recebimento. Para esse tipo de comunicação, o uso de buffers é indicado, pois na troca cíclica de dados, os dados novos sobrescrevem os velhos repetidamente, conforme pode ser observado na Figura 13

Destaca-se a existência de dois processos distintos para entradas e saídas do processo. Cria-se uma $A R$ para as entradas do processo e outra $A R$ para as saídas, sendo que as conexões lógicas são independentes uma das outras. 


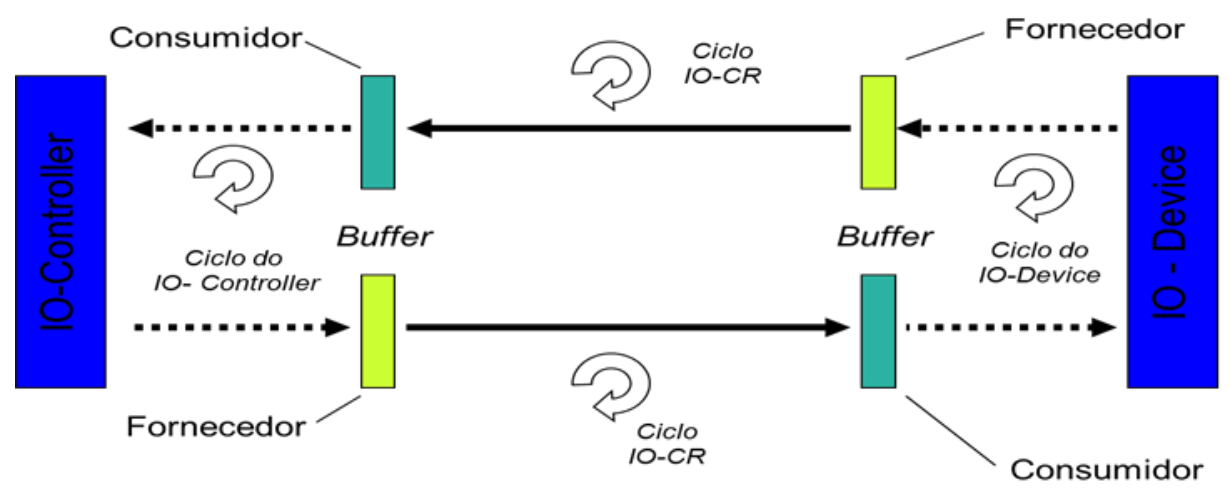

Figura 13: Dinâmica de troca de dados na comunicação RT. FONTE: Adaptado de (PROFIBUS INTERNATIONAL, 2012).

\subsubsection{Comunicação IRT}

Este último modo de comunicação é em tempo real e apresenta mecanismos para o sincronismo de tempo. Denomina-se 'comunicação em tempo real de modo isócrono', IRT. Segundo a teoria, esta tecnologia permite a transferência dos dados sincronizados com um jitter de menos de $1 \mu$ s e tempo de ciclo de $31,25 \mu \mathrm{s}$.

É indicado para áreas onde o tempo de ciclo é crítico, como posicionamento de servo-motores (Motion Control). Para atingir esse desempenho, o Profinet IRT possui mecanismos adicionais como: prioridade na transmissão, hardware especial, protocolos de sincronismo de tempo, protocolo de redundância especial entre outros.

O Profinet IRT não é muito utilizado por demandar hardwares dedicados (PROFIBUS INTERNATIONAL, 2012). Devido a isso, optou-se por não estudar esse modo de comunicação nessa Dissertação.

O Profinet traz a possibilidade de trabalhar com as três tecnologias de comunicação simultaneamente. Para isso, há uma divisão no tempo de ciclo bem definida. Assim, consegue-se ter comunicações lentas em conjunto com aplicações que demandam rapidez e determinismo absoluto.

\subsubsection{Comparativo entre os canais de comunicação}

A comunicação IRT apresenta um tempo de ciclo da ordem de alguns milissegundos e jitter de $1 \mu \mathrm{s}$. Já a comunicação $R T$ se enquadra na casa das dezenas de milissegundos. Há uma tolerância de $15 \%$ variação no tempo de ciclo. Por fim, a comunicação mais lenta e com menos determinismo já trabalha na faixa de centenas de milissegundos e uma tolerância de variação muito alta. A Tabela 7 resume essas informações. 
Tabela 7: Comparação entre os canais de comunicação Profinet. FONTE: Adaptado de (PROFIBUS INTERNATIONAL, 2012).

\begin{tabular}{ccccc} 
Tipo & $\begin{array}{c}\text { Tempo de ciclo } \\
\text { MIN. }[\mathbf{m s}]\end{array}$ & $\begin{array}{c}\text { Tempo de ciclo } \\
\text { MÁX. }[\mathbf{m s}]\end{array}$ & $\begin{array}{c}\text { Ordem de grandeza } \\
\text { do ciclo [ms] }\end{array}$ & Jitter \\
\hline Non-RT & - & - & 100 & Até $100 \%$ \\
\hline RT & 4 & 128 & 10 & Até $15 \%$ do ciclo \\
\hline IRT & 0,03125 & 1 & 1 & $1 \mu \mathrm{s}$ \\
\hline
\end{tabular}

\subsubsection{Mecanismos de troca de dados}

A primeira ação que um IO-Controller faz para trocar dados com um IO-Device é estabelecer uma conexão lógica. Esta conexão chama-se $A R$ - Application Relationship. Após o estabelecimento desta ligação, alguns canais são estabelecidos para configuração dos alarmes que serão utilizados e dos dados de processo que serão trocados. Esses canais são denominados CR - Communication Relationship.

As $A R$ e $C R$ são definidas da seguinte forma (PEGAIA, 2010):

- $A R$ : elemento lógico virtual que representa um canal de comunicação entre dois equipamentos.

- $\quad C R$ : tipo de comunicação dentro de um $A R$.

Conforme ilustra a Figura 14.

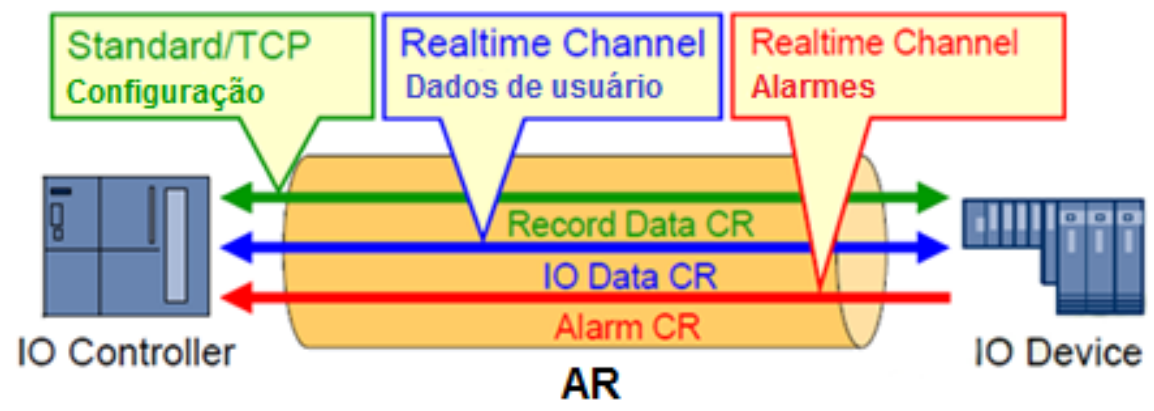

Figura 14: AR e CRs.

FONTE: Adaptado de (PEGAIA, 2010)

Cada dispositivo pode ter mais de uma $A R$ dependendo somente dos recursos disponíveis de memória, do firmware e do processamento do IO-Controller. Desta forma, um dispositivo pode ser controlado por mais de um controlador. Esta possibilidade muitas vezes torna-se importante, pois flexibiliza a utilização dos dispositivos diante das inúmeras aplicações existentes.

Em se tratando de troca de dados, uma vez que se estabelece a comunicação, os IO-Devices, independentemente, enviam os dados de acordo com taxa de atualização previamente configurada. Por exemplo, se o dispositivo for configurado para enviar 
seus dados a cada $2 \mathrm{~ms}$, ele é responsável por controlar esse tempo e enviar seus dados sem que haja solicitação direta para isso.

\subsubsection{Estrutura do frame Ethernet}

A Figura 15 ilustra um típico frame Ethernet em uma rede Profinet. Destaca-se que todos os frames em uma rede Profinet devem possuir um campo dedicado a TAG VLAN. A utilização desse recurso permite a priorização dos frames que necessitam de garantia de tempo real durante o chaveamento/enfileiramento realizado pelo switch (TANENBAUM, 2003).

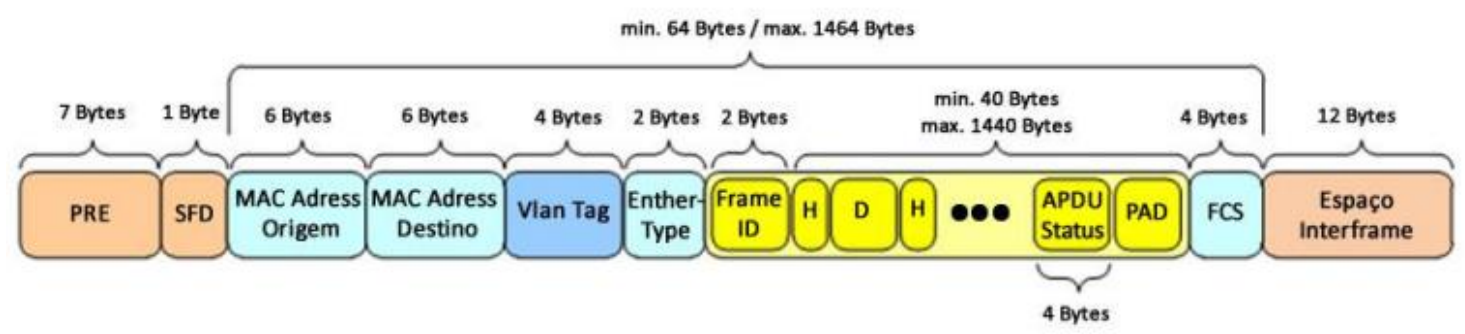

Figura 15: Frame Ethernet.

FONTE: Adaptado de (PNCC BURGDORF, 2005).

Descrição sucinta dos campos da figura:

- PRE: preâmbulo que marca o início do frame.

- SFD (Start Frame Delimiter): um byte, 10101011.

- DA: endereço MAC de destino.

- SA: endereço MAC de origem.

- TIPO: distingue os protocolos encapsulados no frame Ethernet.

- DATA: dado que está sendo transmitido.

- PAD: caso seja enviado menos de 40 bytes, o PAD complementa esse campo para que se atinja o tamanho mínimo.

- FCS (Frame Check Sequence): mecanismo de controle de erros.

O campo Tipo, também conhecido como Ethertype, contém um conjunto de valores que define o protocolo que está sendo transportado dentro do frame Ethernet. A

Tabela 8 apresenta alguns desses possíveis valores utilizados por um dispositivo em uma rede Profinet. 
Tabela 8: Protocolos típicos em uma rede Profinet. FONTE: (PROFIBUS INTERNATIONAL, 2012).

\begin{tabular}{cc}
\hline Tipo & Protocolo \\
\hline 0x0800 & IP \\
0x0806 & ARP \\
0x8100 & VLAN \\
0x8892 & Profinet \\
\hline
\end{tabular}

\subsubsection{O frame Profinet}

A estrutura do frame Profinet é similar à estrutura do frame de dados do padrão Ethernet. A parte amarela do frame ilustrado na Figura 15 refere-se à parte dos dados Profinet propriamente dita. A descrição de cada campo é:

- Frame ID: identificador do tipo de frame Profinet transmitido.

- Header (H): representa o modelo do device, pode ser IO-Consumer ou IOProvider Status.

- Dado do processo (D): este é realmente o dado o usuário.

- APDU Status (Application Protocol Data Unit Status): fornece o diagnóstico que informa se o dado transmitido é valido ou se um erro foi encontrado no dispositivo Profinet.

O Frame ID pode assumir diversos valores que por sua vez, são agrupados em faixas de acordo com o tipo de comunicação existente. A

Tabela 9 descreve essas faixas. 
Tabela 9: Faixas de valores do Frame ID e os protocolos correspondentes. FONTE: Adaptado de (PNCC BURGDORF, 2005).

\begin{tabular}{|c|c|c|}
\hline \multicolumn{2}{|c|}{ Frame ID } & Significado \\
\hline $0 \times 0000$ & $-0 \times 00 F F$ & Time Syncronization \\
\hline $0 \times 0100$ & $-0 \times 7 \mathrm{FFF}$ & RT Class 3 Frames (IRT) \\
\hline $0 \times 8000$ & $-0 x B F F F$ & RT Class 2 Frames $(R T)$ \\
\hline $0 \times \mathrm{C} 000$ & $-0 x F B F F$ & RT Class 1 Frames (IRT) \\
\hline $0 \times F C 00$ & $-0 \times F C F F$ & Acyclic transmission "high" \\
\hline $0 \times F D 00$ & $-0 x F D F F$ & Reserved \\
\hline $0 \times F E 00$ & $-0 \times F E F C$ & Acyclic transmission "low" \\
\hline $0 \times F E F D$ & $-0 x F E F F$ & $D C P$ \\
\hline $0 \times F F 00$ & $-0 x F F F F$ & Reserved \\
\hline
\end{tabular}

Os protocolos mais utilizados para o estabelecimento da comunicação, para troca de dados, gerenciamento de informações e diagnóstico de alarmes são (THOMAS, 2013):

- PNIO DCP (PNIO Discovery and Configuration Protocol): utilizado na atribuição de nomes e endereços IPs;

- PNIO CM (PNIO Context Manager): normalmente utilizado para estabelecimento das ARs e CRs;

- PNIO: protocolo responsável pela troca cíclica de dados;

- PNIO PTCP (PNIO Precision Time Control Protocol): utilizado para sincronismo dos equipamentos na comunicação $I R T$.

- PNIO-AL (PNIO Acyclic Alarms/Events): alarmes acíclicos e eventos;

- ARP (Address Resolution Protocol): utilizado para a tradução de endereços IP em endereços ARP;

- LLDP (Link Layer Discovery Protocol): utilizado para a identificação e anunciação das propriedades dos dispositivos da rede. 


\subsection{Considerações Parciais}

Este capítulo apontou tópicos importantes para o embasamento teórico sobre os protocolos de redes baseados no padrão Ethernet, focando principalmente nas características do protocolo Profinet. Foi dada ênfase nas topologias de rede, na estrutura de comunicação e no formato dos frames. Essas informações são importantes para o entendimento do método de captura, do algoritmo de extração de atributos e dos cenários de testes realizados neste trabalho.

No próximo capítulo serão abordados os conceitos e mecanismos de segurança oficiais recomendados pela PI para utilização em redes Profinet. 


\section{Capítulo 3}

\section{Segurança em redes Profinet}

A comunicação baseada em Ethernet esta cada vez mais assumindo um papel central na área da automação. A principal vantagem de se utilizar a Ethernet é a integração entre diferentes tecnologias. No entanto, esse fator faz com que se aumente o risco de violações de acesso, ataques de vírus e/ou outros programas maliciosos. Assim, há necessidade de se avaliar os riscos potenciais para as redes de automação e assim, implementar conceitos de segurança adequados.

Por estas razões, no documento PROFINET Security Guideline (PROFIBUS INTERNATIONAL, 2013) é apresentado um conceito de segurança para sistemas de automação que incorpora as experiências das empresas associadas na PI, aliado ao conhecimento detalhado do ambiente de automação. A simples proteção das redes e dos componentes de automação não é suficiente, é também essencial que os conceitos e mecanismos utilizados sejam práticos e que não afetem a operação da planta industrial.

Neste capítulo serão apresentados os conceitos e mecanismos oficiais recomendados pela PI para utilização em redes Profinet. Serão apontados os aspectos fundamentais para o estabelecimento de um conceito de segurança abrangente no que tange as redes industriais, mais especificamente, o Profinet. Todas as informações são baseadas em Profibus International (2013), Klasen et al. (2010) e Popp (2007).

\subsection{Introdução}

Frequentemente associa-se o tema segurança em sistemas de informação com termos como: invasão, roubo de informações sigilosas, hackers, ataques cibernéticos e etc. Mas não são apenas as atividades terroristas, que envolvem ataques de hackers, que podem afetar a operação de uma planta industrial. Ao invés disso, uma perturbação pode ser simplesmente causada por um técnico de serviços que, acidentalmente, efetua uma conexão indevida a uma rede de controle de um processo industrial. Com isso, esse técnico acaba inserindo tráfego extra na rede que pode sobrecarrega-la e assim, desencadear uma interrupção completa da operação. 
Desta forma, no contexto dos sistemas de automação, um problema de segurança pode ser considerado como qualquer distúrbio operacional causado intencionalmente e que, consequentemente, acarreta em falha no sistema de automação.

Segurança não deve ser algo associado a somente um local. Todos os membros envolvidos em um sistema de automação devem estar incorporados ao conceito de segurança. Ou seja, isso deve incluir o departamento de TI, especialistas em CLP, a equipe de gestão e de segurança da empresa bem como os fabricantes dos equipamentos para automação.

Existem muitos aspectos a serem considerados quando se trata de segurança. Um deles é a robustez ${ }^{4}$ ou a capacidade de um dispositivo em suportar um volume excessivo de tráfego de dados (dentro de limites pré-estabelecidos). Outro aspecto importante é o mecanismo de acesso que deve ser utilizado para determinar quem/quando pode ter acesso ao sistema.

Estes são apenas alguns dos muitos aspectos que devem ser considerados, sendo que a abordagem escolhida, ao se considerar esses aspectos, é a base para a formação de uma arquitetura de segurança. Uma solução geral e aplicável na definição da melhor arquitetura de segurança não existe, pois a melhor solução deve considerar uma série de fatores tais como: requisitos da aplicação, filosofia da empresa, análise de riscos e etc.

No entanto, existem algumas regras que facilitam a definição de uma arquitetura de segurança, e estas regras formam uma estrutura básica que pode ser utilizada como um guia para a definição da arquitetura.

Uma boa arquitetura de segurança deve ser:

- "Tão simples quanto possível, porém não a mais simples" (Albert Einstein): um bom sistema de segurança deve ser entendido por todas as partes envolvidas para que assim, ele possa ser colocado em prática por toda a equipe. Não deve ser algo que fique apenas nas mãos dos especialistas de segurança.

- 'Tão uniforme quanto possível': se uma regra é aplicada em um caso, ela deve ser seguida também para todos os outros casos similares. Exceções às

\footnotetext{
${ }^{4}$ Robustez: refere-se à capacidade de um dispositivo em garantir o seu funcionamento normal, mesmo em condições desfavoráveis.
} 
principais regras tornam difícil reconhecer violações e deficiências do sistema.

- 'Compreendida e apoiada por todas as partes envolvidas': se a equipe sabe todos os 'o quê?', 'por quê?' e 'como?' das regras e entende sua relevância, muito provavelmente ela será mais eficaz.

- 'Discutida por todos os membros da equipe': o sistema de segurança deve também ser eficaz contra o desconhecido, desta forma, os pontos fracos conhecidos e suas deficiências devem ser corrigidos antes que danos possam ocorrer. Se necessário, deve-se expandir a arquitetura de segurança.

- 'uma atividade diária e não uma atividade de um dia'.

Safety x Security: uma breve explicação acerca dos termos 'safety' e 'security' da língua inglesa torna-se importante neste contexto. Em uma tradução livre, ambos significam segurança, mas a diferença crucial existente entre eles é que 'safety' deve ser entendido como segurança funcional, ou seja, proteção contra os riscos à vida das pessoas, integridade física, saúde, etc., além de riscos contra meio ambiente decorrentes de máquinas ou similares no que diz respeito a erros acidentais. Há uma subdivisão deste termo em: 'functional safety' e 'intrinsic safety'. Por outro lado, o termo 'security' deve ser entendido como uma segurança contra acesso não autorizado, segurança patrimonial, invasão de sistemas tais como de TI ou Automação. Ou seja, está diretamente relacionado à confidencialidade, integridade e autenticidade em relação ao mau uso intencional.

A abordagem utilizada neste trabalho refere-se exclusivamente ao conceito de 'security' em redes industriais.

\subsection{Evolução}

Nos últimos anos, os sistemas de automação evoluíram a partir de computadores isolados com sistemas operacionais e redes proprietárias para sistemas de alta qualidade e performance que dependem de tecnologias populares tais como o sistema operacional Microsoft Windows e protocolos de redes abertos como o TCP/IP.

Os sistemas de automação atuais também estão, cada vez mais, integrados aos sistemas de gerenciamento empresariais (ERP - Enterprise Resource Planning) ou 
ferramentas de negócios, assim como interligados na rede de comunicação de toda a empresa. Este tipo de arquitetura integrada oferece significativas vantagens econômicas, pois aumenta a visibilidade dos parâmetros de produção, do status do sistema, dos planos de produção e etc. permitindo assim uma melhor capacidade na tomada de decisão por parte da diretoria da empresa. A troca de informação entre os sistemas de produção e os outros sistemas corporativos é mais direta o que permite a empresa reagir mais rapidamente reduzindo custos totais no diagnóstico e suporte, uma vez que, agora o suporte remoto torna-se também possível. O acesso mais fácil aos dados permite análises mais rápidas que podem levar a redução de custos de produção, maior produtividade e aumento na competitividade da empresa.

Desde que os primeiros softwares maliciosos apareceram, a questão chave tem sido descobrir a melhor maneira de integrar mecanismos de segurança nos novos ambientes de redes e sistemas de automação.

Conceitos de segurança desenvolvidos para ambientes de escritórios não podem simplesmente ser transferidos para as redes de automação. Medidas de segurança implementadas para os sistemas de automação e redes não devem entrar em conflito com os requisitos relacionados aos protocolos dessas próprias redes, como por exemplo, o Profinet. O principal objetivo das medidas de segurança na área de automação é obter uma rede de automação confiável que atenda a todos os requisitos, sendo outro ponto importante, o fato que sistemas de automação são projetados para o máximo desempenho e não para a máxima segurança. Por exemplo, muitos sistemas não empregam medidas de autenticação para a proteção de acesso indevido (o Profinet é um exemplo desses).

O desafio tornou-se, então, cumprir com todos os requisitos do mundo da automação com um sistema que garanta confidencialidade ${ }^{5}$, integridade $^{6}$ e disponibilidade $^{7}$ dos sistemas e dados mesmo estando sobre ataques maliciosos.

\footnotetext{
${ }^{5}$ Confidencialidade: é a propriedade que garante que os dados ou a informações neles contidas só possam ser acessados por usuários autorizados.

${ }^{6}$ Integridade: é a propriedade pela qual um usuário (pessoas e/ou aplicações) é impedido de gerar, alterar, substituir ou excluir dados de forma despercebida.

${ }^{7}$ Disponibilidade: representa a probabilidade de que o estado de um objeto em questão lhe permite satisfazer uma função requerida, sob condições específicas, em um determinado momento ou durante um período de tempo especificado.
} 


\subsection{Desafios no mundo da Automação}

O crescente uso das tecnologias de TI no contexto da Automação poderia sugerir que as soluções de TI existentes seriam também adequadas para uso em plantas industriais e sistemas de automação e assim, poderiam ser transferidas para esses ambientes. No entanto, as diferenças entre os requisitos diferem significativamente entre o mundo da TI e o mundo da Automação. As principais diferenças estão descritas a seguir.

\subsubsection{Diferentes requisitos funcionais e de desempenho}

Em sistemas de TI típicos, a ênfase do desempenho está na taxa de transferência de dados e na entrega confiável dos mesmos. Atrasos e jitter na transmissão de dados são toleráveis. Por outro lado, atrasos e jitter estão entre as principais características que devem ser levadas em conta na análise do desempenho de um sistema de automação, onde valores altos de atrasos e jitter representam um sério problema.

Além disso, deve-se também considerar que em sistemas de automação existe uma grande variedade de componentes e soluções das quais muitas delas possuem recursos computacionais bem limitados que acabam inviabilizando a utilização de soluções do mundo da TI.

\subsubsection{Interação Homem-Máquina}

Operação e controle confiável dos processos devem ser sempre possíveis em todas as situações. Sistemas de automação devem permanecer disponíveis mesmo em situações críticas. Por esta razão, as medidas de segurança não devem interferir na operacionalidade do sistema de automação.

\subsubsection{Objetivos de segurança}

Um dos principais objetivos na área de TI é a proteção contra perda ou modificação indevida dos dados. Medidas de segurança adequada, muitas vezes, envolvem um conjunto de servidores (controle de acesso, backup, balanceamento de carga, espelhamento de dados e etc.). Em contrapartida, em sistemas de automação industrial, as linhas de produção são dominadas por estruturas granulares que são subdivididas em diversos subcomponentes. Em uma comparação entre as prioridades no ambiente de TI com o da Automação revela posições bem distintas. 
Em TI, os sistemas de segurança possuem objetivos normalmente classificados, em termos de prioridade, da seguinte forma:

1. Confidencialidade;

2. Integridade;

3. Disponibilidade;

Já em muitos sistemas de automação, o ranking de prioridades é bem diferente:

1. Disponibilidade;

2. Integridade;

3. Confidencialidade;

A disponibilidade tem a maior prioridade em sistemas de automação, este aspecto é importante, acima de tudo, para a proteção das pessoas e do meio ambiente.

\subsubsection{Disponibilidade e Confiabilidade}

A maioria das plantas industriais trabalha de forma contínua, sendo que, falhas repentinas no sistema de controle da produção não são aceitáveis. Para garantir a alta disponibilidade dos sistemas de produção, testes intensivos são realizados durante o comissionamento das instalações. Além dos problemas causados por falhas repentinas, em muitos sistemas de controle não é possível desligar e reiniciar o sistema sem afetar negativamente a produção. A necessidade de alta disponibilidade, confiabilidade e facilidade de manutenção faz com que tarefas de manutenção, que necessitem reiniciar o sistema, não sejam aplicáveis. Consequentemente, muitas das atualizações de segurança não são aplicadas de prontidão, porque qualquer mudança de software deve ser exaustivamente testada antes de serem instaladas no processo final (teste de garantia de qualidade). Ambientes de testes, que reproduzam uma planta de produção industrial completa, são necessários para a execução destes, porém não são economicamente viáveis.

\subsubsection{Diferenças na arquitetura de segurança}

Disponibilidade e confiabilidade são fatores críticos em sistemas de automação. Para realizar uma tarefa, geralmente vários dispositivos atuam como um grupo. Isso significa que um funcionamento ininterrupto, livre de erros e com operação simultânea de todos os dispositivos é um fator importante. Se um destes dispositivos falhar, o resultado pode ser uma parada não programada e indesejada no sistema de produção. Assim como na área de TI, mecanismos de redundância são utilizados, porém por 
razões de custo, eles são somente utilizados principalmente onde a falha de algum dispositivo poderia causar sérios danos à planta industrial e/ou ao produto.

O conceito de segurança deve, portanto, considerar o sistema de automação como um todo, uma vez que deve funcionar de forma confiável e contínua como uma só unidade.

\subsubsection{Riscos e requisitos de segurança}

Os requisitos para a segurança funcional de unidades de produção e os riscos associados diferem significativamente dos riscos normalmente associados ao ambiente de TI empresarial. As avaliações de riscos não são transferíveis e geralmente produzem resultados diferentes que, por sua vez, levam a medidas de segurança mais rigorosas.

\subsubsection{Atualização de firmwares $^{8}$ e gerenciamento de patches $^{9}$}

A disponibilidade dos componentes em um sistema de automação é de primordial importância. Isto é porque componentes defeituosos geralmente desencadeiam uma interrupção da operação e consequentemente, uma parada de produção. Em particular, atualizações de firmwares e instalação de patches requerem pelo menos uma reinicialização dos componentes afetados e com isso, afetam diretamente a disponibilidade do sistema. Quando um componente que sofreu uma atualização reinicia, não se pode garantir que o seu comportamento será igual ao que era antes da atualização. Além do mais, muitas vezes, as alterações devem ser previamente feitas em módulos individuais para somente depois, serem aplicados os devidos patches no sistema como um todo. Estes módulos/componentes individuais podem ser atualizados de forma independente um dos outros, mas dependendo da arquitetura do sistema, alguns elementos de hardware são interdependentes e assim, devem ser substituídos concomitantemente.

Assim, nota-se que as condições em que as atualizações de firmware podem ser realizadas, no melhor dos casos, são complicadas e exigem planejamento especial.

\footnotetext{
${ }^{8}$ Firmware: software que está incorporado em uma peça de hardware e que determina a funcionalidade deste.

${ }^{9}$ Patch: atualização de software, incluindo correções de software.
} 


\subsection{Requisitos específicos do Profinet}

\subsubsection{Arquitetura Profinet}

O conjunto de protocolos do Profinet inclui diferentes tipos de endereçamento: um tipo que é exclusivamente baseado no MAC Address e na camada 2 (modelo OSI) de comunicação, e um segundo tipo baseado no protocolo IP da camada 3 (modelo OSI).

Sistemas de automação com esse tipo de arquitetura tendem a ser menos proprietários. Quando o TCP/IP é utilizado, o Profinet pode ser completamente integrado de forma transparente em redes e aplicações baseadas em IP. Estas diferentes relações de comunicação devem ser levadas em consideração no desenvolvimento dos mecanismos de segurança a serem implementados.

O protocolo Profinet pode ser dividido em três diferentes tipos de comunicação: $N R T, R T$ e IRT, conforme apresentado no item 2.4.3 e ilustrado na Figura 12.

\subsubsection{Segurança intrínseca do protocolo}

Os dispositivos Profinet são orientados na confiabilidade e na comunicação em tempo real. Além disso, aspectos de usabilidade desempenham um papel importante na concepção da tecnologia. Um exemplo típico desta situação é a utilização do protocolo DCP (Discovery and Configuration Protocol) na atribuição de nomes aos dispositivos da rede. $\mathrm{O}$ desenvolvimento de mecanismos de segurança deve ser conciliado com os aspectos de usabilidade da tecnologia, pensados para facilitar o trabalho do dia-a-dia com a tecnologia.

O Profinet inclui algumas poucas medidas de segurança, tais como: o campo FrameID (vide item 2.4.5) que é usado para detectar e identificar as relações de comunicação e o CycleCounter que é um contador utilizado na monitoração da troca cíclica de dados.

O objetivo principal dos mecanismos de segurança incorporados no Profinet é melhorar a disponibilidade e confiabilidade operacional das unidades de produção. Uma característica importante é a robustez dos dispositivos Profinet frente a uma carga excessiva de tráfego na rede. Essa característica torna-se ainda mais importante quando se considera que ataques do tipo $\operatorname{DoS}^{10}$ (Denial Of Service) são os mais comuns em

\footnotetext{
${ }^{10}$ DoS (Denial Of Service): tipo de ataque em redes de comunicação cujo objetivo é interromper um serviço.
} 
sistemas de automação. Maiores detalhes sobre esse e outros tipos de ataques em redes de comunicação estão descritos no Capítulo 4.

Além disso, os dispositivos Profinet foram projetados de tal forma a não possuírem intrinsicamente funções de segurança. Desta forma, ataques direcionados a dispositivos Profinet devem ser prevenidos/impedido por medidas de proteção adicionais externas ao dispositivo.

\subsubsection{Tecnologia PROFIsafe}

A PI define o PROFIsafe como uma "tecnologia de segurança funcional integrada, para o uso em todos os setores da automação de manufatura ou automação de processos. Atua independentemente do método de comunicação utilizado com boa relação custobenefício e segurança funcional flexível”. O PROFIsafe está documentado nas normas internacionais IEC 62280-1 e 62280-2.

Conforme estas normas, aplicações seguras (safety) e aplicações convencionais (standard) podem compartilhar simultaneamente o mesmo sistema de comunicação Profinet padrão, por ela denominado de "black channel". No PROFIsafe estão inclusos alguns mecanismos que, deterministicamente, identificam as possíveis falhas e os riscos que podem ocorrer no tráfego de dados do "black channel" e mantém a probabilidade de erro da rede, sobre um certo limite (INTERNATIONAL ELECTROTECHNICAL COMMISSION, 2007).

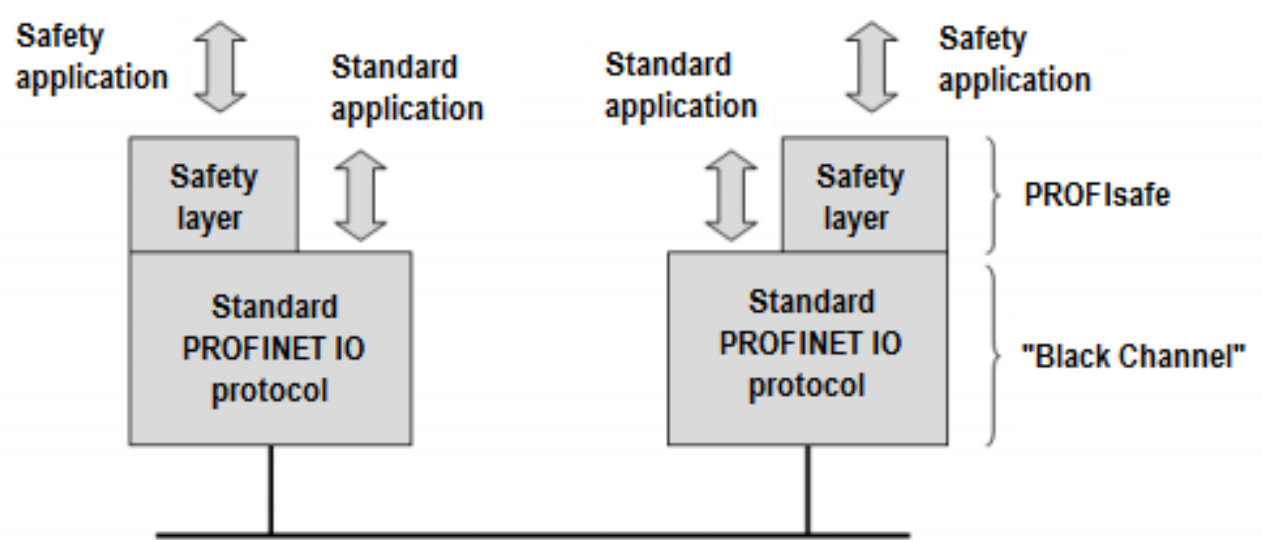

Figura 16: Princípio de funcionamento do Black Channel FONTE: Adaptado de (AKERBERG; BJORKMAN, 2009a)

Utilizando-se esse sistema, é possível estabelecer a comunicação através de duas formas distintas: utilizando-se o sistema de transmissão padrão ou um protocolo de 
segurança adicional sobreposto ao sistema de transmissão padrão, conforme ilustrado na Figura 16.

\subsubsection{Requisitos para o funcionamento seguro do Profinet}

Algumas condições básicas devem ser observadas ao se estabelecer uma arquitetura de segurança no ambiente de redes Profinet. Não basta simplesmente implementar medidas para combater as ameaças, é imprescindível que essas medidas não prejudiquem ou limitem as funcionalidades vitais do Profinet, o que seria improdutivo e sem sentido. Assim, o conhecimento profundo sobre os principais requisitos do Profinet é necessário e essencial para a escolha de mecanismos de segurança adequados que integrem uma arquitetura de segurança ideal.

- Segurança em sistemas sem suas próprias funções de segurança: existem várias razões que explicam o porquê que alguns sistemas de automação atualmente não possuem suas próprias funções de segurança. Como mencionado anteriormente, muitos sistemas não possuem recursos computacionais necessários para a implantação de funções de segurança. Em muitos casos, também, funções de segurança não foram integradas em alguns sistemas por razões econômicas e isso acaba impedindo a instalação e/ou atualização de medidas de segurança. No entanto, a arquitetura de segurança do Profinet deve prover segurança adequada para todos esses casos.

- Operação em tempo real: os mecanismos de segurança não devem interferir com a capacidade da rede em atender os requisitos de tempo real (veja item 2.4.3). Além disso, as funções de segurança não devem retardar as atuações Homem-Máquina que muitas vezes possuem tempos críticos. Um exemplo disso seria a ativação de um botão de parada de emergência que não pode ter seu funcionamento afetado pelos mecanismos de segurança, que poderiam acabar atrasando sua atuação, gerando efeitos negativos e desastrosos.

- Integração transparente e com custo efetivo: os mecanismos de segurança devem ser transparentes e eficientes em termos de custo para o ambiente industrial. A integração das funções de segurança será mais facilmente aceita se forem feitas com um mínimo de reconfiguração do sistema. Lembrando que os especialistas em automação não são, 
geralmente, especialistas em segurança. Uma boa relação custo-benefício pode ser alcançada, sobretudo, por meio da integração de medidas de segurança que também ofereçam segurança por grupos/área.

Adotando-se essa abordagem, torna-se possível criar uma arquitetura de segurança aceita pra o Profinet.

\subsection{Processo de gestão de Segurança}

Uma abordagem para segurança em redes de automação será apresentada em detalhas a seguir.

As diretrizes apresentadas aqui descrevem um modelo de procedimento orientado ao processo, cujo objetivo é apoiar a determinação e validação de soluções de segurança possíveis através de um ciclo de checagem. A Figura 17 ilustra esse ciclo.

No início, o modelo descreve as etapas individuais que são executadas ciclicamente a partir do disparo inicial. Cada passo requer informações de entrada e gera um resultado, que por sua vez, representa a informação de entrada para o próximo passo. Os passos principais desse modelo são: a identificação dos ativos (assets), das metas de segurança relacionadas a estes, e avaliação dos riscos associados com as ameaças identificadas.

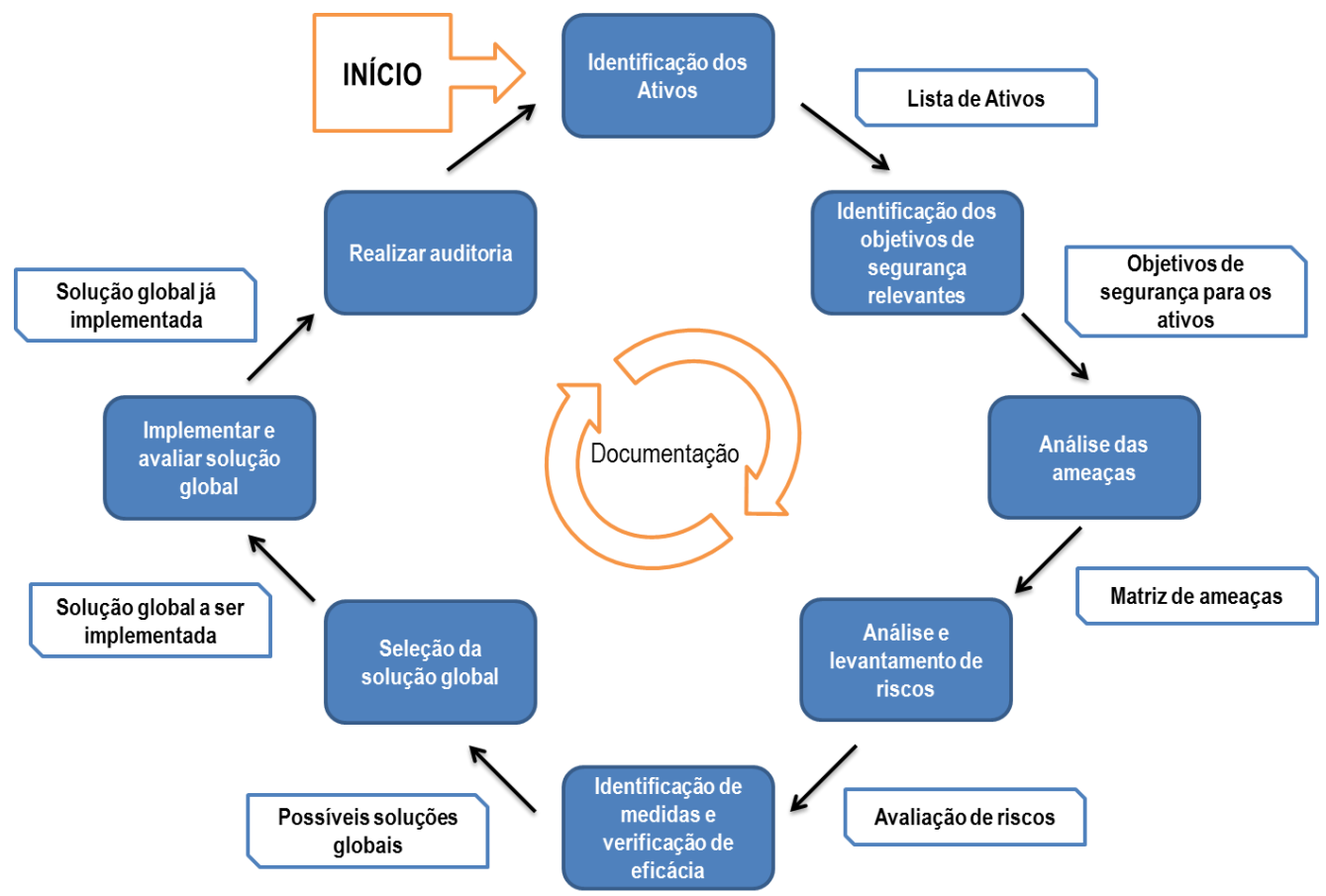

Figura 17: Ciclo do modelo de procedimento.

FONTE: Adaptado de (PROFIBUS INTERNATIONAL, 2013). 


\subsubsection{Inicialização do processo}

Antes de iniciar o planejamento dos mecanismos de segurança, o quadro organizacional da empresa deve ser definido. Um levantamento de dados financeiros, de recursos humanos e de tempo disponível deve estar incluso nesta etapa. As necessidades de uma arquitetura de segurança não são baseadas apenas nas necessidades da empresa, mas também sobre os requisitos legais. Exemplos: requisitos estatutários, obrigações contratuais e até mesmo requisitos relacionados a seguros. Estes não só devem ser considerados no desenvolvimento da arquitetura de segurança, como também afetam diretamente a definição das medidas de segurança. Assim, um passo fundamental na definição das medidas de segurança é, portanto, a triagem das diretrizes, levantamento das regulamentações e normas vigentes, a fim de identificar os requisitos que exigem maiores esclarecimentos.

\subsubsection{Levantamento dos requisitos}

Para permitir um levantamento dos requisitos o mais específico quanto possível, uma análise da estrutura deve ser realizada previamente. Essa análise deve determinar, pelo menos: quais são os aplicativos e serviços essenciais e obrigatórios, quais os sistemas de TI que são utilizados, quais são as reais condições da infraestrutura, quais são os links de comunicação existentes e quais e o tipo de acessos que são necessários.

Esta análise servirá de base para uma definição exata das necessidades que a arquitetura de segurança deve satisfazer.

Somente após este 'inventário' ter sido realizado é que a etapa de levantamento dos requisitos funcionais pode iniciar. Um exemplo de requisito funcional seria o requisito para ser ter acesso remoto aos sistemas por técnicos de serviço qualificados. $\mathrm{O}$ objetivo aqui é responder: o que deve ser protegido?

O resultado nesta etapa é uma visão geral de todos os elementos que necessitam de segurança, e quais os objetivos dessa segurança, além das condições gerais de cada elemento.

Uma vez que todos os requisitos foram levantados e todos os elementos que necessitam de segurança foram identificados uma avaliação deve ser realizada de modo a assegurar que as medidas de segurança a serem adotadas sejam eficazes em termos de custos. Maiores detalhes podem ser obtidos em IEC 62443-2-1 (INTERNATIONAL ELECTROTECHNICAL COMISSION, 2010). 


\subsubsection{Definição das medidas}

Uma vez que todos os fatores foram examinados e avaliados, a definição de medidas pode começar. Uma distinção básica entre os tipos de medidas deve ser considerada:

- Medidas organizacionais

- Medidas técnicas

Os dois tipos de medidas devem estar sintonizados um com o outro, pois uma combinação destes é necessária para produzir uma arquitetura de segurança eficaz. $\mathrm{Na}$ maioria dos casos, as medidas técnicas devem estar acompanhadas de medidas organizacionais, um exemplo seria a adoção de senhas mais complexas para acesso aos equipamentos (medida técnica), que não traria nenhum benefício se não forem acompanhadas de medidas de controle e monitoramento de acesso a essas senhas (medida organizacional).

Em termos de medidas organizacionais, após a análise de risco ter sido concluída, as medidas de segurança podem ser implementadas. O primeiro passo deve ter como objetivo estabelecer a prática de segurança na empresa. Isto irá formar uma base para medidas de segurança bem-sucedidas. Somente quando a segurança é praticada como um processo contínuo é que será possível alcançar e manter a segurança em longo prazo.

Medidas organizacionais formam a base para um conceito de segurança apropriado, enquanto que as medidas técnicas representam o núcleo de sua implementação. Dependendo do tipo de ameaça, uma vasta gama de medidas técnicas pode ser utilizada. Uma solução completa em termos de segurança surge quando diversas medidas são desenvolvidas utilizando-se vários componentes técnicos. Uma combinação de medidas técnicas é essencial para fornecer um alto nível de segurança, uma vez que uma combinação de diferentes tipos de soluções, e não apenas componentes individuais, representa um grande desafio para os potenciais atacantes (hackers). As medidas técnicas podem ser relacionadas à segurança física, à infraestrutura de rede e à segurança intrínseca do equipamento.

Medidas de segurança física referem-se à compartimentação dos elementos dos sistemas de automação em áreas de acesso restrito/controlado. A forma mais simples de se obter uma medida de segurança física é a utilização de painéis de comando com 
chave. Ainda assim, o acesso à áreas de produção deve ser controlado por meio de um controle de acesso rígido. Estas medidas ajudam a manter um melhor controle sobre o acesso as instalações da planta e impede a entrada de pessoas não autorizadas. Com isso, o vazamento de informações confidenciais pode ser limitado e os danos aos equipamentos críticos ao processo de produção podem ser evitados por meio da instalação em áreas fechadas e com controle de acesso.

A implementação de medidas físicas representa um meio, relativamente fácil, de se aumentar significativamente a segurança da planta industrial.

O uso da Ethernet em todos os níveis da empresa simplifica a integração e permite a troca direta de dados entre os diversos setores da empresa. Topologias de redes horizontais facilitam e simplificam a troca de dados entre os componentes do sistema. No entanto, estas representam um enorme desafio para manter a disponibilidade, estabilidade e segurança na operação da rede, pois um único acesso à rede é suficiente para atingir todos os nós.

Portanto, medidas relacionadas à infraestrutura de rede podem contribuir significativamente na proteção das redes de automação. Um exemplo típico de uma medida de infraestrutura é a divisão funcional das redes em células menores, fisicamente independentes.

Para minimizar a quantidade de pontos fracos e de falhas de segurança em uma rede, é recomendável fazer com que cada componente instalado seja o mais seguro possível. Para dispositivos, isso inclui não somente o hardware, mas também as aplicações que rodam neste dispositivo (firmware). Isto pode ser conseguido desativando-se seletivamente aplicações e serviços desnecessários. Além disso, as contas existentes de usuários inativos também devem ser excluídas.

Diversas outras tarefas devem ser realizadas com o propósito de se criar e manter uma arquitetura de segurança eficiente e eficaz. Tarefas essas relacionadas a:

- Identificação e avaliação das medidas de segurança individuais

- Implementação das medidas anteriormente definidas

- Verificação da eficácia das medidas

- Treinamento e envolvimento dos funcionários

- Manutenção dos níveis de segurança 
- Gerenciamento de incidentes

Maiores detalhes acerca dessas medidas citadas podem ser obtidos em (INTERNATIONAL ELECTROTECHNICAL COMISSION, 2010) e (PROFIBUS INTERNATIONAL, 2013).

\subsubsection{Abordagem para resolução de problemas}

Quando soluções de segurança estão sendo desenvolvidas e implementadas, o foco se concentra em encontrar medidas adequadas (organizacionais, físicas, técnicas e/ou de infraestrutura) para controlar e garantir o acesso às áreas, sistemas e equipamentos que necessitam ser protegidos.

Um conjunto de medidas técnicas e organizacionais a serem adotadas divide-se em:

- Políticas e diretrizes

- Gerenciamento de patches

- Gestão de incidentes

- Segurança como um processo da empresa

Gerenciamento da segurança é um componente essencial em qualquer sistema de segurança em plantas industriais. Uma vez que o conceito foi implementado, deve-se realizar verificações periódicas para o levantamento da eficácia das medidas implementadas. Se nesta verificação forem constatados resultados diferentes dos esperados, as medidas devem ser revistas e implementadas novamente. Com isso, o modelo de processo (Figura 17) deve ser executado mais uma vez com as novas medidas e o ciclo se repete. Os objetivos de segurança também podem mudar com o tempo e assim, deve-se prever uma análise de risco periódica para atender as tais mudanças. Um processo de gerenciamento da segurança consistente é essencial para alcançar e manter os níveis de segurança definidos.

\subsubsection{Abordagem por meio de medidas técnicas}

Além de medidas organizacionais, diversas opções de aplicações de medidas técnicas existem e desempenham um papel fundamental na obtenção de altos níveis de segurança na rede. Os principais conceitos de segurança atuais baseiam-se em dois princípios básicos: segmentação e defesa em profundidade. 
O princípio da segmentação considera a abordagem de se estruturar tanto a comunicação vertical quanto a horizontal, a fim de:

- Limitar os ataques (intencionais ou não) e condicioná-los em uma área reduzida.

- Dificultar e limitar o acesso aos possíveis alvos de ataque, que por sua vez, só serão atingidos se a área for invadida.

Estes tipos de soluções são frequentemente referenciados como 'segurança por células'.

O primeiro passo para a implementação de um sistema de segurança baseado na divisão por células é a definição das células. Cada célula pode consistir de uma ou mais células de nível inferior (sub-células) e devem sempre funcionar de forma independente uma das outras. Além disso, o número de componentes pode ser diferente dentro de cada célula, sendo que todos os componentes no interior de uma mesma célula são considerados confiáveis, de tal forma que, não são necessárias medidas de segurança adicionais para a comunicação que ocorre exclusivamente dentro de uma mesma célula.

Assim, tendo-se as células previamente bem definidas, apenas o controle de acesso no ponto de entrada das células precisa ser implementado e, para estes casos, componentes convencionais de segurança podem ser utilizados. A principal vantagem, nesse caso, é que a célula fica protegida de uma possível sobrecarga da rede externa, sendo que o tráfego no interior da célula pode continuar sem perturbação. Isto significa que a comunicação em tempo real no interior da célula não é prejudicada. Além disso, as aplicações e serviços de dentro da célula ficam igualmente protegidos das ameaças oriundas do meio externo.

Considerando-se o conceito de segurança por células, um segmento de rede contido em uma célula, fica protegido contra acesso não autorizado a partir do exterior. Desta forma, os mecanismos de segurança não precisam verificar o tráfego de dados dentro do segmento. Assim, o tráfego de dados deve ser considerado seguro e confiável. O tamanho da célula depende do critério de proteção utilizado, pois em uma célula deve conter apenas os componentes que estão sujeitos aos mesmos requisitos de segurança.

Dependendo dos requisitos de desempenho, as seguintes recomendações devem ser seguidas no dimensionamento dos segmentos de rede: 
- Todos os equipamentos, sobre o domínio de um mesmo controlador, devem pertencer a uma mesma célula.

- Equipamentos que transmitem grande quantidade de dados de um para outro devem pertencer a mesma célula.

- Equipamentos que comunicam com apenas equipamentos pertencentes a uma mesma célula devem ser incorporado a esta célula se os requisitos de segurança forem os mesmos.

Uma rede pode ser segmentada de duas diferentes formas:

- Segmentação lógica

- Segmentação física

A segmentação lógica é feita por meio da utilização do conceito de VLAN (Virtual Local Area Network) que oferece a capacidade de se criar redes separadas logicamente. Isso permite que uma mesma rede física seja dividida em várias sub-redes lógicas de tal forma que os equipamentos que pertencem a uma mesma VLAN só podem trocar informações entre eles. Equipamentos que pertencem a VLANs distintas não podem se comunicar. Todo o tráfego broadcast também fica condicionado dentro da VLAN.

As VLANs são somente estabelecidas entre switches e não entre os dispositivos, de tal forma que não é possível estabelecer uma VLAN entre somente dois dispositivos Profinet. A Figura 18 ilustra um exemplo de uma rede composta por duas VLANs.

$\mathrm{Na}$ segmentação física, as redes de automação são subdivididas em segmentos menores, formando-se pequenas células, conhecidas como ilhas de automação. Essas ilhas por sua vez podem operar independentemente uma das outras. Como não há nenhuma interligação entre as ilhas, não há a possibilidade de acesso exterior a elas, ficando isoladas e com seus componentes protegidos de acesso não autorizado.

Outra forma de segmentação de rede existente é a criação de uma DMZ ${ }^{11}$ (Demilitarized Zone). Todos os equipamentos que requerem ou permitem acesso externo devem ser agrupados dentro desta área. Uma alternativa para aplicações com requisitos de segurança mais rigorosos é a chamada conexão via rede de borda. Para

\footnotetext{
${ }^{11} \mathrm{DMZ}$ (Demilitarized Zone): uma área isolada que só pode ser acessada por meio de pontos de acesso bem definidos e controlados.
} 
estes casos, toda a comunicação entre uma célula de produção e o resto das redes da empresa é bloqueada através de firewalls. Os dados somente podem ser trocados por meio de um servidor intermediário (proxy) localizado na DMZ.

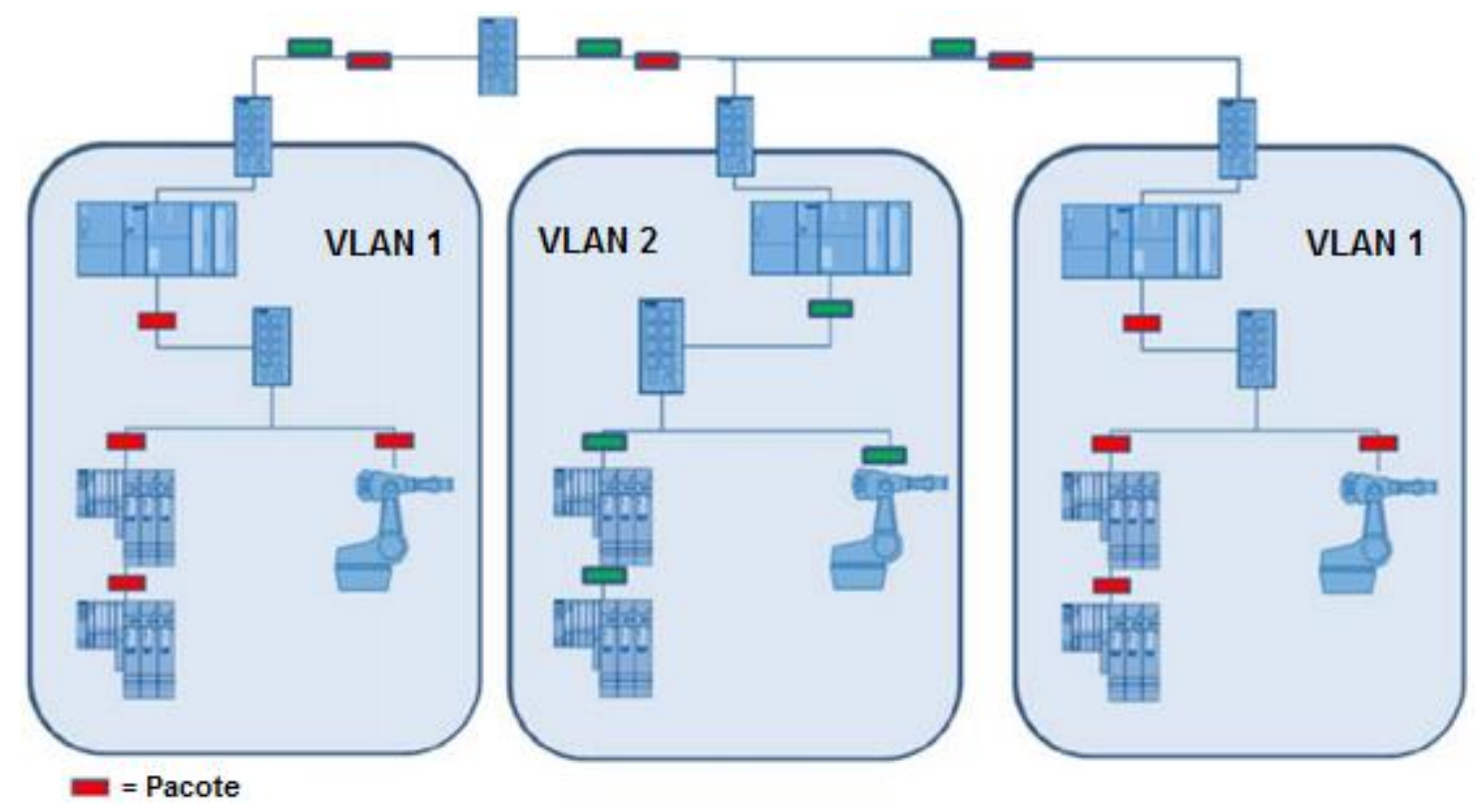

Figura 18: Exemplo de VLANs

FONTE: (PROFIBUS INTERNATIONAL, 2013).

A vantagem principal em se segmentar uma rede é a capacidade de se definir claramente os pontos de acesso entre os segmentos. Com isso, as fronteiras ficam bem estruturadas o que permite que as interfaces sejam facilmente definidas.

Os acessos às redes de automação também podem ser estruturados por meio da definição de sub-redes lógicas. Neste caso, uma sub-rede refere-se ao segmento de rede em que todos os nós podem acessar um ao outro por meio de mecanismos de rede da camada 2 (domínio de broadcast) e possuem o mesmo endereço de sub-rede. As subredes são separadas fisicamente e a ponte de ligação entre elas é feita por meio de um roteador.

Como a comunicação Profinet é fortemente baseada na camada 2 (veja item 2.4.3) e, portanto, não pode atravessar a fronteira do roteador, todos os nós Profinet devem estar localizados em uma mesma sub-rede. No entanto, grandes sub-redes devem ser evitadas uma vez que para esses casos, há um grande aumento de tráfego multicast ${ }^{12} \mathrm{e}$ broadcast $^{13}$.

\footnotetext{
${ }^{12}$ Multicast: mensagem que é transmitida a um conjunto definido de nós (grupo) dentro de uma mesma LAN.

${ }^{13}$ Broadcast: mensagem que é transmitida a todos os nós dentro de uma mesma LAN.
} 
Geralmente, recomendam-se criar sub-redes o quanto menores forem possíveis sem infringir nenhum dos requisitos de desempenho da rede. Na grande maioria das vezes, o critério de divisão em sub-redes coincide com o critério de divisão por células de segurança descrito anteriormente.

A principal vantagem dessa estruturação com sub-redes é que, por exemplo, todo o tráfego multicast e/ou broadcast é enviado exclusivamente dentro de uma sub-rede específica, isso elimina o tráfego de dados adicionais sobre as outras redes do sistema de automação, pois, estas não são atingidas por esse tráfego.

Do ponto de vista de segurança, a formação de sub-redes baseadas em células também é apropriada. Desta forma, por exemplo, as células podem ser facilmente isoladas de um nível superior da rede simplesmente utilizando-se endereços IPs particulares. Isso faz com que não exista a possibilidade de se estabelecer uma comunicação direta com a célula a partir de um nível superior. A comunicação só se torna possível por meio do uso de gateways entre as redes.

Portanto, ao se implementar a segmentação da rede de automação baseada no conceito de células de segurança, garante-se que qualquer acesso não autorizado a uma célula só é possível pelos nós contidos naquela célula, simplificando o processo de rastreio e identificação da origem do acesso indevido.

Uma vez definidas as segmentações da rede, mecanismos de controle de acesso a estas redes devem ser implementados. Os pontos de acesso devem ser escolhidos de tal maneira que eles não estejam colocados diretamente no interior das células por questões de segurança, assim, eles devem sempre ser implementados na parte de fora da célula. Muitas soluções existem para os pontos de acesso, sendo que as três variantes mais comuns de componentes ativos da infraestrutura são:

- Switches: geram integração plena, sem segmentação;

- Roteadores: endereços IP privados x endereços públicos, incorporam segurança básica dependendo do critério de seleção dos endereços;

- Gateways/Proxies: impedem toda e qualquer comunicação direta entre os nós por meio do controle baseado em aplicação.

Praticamente todas as soluções de segurança disponíveis atualmente se baseiam em uma dessas três tecnologias básicas. Por exemplo, a tecnologia base da qual os 
firewalls se baseiam é a de roteador. Nestes casos, o roteador apenas utiliza regras adicionais que são configuradas para o controle preciso da comunicação (endereço IP de origem/destino, protocolo, porta de comunicação, conteúdo e etc.).

Destaca-se que se toda a rede é composta pelos mesmos produtos, existe um grande risco de um ponto-fraco destes produtos ser descoberto e isto irá acarretar em uma falha de segurança em toda a rede.

O caso mais simples de pontos de acesso nas redes é por meio dos switches e dos roteadores. Os roteadores conectam sub-redes distintas enquanto que os switches interligam os equipamentos dentro de uma mesma sub-rede.

Se há a necessidade de comunicação baseada somente na camada 2 (como é o caso predominante no Profinet), a forma mais recomendada para se interligar os segmentos de rede é através de um switch. No entanto, deve-se levar em consideração que quanto maior o número de nós conectados ao switch, maior a quantidade de dados multicast/broadcast propagados pela rede. Isto pode, de certa forma, ser atenuado utilizando-se recursos adicionais no switch que gerencia a comunicação multicast de forma eficiente (CISCO, 2008).

Se os equipamentos envolvidos na comunicação estiverem em sub-redes diferentes, a única forma de se estabelecer uma comunicação entre eles é através do uso de roteadores. A vantagem em se utilizar um roteador é a limitação inerente do tráfego de broadcast/multicast entre os segmentos de rede, pois os roteadores não encaminham esse tipo de tráfego para a outra rede. Assim, o tráfego fica limitado a célula do qual ele originou.

A utilização de gateways pode constituir um mecanismo de segurança muito eficiente, desde que não seja um requisito a comunicação direta entre os segmentos de rede. Um exemplo típico de soluções que utilizam esse conceito são os controladores que possuem mais de uma interface de rede (conector), de tal forma que cada segmento de rede é conectado em uma interface diferente (o controlador atua como ponte de ligação entre os segmentos de rede). Esse desacoplamento entre as redes implica em um amento na segurança.

O firewall representa o mecanismo de controle de acesso mais conhecido e utilizado. Por definição, o firewall é o equipamento utilizado no controle do tráfego entre duas redes. Isto é feito por meio das chamadas ACL (Access Control List) 
(CISCO, 2014). Para a definição destas listas de regras de acesso, são necessárias, pelo menos, as seguintes informações sobre os pacotes que trafegam na rede:

- Quais serviços são necessários estarem ativos entre as redes?

- Quem pode trocar informações entre as redes?

- Em qual(is) direção(ões) a comunicação é permitida?

Um mecanismo que atua como um filtro de pacotes representa a forma mais simples de um firewall.

Os principais tipos de firewall são:

- Tipo 'Stateful Inspection': também conhecida como inspeção inteligente, fornece uma forma expandida e avançada na filtragem de pacotes. Este método permite uma avaliação de todo o contexto da comunicação e não apenas dos pacotes individuais que trafegam na rede. Assim, permitem maiores níveis de segurança, porém possuem custo elevado, são mais complexos para configurar e ocasionam maiores atrasos na rede.

- Tipo 'Firewall de aplicação (Layer 7)': como muitas das ameaças podem ocorrer dentro das aplicações (e não somente nos protocolos da rede), este tipo de firewall também contribui positivamente para a segurança. Ele possui a capacidade de examinar os dados de usuário, que trafegam no interior dos pacotes, e tomar as devidas ações, caso alguma anomalia seja identificada. É possível, por exemplo, prevenir o acesso ou troca de dados com servidores de streaming (transferência de dados constante e em alta velocidade, típica de aplicações multimídias).

- Tipo 'Firewall de usuário (user-specific)': este representa um tipo especial de firewall, não filtra o tráfego de dados baseando-se apenas nas informações contidas nos pacotes (endereço origem/destino, porta, protocolo e etc.), mas também permite ou nega a comunicação baseada nas credenciais de usuários. Isso requer que os usuários se autentiquem no firewall, por exemplo, por meio de login e senha. Desta forma, um conjunto de regras pré-definidas específicas para cada usuário é ativado.

Os Intrusion Prevention System (IPS) e Intrusion Detection System (IDS) podem ser usados como elementos adicionais de segurança. Ambos são capazes de reconhecer ataques e/ou sequência de ataques. A diferença básica entre eles é que o IPS é capaz de 
prevenir o ataque, enquanto que o IDS pode apenas detectá-lo (MUKKAMALA; SUNG, 2003).

A Figura 19 ilustra um exemplo de utilização de firewalls para a segmentação da rede Corporativa e da rede de Controle/Automação, além da utilização de IDS para o aumento do nível de segurança destas redes.

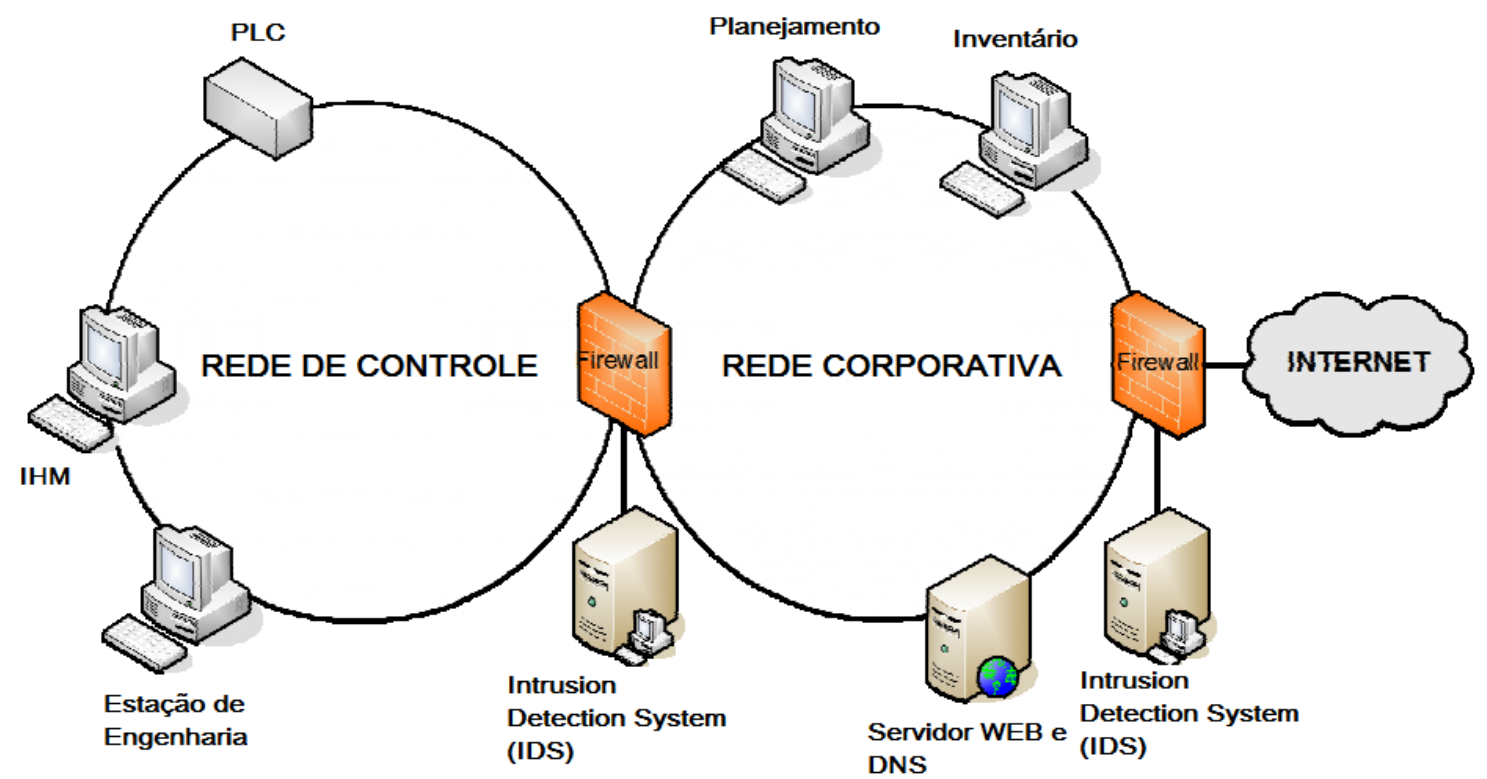

Figura 19: Exemplo de Segmentação de rede com Firewalls e IDS FONTE: Adaptado de (HAHN; GUILLEN; ANDERSON, 2005)

Uma Virtual Private Network (VPN) é utilizada quando se deseja interligar duas redes independentes com recursos avançados de segurança. No mundo da TI, é comum a utilização deste recurso para acesso externo às redes corporativas das empresas. Desta forma, o usuário, que está localizado na parte de fora da rede, passa a pertencer logicamente a esta rede e pode usufruir dos recursos contidos nela (impressoras, repositório de arquivos, base de dados e etc.). Dois componentes básicos são necessários para isso: um VPN Gateway e um VPN Client. O primeiro é responsável pela porta de entrada da rede e o segundo pelo acesso à rede (conforme Figura 20). Todo o tráfego é encapsulado dentro de protocolos seguros que garantem a segurança na transmissão.

A principal função de uma VPN é garantir:

- Confidencialidade 
- Integridade

- Autenticidade.

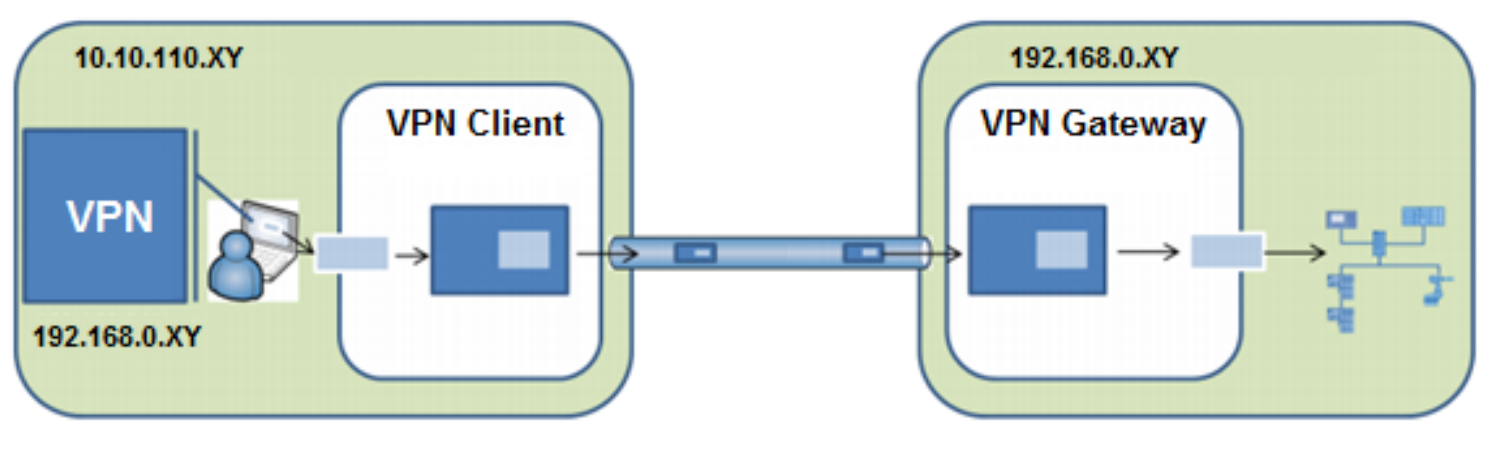

FONTE: Adaptado de (PROFIBUS INTERNATIONAL, 2013).

A maneira com a qual os dados são encapsulados difere para cada caso. Protocolos que utilizam criptografia são geralmente utilizados a fim de garantir os requisitos de confidencialidade, integridade e autenticidade sejam satisfeitos. Os protocolos IPSec (Internet Protocol Security), SSL (Secure Sockets Layer) e TLS (Transport Layer Security) são provavelmente os mais conhecidos e utilizados nesses mecanismos de segurança (CISCO, 2002) (STALLINGS, 1998).

No entanto, antes de se utilizar uma VPN, é necessário o total esclarecimento dos requisitos de segurança e as condições gerais de utilização precisam ser bem definidas. Por exemplo, se a VPN for utilizada para se ter acesso externo por parte de técnicos de serviços, deve ficar claro que isso irá abrir um acesso direto a rede interna por parte de terceiros. É necessária uma definição precisa do gerenciamento de acesso, pois somente a criação de mecanismos de autenticação não é suficiente.

A técnica de encapsulamento de dados deve ser criteriosamente analisada quando se utiliza VPN em conjunto com sistemas IPS/IDS. Como os dados são encapsulados de forma embaralhada (criptografada) e somente as extremidades da VPN pode desembaralhá-los, os sistemas de proteção contra intrusão não poderão ter acesso direto aos dados contidos nos pacotes. Com isso, pode ser que o usuário da VPN acesse dados sigilosos e não seja detectado.

A técnica Defense-in-Depth ("Defesa em Profundidade") consiste na utilização de uma combinação de conceitos e soluções técnicas de tal forma que, quando uma medida de segurança individual falhar, outras medidas irão atuar. Do ponto de vista de um 
sistema de automação, a utilização desta abordagem resulta em um sistema de segurança que abrange todo o perímetro da rede e o seu interior. Isso significa, em outras palavras, que a existência de uma variedade de medidas de segurança, complementares entre si, previnem diferentes tipos de ameaças e cumprem com mais requisitos de segurança, desde proteção contra vírus até proteção de acesso indevido. Desta forma, isso significa que existem várias barreiras que um invasor em potencial deve superar.

Os componentes essenciais do conceito de segurança são: a segurança da planta, a segurança da rede e integridade do sistema.

As medidas para a segurança da planta incluem todos os tipos de medidas físicas para o controle de acesso, bem como medidas organizacionais e o estabelecimento de um processo de gerenciamento de segurança (conforme visto na Seção 3.5).

Já as medidas para a segurança da rede contemplam a proteção das redes de automação contra acesso não autorizado. Isto inclui o controle de todas as interfaces, tais como as interfaces entre o escritório e as unidades de produção, o controle de acesso remoto por parte da equipe de manutenção utilizando-se firewalls e se necessário, uma $\mathrm{DMZ}$ que torna os dados disponíveis para outras redes sem permitir o acesso direto à rede de automação. Já a segmentação das redes das unidades de produção em células de automação individuais serve para minimizar os risco de ataques e aumentar a segurança.

A proteção da integridade do sistema refere-se aos dispositivos, tipo os PC (Personal Computer) com proteção contra vírus, sistemas de automação com mecanismos de controle de acesso aos softwares e equipamentos. Aqui também incluem o fortalecimento de medidas para a redução dos pontos fracos de dispositivos e sistemas.

A abordagem Defense-in-Depth determina que todas as medidas de segurança devem estar alinhadas para se alcançar uma segurança abrangente e confiável em uma planta de automação. Estas medidas incluem os processos para estabelecer e manter a segurança, utilização exclusiva de componentes seguros, e por último, mas não menos importante, a conscientização de todas as partes envolvidas com a segurança.

Esta forma de proteção impede uma variedade de ataques em vários níveis e, portanto, representa um obstáculo maior a ser superado por um potencial invasor. Cada nível individual por si só, representa uma barreira de segurança relativamente fácil de 
superar, no entanto, quando combinado com outros mecanismos, o resultado é muito difícil de superar.

Em suma, os principais pontos a serem destacados quando se utiliza uma abordagem Defense-in-Depth são:

- Vários níveis de segurança devem estar presentes.

- Cada nível deve implementar um mecanismo de segurança diferente.

- Cada nível é construído de acordo com um contexto específico.

\subsection{Considerações Parciais}

Neste capítulo foram apresentados os conceitos e mecanismos de segurança oficiais recomendados pela PI para utilização em redes Profinet. Também foram apontados os aspectos fundamentais para o estabelecimento de um conceito de segurança abrangente no que tange as redes industriais, mais especificamente, o Profinet.

No próximo capítulo, serão demonstrados os principais tipos de ataques em redes Ethernet e como muitos desses ataques são ou podem ser detectados por meio da utilização de Sistemas de Detecção de Intrusão (IDS - Intrusion Detection System). Com isso, também serão apresentados os dois principais tipos de IDS existentes atualmente, suas vantagens e desvantagens além de suas aplicações. 


\section{Capítulo 4}

\section{Ataques em redes Ethernet}

\subsection{Introdução}

Todos os ataques efetuados em redes de comunicação devem ser considerados anomalias nestas redes. Anomalias estas que podem ser definidas como ações diferentes das observadas no comportamento normal do tráfego, que podem ser indicativos de ataques, abuso (mau uso) na rede, eventos de falha na rede, problemas de infraestrutura na coleta de dados, entre outros. Assim, nem toda anomalia na rede pode ser considerada um ataque, mas sempre representa uma informação suspeita que deve ser analisada.

As anomalias de redes são classificadas em quatro categorias principais, sendo: anomalias de operação da rede, anomalias flash-crowd, anomalias de medição e ataques (BARFORD; PLONKA, 2001).

As anomalias de operação da rede incluem os eventos de falhas na rede, tais como interrupção do funcionamento de dispositivos, adição de equipamentos ou configuração inadequada de dispositivos na rede. As anomalias flash-crowd são aquelas que representam um rápido aumento no tráfego da rede, geralmente de um determinado tipo ou para um destino bem conhecido (um servidor, por exemplo). Sendo que, geralmente esse tráfego excessivo é gradualmente reduzido com o tempo. Já as anomalias de medição representam as falhas no sistema de diagnóstico e de coleta de dados que acarretam na obtenção distorcida das informações de status da rede.

Os ataques podem ser considerados como anomalias na rede que podem ser identificados principalmente por meio do fluxo do tráfego de dados. Estes ataques compreendem um "conjunto de ações ilícitas que tentam comprometer a integridade, confidencialidade, ou disponibilidade de recursos na rede", independente do êxito ou não. A infraestrutura de rede pode ficar comprometida, regras de privacidade podem ser quebradas, comprometendo assim a confidencialidade da informação, e essas informações podem também ser modificadas comprometendo a integridade dos dados (SILVA, 2008). 
A maioria dos ataques bem sucedidos ocorre devido a vulnerabilidades ou falhas potenciais existentes nos elementos da rede, tais como configurações incorretas e/ou falhas no desenvolvimento dos protocolos. Essas vulnerabilidades são exploradas por meio de vários tipos de ataques, desde tentativas simples de negação de serviço a ataques mais sofisticados que visam um impacto maior, comprometendo todo o sistema.

Conhecer os principais ataques e as vulnerabilidades mais exploradas é fundamental para a criação de mecanismos de identificação e proteção das redes.

Diversas formas de classificações existem para ataques em redes. Para isso, são utilizados critérios tais como a origem, o alvo, objetivos e etc. desses ataques.

Quanto à origem, os ataques podem ser internos ou externos. Os externos são aqueles que são disparados por um atacante de fora da rede enquanto os internos são aqueles provenientes de usuários internos à rede que abusam de seus direitos e privilégios para realizar atividades não autorizadas.

Já, a classificação com base em alvo é dividida em ataques à rede propriamente dita e ataques a sistemas. $\mathrm{O}$ primeiro tipo refere-se àqueles ataques que visam impedir que os recursos da rede sejam utilizados ou algum serviço fique indisponível e o segundo tipo refere-se aos ataques que tem como propósito comprometer o sistema todo, alterando senhas e adulterando configurações críticas dos equipamentos.

Quanto a seus objetivos, os ataques mais frequentes a redes podem ser classificados como DoS (Denial of Service), Probing, R2L(Remote to Local) e U2R (User to Root). Estes ataques podem ser lançados no local, ou lançados remotamente, através de uma conexão de rede que utiliza o acesso público previamente concedido pelo sistema alvo (SUNG; MUKKAMALA, 2003).

A solução de segurança comumente utilizada em sistemas de automação é a 'defesa de perímetro' entre as diferentes redes, onde cada rede é considerada como uma 'zona de confiança' e assim, todos os nós, pertencentes a ela, podem se comunicar um com os outros sem quaisquer restrições. Para tanto, é comum a utilização de firewalls na interligação das redes e assim, cria-se regras para restringir as mensagens recebidas e enviadas que trafegam entre duas redes adjacentes. Para comunicação através das fronteiras da rede, o uso de VPN - Virtual Private Network é recomendado (AKERBERG; BJORKMAN, 2009c). 
No trabalho de Akerberg e Bjorkman (2009b), os autores propõem a criação de uma camada adicional de segurança na pilha de protocolos do Profinet, denominada de "Security Modules", para se alcançar um nível de segurança de rede que garanta autenticação, integridade e confidencialidade para a comunicação em tempo real. Neste trabalho é mostrado que, utilizando-se a especificação original do Profinet, é possível atacar e assumir o controle dos nós de uma rede Profinet IO sem que nenhum membro da rede detecte esse ataque. Em Akerberg e Bjorkman (2009a), os autores demonstram que mesmo utilizando-se o conceito de PROFIsafe (veja Seção 3.4.3) em conjunto com uma rede Profinet, é possível efetuar um ataque na rede e alterar dados de processo sem que nenhum mecanismo de segurança do protocolo detecte este ataque.

A utilização de firewalls e os métodos de autenticação não são suficientes para assegurar a segurança dos sistemas em rede. Os firewalls não podem evitar todos os ataques provenientes de fora da rede e são inúteis para defender sistemas contra ataques internos. Sistemas de autenticação, por sua vez, não podem evitar que usuários legítimos realizem operações nocivas em um sistema computacional.

Os ataques $D o S$ podem ser classificados basicamente em dois tipos: o primeiro deles representa aqueles ataques em que o atacante tenta interromper apenas um único nó da rede, esse tipo de ataque é conhecido como Host-Based DoS Attack. Os principais alvos desses ataques são dispositivos críticos para a operação do sistema, como controladores, estações IHM (Interface Homem-Máquina) e servidores. Já no segundo tipo, a própria rede é o alvo do ataque. Neste caso, o atacante tenta interromper completamente a comunicação entre os equipamentos da rede. Este tipo de ataque é conhecido como Network-Based DoS Attack (GRANZER; REINISCH; KASTNER, 2008).

Para ambos os casos, existem duas possibilidades de se lidar com o ataque $D o S$ : a prevenção e a detecção do ataque. A prevenção consiste em limitar ao máximo o acesso aos recursos do sistema, de forma que o atacante não possa agir. Uma forma de se fazer isso é impedir o acesso físico aos dispositivos da rede. Para redes cabeadas, isto pode ser feito enclausurando os cabos e os equipamentos em um local seguro e bloqueado (physical security). Obviamente, tal isolação nem sempre é fácil de conseguir devido às restrições do ambiente e principalmente para as redes wireless. Contudo, para os casos em que os métodos de prevenção não são aplicáveis, os ataques $D o S$ devem, pelo menos, serem detectados. Para isso, os métodos de detecção tentam identificar 
comportamentos anormais do sistema. E assim, após a anomalia ser detectada, determinam se essa situação anormal pode resultar em um ataque DoS. Em caso afirmativo, contramedidas devem ser tomadas a fim de minimizar as consequências e de tentar evitar que outros segmentos de rede também sejam atingidos.

Para combinar as vantagens de ambos os métodos, Granzer et al. (2008) sugere que uma solução híbrida seja a mais apropriada para os sistemas de automação.

Uma camada complementar de proteção à rede, identificando e/ou prevenindo contra ações maliciosas e acessos não autorizados é de suma importância. Essa camada é implementada por meio de tecnologias de detecção de intrusão (detalhes no item 4.3).

\subsection{Anomalias no tráfego de rede}

Nesta seção será apresentada uma classificação para as anomalias mais frequentes observadas no tráfego de redes Ethernet, e uma breve descrição e classificação das principais ameaças existentes.

\subsubsection{Definição de anomalias no tráfego de rede}

Anomalias do tráfego de redes de comunicação são ações diferentes das observadas no comportamento normal do tráfego. Estas anomalias podem ser abuso ou mau uso da rede, eventos de falha na rede, falha no sistema de coleta de dados, ataques à rede, entre outros. Com isso, nem toda anomalia de uma rede pode ser considerada como um ataque à ela, mas representa um informação suspeita que deve ser analisada.

No entanto, sejam as anomalias de rede maliciosas ou não intencionais, é importante analisá-las por dois motivos (LAKHINA; CROVELLA; DIOT, 2004):

- Anomalias podem criar congestão na rede e estressar a utilização de recursos de um equipamento;

- Algumas anomalias podem não necessariamente gerar impacto na rede, mas causar grande impacto para um cliente ou um usuário final.

Quando se avalia anomalias em redes, nota-se que suas causas e tipos podem variar consideravelmente: desde abusos á rede, tais como ataques $D o S$, a falhas em algum equipamento, como por exemplo, uma configuração incorreta em um switch gerenciável. A equipe responsável pelo gerenciamento da rede deve detectar as anomalias o mais rápido possível e tomar as devidas ações corretivas de acordo com o 
tipo identificado. O grande desafio, em se tratando de detectar uma anomalia, é que as anomalias podem ser de diferentes origens e propósitos. Assim, um sistema de diagnóstico de anomalias deve ser capaz de detectar uma variedade de anomalias com diferentes estruturas, tendo discernimento entre os diferentes tipos existentes.

O mesmo autor afirma que, apesar de um grande volume de trabalhos na literatura científica, as anomalias de rede ainda permanecem pouco entendidas por três principais motivos. Primeiro, identificar anomalias requer uma sofisticada infraestrutura de monitoramento. Segundo o autor, por questões do alto custo envolvido com o armazenamento dos dados, muitas empresas coletam apenas medições simples do tráfego (usando o protocolo SNMP- Simple Network Management Protocol). Outro motivo que dificulta o entendimento de anomalias no tráfego de redes é que a maioria das empresas não possui ferramentas rápidas o suficiente para processarem os dados de modo a detectar as anomalias em tempo real. Acaba que, a equipe de segurança só é informada após o término da ocorrência, não conseguindo identificá-las quando ainda estão em progresso. O terceiro motivo refere-se à natureza do tráfego de rede, que é multidimensional e com muitos ruídos, essa característica torna difícil a extração de informações significativas acerca de seu comportamento.

Alguns tipos de ataques dificilmente são detectados utilizando-se sistemas baseados em hosts (HIDS). Exemplos desses ataques são: sequestro de conexões TCP, varredura de portas, negação de serviço, entre outros. Estes somente podem ser identificados por meio de ferramentas que capturam e analisam os pacotes de rede $(N I D S)$, permitindo a busca por ataques direcionados a elementos de rede, e inclusive, a determinadas máquinas, por meio dos dados contidos nos pacotes (NORTHCUTT; NOVAK, 2002).

\subsubsection{Classificação de anomalias na rede}

As anomalias no tráfego de rede podem ser classificadas em quatro categorias principais (BARFORD; PLONKA, 2001):

- Anomalias de operação da rede

- Anomalias flash-crowd

- Anomalias de medição

- Ataques 
Uma breve descrição acerca de cada categoria é apresentada a seguir.

\subsubsection{Anomalias de operação da rede}

Nesta categoria estão inclusos os eventos de falhas na rede, tais como interrupção de funcionamento dos dispositivos na rede, ou eventos que geram mudanças significativas no comportamento da rede, tais como a adição de novos equipamentos e configuração incorreta de dispositivos (mesmo que temporariamente). Por exemplo, quando um dispositivo IO-Supervisor insere uma série de pacotes ARP/SNMP na rede para levantamento de informações. Anomalias desta categoria podem ser identificadas visualmente por meio de aclives e declives (alterações súbitas da taxa de bits seguidas de uma estabilidade da taxa) para um nível diferente durante certo período de tempo.

\subsubsection{Anomalias 'Flash Crowd'}

Anomalias desta categoria são caracterizadas por um rápido crescimento de tráfego de um determinado tipo (exemplo, tráfego DCP) ou para um destino bem definido, com redução gradativa com o passar do tempo. Por exemplo, um acréscimo no tráfego oriundo de uma Estação de Engenharia para um IO-Controler representando um download de configuração neste controlador.

\subsubsection{Anomalias de Medição}

Problemas com a infraestrutura de coleta de dados, tal como uma sobrecarga na porta espelhada do switch de captura, ou o rompimento/desconexão do cabo de interligação com a estação de captura, representam tipos de anomalias de medição. Nota-se aqui que este tipo de anomalia não ocorre devido a problemas de infraestrutura ou uso abusivo da rede.

\subsubsection{Ataques}

Também conhecidas como abusos à rede, este tipo de anomalia pode ser identificada, principalmente, por meio da análise de fluxo de dados do tráfego. São exemplos desta categoria os ataques DoS (Denial-of-Service) e de varredura de portas (port scan).

Os ataques se distinguem das anomalias 'flash crowd' e das anomalias de operação da rede ou de medição por não serem detectados por meio de medições de taxas de bits e/ou pacotes. No entanto, uma análise sobre as tendências do 
comportamento do fluxo da rede claramente indicam essas atividades abusivas a partir de atributos específicos extraídos desse fluxo.

A detecção deste tipo de anomalia é o foco deste trabalho.

\subsubsection{Classificação de ataques a redes}

Ataques em redes de comunicação compreendem um conjunto de ações ilícitas que tentam comprometer a integridade, confidencialidade, ou disponibilidade de recursos na rede (NORTHCUTT; NOVAK, 2002). Informações podem ser adulteradas quebrando a integridade dos dados. Regras de privacidade podem não ser respeitadas devido ao um ataque, comprometendo a confidencialidade da informação. A infraestrutura de rede pode ficar indisponível e não confiável afetando assim, a disponibilidade de recursos na rede.

Segundo estatísticas do CERT/BR (CERT - Estatísticas do CERT.br - Incidências, 2015), com o passar dos anos, o número de ataques (incidentes) cresce de forma significativa. Veja na Figura 21 a evolução do crescimento do total de incidentes nos últimos anos.

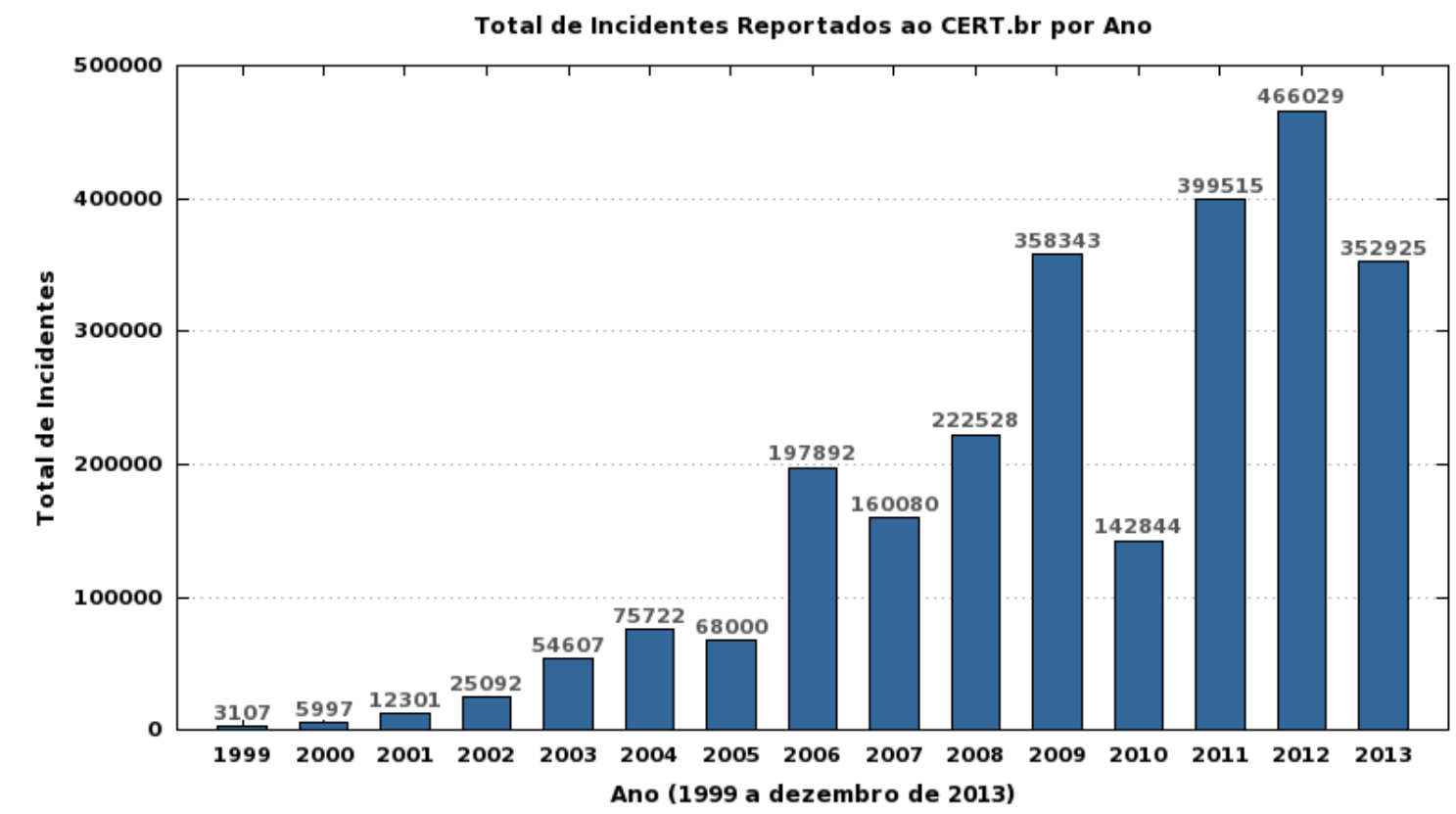

Figura 21: Incidentes reportados no Brasil entre 1999 e 2013. FONTE: (CERT - Estatísticas do CERT.br - Incidências, 2015)

As violações aos mecanismos de segurança de dados e aos sistemas computacionais interligados em redes podem ser descritas como: 
- Acesso implícito ou explícito, não autorizado pelo proprietário, a dados sigilosos (violação de confidencialidade).

- Impedimento de acesso legítimo a recursos e sistemas em rede por certo usuário, humano ou máquina (violação de confidencialidade).

- Alteração ilegal de dados armazenados ou transmitidos pela rede (violação de integridade).

A maioria dos ataques bem sucedidos ocorre devido a vulnerabilidades ou falhas existentes nos protocolos de rede e/ou mecanismos de segurança destas. Podem ser falhas relacionadas à incorreta configuração do sistema ou falha no desenvolvimento dos softwares. Essas falhas e vulnerabilidades podem ser exploradas por meio de diversos tipos de ataques. Portanto, conhecer os principais ataques, as vulnerabilidades exploradas e os alvos principais dos atacantes, é fundamental para a criação de medidas de segurança eficazes.

Os ataques podem ser classificados de diversas formas, tomando-se critério de classificação a sua origem, o seu destino ou alvo e objetivos (SHIREY, 2000).

Quanto à origem, os ataques podem ser internos ou externos.

\subsubsection{1 $\underline{\text { Ataques internos }}$}

São aqueles provenientes de membros internos à rede que abusam de seus direitos e privilégios para realizar atividades não autorizadas e/ou para obter acesso não autorizado a recursos e sistemas em rede.

\subsubsection{Ataques externos}

Representam os ataques lançados de fora da rede por um atacante que tenta, sem autorização, acessar a rede para obter informações confidenciais ou tornar indisponíveis determinados serviços da rede alvo.

Quanto ao alvo, os ataques podem ser classificados como ataques à rede e ataques aos sistemas. 


\subsubsection{Ataques à rede}

Esta modalidade de ataque visa impedir a utilização de recursos de rede ou tornar os serviços de rede indisponíveis. Podem também, monitorar o tráfego de rede para, convenientemente, analisá-lo e coletar informações sigilosas.

\subsubsection{Ataques aos sistemas}

A finalidade destes ataques é comprometer o sistema, bem como alterar ou excluir arquivos críticos, tais como arquivos de senhas e de configurações do sistema. No contexto da Internet, encontram-se os ataques que visam à modificação de páginas WEB para depreciação ou banalização da imagem de empresas. Já no contexto da Automação, têm-se os ataques que tentam inserir códigos de lógica ladder nos CLPs a fim de comprometer o controle do processo industrial do qual o controlador é responsável. O mais famoso ataque deste tipo, no contexto da Automação Industrial, é o Stuxnet (MIYACHI et al., 2011).

Segundo Sung et al. (2003), quanto aos objetivos, os ataques mais frequentes em redes de computadores podem ser classificados como:

\subsubsection{Denial of Service $(D o S)$ :}

Este tipo de ataque é aquele em que o atacante faz com que os recursos computacionais ou de memória dos equipamentos fiquem sobrecarregados de tal forma que, as requisições normais oriundas da rede não possam ser atendidas e assim, o equipamento fique indisponível por não poder ser acessado. Este tipo de ataque aproveita falhas de protocolos e/ou programas para deixarem o equipamento, ou até mesmo uma rede inteira, impossibilitada de executar sua tarefa. Exemplos tradicionais desse tipo de ataque em redes de computadores são: smurf, Neptune, ping-of-death, mail-bomb e UDPStorm.

As principais estratégias utilizadas nos ataques DoS incluem (BERTHOLDO; ANDREOLI; TAROUCO, 2003):

- Inundar uma rede visando impedir que usuários legítimos façam uso dela;

- Impedir ou romper a conexão entre duas máquinas visando impedir o acesso a um serviço;

- Impedir o acesso de um determinado serviço ou servidor; 
- Impedir ou negar um serviço a um sistema ou pessoa específica.

Os três tipos principais de ataques $D o S$ são:

- Exploração de falhas: exploram vulnerabilidades no software do sistema alvo causando falhas em seu processamento ou extinguindo seus recursos.

- Flooding: sobrecarregam um sistema enviando mais informação do que ele é capaz de manipular. Mesmo que a capacidade de processamento do sistema não seja totalmente tomada, o atacante pode ser capaz de monopolizar a conexão de rede do alvo, bloqueando assim qualquer tipo de uso deste recurso.

- $\quad D D o S$ (Distributed DoS): representam uma série de ataques $D o S$ onde os atacantes utilizam-se de vários locais para lançar o ataque e assim, rapidamente sobrecarregar um determinado sistema alvo. Neste tipo de ataque é realizada uma sobrecarga ou inundação de pacotes contra um determinado serviço, host ou rede, gerando muitas vezes uma quantidade de dados global maior que a rede ou host pode suportar, tornando a rede ou serviços instáveis e consequentemente prejudicando o seu desempenho. Esses ataques fazem uso de várias 'máquinas zumbis' para que o número de requisições de conexão ao servidor seja expressivamente maior. São ataques mais eficientes e complexos e, portanto, mais difíceis de detectar.

\subsubsection{Probing (scan)}

Neste tipo de ataque o invasor efetua uma varredura na rede ou nos equipamentos da rede com o propósito de identificar fraquezas ou vulnerabilidades que posteriormente possam ser exploradas de modo a comprometer o sistema. Estes tipos de ataques por sondagem não penetram ou comprometem os sistemas. Estes ataques possuem várias denominações, dependendo das atividades que executam: network/port scanners, port/network mappers ou vulnerability scanners. Essa técnica é geralmente usada na mineração de dados por meio das ferramentas saint, portsweep, mscan e nmap.

As respostas recebidas destes sistemas são utilizadas pelo atacante para aprender sobre as características da rede e dos sistemas, incluindo a topologia da rede, os hosts ativos e suas respectivas configurações de software, incluindo sistema operacional, software do servidor e versões de aplicativos. 


\subsubsection{Ataques de Penetração}

Os ataques de penetração, conhecidos como ataques R2L e U2R, realizam aquisição ou alteração não autorizada dos privilégios, recursos ou dados do sistema, violando as propriedades de integridade e controle dos recursos e dados. Com estes ataques, pode-se ganhar controle de um sistema ao explorar uma variedade de falhas de software.

\section{A. Remote to Local $(R 2 L)$}

Nessa modalidade de ataque, o atacante envia pacotes para o equipamento através da rede externa (Internet, por exemplo), a fim de expor as vulnerabilidades e explorar privilégios que somente um usuário local poderia ter acesso. Exemplos desse tipo de ataque são: xlock, guest, xnsnoop e phf.

\section{B. User to Root (U2R)}

Nesta categoria os ataques consistem daqueles casos em que, localmente, o atacante tenta explorar as vulnerabilidades do sistema a fim de obter privilégios adicionais. Exemplos desse tipo de ataque são: perl e xterm.

Estatísticas de incidentes de segurança notificados ao CERT.br (CERT Estatísticas do CERT.br - Incidências, 2015), comprovam a proliferação de ataques a redes, incluindo worms, varreduras de portas, ataques de negação de serviços e incidentes em aplicações e estações servidoras Web, conforme ilustra a Figura 22. 


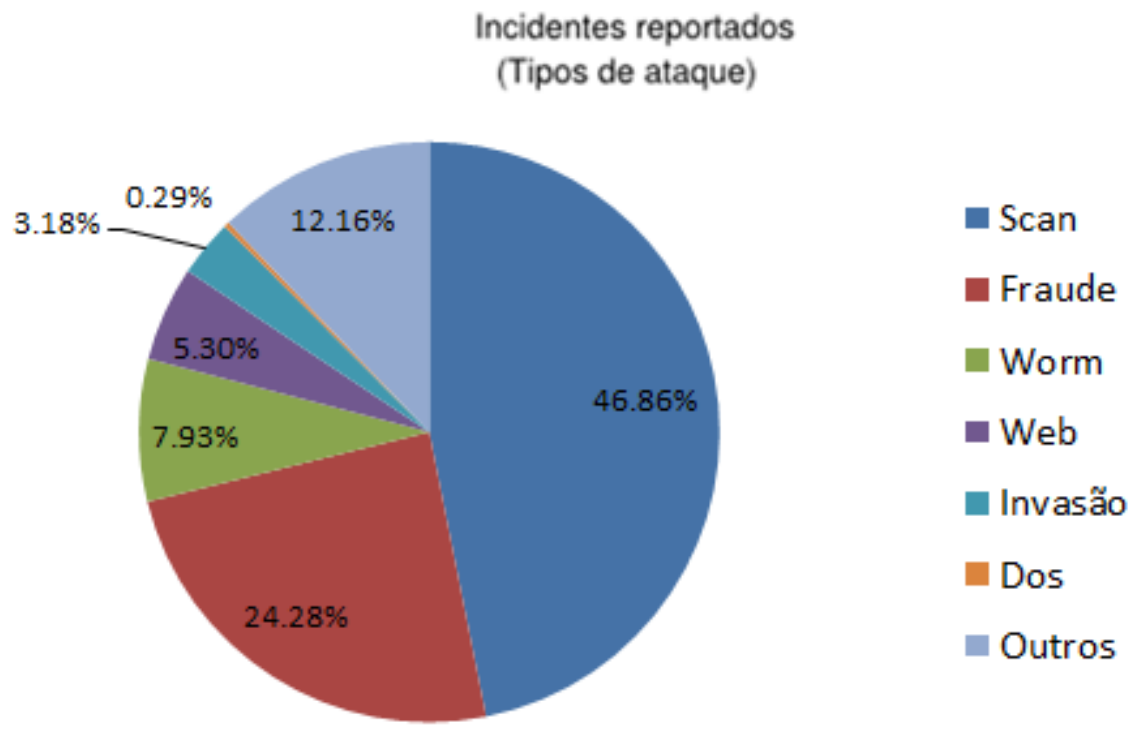

Worm: notificaçäes de atividades maliciosas relacionadas como processo automatizado de propagaçăo de códigos maliciosos na rede.

DoS (Denial of Service): notificaçāes de ataques de negação de serviço, onde 0 atacante utiliza um computador ou um conjunto de computadores para tirar de operação um serviç, computador ou rede.

Invasão: um ataque bem sucedido que resulte no acesso não autorizado a um computador ou rede.

Web: um caso particular de ataque visando especificamente o comprometimento de servidores Web ou desfigurações de páginas na Internet.

Scan notificações de varreduras em redes de computadores, com o intuito de identificar quais computadores estão ativos e quais serviços estão sendo disponibilizados por eles. Ė amplamente utilizado por atacantes para identificar potenciais alvos, pois permite associar possiveis vulnerabilidades aos serviços habilitados em um computador.

Fraude: segundo Houaiss, é "qualquer ato ardiloso, enganoso, de má-fé, com intuito de lesar ou ludibriar outrem, ou de não cumprir determinado dever, logro". Esta categoria engloba as notificações de tentativas de fraudes, ou seja, de incidentes em que ocorre uma tentativa de obter vantagem.

Outros: notificações de incidentes que não se enquadram nas categorias anteriores.

Figura 22: Ataques reportados no Brasil entre Janeiro e Dezembro de 2013 FONTE: (CERT - Estatísticas do CERT.br - Incidências, 2015)

Estas informações aceleram as pesquisas e o mercado de software de segurança, tais como os firewalls, as aplicações de criptografia, as ferramentas de software conhecidas como 3A (Autenticação, Autorização e Administração de usuários) e os sistemas de detecção de intrusão (IDS).

\subsection{Sistemas de detecção de intrusão}

Sistemas IDS são ferramentas que visam incrementar o nível de segurança em um sistema computacional (NORTHCUTT; NOVAK, 2002). Detecção de Intrusão é uma técnica utilizada para detectar ataques ou perturbações a um sistema computacional ou rede de computadores. O IDS usa as informações coletadas do sistema monitorado (computador, rede ou segmento de rede) para detectar intrusões. Enquanto as medidas de prevenção ativamente buscam evitar que ataques aconteçam, os sistemas de detecção procuram identificar ataques pela análise passiva do tráfego da rede ou os logs do 
sistema. Após a detecção de um ataque, um IDS deve gerar uma resposta, que pode ser uma intervenção automatizada no sistema ou um alerta para intervenção humana (KIZZA, 2005).

Especificamente para redes de comunicação, existem os NIDS (Network Intrusion Detection System) que utilizam informações coletadas da própria rede ou segmento de rede para identificar ataques que estejam ocorrendo ou que já tenham ocorrido. Os sistemas NIDS usam geralmente dois tipos de abordagem: abordagem baseada em assinatura e abordagem baseada em anomalia sendo que cada uma dessas abordagens possui suas vantagens e desvantagens. A abordagem baseada em assinaturas requer um conhecimento prévio a respeito da forma como cada ataque ocorre, ou seja, sua assinatura. Assim, os NIDS baseados em assinaturas são menos eficientes na identificação de ataques que usam técnicas ainda desconhecidas (SILVA et al., 2008). Já a abordagem baseada na detecção de anomalias, que por sua vez, procura detectar alterações no padrão do tráfego em relação ao comportamento normal, pode gerar um excesso de falsos positivos, inviabilizando a intervenção automatizada ou acarretando na geração de excessivos falso-positivos (KRUEGEL; VIGNA, 2003).

Na pesquisa e desenvolvimento de um NIDS baseado em anomalia, um dos pontos essenciais é a construção de um perfil da rede. A construção do perfil da rede depende do método de análise usado e implica o conhecimento das características específicas do tráfego de rede. Nesse sentido, há diversos métodos de detecção de anomalias no tráfego de rede, como métodos baseados em análise estatística (SAMAAN; KARMOUCH, 2008), estatística bayesiana (LIU et al., 2008), cadeias de Markov (PANHONG et al., 2011); métodos de mineração de dados, como algoritmos de agrupamento (LI; LEE, 2003), de formação de rankings (QUAN et al., 2013) e lógica fuzzy (YAO; ZHITANG; SHUYU, 2006); alguns métodos de inteligência artificial, como sistemas imunológicos artificiais (GUANGMIN, 2008), SVM (Support Vector Machine) (MAFRA et al., 2008), Redes neurais Perceptron Multi Layer (LINDA; VOLLMER; MANIC, 2009), Hamming Net (SILVA; SANTOS; MONTES, 2004) e algoritmos genéticos (SELVAKANI; RAJESH, 2007) e (OJUGO et al., 2012); métodos baseados na análise de sinais com transformada wavelet (BARFORD et al., 2002) (LU; TAVALLAEE; GHORBANI, 2008), (KIM; REDDY, 2008) e (PERLIN; NUNES; KOZAKEVICIUS, 2011). 
Nos diversos métodos citados, o processo de detecção de ataques realizado por um NIDS pode ser dividido em três atividades fundamentais: Coleta, Análise e Resposta (NORTHCUTT; NOVAK, 2002). A Coleta corresponde à obtenção dos dados do sistema monitorado e pode ser feita diretamente ou por meio de uma ferramenta de software ou hardware chamado sniffer. Os dados geralmente são oriundos de um computador, uma rede ou um segmento de rede. A Análise consiste no processamento desses dados coletados, procurando identificar a ocorrência de uma intrusão. Há diferentes métodos de análise que seguem a abordagem baseada em assinaturas ou baseada em anomalias que serão apresentados nas próximas seções. Já a Resposta é o conjunto de ações que o IDS realiza quando detecta uma intrusão. É muito comum a geração de alarmes e registro em relatórios, mas o IDS também pode ser programado para fazer uma intervenção automatizada no sistema em caso de intrusão.

\subsubsection{Classificação dos IDS}

Os sistemas de detecção de intrusão podem ser classificados considerando-se vários critérios: o método de detecção utilizado, a arquitetura do sistema, o comportamento deste após a detecção dos eventos intrusivos e a frequência de uso (SILVA, 2008). A Figura 23 ilustra essa classificação.

\subsubsection{Frequência de uso}

Quanto à frequência de uso, o IDS pode ser projetado para continuamente analisar os eventos de rede (análise online ou em tempo real) ou ser configurado para análise periódica dos eventos de rede (análise off-line ou post-mortem).

\subsubsection{Comportamento pós-detecção}

Um IDS que é projetado para realizar, por exemplo, um bloqueio de conexões provenientes de uma origem não confiável, é denominado ativo, pois executa ações reativas após a detecção de intrusos. Alguns autores denominam esse tipo de sistema como IPS (Intrusion Prevention System) (MUKKAMALA; SUNG, 2003). Já os IDS passivos são aqueles que examinam as informações da rede ou sistemas e alertam sobre os ataques e ameaças emergentes, não reagindo aos ataques. 


\subsubsection{3 $\underline{\text { Arquitetura - segundo a localização }}$}

Segundo a localização, o IDS pode ter arquitetura centralizada, hierárquica ou distribuída. Um IDS de arquitetura centralizada possui seus módulos de detecção instalados em um único host e apresenta a vantagem da facilidade no desenvolvimento, na instalação e na configuração. O IDS de arquitetura distribuída possui seus módulos de detecção distribuídos em várias máquinas pela rede, que se comunicam de modo cooperativo por meio da troca de mensagens para garantir uma redundância intrínseca. A grande vantagem desta arquitetura, além de maior robustez, é a modularidade. Por ser dividido em vários elementos, há certa facilidade na adição de novos mecanismos ao sistema de acordo com a necessidade. Outra vantagem desta arquitetura é a possibilidade da distribuição de tarefas, retirando-se de um único ponto o custo e a responsabilidade de todo o processamento, além da vantagem adicional de se ter uma maior abrangência de detecção, com módulos espalhados pelos mais diferentes pontos do sistema. A Figura 23 ilustra esses critérios de classificação.

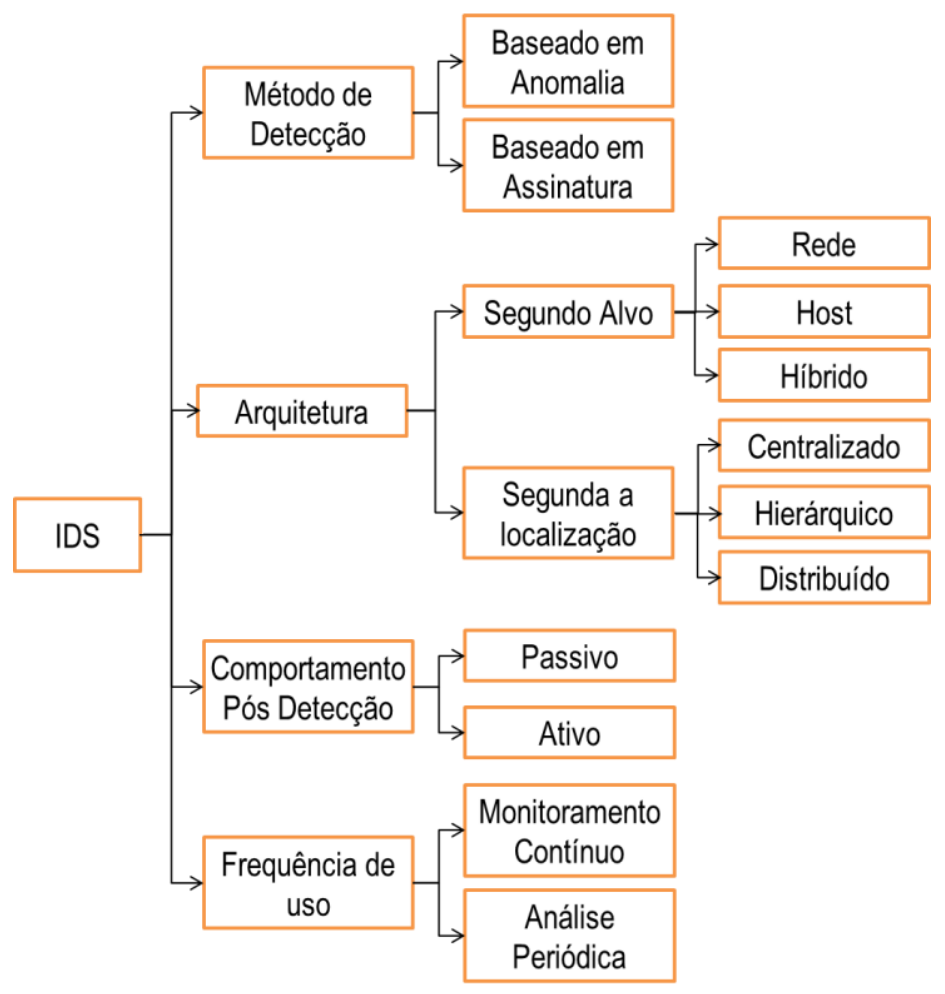

Figura 23: Classificação dos IDS FONTE: (SILVA, 2008)

Já uma arquitetura hierárquica para IDS consiste na distribuição parcial dos componentes do IDS de modo que os módulos de detecção distribuídos fiquem subordinados a alguns módulos 'gerentes' e se comuniquem segundo a coordenação uma coordenação centralizada, ou seja, os módulos obedecem a uma estrutura 
hierárquica, com a interação entre os módulos do sistema sendo regida por relações de subordinação. Esta abordagem foi desenvolvida para resolver alguns problemas referentes à implementação de sistemas completamente distribuídos. Algumas vantagens próprias dos sistemas distribuídos continuam existindo enquanto que a solução de problemas, por exemplo, a detecção de falhas nos módulos do sistema, é facilitada devido à estrutura hierárquica. No entanto, aumentam as chances de ataques ao sistema, principalmente pela criação de pontos únicos de falha, representados pelos módulos 'gerentes' mais altos da estrutura hierárquica. Se um desses módulos falhar, todo o sistema pode tornar-se indisponível, sendo este, um contrassenso à principal motivação no uso de sistemas distribuídos (SILVA, 2008).

\subsubsection{Arquitetura segundo o alvo}

Um IDS pode ser classificado pelo tipo de alvo a ser monitorado:

- Baseado em rede

- Baseado em host

- Híbrido.

Uma das vantagens de um IDS em relação aos métodos tradicionais de análise de incidentes é a possibilidade de correlacionar diferentes tipos de dados coletados. Estas atividades de coleta de dados, no entanto, sejam elas feitas no próprio host ou na rede, determinam o tipo do IDS, baseado em host, em rede ou híbrido.

IDS baseado em host. Sigla HIDS (Host Intrusion Detection System), utilizam dados coletados na própria máquina como arquivos de log e registros de auditoria o que permite a determinação exata de quais usuários e processos executaram operações indevidas no sistema, o que garante boa precisão na detecção. Este tipo de IDS é capaz de monitorar os acessos à máquina, as alterações em arquivos críticos do sistema, modificações nos privilégios dos usuários, processos, programas que estão sendo executados, a disponibilidade de processamento e memória, entre outros eventos. Após a coleta destas informações, o sistema busca por padrões de ataques ou de desvios de comportamento de hosts ou usuários.

Segundo (DEMIRAY, 2005), as principais vantagens de um HIDS são:

- Como eles monitoram atividades locais, eles podem identificar ataques que não são detectados por um sistema NIDS; 
- A base de dados desses sistemas geralmente é composta por arquivos textos simples, armazenados localmente e, portanto, podem operar perfeitamente em redes cujo tráfego de rede é criptografado;

- O desempenho de um sistema baseado em Host não é afetado pela topologia de rede que operam e podem funcionar perfeitamente em redes comutadas (switches).

Contudo, as principais desvantagens são:

- É mais custoso gerenciar e manter um HIDS porque eles devem ser instalados/configurados em cada Host (individualmente);

- Um ataque sobre a máquina que executa o HIDS pode fazer com que o próprio sistema de detecção seja desativado;

- Um sistema HIDS visualiza apenas os pacotes que são recebidos pela máquina onde ele está instalado, ou seja, seu funcionamento é ineficaz para ataques que envolvem toda a rede;

- Os sistemas HIDS compartilham os recursos da máquina onde estão instalados (CPU, memória RAM, HD e etc.), consequentemente podem afetar o desempenho da máquina que o hospeda.

IDS baseado em rede. Sigla NIDS (Network Intrusion Detection System). Realizam a monitoração do sistema por meio da captura e análise de cabeçalhos (header) e conteúdo de pacotes (payload) de rede, os quais podem ser comparados com padrões de ataques conhecidos ou assinaturas previamente armazenadas em regras, arquivos ou bancos de dados, ou com padrões normais do tráfego, para verificação de algum desvio do comportamento normal da rede. A fonte de informação usada por um IDS de rede é a coleta dos dados que trafegam na própria rede (pacotes) e sendo essa informação bem diversificada devido aos inúmeros protocolos que podem coexistir em um mesmo segmento de rede.

Segundo (DEMIRAY, 2005), as principais vantagens de um NIDS são: 
- Uma grande rede pode ser monitorada por um número reduzido de sensores, pois estes sensores são instalados apenas nos pontos críticos da rede, como nos switches, hubs, roteadores e etc.;

- Um sistema NIDS geralmente atua em modo passivo e, consequentemente, não afeta o funcionamento normal da rede;

- Um sistema NIDS, muitas vezes, nem sequer é percebido pelos atacantes das redes.

Entretanto, as principais desvantagens são:

- Em redes em que o tráfego de rede é elevado, pode ser difícil processar todos os pacotes que trafegam na rede;

- Sistemas NIDS não conseguem analisar integralmente os pacotes de tráfego criptografado (somente dados do header, como origem/destino e tipo);

- Pacotes de redes malformados podem fazer com que um sistema baseado em rede pare de funcionar.

IDS Híbrido. Em busca de equilíbrio entre desempenho, simplicidade, abrangência e robustez, algumas implementações, mais avançadas de IDS, coletam diferentes dados de hosts e do tráfego de rede, mesclando mecanismos centralizados com distribuídos. Grande parte das ferramentas atuais de detecção de intrusão explora o melhor das arquiteturas baseadas em host e rede, adotando soluções híbridas (NORTHCUTT; NOVAK, 2002).

A análise de todas essas informações oferece bons subsídios aos sistemas de detecção de intrusão, agregando precisão e desempenho às suas tarefas.

\subsubsection{Método de detecção}

Um IDS pode ser baseado em assinatura (abuso ou baseado em conhecimento) ou em anomalia (baseado em comportamento). Anomalias são desvios do comportamento normal de uso e assinaturas, por outro lado, são padrões conhecidos de ataques.

O método de detecção baseado em assinatura consiste no casamento de padrões de dados contra bases de dados contendo padrões de ataques conhecidos por eventos 
passados. Sistemas deste tipo são altamente eficientes na identificação de ataques e vulnerabilidades conhecidos, mas ineficientes na identificação de novas ameaças aos sistemas. O método de detecção baseado em anomalia, por outro lado, busca dados inéditos ou não usuais em um conjunto de dados, aplicando várias técnicas matemáticas, estatísticas, de inteligência artificial e outros (veja alguns exemplos na Seção 4.3), para comparar as atividades dos usuários, rede ou sistemas com o conhecimento histórico armazenado sobre estes elementos. Os problemas mais comuns, com os sistemas baseados em anomalias, são os que requerem treinamento extensivo por meio de algoritmos de aprendizagem artificial, grande quantidade de dados históricos, e tendem a ser computacionalmente mais caros, porque devem realizar medições com mais frequência, alta capacidade armazenamento para manter os dados coletados e serem atualizados a cada novo comportamento do sistema, usuários ou rede. Isto resulta em armazenamento de grande quantidade de dados e consideráveis recursos de CPU para processá-los.

A seleção do conjunto de variáveis, usadas no processo de análise dos dados capturados, tem grande influência na capacidade de detecção do IDS. O número de variáveis tem grande impacto no desempenho computacional da ferramenta, contudo, a seleção das variáveis, geralmente, é feita por meio de métodos empíricos. Esta seleção, que consiste em uma tarefa preliminar de um sistema IDS, é muito importante, porque o sucesso do sistema de detecção de intrusão depende fortemente da decisão tomada sobre o conjunto das características que o sistema vai utilizar para detectar o ataque (ABDOLLAH et al., 2008).

As variáveis selecionadas dependem também do tipo de IDS usado e dos tipos de anomalias de interesse. Por exemplo, para um IDS normalmente se está interessado nos endereços de origem e destino, portas e protocolos dos pacotes de rede. Quanto aos dados coletados em uma rede, um NIDS pode utilizar os dados do payload do pacote, como em (KRUEGEL; VIGNA, 2003), ou apenas as informações do header, como em (LONGCHUPOLE; MANEERAT; VARAKULSIRIPUNTH, 2009) e (KIM; REDDY, 2008).

A seleção de variáveis consiste na escolha das características (ou atributos) de rede a serem utilizadas na análise do tráfego capturado. Normalmente, faz-se a distinção entre as características referentes a uma única conexão ou a nenhuma conexão, daquelas referentes a múltiplas conexões. As características do tráfego de rede podem ser 
classificadas como Primitivas ou Derivadas. As Primitivas se referem às características retiradas diretamente dos pacotes de tráfego da rede, enquanto que as características Derivadas relacionam dados de vários pacotes a fim de identificar padrões de comportamento dinâmico. São também conhecidas como características de tráfego (ONUT; GHORBANI, 2007).

$\mathrm{Na}$ coleta destas características, podem ser usados dois métodos baseados em Janela de Observação: o primeiro tipo é baseado em uma janela com intervalo de tempo (por exemplo, 3 segundos), enquanto que no segundo tipo é baseado em uma janela com intervalo de pacotes ou conexões (por exemplo, 20 pacotes). Devido à diversidade de protocolos e serviços de rede existentes, a quantidade de características possíveis é imensa. Embora seja factível o desenvolvimento de um IDS que considera um número grande de características de rede para a detecção de anomalias, o esforço computacional é altíssimo. Portanto, as características de rede devem ser escolhidas conforme a necessidade do IDS. O conjunto de amostragens, ordenadas no tempo, de uma variável forma uma série temporal, que é usada pela maioria dos métodos baseados em anomalias.

Este tipo de método de detecção baseado em anomalias é especialmente aplicável na segurança de sistemas SCADA que, por sua vez, são caracterizados por atividades rotineiras e repetitivas (YANG; USYNIN; HINES, 2006).

No trabalho de Linda et al. (2009), um método estatístico chamado de leave-oneout (KOHAVI, 1995) foi utilizado para identificar as características mais significantes na identificação das anomalias por meio da análise do tráfego capturado. Em Zaman e Karray (2009), os autores utilizaram uma técnica de aprendizagem de máquina conhecida como Support Vector Machines (SVM) para a classificação e seleção das características de rede. Em Ghali (2009) é proposto um algoritmo baseado em Rede Neural Artificial para a seleção de variáveis. Já em Chou et al. (2008), os autores propõem o uso de um algoritmo baseado em lógica fuzzy.

O crescente número de ataques requer uma atualização contínua da base de conhecimento dos sistemas de detecção baseados em assinaturas. Além disto, existe também um número desconhecido de vulnerabilidades descobertas, mas não reveladas e que não se encontram disponíveis para análise e inclusão na base de conhecimento. A maioria dos ataques é polimorfa e os atacantes exploram este polimorfismo para enganar os sistemas detectores (SILVA, 2008). 
Conclui-se que a melhor abordagem seria então utilizar um sistema de detecção baseado em anomalias, modelando o que é dito normal ao invés do que é anômalo. Desta forma, nesta dissertação determinou-se o desenvolvimento e avaliação de um NIDS baseado em Anomalia, com arquitetura segundo o alvo de Rede e segundo a localização Centralizado, com comportamento pós-detecção Passivo e frequência de uso por Análise Periódica (conforme critérios de classificação apresentados na Figura 23).

\subsubsection{Avaliação de um IDS}

Avaliar um sistema de detecção de intrusão representa uma tarefa complexa, pois:

- Rotular os dados coletados como normal ou anômalo nem sempre é uma tarefa fácil e requer muito esforço por parte dos especialistas humanos;

- Mudanças constantes no tráfego podem, não somente introduzir novos conceitos de anomalia, mas também podem alterar aspectos de comportamento normal, tornando a construção de referências muito difícil;

- Quando se avalia o desempenho de um $I D S$, há a necessidade de medir a taxa de detecção (ou seja, quantos ataques foram detectados corretamente), e também a taxa de alarmes falsos (ou seja, quantas conexões normais foram incorretamente detectadas como ataques) bem como o custo de uma classificação incorreta;

- A complexidade da avaliação de um IDS torna-se também alta pelo fato de que alguns tipos de ataques (por exemplo, DoS e Probing) podem usar centenas de pacotes ou conexões de rede, enquanto outros tipos de ataques, tais como $\mathrm{U} 2 \mathrm{R}$ e R2L, geralmente usam somente algumas poucas conexões.

Dois tipos de alarmes podem ser gerados pelo IDS: falso-negativo ou falsopositivo (alarme falso). Falso-negativos são ocorrências de eventos intrusivos sinalizados pelo IDS como normais, geralmente ocorrem nos sistemas baseados em assinaturas. Falso-positivos (ou alarmes falsos) são ocorrências de eventos normais sinalizados pelo IDS como intrusivos, gerados com frequência pelos IDS baseados em anomalias. 
A taxa de detecção (TD) é calculada como a razão entre o número de ataques corretamente detectados (NA) e o número total de ataques (NTA). A taxa de alarmes falsos (falso-positivos) (TAF) é calculada como a razão entre o número de conexões normais (NNI) que são incorretamente classificadas como anômalos (alarmes falsos) e o número total de conexões normais (NTN).

A métrica utilizada neste trabalho para a avaliação do IDS proposto é a mesma adotada em Linda et al. (2009):

$$
\begin{aligned}
& T D=\frac{N A}{N T A}[\%] \\
& T A F=\frac{N N I}{N T N}[\%]
\end{aligned}
$$

A taxa de falsos positivos é importante no que se refere à aceitação do sistema pelo usuário. Frente aos diversos alarmes falsos, os usuários aprendem a ignorar as advertências do sistema. Deste modo, positivos verdadeiros são ignorados e não levados a sério. Portanto, um classificador bem sucedido tem que exibir especificidade excepcional.

Sistemas baseados em detecção por anomalia são mais flexíveis, ou seja, generalizam bem para novos cenários de ataques. Porém, devido a grande diversidade das atividades de comunicação que normalmente ocorre em um ambiente de rede (veja Subseção 4.2.3), estes modelos em geral produzem uma grande taxa de alarmes falsos.

\subsection{Considerações Parciais}

Neste capítulo foram apresentados os principais tipos de ataques em redes Ethernet e como muitos desses ataques são ou podem ser detectados por meio da utilização de dois diferentes tipos de IDS, que por sua vez, apresentam vantagens e desvantagens para certas aplicações. Pesquisas correlatas também foram apresentadas, a fim de embasar o estudo e metodologia utilizados neste trabalho. 
No próximo capítulo, os principais aspectos sobre as RNA e sua aplicação no reconhecimento e classificação de padrões serão apresentados para servirem de embasamento teórico no desenvolvimento da metodologia apresentada no Capítulo 6.

\section{Capítulo 5}

\section{Fundamentos de Redes Neurais Artificiais}

\subsection{Introdução}

A ideia de se construir uma máquina ou mecanismo autônomo constitui um sonho antigo dos pesquisadores da área de ciências e engenharia. Embora os primeiros trabalhos desta área tenham sido publicados há mais de 50 anos, esse campo começou a ser fortemente pesquisado a partir dos anos 90, por isso, pode-se afirmar que ainda é uma área relativamente nova. As aplicações destes sistemas considerados inteligentes são as mais diversas possíveis, tais como:

- No sistema de controle de aeronaves.

- No reconhecimento de novos sistemas estelares.

- No diagnóstico do tráfego de dados em redes de comunicação.

- Na análise de imagens de satélite.

- No reconhecimento da escrita e da fala.

Além de outras aplicações como em elevadores, onde quase não se nota a partida e parada do mesmo; e em eletrodomésticos, como máquinas de lavar roupa e fritadeiras. A indústria cinematográfica também tem explorado o assunto por meio dos vários filmes de ficção sobre inteligência artificial e suas implicações.

De qualquer forma, isto tudo mostra o grande crescimento desta área, evidenciado cientificamente por meio dos inúmeros trabalhos apresentados nos congressos e nas revistas especializadas. 
A área de sistemas inteligentes é constituída por uma combinação de técnicas de modelagem e computação que podem ser também denominadas como técnicas de Soft Computing, cujo objetivo de destaque desse conjunto de técnicas está em alcançar acessibilidade, robustez, baixo custo e altas taxas de eficiência.

Mais especificamente, a utilização de sistemas inteligentes, notadamente aqueles baseados em redes neurais artificiais, em sistemas e controladores fuzzy, e em algoritmos genéricos, já têm sido aplicados com sucesso na solução de diversos problemas envolvidos com a identificação de sistemas. As características mais atrativas desses sistemas consistem em sua elevada habilidade em mapear sistemas não lineares e à sua facilidade de ser integrado com outras ferramentas numéricas e computacionais já existentes.

Essa seção aborda os principais aspectos sobre as redes neurais artificiais.

\subsection{Breve histórico}

A primeira publicação relacionada à neuro-computação é datada de 1943 por meio do artigo de McCulloch e Pitts (MCCULLOCH; PITTS, 1943). Neste trabalho, os pesquisadores realizaram o primeiro modelamento matemático inspirado no neurônio biológico, resultando assim na constituição do neurônio artificial.

Vários pesquisadores continuaram o trabalho de desenvolvimento de modelos matemáticos baseados no neurônio biológico, gerando uma série de topologias e algoritmos de aprendizado novos. Entre as linhas de pesquisa que surgiram, destaca-se o trabalho de Frank Rosenblatt (ROSENBLATT, 1959), que no período de 1957 a 1958, desenvolveu o primeiro neuro-computador, denominado Mark I Perceptron, idealizando o modelo básico do Perceptron. O modelo do Perceptron despertou interesse devido sua capacidade em reconhecer padrões simples.

Em 1960, Widrow e Hoff (WIDROW; HOFF, 1960) desenvolveram um tipo de rede denominada ADALINE. A palavra ADALINE é a abreviatura de ADAptive LINear Element. Posteriormente foi proposto o MADALINE (Múltipla ADALINE), uma rede cujo aprendizado é baseado na chamada 'Regra Delta', também conhecida como algoritmo de aprendizado LMS (Least Mean Square).

Após estes trabalhos, muitos pesquisadores da época ficaram incentivados a realizar trabalhos nesta linha. Porém no ano de 1969, a neuro-computação sofreu um 
duro impacto com a publicação do livro "Perceptrons - An Introduction to Computation Geometry", dos autores Minsky e Papert (MINSKY; PAPERT, 1969). Neste livro, os autores criticam fortemente as redes neurais mostrando uma limitação das redes neurais com uma única camada, como o Perceptron e o ADALINE, em aprender um padrão de uma função lógica simples como o XOR (OU-Exclusivo). A partir da publicação deste livro, houve um período em que as pesquisas na área de redes neurais artificiais praticamente ficaram paralisadas.

Somente nos anos 80 , os pesquisadores voltaram a ter interesse nesta área. A retomada das pesquisas se deve a diversos fatores, tais como o desenvolvimento de computadores com maior capacidade de processamento, e a criação de algoritmos de aprendizado mais eficientes.

Nesta época um trabalho de grande destaque, o qual trouxe muitos pesquisadores para área de redes neurais artificiais, foi o artigo publicado pelo físico John Hopfield, intitulado "Neural Network and Physical Systems with Emergent Collective Computational Abilities" (HOPFIELD, 1982). Outro destaque importante desta época foi o livro de Rumelhart, Hinton e Williams, intitulado "Parallel Distributed Processing", publicado em 1986 (RUMELHART; HINTON; WILLIAMS, 1986). Neste livro, os autores desenvolveram um algoritmo que permitia ajustar os pesos em uma rede com mais de um nível, solucionando inclusive o antigo problema de aprendizado dos padrões da função lógica XOR (OU-Exclusivo). O algoritmo, chamado de "Backpropagation", reascendeu ainda mais as pesquisas em redes neurais artificiais.

Nos dias de hoje, pode-se destacar importantes trabalhos na área de redes neurais artificiais, tais como em robótica, em controle de processos, em reconhecimentos de padrões, e em processamento de sinais.

\subsection{Relação entre neurônio biológico e neurônio artificial}

\subsubsection{Neurônio biológico}

O neurônio biológico é uma célula que pode ser dividida em três partes, ou seja, o corpo da célula, os dendritos e o axônio. $\mathrm{O}$ corpo do neurônio mede alguns milésimos de milímetros e os dendritos apresentam poucos milímetros de comprimento. $\mathrm{O}$ axônio pode ser mais longo. Os dendritos têm como funções, receber informações, ou impulsos nervosos, provenientes de outros neurônios, e conduzi-las até o corpo celular onde a 
informação é processada e novos impulsos são gerados. Estes impulsos são transmitidos a outros neurônios, passando pelo axônio, e atingindo os dendritos dos neurônios seguintes.

O contato entre a terminação do axônio de um neurônio e o dendrito de outro é chamado sinapse. São pelas sinapses que os neurônios se unem, formando as redes neurais. As sinapses funcionam como válvulas, sendo capazes de controlar a transmissão de impulsos, isto é, o fluxo da informação entre os neurônios da rede neural. O efeito das sinapses é variável, e é esta variação que dá ao neurônio a capacidade de adaptação. Na Figura 24 tem-se uma ilustração de um neurônio biológico.

Os sinais das conexões sinápticas são passados para o corpo do neurônio, onde são comparados com outros sinais recebidos pelo neurônio. Se determinado percentual desses sinais em um intervalo curto de tempo é suficientemente alto, a célula "dispara", produzindo um impulso que é transmitido para as células seguintes. Este sistema simples é responsável pela maioria das funções realizadas pelo cérebro humano, o qual tem em média $10^{11}$ neurônios interligados por $10^{14}$ sinapses. A capacidade de solucionar funções complexas surge com a operação em paralelo de todos estes neurônios e sinapses do cérebro (SILVA; SPATTI; FLAUZINO, 2010).

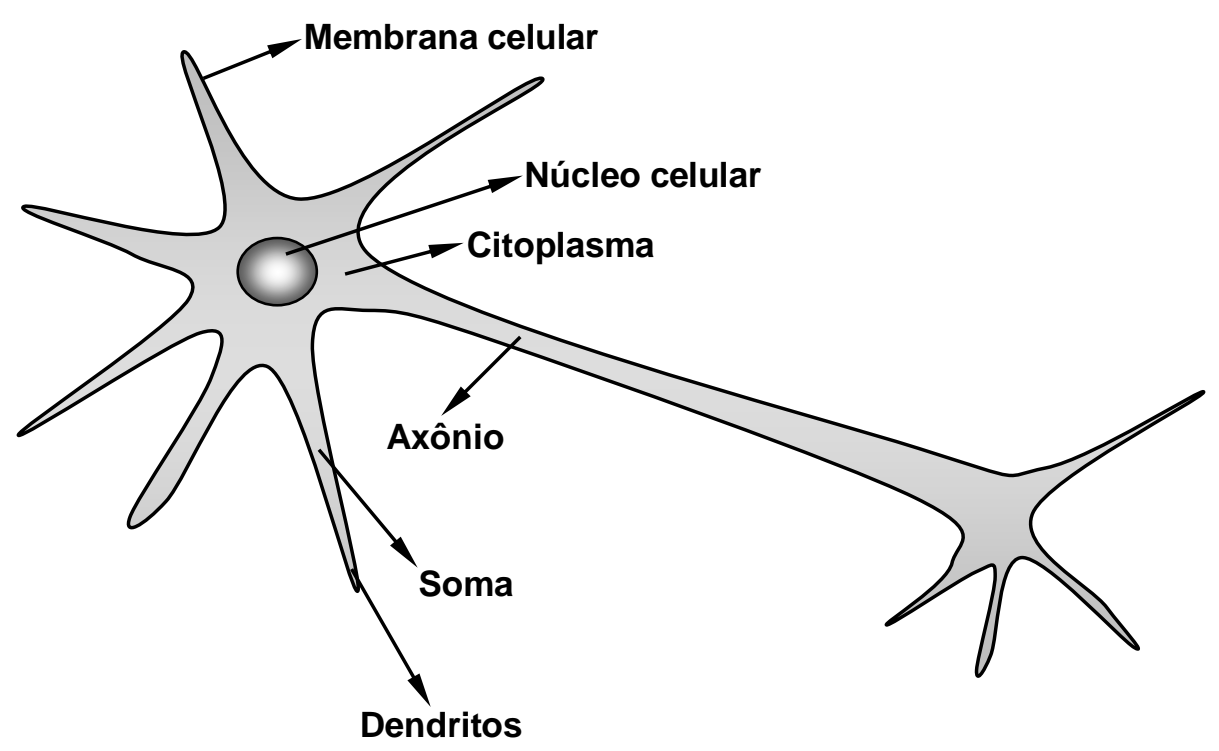

Figura 24: Representação de um neurônio biológico FONTE: (SILVA; SPATTI; FLAUZINO, 2010) 


\subsubsection{Neurônio Artificial}

O modelo de neurônio, proposto por McCulloch e Pitts em 1943, na realidade era um modelo simplificado do que se conhecia a respeito do neurônio biológico naquela época, e até hoje o mesmo é utilizado na maioria das arquiteturas neurais. A descrição matemática resultou em um modelo com $n$ terminais de entrada, ou seja, $x_{1}, x_{2}, \ldots, x_{n}$ (que representam os dendritos), e apenas um terminal de saída y (que representa o axônio). Para simular o comportamento das sinapses, os terminais de entrada do neurônio são influenciados por pesos sinápticos dados por $w_{1}, w_{2}, \ldots, w_{n}$, cujos valores podem ser valores reais positivos ou negativos. O efeito de uma sinapse particular $i$ no neurônio é dado pela multiplicação de $x_{i}$ por $w_{i}$. Portanto, cada neurônio da rede pode ser modelado conforme mostra a Figura 25.

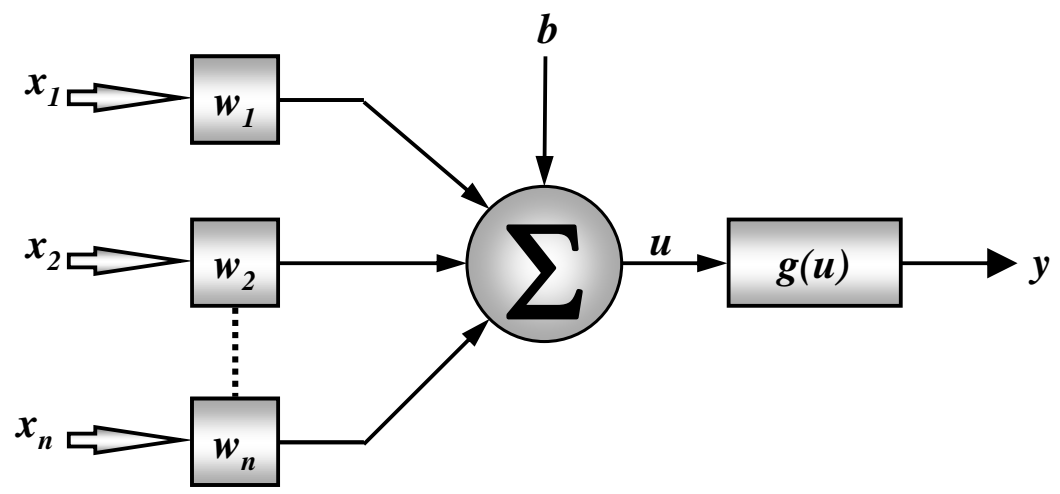

Figura 25: Representação de um neurônio artificial FONTE: (SILVA; SPATTI; FLAUZINO, 2010)

O modelo matemático que descreve o comportamento do neurônio artificial é expresso pela seguinte equação:

$$
y=g\left(\sum_{i=1}^{n} w_{i} \cdot x_{i}+b\right)
$$

Onde:

- $\quad n$ é o número de entradas do neurônio;

- $w_{i}$ é o peso associado com a i-ésima entrada;

- $\quad b$ é o limiar associado ao neurônio;

- $\quad x_{i}$ é a $i$-ésima entrada do neurônio;

- $\quad g($.$) é a função de ativação do neurônio;$

- $\quad y$ representa a saída do neurônio. 
Desta forma, um neurônio artificial opera da seguinte forma:

i. $\quad$ Os sinais são apresentados à entrada;

ii. Cada sinal é multiplicado por um peso que representa o seu nível de relevância na saída da unidade;

iii. É feita uma soma ponderada dos sinais, resultando assim em um nível de atividade;

iv. Caso este nível de atividade exceda certo limite (threshold), então a unidade produz uma saída.

A função de ativação $g($.) é a responsável pelo processamento do conjunto de informações recebidas. É também a função de ativação que é responsável pelo valor de saída do neurônio, podendo assumir valores do tipo:

- Binários (0 ou 1);

- Bipolares (-1 ou 1);

- Reais.

Durante a etapa de treinamento das redes neurais artificiais, ao final de cada treinamento, é comum a alteração de alguns parâmetros da rede de modo a buscar uma configuração de rede eficiente. Um dos parâmetros comuns de ser alterado é a função de ativação.

As principais funções de ativação utilizadas são:

a. Função Degrau Binária

A função degrau é definida por:

$$
g(u)= \begin{cases}1, & \text { se } u \geq 0 \\ 0, & \text { se } u<0\end{cases}
$$

Ou seja, se o nível de atividade interna do neurônio for um valor positivo ou igual a zero, a saída assumirá o valor 1; caso contrário, assumirá o valor 0. A Figura 26 mostra a representação gráfica desta função. 


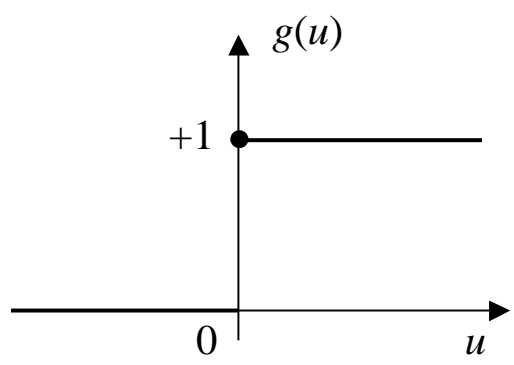

Figura 26: Função Degrau Binária FONTE: (SILVA; SPATTI; FLAUZINO, 2010)

b. Função Degrau Bipolar

A função degrau bipolar é definida por:

$$
g(u)= \begin{cases}+1, & \text { se } u \geq 0 \\ -1, & \text { se } u<0\end{cases}
$$

Assim como a função de degrau binária, se o nível de atividade interna do neurônio for um valor positivo ou igual a zero, a saída assumirá o valor 1; porém, neste caso, se o nível de atividade interna do neurônio for um valor negativo, a saída do neurônio assumirá o valor -1. A Figura 27 mostra a representação gráfica desta função.

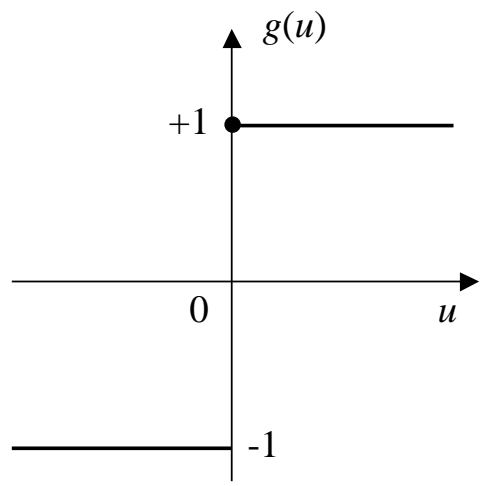

Figura 27: Função Degrau Bipolar FONTE: (SILVA; SPATTI; FLAUZINO, 2010)

\section{c. Função Rampa}

A função rampa é definida por:

$$
g(u)=\left\{\begin{array}{rcc}
+1, & \text { se } & u \geq a \\
u, & \text { se } & -a<u<a \\
-1, & \text { se } & u \leq-a
\end{array}\right.
$$


Nesta função, os valores máximos e mínimos da saída do neurônio são +1 e -1 , respectivamente. Os valores de saída poderão variar de acordo com a função $g(u)$ no intervalo definido em $\{-a, a\}$, sendo $a \neq 0$. Na Figura 28, tem-se uma representação gráfica desta função.

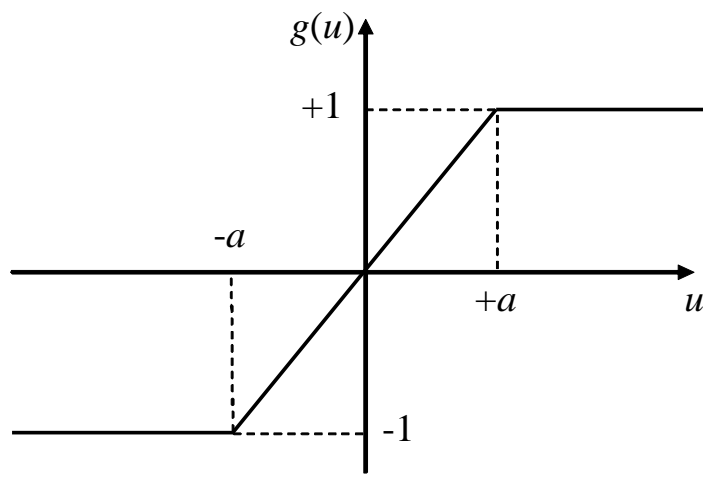

Figura 28: Função Rampa

FONTE: (SILVA; SPATTI; FLAUZINO, 2010)

d. Função Sigmoide

A definição da função sigmoide é dada por:

$$
g(u)=\frac{1}{1+e^{(-\beta u)}}
$$

O parâmetro $\beta$ desta função define a suavidade ou grau de inclinação da curva da função sigmoide. A saída no neurônio assumirá valores entre 0 e 1. A Figura 29 mostra a representação gráfica desta função.

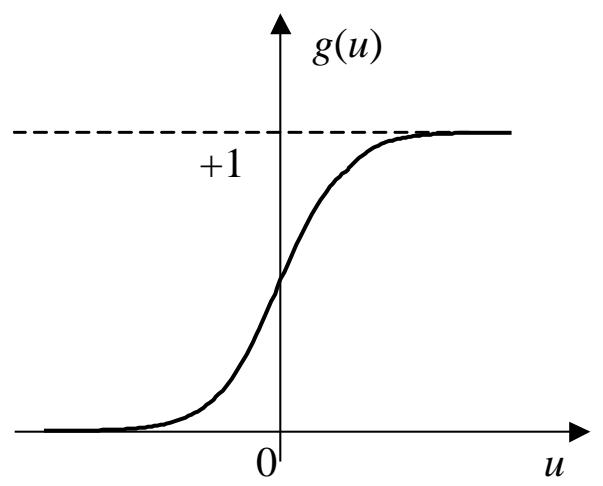

Figura 29: Função Sigmoide FONTE: (SILVA; SPATTI; FLAUZINO, 2010)

e. Função Tangente Hiperbólica 
A definição da função tangente hiperbólica é dada por:

$$
g(u)=\tanh (u)=\frac{1-e^{-u}}{1+e^{-u}}
$$

Usando a função tangente hiperbólica, a saída do neurônio assumirá valores positivos e negativos, oscilando no domínio de -1 a 1 . Graficamente, esta representação pode ser ilustrada através da Figura 30.

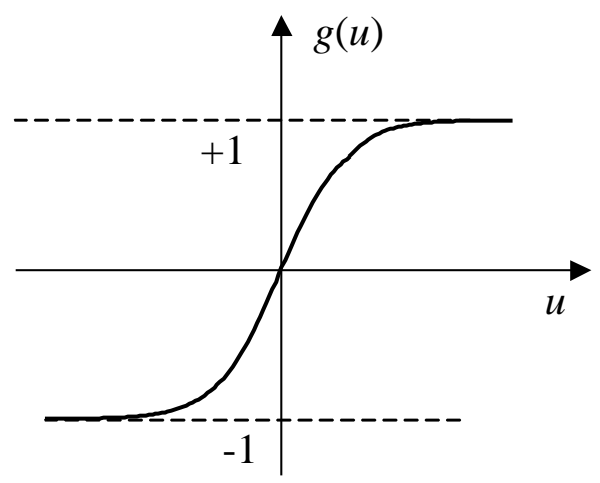

Figura 30: Função Tangente Hiperbólica FONTE: (SILVA; SPATTI; FLAUZINO, 2010)

\subsection{Topologias de Redes Neurais Artificiais}

Outro fator muito importante na utilização de redes neurais é a escolha da topologia da rede. A modelagem da topologia da rede está diretamente ligada à configuração das interligações entre os neurônios.

Desta forma, a topologia da rede escolhida tem reflexos diretos nas características e propriedades apresentadas pelo modelo. A topologia também está intimamente ligada ao algoritmo de treinamento.

Basicamente, a estrutura de uma rede neural artificial se divide em três partes:

\subsubsection{Camada de entrada}

Esta camada é responsável pelo recebimento das informações e é onde os padrões são inicialmente apresentados à rede. 


\subsubsection{Camadas intermediárias ou ocultas}

São estas camadas as responsáveis pela extração das características do processo ou sistema ao qual se está inferindo. Quase todo o processamento da rede é realizado nestas camadas.

\subsubsection{Camada de saída}

A camada de saída é responsável pela apresentação do resultado alcançado, o qual foi processado através de todas as camadas da rede.

A Figura 31 mostra uma representação das camadas de uma rede neural artificial.

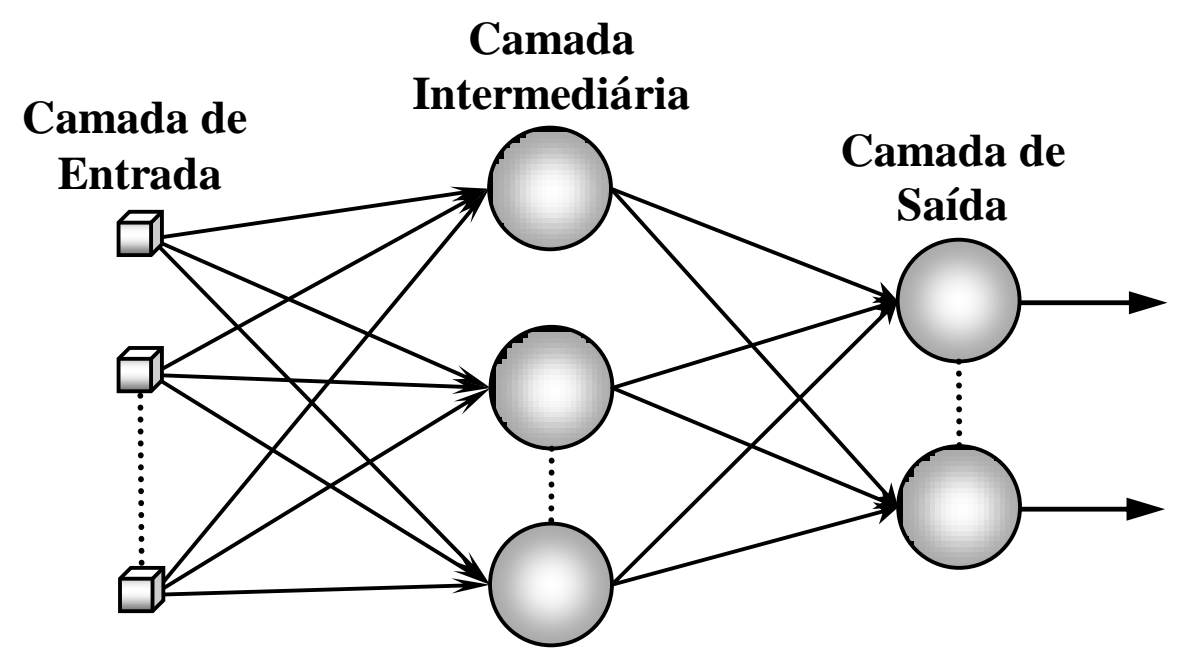

Figura 31: Representação das camadas de uma rede neural artificial. FONTE: (SILVA; SPATTI; FLAUZINO, 2010)

\subsubsection{Principais Topologias}

As principais topologias ou arquiteturas de redes neurais artificiais são as seguintes:

\subsubsection{Redes FeedForward (Camada Única)}

Esta topologia caracteriza-se por ter uma camada de entrada e uma única camada de neurônios que é a própria camada de saída. Esta é a configuração utilizada pelo Perceptron e ADALINE. Estas redes são aplicadas, principalmente, em reconhecimento de padrões e em memórias associativas. Por meio da Figura 32 pode-se visualizar a representação gráfica desta rede, a qual é composta de $n$ entradas e $m$ saídas. 


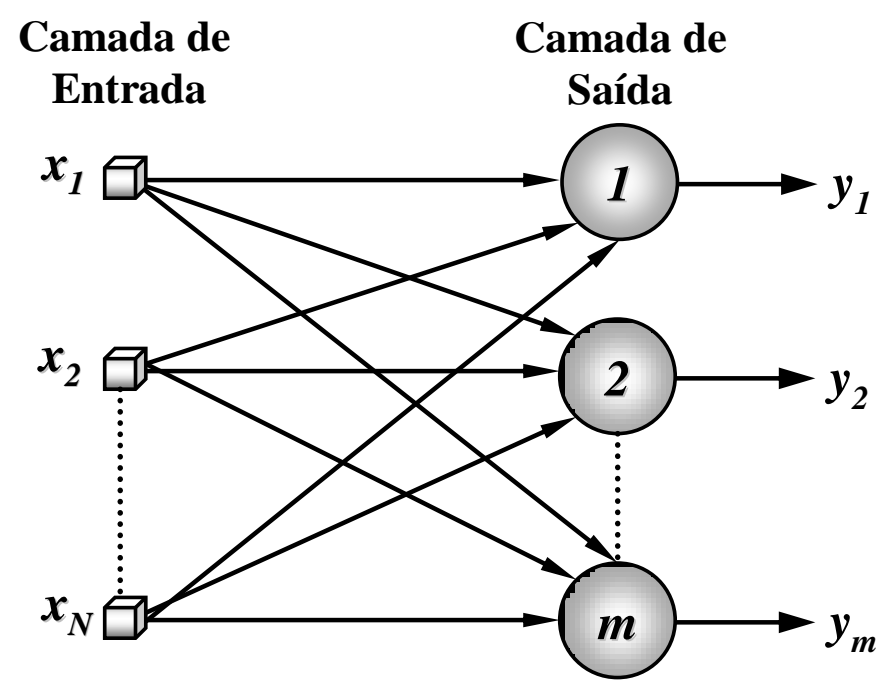

Figura 32: Representação de uma rede FeedForward (camada única). FONTE: (SILVA; SPATTI; FLAUZINO, 2010)

\subsubsection{Redes FeedForward (Multicamadas)}

Esta rede se diferencia da anterior por possuir uma ou mais camadas escondidas ou intermediárias. Nesta rede as informações são recebidas pela camada de entrada, processadas pela camada escondida, e apresentadas pela camada de saída. Geralmente, esta topologia é aplicada em reconhecimento de padrões e como aproximador universal de funções, uma vez que se pode aproximar funções não lineares.

As principais redes que usam esta topologia são o Perceptron Multicamadas e a de Função Base Radial.

A Figura 33 mostra uma representação desta topologia.

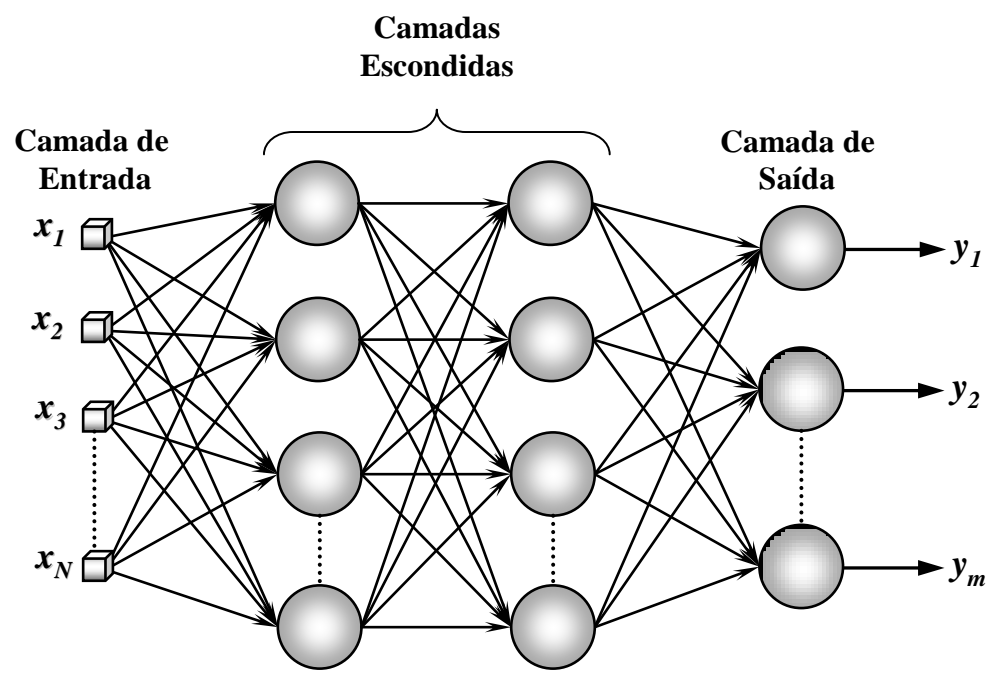

Figura 33: Representação de uma rede FeedForward (multicamadas). FONTE: (SILVA; SPATTI; FLAUZINO, 2010) 


\subsubsection{Redes Recorrentes}

As redes recorrentes se diferenciam por terem realimentação entre neurônios de camadas diferentes. Estas redes têm capacidade de "lembrar" seu comportamento com relação aos padrões anteriormente apresentados, e desta forma, processar sequências de informações. São aplicadas em sistemas dinâmicos, séries temporais, previsões, identificação e controle.

Este tipo de topologia é utilizado principalmente pelas redes Perceptron com realimentação e redes de Hopfield.

A representação da topologia de uma rede recorrente é mostrada na Figura 34.

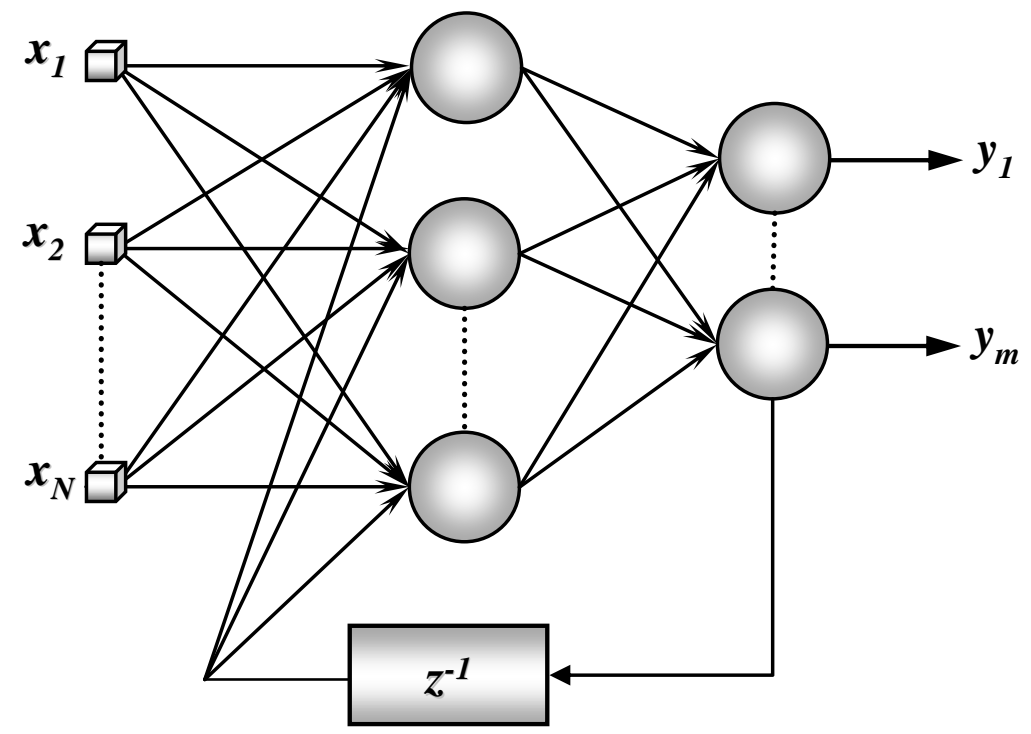

Figura 34: Representação de uma rede recorrente. FONTE: (SILVA; SPATTI; FLAUZINO, 2010)

\subsection{Treinamento de Redes Neurais Artificiais}

As redes neurais artificiais se destacam por possuírem capacidade de aprenderem a partir de seu ambiente, e em seguida, generalizar soluções.

A utilização de uma rede neural artificial supervisionada sempre se inicia através do processo de treinamento ou aprendizagem. Durante esta fase a rede extrai as características do processo ou sistema que lhe está sendo apresentada. Existe um processo de ajuste dos pesos das conexões entre as unidades de processamento, que guardam o conhecimento que a rede adquiriu do ambiente que lhe foi apresentado. A 
etapa de treinamento só termina quando a rede neural artificial consegue generalizar soluções, dentro de um nível satisfatório, para o problema apresentado.

$\mathrm{Na}$ fase de treinamento, os parâmetros da rede são alterados de acordo com um conjunto de regras predefinidas. Este conjunto de regras é chamado de algoritmo de aprendizagem. Existem vários tipos de algoritmos de aprendizagem que são usados em redes neurais artificiais. O que diferencia um de outro é a forma com que cada um altera os pesos sinápticos da rede.

Portanto, a alteração dos pesos sinápticos da rede, ou seja, o processo de treinamento ou aprendizagem está fortemente ligado ao tipo de algoritmo e rede utilizados.

Uma 'época de treinamento' é definida como sendo a apresentação à rede de todos os pares (entrada e saída) do conjunto de treinamento.

Normalmente, a rede é treinada com cerca de $80 \%$ a $90 \%$ dos dados coletados, o restante dos dados, de $10 \%$ a $20 \%$, são usados para validação da modelagem neural proposta.

Os dois principais processos de aprendizagem são os seguintes:

\subsubsection{Aprendizado Supervisionado}

Neste aprendizado a saída desejada é fornecida à rede, juntamente com o estímulo (sinal) de entrada correspondente. A rede faz o mapeamento das variáveis, buscando a generalização para o problema. Os parâmetros da rede são alterados por um agente externo ou "supervisor" até que a generalização seja satisfatória, isto é, até que a diferença entre a saída fornecida pela rede e a saída desejada se minimize para um valor aceitável.

\subsubsection{Aprendizado Não Supervisionado}

Neste caso, não existe uma saída específica relacionada ao estímulo de entrada, e não existe também a presença do agente externo ou "supervisor". A rede se organiza de forma a buscar características similares nos subconjuntos que lhe são apresentados. Os pesos sinápticos da rede são alterados pelo algoritmo de treinamento, de forma que o sistema crie sua própria representação para os estímulos de entrada. Portanto, quanto mais "evidente" forem as particularidades marcantes da população de entrada, mais "fácil" será a aprendizagem da rede, e vice-versa. 


\subsection{Redes Perceptron Multicamadas (PMC)}

As redes Perceptrons Multicamadas (PMC) são os tipos de redes mais usados em problemas envolvendo classificação de padrões ou aproximação de funções não lineares, sendo que sua topologia é similar àquela apresentada na Figura 33.

Em redes Perceptrons Multicamadas, as "tarefas" são distribuídas através das várias camadas. Os estímulos ou sinais são apresentados à rede na camada de entrada. A camada intermediária extrai as informações e as codificam por meio dos pesos sinápticos, formando assim uma representação própria do ambiente externo. Finalmente, a camada de saída recebe os estímulos da camada intermediária, mapeando o padrão de resposta que será a saída da rede.

As redes PMC são caracterizadas pela enorme quantidade de aplicações em diversos problemas relacionados com as mais diferentes áreas do conhecimento. Entre essas potências áreas, têm-se os seguintes destaques:

- Reconhecimento de padrões

- Aproximação universal de funções

- Identificação e controle de processos

- Previsão de séries temporais

- Otimização de sistemas

São redes com arquitetura FeedFoward de camadas múltiplas cujo treinamento é efetuado de forma Supervisionada, por meio do algoritmo Backpropagation (RUMELHART; HINTON; WILLIAMS, 1986).

\subsubsection{Algoritmo Backpropagation}

O processo de treinamento de uma rede PMC é realizado utilizando-se o algoritmo Backpropagation (regra Delta Generalizada) que é, geralmente, realizado mediante as aplicações de sucessivas de duas fases bem específicas.

A primeira fase a ser aplicada é denominada de 'propagação adiante' (forward), na qual os sinais de entrada de uma amostra do conjunto de treinamento são inseridos na entrada da rede e são propagados camada-a-camada até a produção das respectivas saídas. A aplicação desta fase visa tão somente obter as respostas da rede, levando-se 
em consideração apenas valores atuais de pesos sinápticos e limiares de seus neurônios, os quais permanecerão inalterados durante cada execução desta fase. Em seguida, as respostas produzidas pela rede são comparadas com as respectivas respostas desejadas que estejam disponíveis no conjunto de treinamento. $\mathrm{O}$ erro, que é diferença entre as respostas desejadas e aquelas produzidas pelos neurônios de saída da rede, é calculado e utilizado para ajuste subsequente dos pesos e limiares de todos os neurônios da rede.

Assim, em função dos valores de erros, aplica-se em seguida, a segunda fase do método, denominada 'propagação reversa' (backward). Diferente da anterior, as alterações dos pesos sinápticos e limiares de todos os neurônios da rede são executados no decorrer desta fase (SILVA; SPATTI; FLAUZINO, 2010).

Desta forma, sucessivas aplicações das fases forward e backward fazem com que os pesos sinápticos e limiares dos neurônios se ajustem com o passar das iterações e gradativamente convergindo para valores que ocasionam menor erro produzidos pelas respostas da rede frente àquelas desejadas.

\subsubsection{Algoritmo Levenberg-Marquardt}

Como descrito no tópico anterior, o algoritmo backpropagation ajusta os valores dos pesos de cada neurônio a cada iteração. No entanto, na prática, a utilização deste algoritmo tende a convergir muito lentamente, exigindo-se assim, um elevado esforço computacional. Para contornar este inconveniente, várias técnicas tem sido incorporadas ao algoritmo backpropagation na tentativa de reduzir o seu tempo de convergência e diminuir o esforço computacional requerido. Dentre as técnicas de otimização mais utilizada destacam-se: método de inserção do termo momentum, método resilientpropagation e o método de Levenberg-Marquardt (HAGAN; MENHAJ, 1994).

Detalhes acerca do funcionamento desses métodos de otimização podem ser encontrados em (SILVA; SPATTI; FLAUZINO, 2010).

\subsection{Considerações Parciais}

Os principais aspectos sobre as RNA e sua aplicação no reconhecimento e classificação de padrões foram apresentados neste capítulo, para servirem de embasamento teórico no desenvolvimento da metodologia a ser apresentada posteriormente. 
No próximo capítulo, é exposta a metodologia que será aplicada nos testes a serem realizados em laboratório e as atividades futuras organizadas em um cronograma. 


\section{Capítulo 6}

\section{Metodologia e Resultados}

\subsection{Introdução}

Este capítulo descreve a metodologia desenvolvida neste trabalho, a qual é composta por um conjunto de fases, métodos, técnicas e ferramentas para o apoio a detecção de anomalias em redes Profinet.

A metodologia foi testada em uma rede instalada no LAI - Laboratório de Automação Industrial da Escola de Engenharia de São Carlos - USP e se baseia no trabalho de Linda et al. (2009) possibilitando a realização de estudos de caso a partir de dados simulados e dados reais de tráfego.

A metodologia deste trabalho é composta por seis fases, sendo:

1. Coleta de dados do tráfego da rede;

2. Extração dos atributos do tráfego da rede;

3. Análise e seleção dos principais atributos;

4. Preparação dos dados para o treinamento das RNAs;

5. Treinamento das RNAs;

6. Análise dos resultados.

\subsection{Coleta de dados do tráfego da rede}

Esta primeira etapa refere-se à captura, propriamente dita, do tráfego da rede. Para isso, uma estação de trabalho foi configurada para a captura de pacotes e armazenamento de dados. A esta estação foi atribuído o nome de 'Estação De Captura' ou simplesmente 'captura'.

A Estação de Captura pode ser posicionada em diferentes pontos da rede. Em geral, em aplicações de rede Profinet com apenas um IO-Controller, posiciona-se a Estação de Captura em um ponto da rede que todo o tráfego oriundo e/ou destinado ao controlador seja também enviado para esta estação e assim, seja capturado. Essa 
configuração permite a observação de ataques dirigidos ao IO-Controller (elemento principal da rede) e também ataques gerais aos recursos da rede. Uma limitação desta configuração é que ataques internos que tenham como alvo específico algum IO-Device não são observados.

Outra técnica que pode ser utilizada é a adoção de vários pontos de captura espalhados pelos diversos segmentos da rede de tal forma que, todo esse tráfego capturado seja mesclado na Estação de Captura e represente com precisão todo o tráfego que circula na rede, em contrapartida, exige vários equipamentos de captura e gera grandes volumes de dados.

Uma estratégia muito comum para a captura de dados do tráfego é o uso de ferramentas de monitoração de rede, tais como Wireshark (Wireshark, 2015), que realiza a coleta em tempo real para obter os dados brutos do tráfego de rede.

O software Wireshark é uma ferramenta que utiliza a biblioteca de captura de pacotes libpcap ${ }^{14}$ (Packet Capture Library) para a comunicação com o dispositivo de rede, a qual executa as seguintes tarefas:

- Especificar o dispositivo de rede onde a coleta deve ser efetuada;

- Criar uma sessão de captura e associá-la a um descritor da biblioteca;

- Compilar uma expressão de filtragem para o formato que pode ser entendido pela biblioteca;

- Aplicar a expressão de filtragem já compilada à sessão de captura previamente criada;

- Iniciar o processo de obtenção de pacotes da rede.

O dispositivo de rede é colocado em "modo promíscuo", o qual permite à máquina ter acesso aos pacotes que não sejam destinados a ela.

Um grande e crescente número de ferramentas de segurança pode ser utilizado para monitorar uma rede. O Wireshark se destaca por prover uma saída refinada além de fornecer uma boa quantidade de detalhes que permitem avaliações sobre a atividade do tráfego. Inclusive, o próprio software Wireshark é indicado pela PI para diagnóstico em

\footnotetext{
${ }^{14}$ TCPDUMP/LIBPCAP public repository - http://www.tcpdump.org
} 
redes Profinet (PROFIBUS INTERNATIONAL, 2015). A Figura 35 ilustra a tela principal do software.

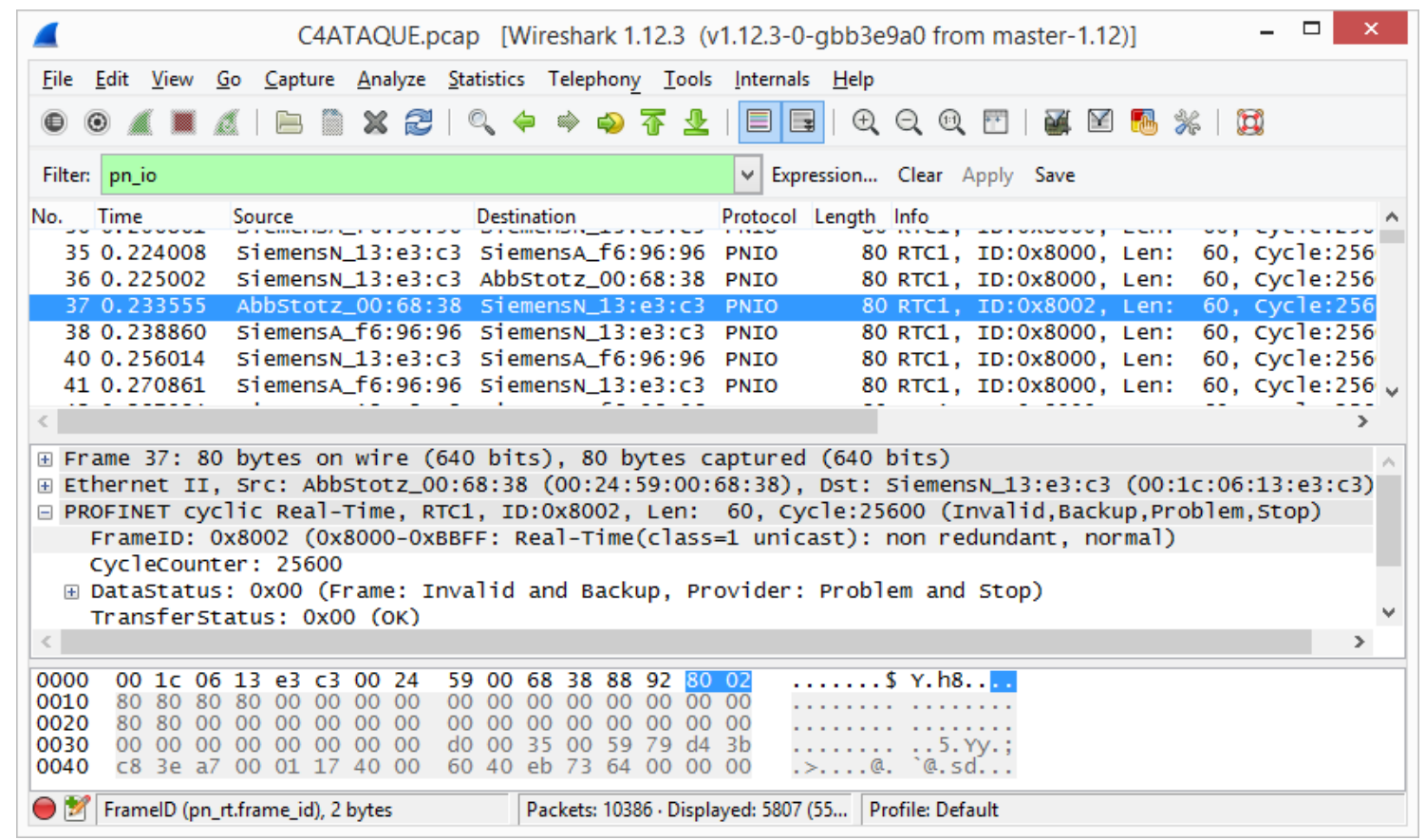

Figura 35: Software Wireshark.

Durante esta etapa foram criados, em laboratório, quatro cenários distintos de captura para aquisição do tráfego e composição da base de dados. Estes cenários foram pensados com o propósito de representarem as aplicações mais comuns de redes Profinet encontradas em instalações reais (plantas industriais).

A lista dos equipamentos e softwares utilizados durante os testes pode ser encontrada nas Tabela 10 e Tabela 11. 
Tabela 10: Equipamentos utilizados durante os testes em laboratório.

\begin{tabular}{|c|c|c|c|c|c|}
\hline Item & Modelo & Fabricante & Order Number & Função & Nome \\
\hline 1 & CPU 1214C & Siemens & $\begin{array}{l}\text { 6ES7 214-1AG31- } \\
\text { 0XP0 }\end{array}$ & IO-Controller & controlador \\
\hline 2 & IM 151-3 & Siemens & $\begin{array}{l}\text { 6ES7 151-3BA23- } \\
\text { 0AB0 }\end{array}$ & IO-Device & remota1 \\
\hline 2.1 & $\begin{array}{l}\text { PM-E RO DC } \\
24 \text { V/8A }\end{array}$ & Siemens & $\begin{array}{l}\text { 6ES7 138-4CA80- } \\
\text { 0AB0 }\end{array}$ & $\begin{array}{l}\text { Fonte de } \\
\text { alimentação }\end{array}$ & - \\
\hline 2.2 & $8 \mathrm{DI} 24 \mathrm{~V}$ & Siemens & $\begin{array}{l}\text { 6ES7 131-4BF00- } \\
\text { 0AA0 }\end{array}$ & $\begin{array}{l}\text { Módulo com } \\
8 \text { entradas } \\
\text { digitais }\end{array}$ & - \\
\hline 2.3 & $8 \mathrm{DO}$ DC $24 \mathrm{~V}$ & Siemens & $\begin{array}{l}\text { 6ES7 132-4BF00- } \\
\text { 0AA0 }\end{array}$ & $\begin{array}{l}\text { Módulo com } \\
8 \text { saídas } \\
\text { digitais }\end{array}$ & - \\
\hline 2.4 & ST DC 24V & Siemens & $\begin{array}{l}\text { 6ES7 131-4BB01- } \\
\text { 0AA0 }\end{array}$ & $\begin{array}{l}\text { Módulo com } \\
2 \text { entradas } \\
\text { digitais }\end{array}$ & - \\
\hline 3 & CI501-PNIO C2 & $\mathrm{ABB}$ & 1SAP220700R0001 & IO-Device & remota2 \\
\hline 4 & TH-Link & $\begin{array}{l}\text { Trebing + } \\
\text { Himstedt }\end{array}$ & 10003007 & $\begin{array}{l}\text { IO- } \\
\text { Supervisor }\end{array}$ & supervisor \\
\hline 5 & $\begin{array}{l}\text { SCALANCE } \\
\text { X208 }\end{array}$ & Siemens & 208-0BA10-2AA3 & Switch & switch \\
\hline 6 & ThinkPad X220 & Lenovo & - & $\begin{array}{l}\text { Estação de } \\
\text { Engenharia e } \\
\text { Supervisão }\end{array}$ & engenharia \\
\hline 7 & Inspiron $15 R$ & Dell & - & $\begin{array}{l}\text { Estação de } \\
\text { Captura }\end{array}$ & captura \\
\hline 8 & Vostro 1310 & Dell & - & $\begin{array}{l}\text { Estação de } \\
\text { Ataque }\end{array}$ & ataque \\
\hline
\end{tabular}

Tabela 11: Softwares utilizados durante os testes em laboratório.

\begin{tabular}{cllll} 
Item & Nome & Fabricante & Função & Versão \\
\hline 1 & TIA Portal & Siemens & $\begin{array}{l}\text { Configuração das } \\
\text { redes Profinet }\end{array}$ & V11 SP2 \\
\hline 2 & Wireshark & Wireshark & $\begin{array}{l}\text { Captura de tráfego da } \\
\text { rede }\end{array}$ & 1.12 .3 \\
\hline 3 & SharpPcap & SourceForge.Net & $\begin{array}{l}\text { Extração dos atributos } \\
\text { do tráfego }\end{array}$ & 4.2 .0 \\
\hline 4 & Excel 2010 & Microsoft & $\begin{array}{l}\text { Pré-processamento } \\
\text { dos dados }\end{array}$ & 14.0 .7143 \\
\hline 5 & Matlab & MathWorks & $\begin{array}{l}\text { Processamento dos } \\
\text { dados e Treinamento e } \\
\text { Execução das RNA }\end{array}$ & R2011b \\
\hline 6 & Nmap & Nmap.org & $\begin{array}{l}\text { Geração do tráfego } \\
\text { anômalo }\end{array}$ & 6.47 \\
\hline 7 & Nessus & $\begin{array}{l}\text { Tenable Network } \\
\text { Security }\end{array}$ & $\begin{array}{l}\text { Geração do tráfego } \\
\text { anômalo }\end{array}$ & 5.2 .7 \\
\hline & & & & \\
\hline
\end{tabular}


Utilizando-se o software TIA Portal da Siemens, foi configurada uma topologia de rede Profinet conforme Figura 36.

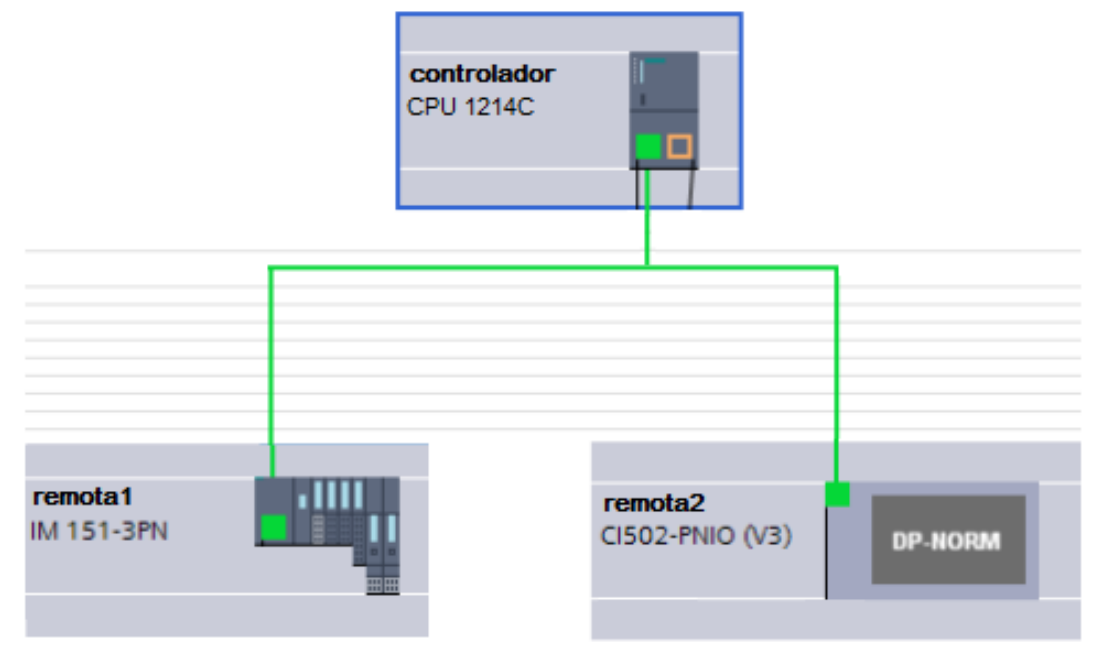

Figura 36: Configuração da rede Profinet no software TIA Portal.

Informações detalhadas sobre os parâmetros de comunicação da rede podem ser obtidas na Tabela 12.

Tabela 12: Parâmetros da rede Profinet configurada.

\begin{tabular}{cllll} 
Item & Nome & MAC Address & IP Address & Update time \\
\hline 1 & controlador & 00-1C-06-13-E3-C3 & $192.168 .0 .10 / 24$ & - \\
\hline 2 & remota1 & $00-0 \mathrm{E}-8 \mathrm{C}-\mathrm{F} 6-96-96$ & $192.168 .0 .11 / 24$ & $32 \mathrm{~ms}$ \\
\hline 3 & remota2 & $00-24-59-00-68-38$ & $192.168 .0 .12 / 24$ & $64 \mathrm{~ms}$ \\
\hline
\end{tabular}

Após o estabelecimento da comunicação na rede Profinet, é necessário também efetuar uma modificação para a correta captura do tráfego da rede. Essa modificação consiste no espelhamento de porta no switch. Este espelhamento consiste em copiar todo tráfego que passa pela porta onde o IO-Controller está conectado e transferir essas informações para uma porta livre. Esta porta livre, por sua vez, é conectada ao computador com software Wireshark (estação de captura). O modelo de switch utilizado nos testes (apresentado na Tabela 10) permite a configuração por meio do navegador Web e assim, é possível escolher as portas que serão espelhadas sem a necessidade de software adicional. Conforme ilustra a Figura 37, todas os pacotes que trafegam na Porta 1 (P1) são então copiados e direcionados à Porta 8 (P8). 


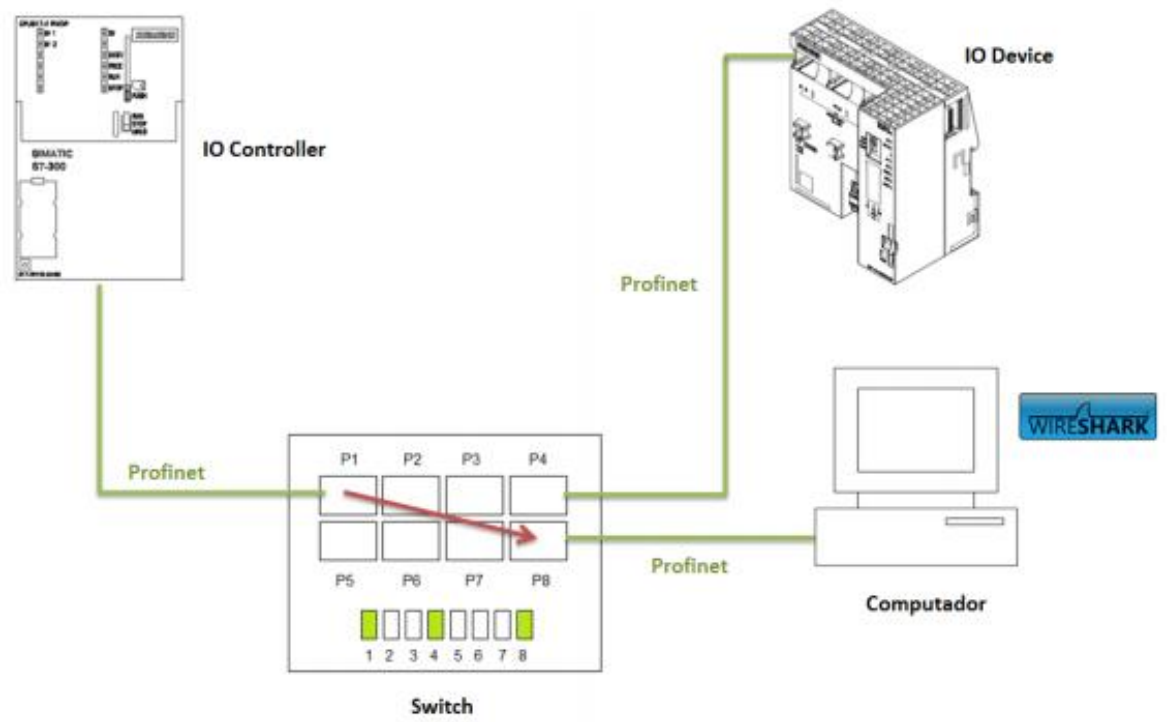

Figura 37: Exemplo de captura de pacotes com espelhamento de porta no switch.

Uma importante característica do espelhamento de porta de um switch é que, com essa funcionalidade ativa, nenhum pacote oriundo da Estação de Captura é inserido na rede e, desta forma, a ferramenta de captura não influencia no tráfego original da rede.

Além dos equipamentos ilustrados nas Figura 36 e Figura 37, os cenários de capturas utilizados possuíam outros equipamentos envolvidos (conforme Tabela 10). Detalhes da interligação de todos estes equipamentos e informações adicionais sobre os parâmetros de configuração da rede são encontrados na Figura 38 e na Tabela 13.

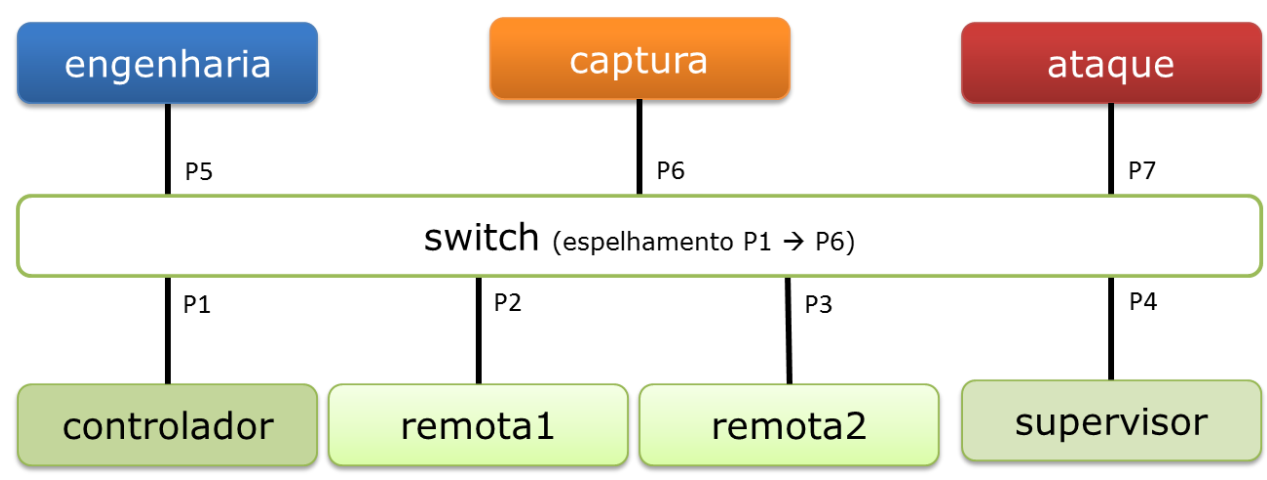

Figura 38: Interligação dos equipamentos para a captura. 
Tabela 13: Parâmetros de rede dos equipamentos envolvidos na captura

\begin{tabular}{cllll} 
Item & Nome & MAC Address & IP Address & Descrição \\
\hline 1 & controlador & 00-1C-06-13-E3-C3 & $192.168 .0 .10 / 24$ & IO-Controller \\
\hline 2 & remota1 & 00-0E-8C-F6-96-96 & $192.168 .0 .11 / 24$ & IO-Device \\
\hline 3 & remota2 & 00-24-59-00-68-38 & $192.168 .0 .12 / 24$ & IO-Device \\
\hline 4 & supervisor & 00-14-13-00-0C-89 & $192.168 .0 .125 / 24$ & IO-Supervisor \\
\hline 5 & engenharia & F0-DE-F1-FF-5E-C4 & $192.168 .0 .201 / 24$ & Laptop \\
\hline 6 & captura & D4-AE-52-FE-B1-9B & $192.168 .0 .202 / 24$ & Laptop \\
\hline 7 & ataque & 00-1E-C9-24-5A-F9 & $192.168 .0 .254 / 24$ & Laptop \\
\hline
\end{tabular}

Conforme descrito na Seção 2.4, o IO-Supervisor é um equipamento com a finalidade de enviar/receber parâmetros dos outros dispositivos da rede (configuração), sejam eles um IO-Device ou um IO-Controller e também podem ser utilizados na identificação de falhas nesses dispositivos e/ou na rede (diagnóstico da rede). Na prática, costuma-se deixar um IO-Supervisor operando constantemente na rede para levantamento das causas das possíveis falhas. Basicamente este equipamento envia comandos broadcast/multicast na rede com finalidade de levantar informações sobre o estado da rede. Sendo que, este tráfego adicional, gerado pelo supervisor, não deve ser identificado como um tipo de ataque na rede pelo IDS.

Já a estação apelidada como 'ataque' é a geradora do tráfego adicional na rede responsável pela "intrusão" propriamente dita. Os pacotes inseridos na rede por esta estação possuem, exclusivamente, a finalidade invadir essa rede, seja para levantar informações 'sigilosas' sobre os equipamentos e/ou derrubar algum serviço (mais detalhes sobre os tipos de ataques podem ser obtidos no item 4.2.3).

Para gerar o tráfego a ser caracterizado como 'intrusão', foram instalados nessa máquina dois softwares específicos para essa finalidade, são eles: $\mathrm{Nmap}^{15}$ e Nessus ${ }^{16}$. Estes softwares possuem inúmeros recursos disponíveis para gerar os mais variados tipos de ataques, principalmente ataques do tipo probing (varredura), podendo-se ter como alvo toda a rede ou então, algum host específico.

Sendo assim, após análises sobre os diversos tipos de ataques disponíveis nas configurações dos softwares e como estes poderiam ser disparados em uma rede Profinet típica, optou-se por efetuar um ataque de varredura oriundo da estação 'ataque' direcionado especificamente ao 'controlador' (alvo).

\footnotetext{
${ }^{15}$ Nmap Free Security Scanner for Network Exploration and Security Audits - http://nmap.org/

${ }^{16}$ Nessus Vulnerability Scanner - http://www.tenable.com/products/nessus-vulnerability-scanner
} 
Para disparar esse ataque, os seguintes parâmetros foram utilizados em conjunto com o software Nmap:

nmap -T4 -F 192.168.0.10

Já para o software Nessus, criou-se uma Policy do tipo Host Discovery com o subtipo Port Scan (common ports) tendo como alvo o endereço IP 192.168.0.10 (controlador).

Detalhes sobre todas as funcionalidades existentes nesses softwares e o que representam cada opção citada acima podem ser obtidas em (NMAP.ORG, 2014) e (TENABLE NETWORK SECURITY, 2014).

Em cada cenário de captura realizado em laboratório, foi disparado o mesmo tipo de ataque tendo-se sempre o mesmo alvo. Sendo que, a diferença existente entre cada cenário consiste na diversidade do tráfego que, por sua vez, fica progressivamente mais heterogêneo e ao final, aproxima-se do tráfego encontrado em uma aplicação industrial real.

Detalhes de como os cenários foram projetados, como foram feitas as interligações dos equipamentos e como foram realizadas as capturas do tráfego na rede podem ser encontrados na sequência.

\subsubsection{Cenário de Teste 1}

Este cenário de teste consiste em reproduzir uma situação de tráfego de rede que contenha apenas dados referentes à troca cíclica de dados entre o $I O$-Controller e os $I O$ Devices. Desta forma, após o estabelecimento da comunicação Profinet, os equipamentos foram interligados conforme Figura 39.

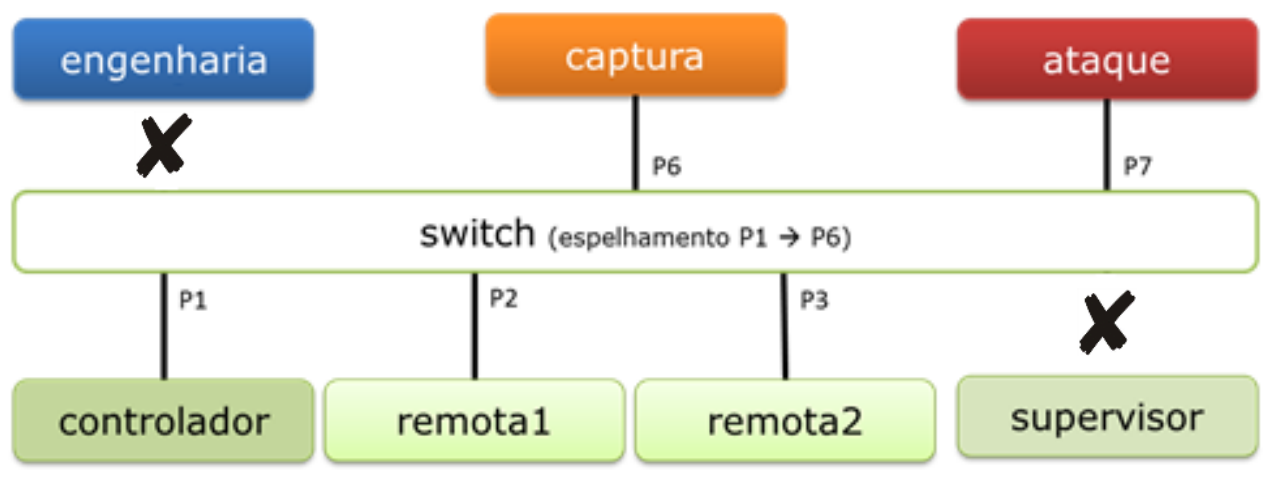

Figura 39: Interligação dos equipamentos no Cenário 1. 


\subsubsection{Cenário de Teste 2}

Este cenário de teste consiste em reproduzir uma situação de tráfego de rede que contenha dados referentes à troca cíclica de dados entre o IO-Controller e os $I O$ Devices e também uma troca de informações entre a Estação de Engenharia (representando um sistema SCADA) com o controlador com a finalidade de monitorar as informações de processo (valores das entradas e saídas digitais das remotas e alguns registros de memória internos do controlador). Assim, os equipamentos foram interligados conforme Figura 40.

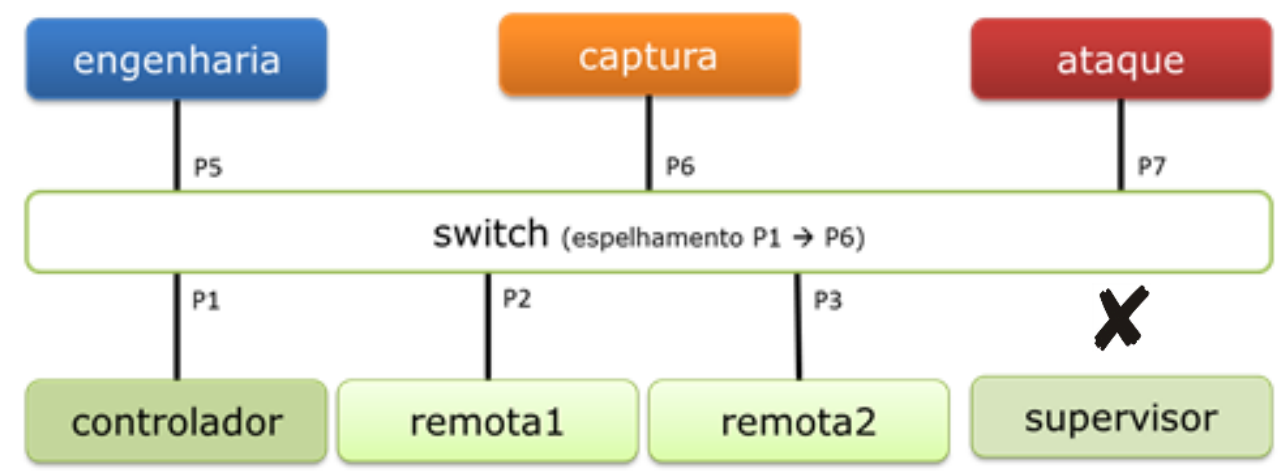

Figura 40: Interligação dos equipamentos no Cenário 2.

\subsubsection{Cenário de Teste 3}

Este cenário de teste consiste em reproduzir uma situação de tráfego de rede que contenha dados referentes à troca cíclica de dados entre o IO-Controller e os IODevices e também uma troca de informações entre o IO-Supervisor e os outros elementos da rede com o propósito de diagnóstico dos componentes da rede. Assim, os equipamentos foram interligados conforme Figura 41.

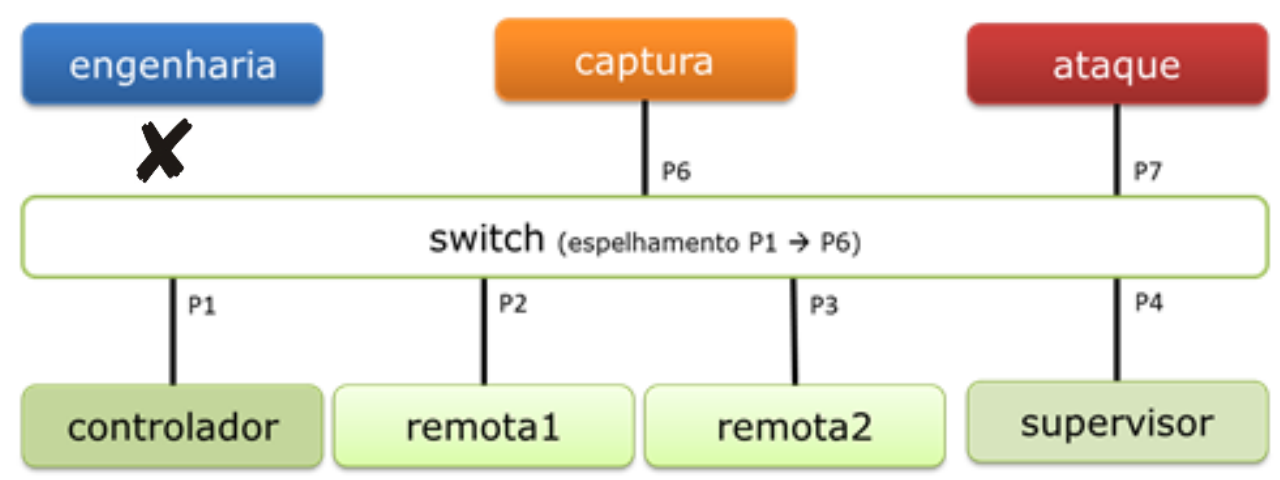

Figura 41: Interligação dos equipamentos no Cenário 3. 


\subsubsection{Cenário de Teste 4}

Este cenário de teste consiste em reproduzir uma situação de tráfego de rede que contenha dados referentes à troca cíclica de dados entre o IO-Controller e os $I O$ Devices, troca de informações entre a Estação de Engenharia (representando um sistema SCADA) com o controlador com o propósito de monitorar as informações de processo (valores das entradas e saídas digitais das remotas e alguns registros de memória internos do controlador) e também uma troca de informações entre o IO-Supervisor e os outros elementos da rede com o propósito de obter diagnóstico dos componentes da rede. Assim, os equipamentos foram todos interligados conforme Figura 42.

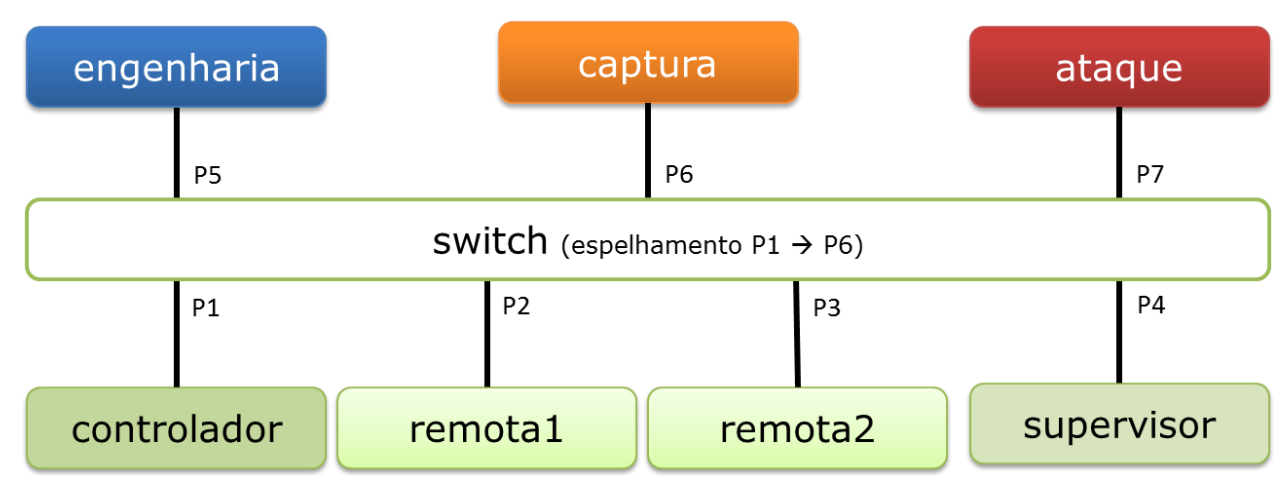

Figura 42: Interligação dos equipamentos no Cenário 4.

O tráfego gerado nesse cenário de captura é o mais heterogêneo de todos os anteriores por contemplar pacotes de diversos protocolos, com suas diversas finalidades.

Para todos os cenários de teste criados foram feitas capturas de 5500 pacotes contendo tanto tráfego "normal" quanto tráfego "anômalo".

O tráfego "anômalo", em todos os cenários, foi gerado por um ataque do tipo 'probing' ao 'controlador' realizado pela estação 'ataque' por meio dos comandos dos softwares Nmap e Nessus listados acima.

Todo o tráfego direcionado ao 'controlador' é espelhado pelo 'switch' e encaminhado para a estação 'captura' que por sua vez, armazena os dados para posterior análise. 


\subsection{Extração dos atributos pertinentes do tráfego da rede}

Cada pacote que trafega na rede carrega grande quantidade de informação sobre a conexão da qual participa. Uma análise do pacote por meio dos seus diversos campos de header em suas diferentes camadas indica características como origem, destino e o propósito da conexão. Obtendo-se essas informações, é possível utilizá-las para definir um perfil do fluxo de dados na rede e assim, utilizá-lo, por exemplo, para reconhecer quando há uma tentativa de intrusão em ocorrência e/ou quando o comportamento está de acordo com o normal e esperado.

A seleção dos atributos consiste na escolha das características de rede a serem utilizadas na análise do tráfego capturado. Normalmente, faz-se a distinção entre as características referentes a uma única conexão ou a nenhuma conexão, daquelas referentes a múltiplas conexões. As características do tráfego de rede podem ser classificadas como Primitivas ou Derivadas. As Primitivas se referem às características retiradas diretamente dos pacotes de tráfego da rede, enquanto que as características Derivadas relacionam dados de vários pacotes a fim de identificar padrões de comportamento dinâmico.

Assim, para cada pacote capturado são extraídas informações importantes sobre o seu papel no tráfego da rede, e isso permite a definição de um perfil específico de tal pacote e sua importância no tráfego. Alguns exemplos de informações que podem ser extraídas em um pacote, por meio dos campos dos protocolos que o compõem, estão listados na Tabela 14.

$\begin{gathered}\text { Tabela 14: Exemplo de informações extraídas de cada pacote. } \\
\text { Item }\end{gathered}$
\begin{tabular}{cl} 
Descrição \\
\hline 1 & Data/Hora da captura \\
\hline 2 & Endereço de Destino \\
\hline 3 & Endereço de Origem \\
\hline 4 & Tamanho do payload \\
\hline 5 & Tipo de protocolo embarcado \\
\hline
\end{tabular}

Embora a extração de informações individuais de cada pacote seja necessária, isso não é suficiente para se definir um perfil comportamental do ponto monitorado. Tornase necessário a adoção de algum mecanismo que relacione a sequência de vários pacotes que formam o tráfego momentâneo da rede e assim, identificar o seu 'padrão comportamental' em função do tempo. Portanto, com o propósito de tornar possível a 
definição desse perfil comportamental do tráfego da rede a partir de uma série temporal e finita de pacotes, ao mesmo tempo em que, permite a utilização de Redes Neurais Artificiais (RNA) para classificação do tráfego da rede, foi desenvolvido um mecanismo de extração de informações baseado em uma Janela de Análise Deslizante (Janela de Observação).

Do grande número de atributos que pode ser monitorado para o propósito de detecção de intrusão, é importante definir quais são os realmente úteis, os menos significativos e quais são os mais pertinentes para a análise. A questão é relevante porque a eliminação de atributos pode melhorar a precisão no processo de detecção e acelerar o processamento, assim melhorando a desempenho do IDS como um todo (MUKKAMALA; SUNG, 2003). Bons atributos devem prover informação útil (se o tráfego de rede é normal ou não) e gerar alta taxa de detecção com baixa taxa de alarme falso.

O algoritmo utilizado para extração dos atributos do tráfego consiste em uma ‘janela deslizante' de comprimento $\beta$ (pacotes) que é deslocada em ordem temporal sobre a sequência dos pacotes capturados do tráfego da rede (entre os pacotes vizinhos), permitindo que seja possível representar diversas características instantâneas do tráfego em um único vetor de valores. Ou seja, considerando-se os últimos $\beta$ pacotes que trafegaram na rede, são extraídas as informações individuais de cada pacote, com o objetivo de permitir que se defina uma série de valores numéricos (reais ou inteiros) que representem a janela e, consequentemente, o estado momentâneo do tráfego. Na Tabela 15 estão listados os vinte atributos extraídos do tráfego capturado utilizando-se esse algoritmo. Cada linha da tabela resulta em um valor numérico, sendo que a sequência de todos esses valores obtidos consiste em uma representação da janela que por sua vez, serve de entrada para a RNA.

O processo de extração dos atributos por meio da Janela Deslizante é ilustrado na Figura 43 e Figura 44. 


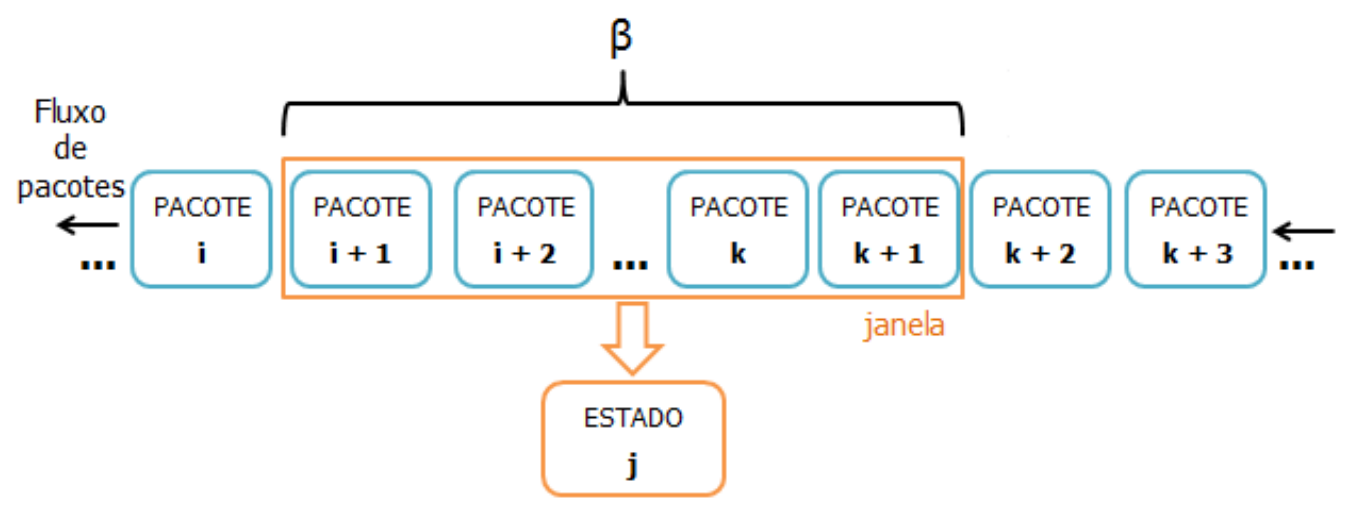

Figura 43: Processo de extração de atributos por meio da Janela Deslizante (estado j).

A janela é deslocada de um em um pacote até percorrer todo o fluxo capturado. Sendo que, para cada posição da janela, são extraídas informações estatísticas a respeito dos pacotes contidos nela. Informações estas que servirão de base para o cálculo dos atributos, que por sua vez, representarão o estado momentâneo do tráfego.

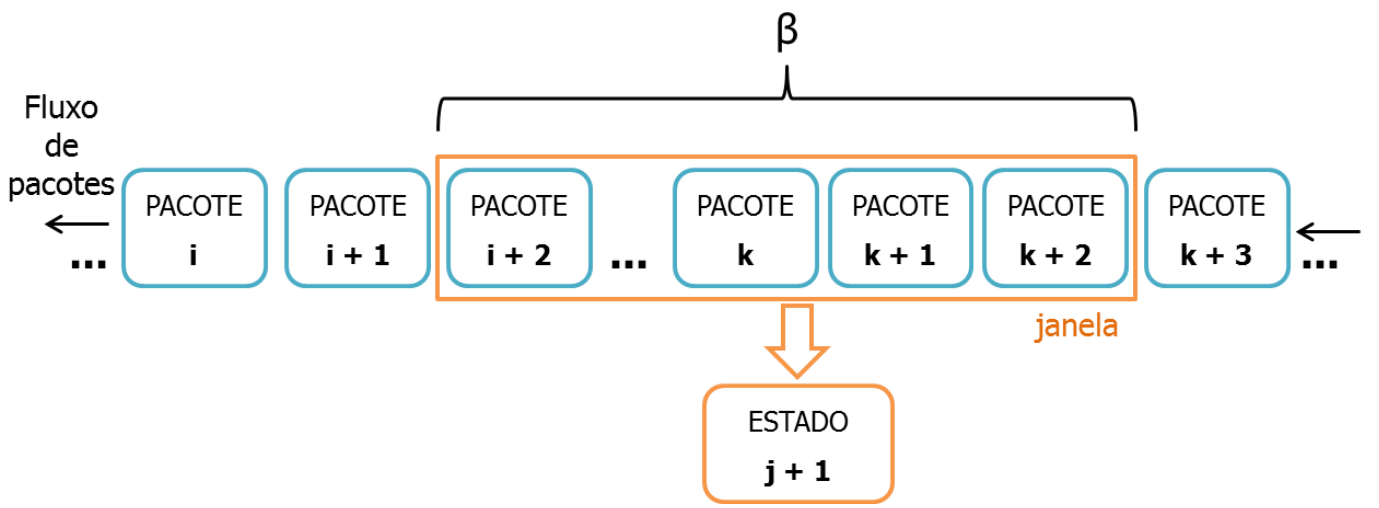

Figura 44: Processo de extração de atributos por meio da Janela Deslizante (estado j+1).

O parâmetro $\beta$ foi obtido por meio de várias análises, onde o objetivo foi manter um compromisso entre obter um valor suficiente grande para o cálculo preciso de informações estatísticas sobre o fluxo de pacotes e um valor suficientemente pequeno para não mascarar os ataques de curta duração. Ressalta-se aqui que, diante de outros tipos de ataques não tratados neste trabalho, o valor do parâmetro $\beta$ deve ser revisto para melhor se adequar aos novos cenários. Uma das possibilidades sugeridas seria a criação de um sistema inteligente adaptativo que calcule o melhor valor de $\beta$ em cada caso, através da utilização de Sistemas Fuzzy, Algoritmos Genéticos ou uma solução híbrida. Detalhes acerca do método utilizado serão expostos adiante. 
Inúmeros atributos foram verificados neste trabalho, sendo que os atributos A01 ao A16 foram propostos por Linda et al. (2009) enquanto que os outros atributos A17 ao A20 foram levantados após uma análise sobre o perfil comportamental da rede Profinet quando submetida ao ataque. A Tabela 15 descreve a lista dos atributos levantados.

Nome Descrição

Tabela 15: Lista dos atributos levantados

\begin{tabular}{ll}
\hline A01 & Número de pacotes que contém Datagrama IP \\
\hline A02 & Número Máximo de pacotes que contêm Datagrama IP de um mesmo endereço IP \\
\hline A03 & Número Mínimo de pacotes que contém Datagrama IP de um mesmo endereço IP \\
\hline A04 & Intervalo Médio de tempo entre pacotes \\
\hline A05 & Tamanho da janela em unidade de tempo \\
\hline A06 & Taxa de transmissão \\
\hline A07 & Número de protocolos distintos dentro de uma mesma janela \\
\hline A08 & Número Máximo de pacotes com o mesmo protocolo dentro de uma mesma janela \\
\hline A09 & Número Mínimo de pacotes com o mesmo protocolo dentro de uma mesma janela \\
\hline A10 & Número de 'flags codes' contidos dentro de uma mesma janela \\
\hline A11 & $\begin{array}{l}\text { Número Máximo de pacotes com o mesmo 'flag code' contido dentro de uma mesma } \\
\text { janela }\end{array}$ \\
\hline A12 & $\begin{array}{l}\text { Número Mínimo de pacotes com o mesmo 'flag code' contido dentro de uma mesma } \\
\text { janela }\end{array}$ \\
\hline A13 & Número de pacotes com campo Window Size = 0 \\
\hline A14 & Número de pacotes com campo Data Length = 0 \\
\hline A15 & Valor médio do campo Window Size \\
\hline A16 & Valor médio do campo Data Length \\
\hline A17 & Número de pacotes 'non-Profinet' na janela \\
\hline A18 & Número de protocolos distintos dentro de um Datagrama IP em uma mesma janela \\
\hline A19 & Número de portas distintas dentro de um pacote TCP em uma mesma janela \\
\hline A20 & Número de portas distintas dentro de um pacote UDP em uma mesma janela \\
\hline
\end{tabular}

A seguir é apresentada uma breve descrição sobre cada um dos atributos e como estes podem ser obtidos por meio da captura dos pacotes do tráfego da rede.

\subsubsection{Atributo A01}

Descrição: Número de pacotes que contém Datagrama IP.

Tipo: Inteiro

Valor Máx.: $\beta$

Valor Mín.: 0

Este atributo contém a quantidade de pacotes (frames Ethernet), contidos em uma mesma janela, e que possuem o campo Ethertype $=0 x 0800$ (detalhes na Figura 15). 


\subsubsection{Atributo A02}

Descrição: Número Máximo de pacotes que contêm Datagrama IP de um mesmo endereço IP.

Tipo: $\quad$ Inteiro

Valor Máx.: $\beta$

Valor Mín.: 0

Este atributo contém a quantidade máxima de pacotes (frames Ethernet), contidos em uma mesma janela, que possuem o campo Ethertype $=0 \mathrm{x} 0800$ e que são oriundos ou destinados a um mesmo endereço IP.

\subsubsection{Atributo A03}

Descrição: Número Mínimo de pacotes que contêm Datagrama IP de um mesmo endereço IP.

Tipo: $\quad$ Inteiro

Valor Máx.: $\beta$

Valor Mín.: 0

Este atributo contém a quantidade mínima de pacotes (frames Ethernet), contidos em uma mesma janela, que possuem o campo Ethertype $=0 \mathrm{x} 0800$ e que são oriundos ou destinados a um mesmo endereço IP.

\subsubsection{Atributo A04}

Descrição: Intervalo Médio de tempo entre pacotes

Tipo: Real

Valor Máx.: -

Valor Mín.: $\quad 0,0 \mu \mathrm{s}$

Este atributo contém a diferença de tempo média (em microssegundos) entre todos os pacotes contidos na janela.

\subsubsection{Atributo A05}

Descrição: Tamanho da janela em unidade de tempo

Tipo: Inteiro

Valor Máx.: -

Valor Mín.: $0 \mu \mathrm{s}$

Este atributo contém a diferença de tempo (em microssegundos) entre o primeiro e o último pacote contido na janela. 


\subsubsection{Atributo A06}

Descrição: Taxa de transmissão

Tipo: Real

Valor Máx.: -

Valor Mín.: $\quad 0,0$

$\mathrm{B} / \mathrm{s}$

Este atributo contém a taxa de transferência efetiva (em bytes/segundo) dos dados transmitidos nos pacotes contidos na janela.

\subsubsection{Atributo A07}

Descrição: Número de protocolos distintos dentro de uma mesma janela

Tipo: Inteiro

Valor Máx.: $\beta$

Valor Mín.: 0

Este atributo contém a quantidade de pacotes, contidos em uma mesma janela, e que possuem os campos Ethertype distintos entre si.

\subsubsection{Atributo A08}

Descrição: Número Máximo de pacotes com o mesmo protocolo dentro de uma mesma janela

Tipo: Inteiro

Valor Máx.: $\beta$

Valor Mín.: 0

Este atributo contém a quantidade máxima de pacotes, contidos em uma mesma janela, que possuem o mesmo valor para o campo Ethertype.

\subsubsection{Atributo A09}

Descrição: Número Mínimo de pacotes com o mesmo protocolo dentro de uma mesma janela

Tipo: $\quad$ Inteiro

Valor Máx.: $\beta$

Valor Mín.: 0

Este atributo contém a quantidade mínima de pacotes, contidos em uma mesma janela, que possuem o mesmo valor para o campo Ethertype. 


\subsubsection{Atributo A10}

Descrição: Número de 'flags codes' contidos dentro de uma mesma janela

Tipo: Inteiro

Valor Máx.: $6 \beta$

Valor Mín.: 0

Este atributo contém a somatória da quantidade de 'flag codes' do protocolo TCP habilitados em todos os pacotes contidos em uma mesma janela.

O protocolo TCP possui seis 'flags codes' utilizados para a sinalização do tráfego de pacotes. Estes códigos permitem um controle sofisticado da troca de mensagens entre o remetente e o destinatário. São eles (TANENBAUM, 2003):

- URG (Urgent): usado para indicar um deslocamento de bytes a partir do número de sequência atual em que dados urgentes devem ser encontrados. Esse recurso permite o envio de informações consideradas prioritárias pelo protocolo TCP.

- ACK (Acknowledgment): utilizado para indicar a confirmação de recebimento de mensagem por parte do destinatário.

- PSH (Push): quando habilitado, força o receptor a entregar os dados para aplicação mediante a sua chegada, em vez de armazená-los em buffer.

- RST (Reset): utilizado para reinicializar uma conexão que tenha ficado confusa devido a uma falha no remetente/destinatário ou por qualquer outra razão. É também utilizado para rejeitar um segmento de mensagem inválido ou para recusar uma tentativa de conexão, em geral, receber um segmento com o flag RST ativado, isso significa problemas na comunicação.

- SYN (Synchronization): usado no estabelecimento de conexões. A solicitação de conexão tem $S Y N=1$ e $A C K=0$ e a resposta contém uma confirmação e, portanto, tem $S Y N=1$ e $A C K=1$. Basicamente, o bit $S Y N$ é usado para denotar CONNECTION REQUEST e CONNECTION ACCEPTED, enquanto o bit $A C K$, é usado para distinguir entre essas duas possibilidades.

- FIN (Finish): utilizado para encerrar uma conexão. Ele indica que o transmissor não tem mais dados para enviar, entretanto, um processo pode continuar a receber dados indefinidamente, mesmo depois de a conexão ter sido encerrada. Tanto o segmento SYN quanto o segmento FIN possuem números de sequência e, portanto, são processados na ordem correta. 


\subsubsection{Atributo A11}

Descrição: Número Máximo de pacotes com o mesmo 'flag code' contido dentro de uma mesma janela

Tipo: Inteiro

Valor Máx.: $\beta$

Valor Mín.: 0

Este atributo contém a quantidade máxima de pacotes, contidos em uma mesma janela, que possuem o mesmo 'flag code' do protocolo TCP habilitado.

\subsubsection{Atributo A12}

Descrição: Número Mínimo de pacotes com o mesmo 'flag code' contido dentro de uma mesma janela

Tipo: $\quad$ Inteiro

Valor Máx.: $\beta$

Valor Mín.: 0

Este atributo contém a quantidade mínima de pacotes, contidos em uma mesma janela, que possuem o mesmo 'flag code' do protocolo TCP habilitado.

\subsubsection{Atributo A13}

Descrição: Número de pacotes com campo Window Size $=0$

Tipo: Inteiro

Valor Máx.: $\beta$

Valor Mín.: 0

Este atributo contém a quantidade de pacotes, contidos em uma mesma janela, e que possuem o campo Windows Size nulo. Esse campo, implementado pelo protocolo TCP, é utilizado para o controle de fluxo. Este campo indica quantos bytes podem ser enviados a partir do byte confirmado. Um campo Window Size igual a zero é válido e informa que todos os bytes foram recebidos, mas que o receptor precisa de um descanso no momento e agradeceria muito se nenhum outro dado fosse enviado. A permissão para retomar a transmissão de dados pode ser enviada mais tarde com o campo Window Size diferente de zero (TANENBAUM, 2003).

\subsubsection{Atributo A14}

Descrição: Número de pacotes com campo Data Length $=0$

Tipo: Inteiro

Valor Máx.: $\quad \beta$

Valor Mín.: 0 
Este atributo contém a quantidade de pacotes, contidos em uma mesma janela, e que possuem o campo Data Length nulo. Essa condição indica que o pacote é exclusivamente utilizado para controle da transmissão, pois não carrega nenhuma informação no campo de dados (payload).

\subsubsection{Atributo A15}

Descrição: Valor médio do campo Window Size

Tipo: Real

Valor Máx.: -

Valor Mín.: 0

bytes

Este atributo contém a média aritmética dos valores do campo Window Size (em bytes) de todos os pacotes contidos na janela.

\subsubsection{Atributo A16}

Descrição: Valor médio do campo Data Length

Tipo: Real

Valor Máx.: -

Valor Mín.: 0

bytes

Este atributo contém a média aritmética dos valores do campo Data Length (em bytes) de todos os pacotes contidos na janela.

\subsubsection{Atributo A17}

Descrição: Número de pacotes 'non-Profinet' na janela

Tipo: Inteiro

Valor Máx.: $\beta$

Valor Mín.: 0

Este atributo contém a quantidade de pacotes (frames Ethernet), contidos em uma mesma janela, e que possuem o campo Ethertype diferente de 0x8892 (detalhes na

Tabela 8).

\subsubsection{Atributo A18}

Descrição: Número de protocolos distintos dentro de um Datagrama IP em uma mesma janela

Tipo: $\quad$ Inteiro

Valor Máx.: $\beta$

Valor Mín.: 0 
Este atributo contém a quantidade de pacotes, que contenham um Datagrama IP, contidos em uma mesma janela, e que possuem os campos Protocol distintos entre si.

O campo Protocol informa a que processo de transporte o datagrama deve ser entregue. O TCP é uma possibilidade, mas também há o UDP e alguns outros. A numeração dos protocolos se aplica a toda a Internet e estão contidos em bando de dados online localizado em (IANA.ORG - Protocol Numbers, 2015) (TANENBAUM, 2003).

\subsubsection{Atributo A19}

Descrição: Número de portas distintas dentro de um pacote TCP em uma mesma janela

Tipo: Inteiro

Valor Máx.: $\quad 2 * \beta$

Valor Mín.: 0

Este atributo contém a somatória da quantidade de campos Source Port e Destination Port distintos do protocolo TCP de todos os pacotes contidos em uma mesma janela.

Os campos Source Port e Destination Port identificam os pontos terminais locais da conexão. Os números de portas conhecidos são definidos pela IANA (Internet Assigned Numbers Authority), mas cada host pode alocar as outras portas como desejar. Uma porta e o endereço IP de seu host formam um único ponto terminal de 06 bytes sendo que, o número de pontos terminais de origem e de destino identifica a conexão (TANENBAUM, 2003).

\subsubsection{Atributo A20}

Descrição: Número de portas distintas dentro de um pacote UDP em uma mesma janela

Tipo: Inteiro

Valor Máx.: $\quad 2 * \beta$

Valor Mín.: 0

Este atributo contém a somatória da quantidade de campos Source Port e Destination Port distintos do protocolo UDP de todos os pacotes contidos em uma mesma janela.

As mesmas características dos campos Source Port e Destination Port, descritas para o protocolo TCP, são válidas para o protocolo UDP. 


\section{Escolha de $\beta$}

O método utilizado para escolha mais apropriada do valor do parâmetro $\beta$, do algoritmo de extração de atributos descrito acima, baseia-se no cálculo do Coeficiente de Correlação Cruzada dos atributos com o valor da saída desejada, considerando-se vários valores de $\beta$ (adotou-se uma faixa entre 10 e 100 com incremente de dez unidades). Detalhes acerca deste processo serão apresentados a seguir.

Foram analisados todos os atributos tanto diante dos instantes de tráfego normal quanto frente às condições de tráfego anômalo para o Cenário 4 (que possuiu o tráfego mais heterogêneo comparado aos outros cenários). A referida análise contemplou o cálculo da correlação entre o valor de cada atributo com as condições de tráfego normal e tráfego anômalo para conjunto de dados obtidos com diferentes valores do parâmetro $\beta$. Esses valores, em módulo, estão contemplados na Tabela 16 e Tabela 17.

Tabela 16: Coeficiente de Correlação (em módulo) dos atributos A01 a A10 com a saída para cada $\beta$.

\begin{tabular}{ccccccccccc}
$\boldsymbol{\beta}$ & $\mathbf{A 0 1}$ & $\mathbf{A 0 2}$ & $\mathbf{A 0 3}$ & $\mathbf{A 0 4}$ & $\mathbf{A 0 5}$ & $\mathbf{A 0 6}$ & $\mathbf{A 0 7}$ & $\mathbf{A 0 8}$ & $\mathbf{A 0 9}$ & $\mathbf{A 1 0}$ \\
\hline $\mathbf{1 0}$ & 0,4268 & 0,6737 & 0,3912 & 0,2953 & 0,2965 & 0,3903 & 0,1372 & 0,1682 & 0,0494 & 0,1536 \\
\hline $\mathbf{2 0}$ & 0,6266 & 0,8297 & 0,2665 & 0,3841 & 0,3856 & 0,3468 & 0,1427 & 0,0394 & 0,2002 & 0,3372 \\
\hline $\mathbf{3 0}$ & 0,6676 & 0,8770 & 0,3290 & 0,3981 & 0,3997 & 0,3654 & 0,1392 & 0,0165 & 0,2383 & 0,3704 \\
\hline $\mathbf{4 0}$ & 0,6899 & 0,8726 & 0,3571 & 0,4220 & 0,4236 & 0,4038 & 0,1365 & 0,0256 & 0,2275 & 0,4085 \\
\hline $\mathbf{5 0}$ & 0,6872 & 0,8772 & 0,3592 & 0,4266 & 0,4282 & 0,4020 & 0,1251 & 0,0465 & 0,2076 & 0,3970 \\
\hline $\mathbf{6 0}$ & 0,6793 & 0,8559 & 0,3578 & 0,4184 & 0,4200 & 0,4067 & 0,1008 & 0,0468 & 0,1858 & 0,4034 \\
\hline $\mathbf{7 0}$ & 0,6728 & 0,8530 & 0,3553 & 0,4210 & 0,4225 & 0,4193 & 0,0987 & 0,0711 & 0,1851 & 0,3959 \\
\hline $\mathbf{8 0}$ & 0,6580 & 0,8413 & 0,3497 & 0,4168 & 0,4183 & 0,4181 & 0,0893 & 0,0820 & 0,1810 & 0,3817 \\
\hline $\mathbf{9 0}$ & 0,6440 & 0,8255 & 0,3446 & 0,4110 & 0,4125 & 0,4242 & 0,0819 & 0,0901 & 0,1757 & 0,3727 \\
\hline $\mathbf{1 0 0}$ & 0,6280 & 0,8123 & 0,3382 & 0,4063 & 0,4077 & 0,4266 & 0,0755 & 0,0984 & 0,1739 & 0,3575 \\
\hline
\end{tabular}

Tabela 17: Coeficiente de Correlação (em módulo) dos atributos A11 a A20 com a saída para cada $\beta$.

$\begin{array}{lllllllllll}\boldsymbol{\beta} & \mathbf{A} 11 & \mathbf{A} 12 & \mathbf{A 1 3} & \mathbf{A 1 4} & \mathbf{A} 15 & \text { A16 } & \text { A17 } & \text { A18 } & \text { A19 } & \text { A20 }\end{array}$

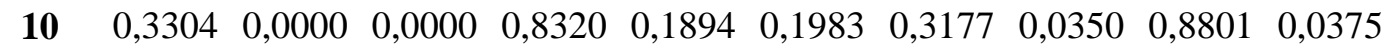

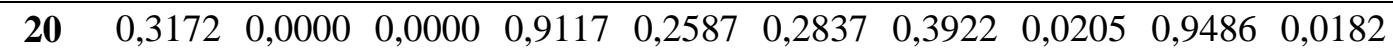

$\begin{array}{lllllllllll}30 & 0,2321 & 0,0000 & 0,0000 & 0,9608 & 0,2951 & 0,3240 & 0,4068 & 0,0434 & 0,9782 & 0,0434\end{array}$

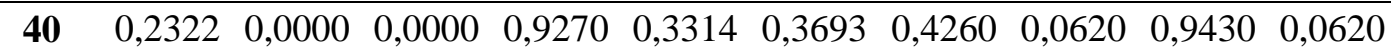

$\begin{array}{lllllllllll}50 & 0,1980 & 0,0000 & 0,0000 & 0,9469 & 0,3393 & 0,3765 & 0,4332 & 0,0763 & 0,9459 & 0,0763\end{array}$

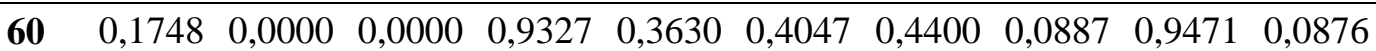

$\begin{array}{lllllllllll}70 & 0,1584 & 0,0000 & 0,0000 & 0,9215 & 0,3583 & 0,3978 & 0,4420 & 0,0987 & 0,9534 & 0,0967\end{array}$

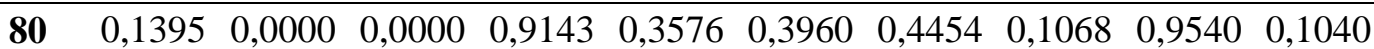

$90 \begin{array}{lllllllllll}0,1251 & 0,0000 & 0,0000 & 0,9005 & 0,3630 & 0,4015 & 0,4473 & 0,1135 & 0,9412 & 0,1099\end{array}$

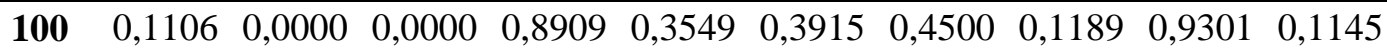


Para ilustrar o comportamento de cada atributo diante dos diversos valores considerados, foram traçados os gráficos contidos nas Figura 45 a Figura 64.

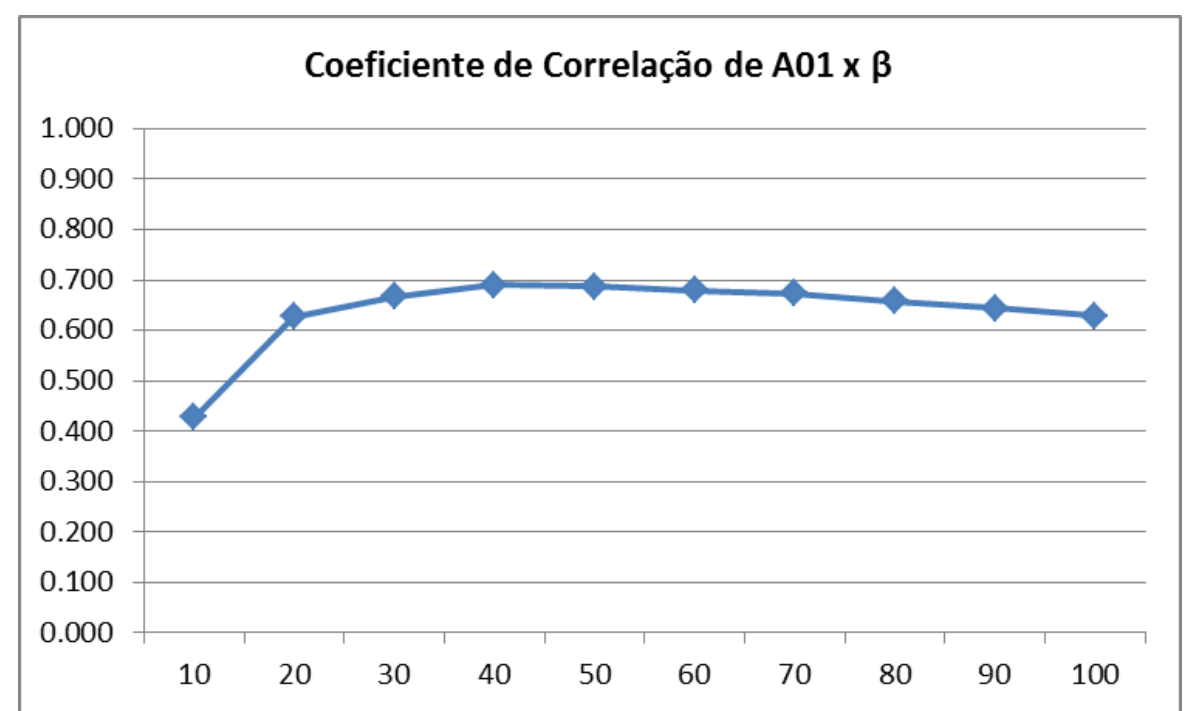

Figura 45: Coeficiente de Correlação (em módulo) do atributo A01 para cada $\beta$.

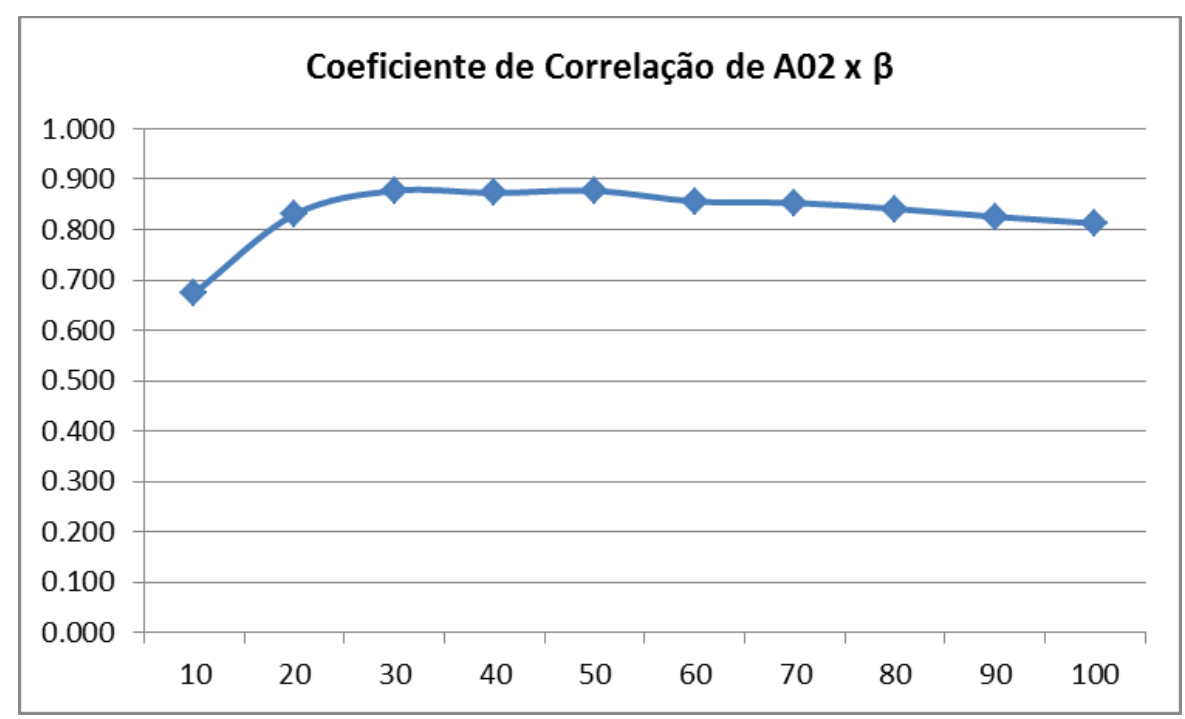

Figura 46: Coeficiente de Correlação (em módulo) do atributo A02 para cada $\beta$. 


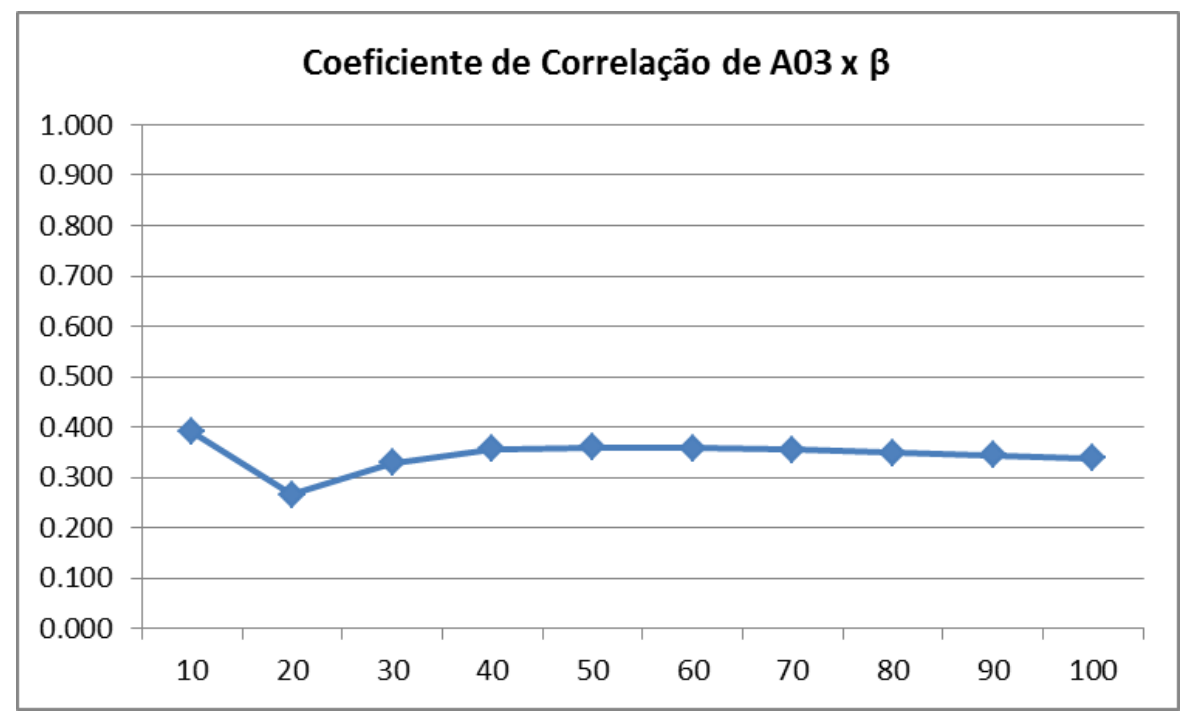

Figura 47: Coeficiente de Correlação (em módulo) do atributo A03 para cada $\beta$.

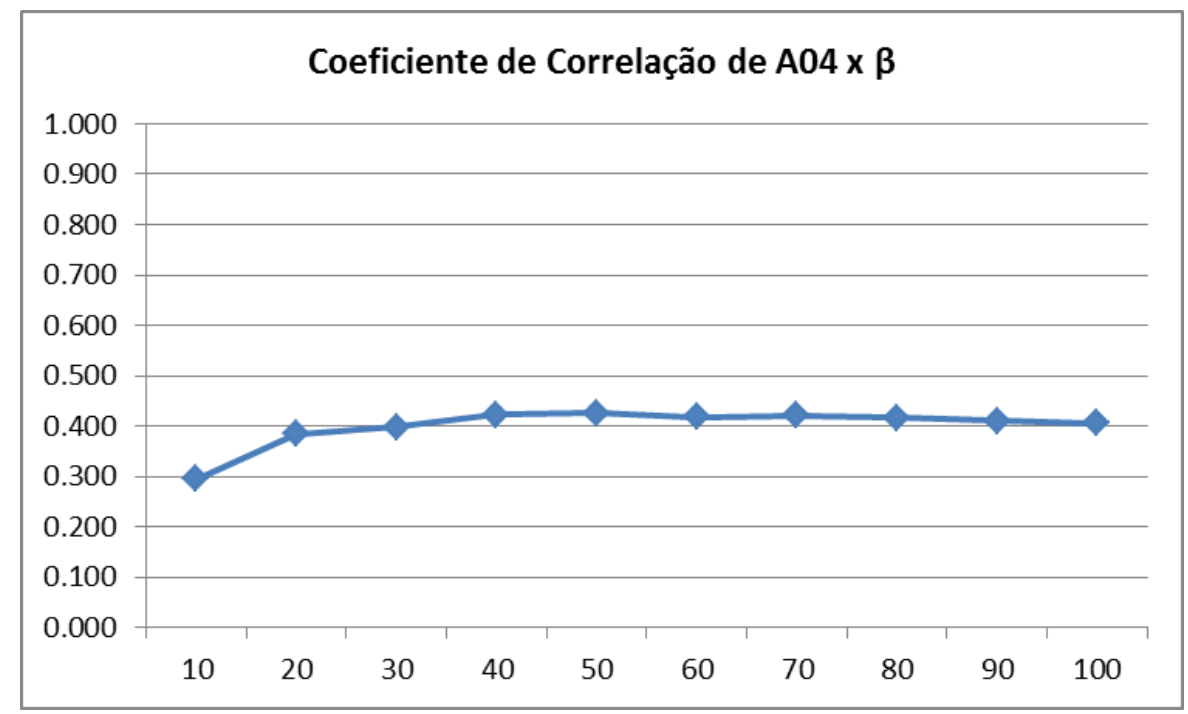

Figura 48: Coeficiente de Correlação (em módulo) do atributo A04 para cada $\beta$.

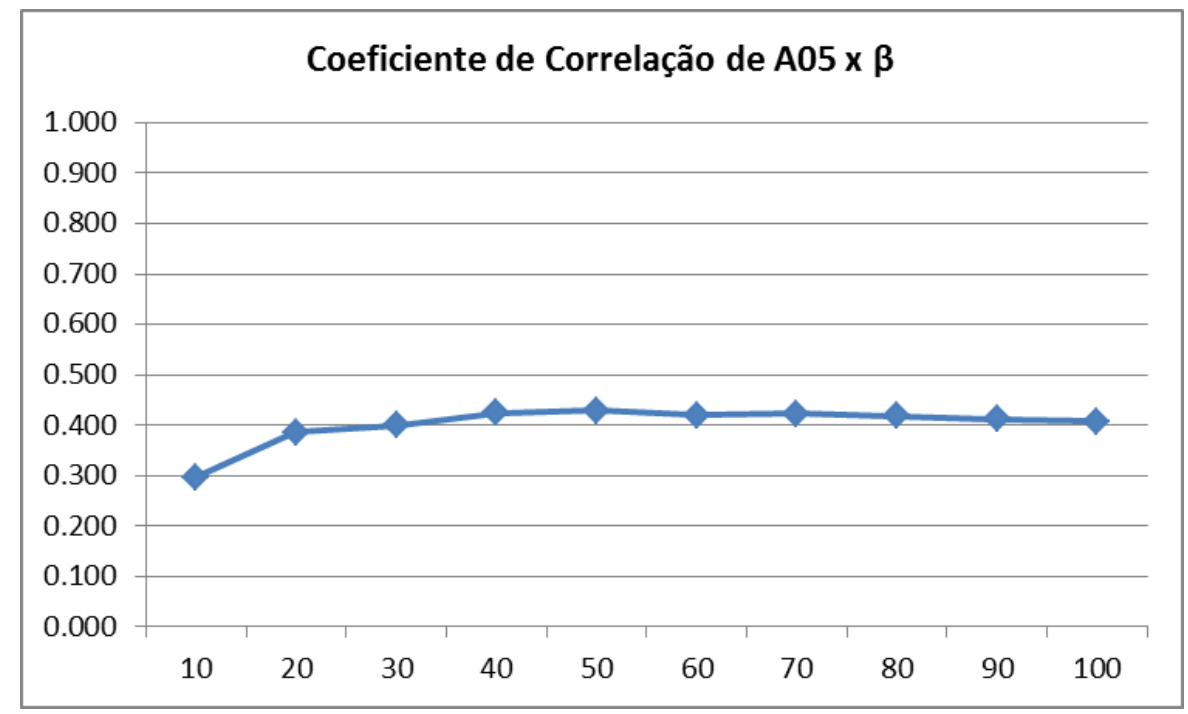

Figura 49: Coeficiente de Correlação (em módulo) do atributo A05 para cada $\beta$. 


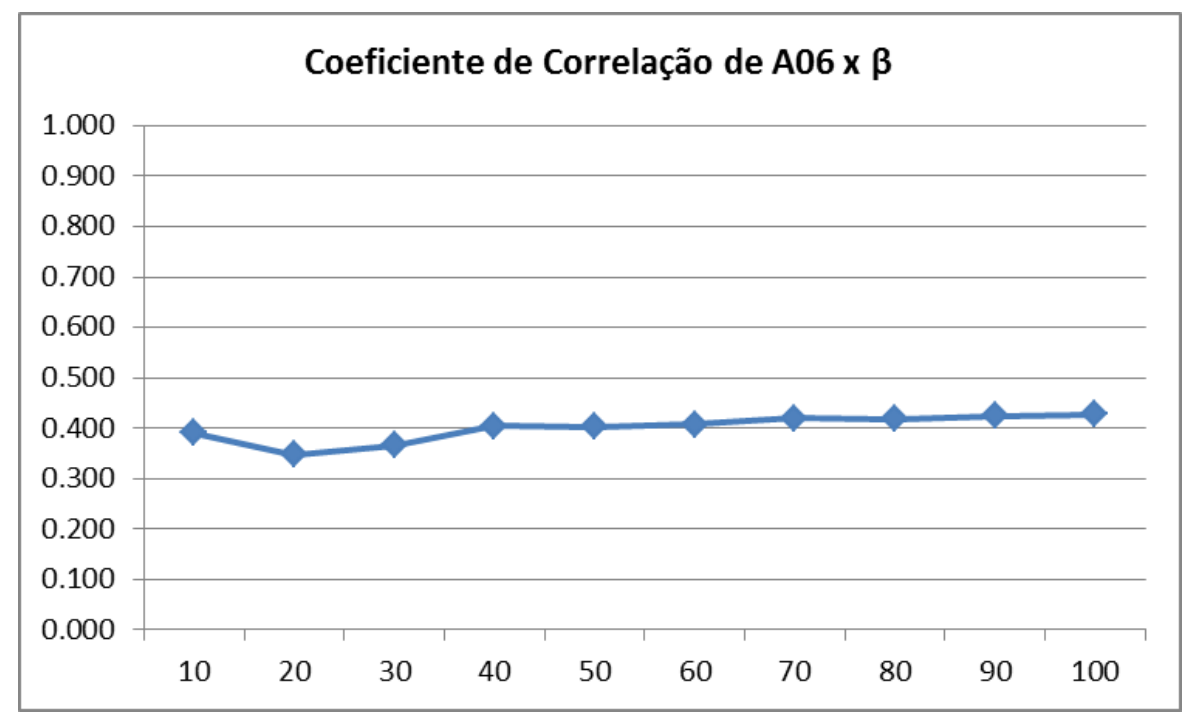

Figura 50: Coeficiente de Correlação (em módulo) do atributo A06 para cada $\beta$.

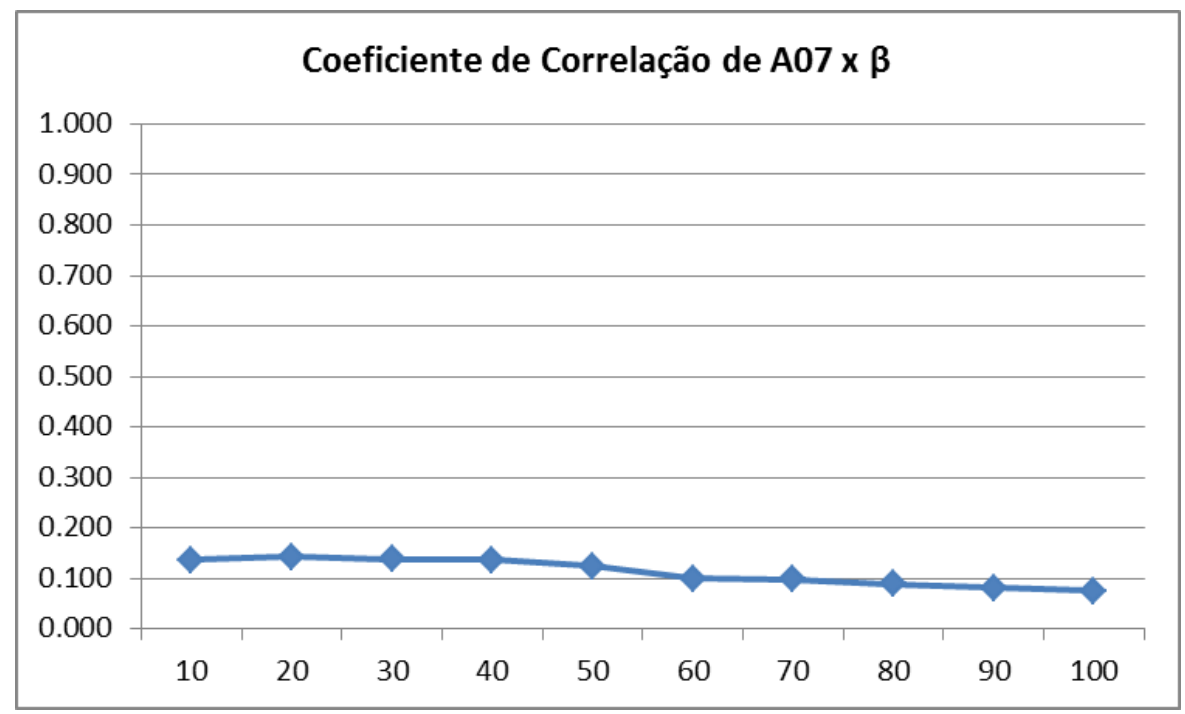

Figura 51: Coeficiente de Correlação (em módulo) do atributo A07 para cada $\beta$.

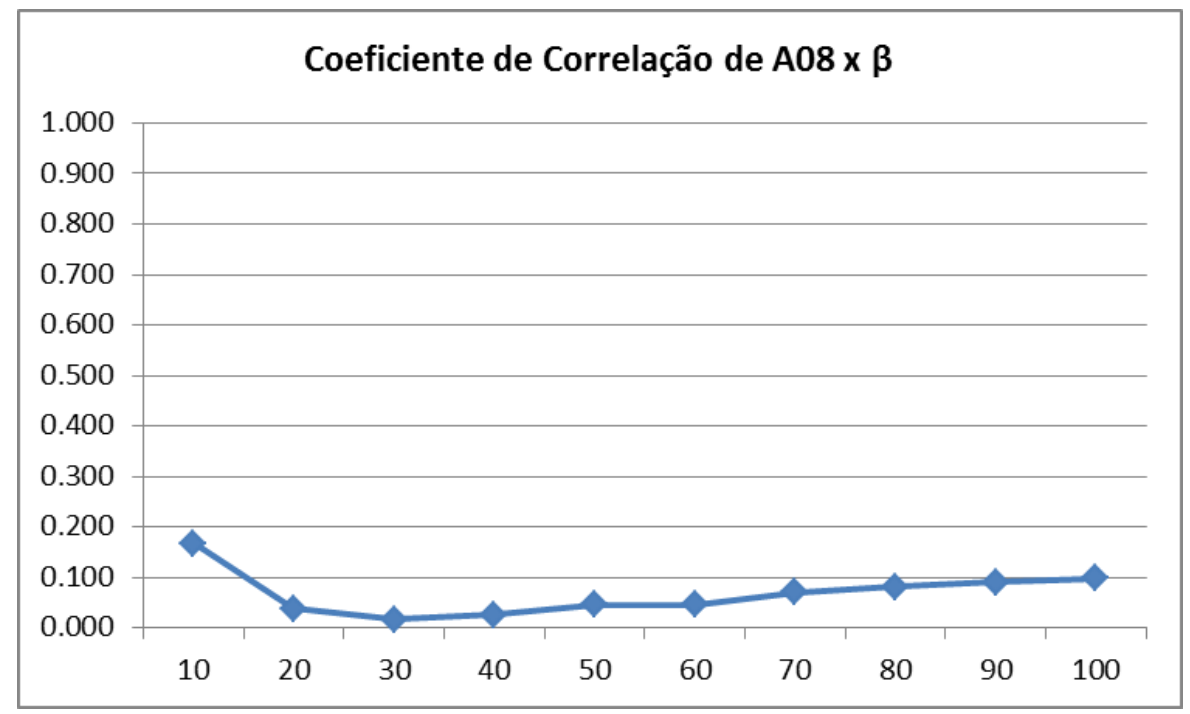

Figura 52: Coeficiente de Correlação (em módulo) do atributo A08 para cada $\beta$. 


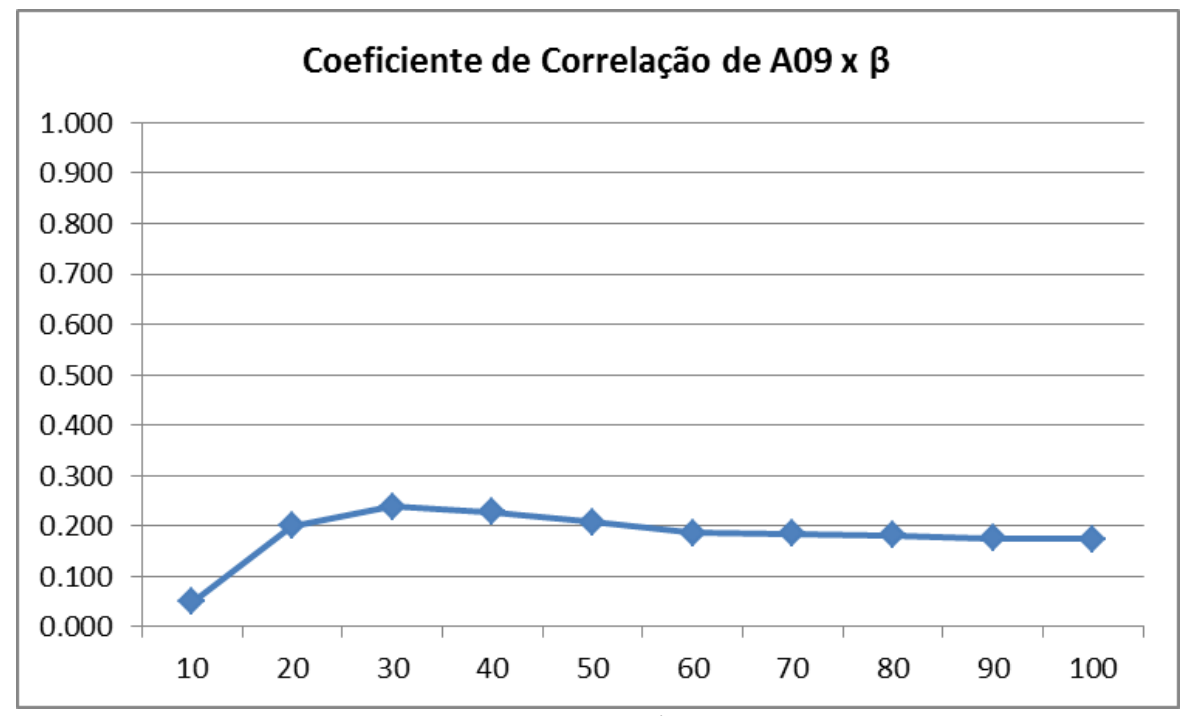

Figura 53: Coeficiente de Correlação (em módulo) do atributo A09 para cada $\beta$.

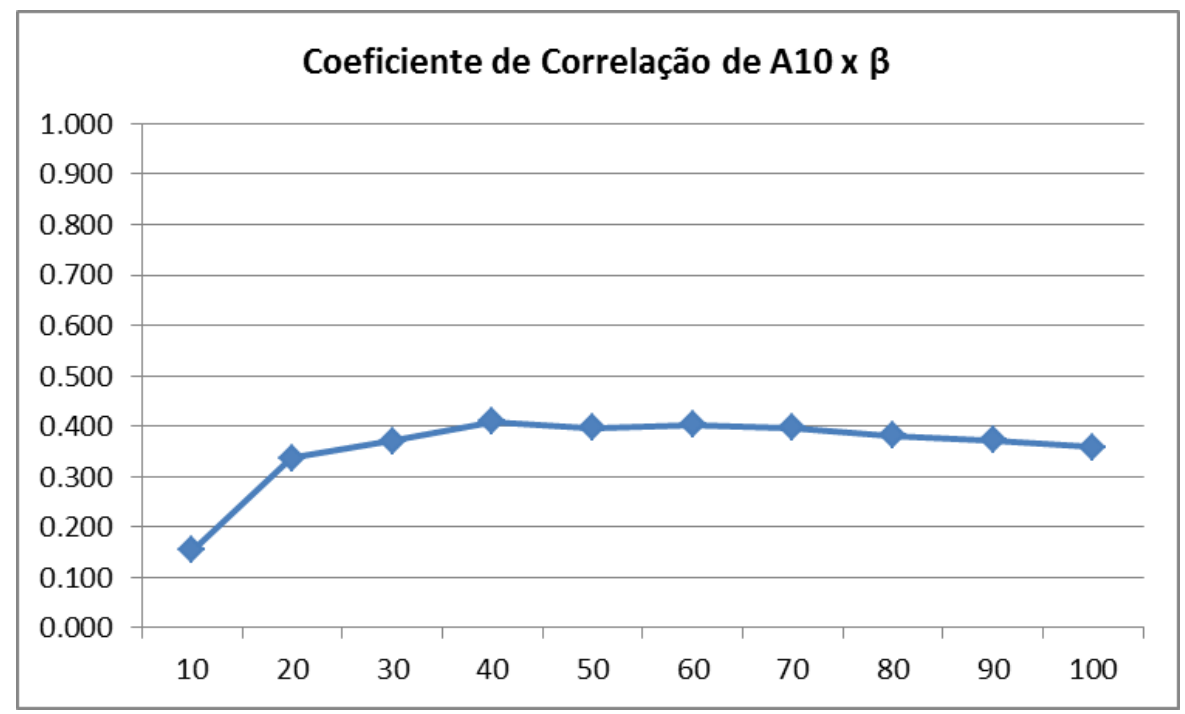

Figura 54: Coeficiente de Correlação (em módulo) do atributo A10 para cada $\beta$.

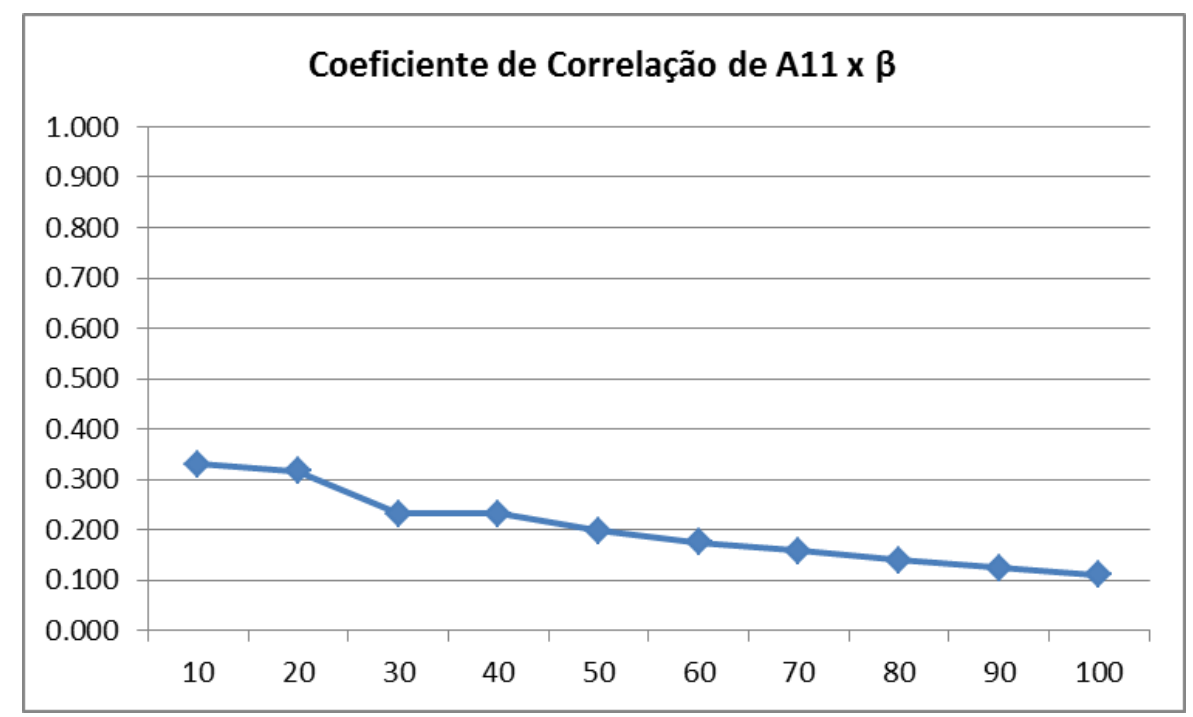

Figura 55: Coeficiente de Correlação (em módulo) do atributo A11 para cada $\beta$. 


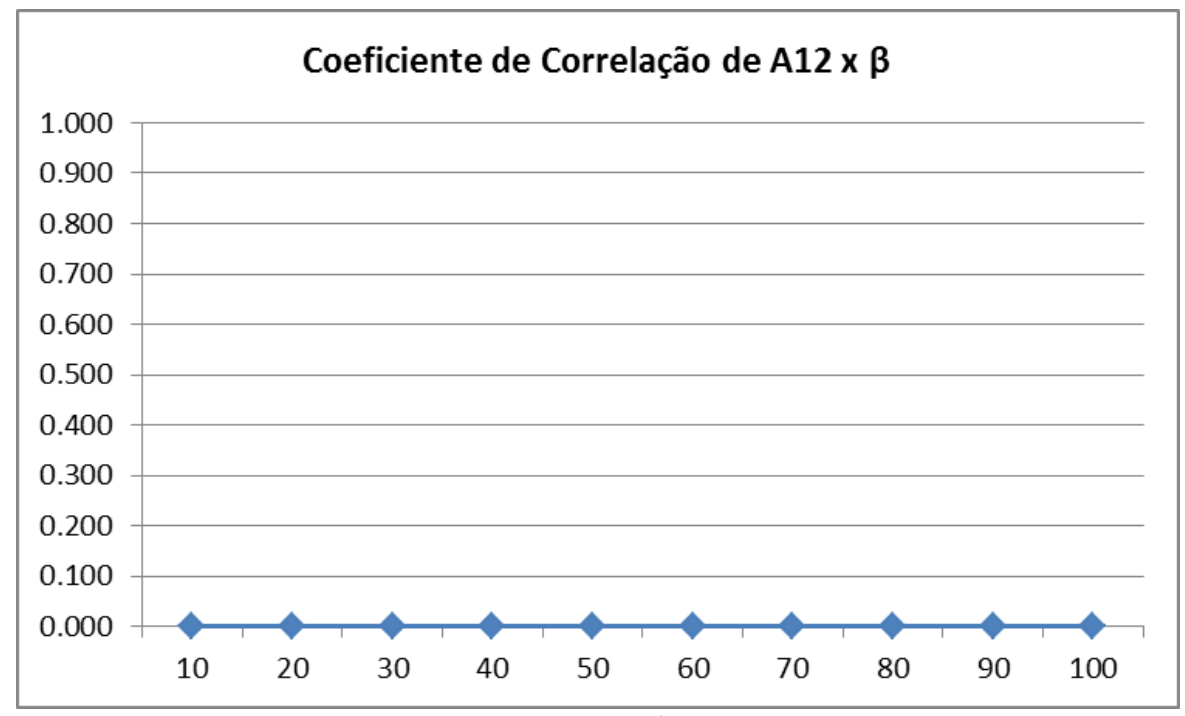

Figura 56: Coeficiente de Correlação (em módulo) do atributo A12 para cada $\beta$.

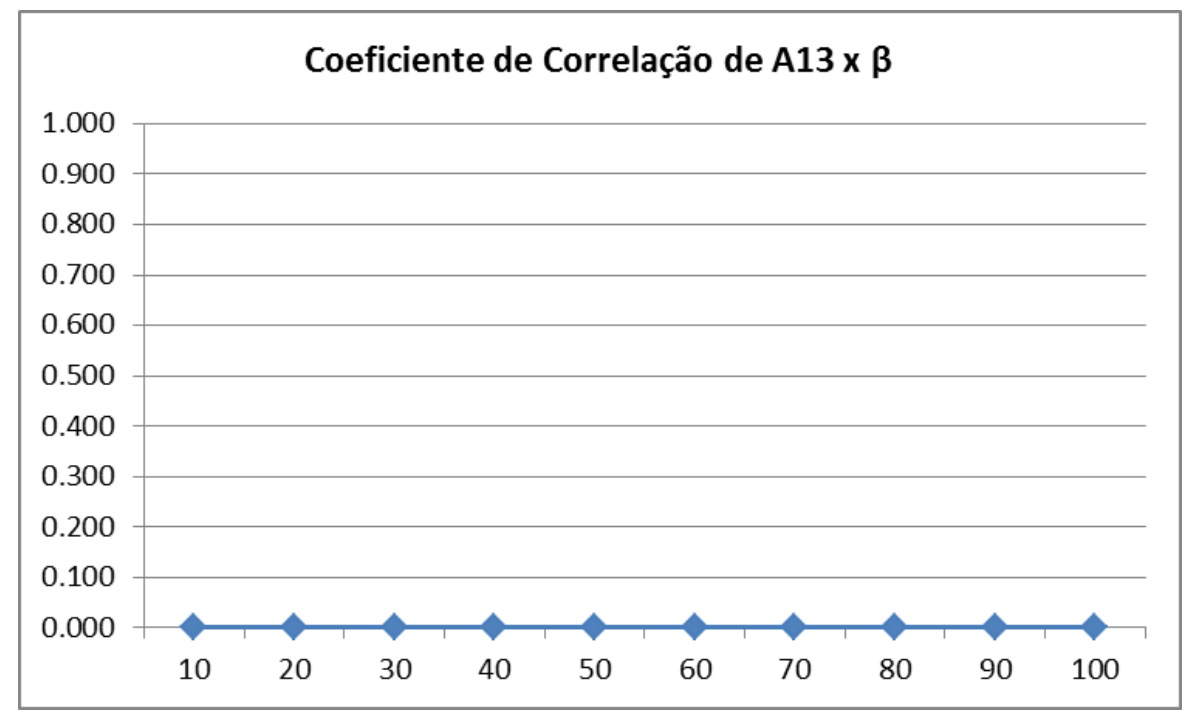

Figura 57: Coeficiente de Correlação (em módulo) do atributo A13 para cada $\beta$.

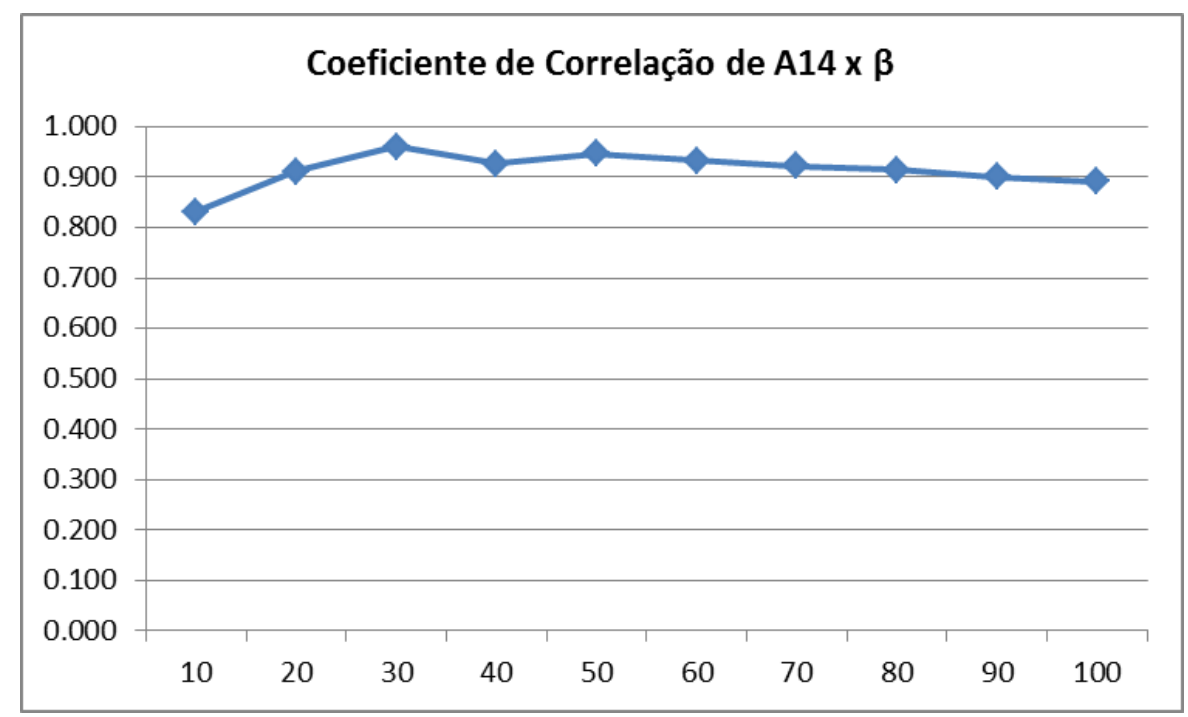

Figura 58: Coeficiente de Correlação (em módulo) do atributo A14 para cada $\beta$. 


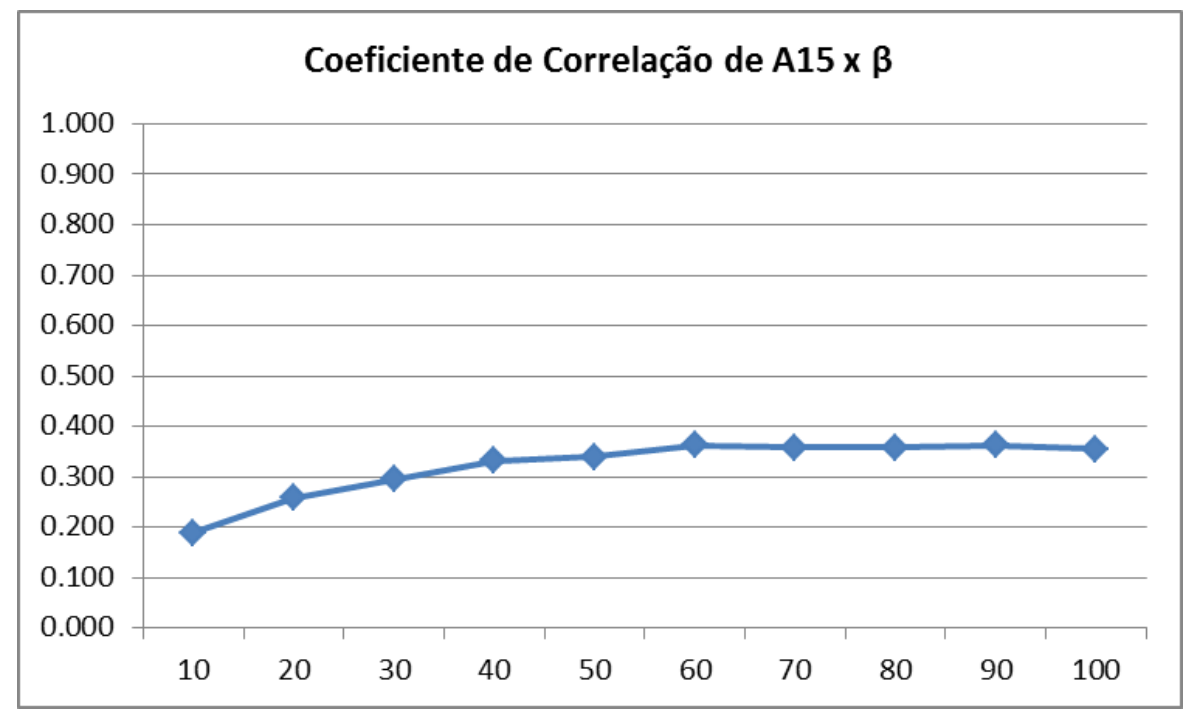

Figura 59: Coeficiente de Correlação (em módulo) do atributo A15 para cada $\beta$.

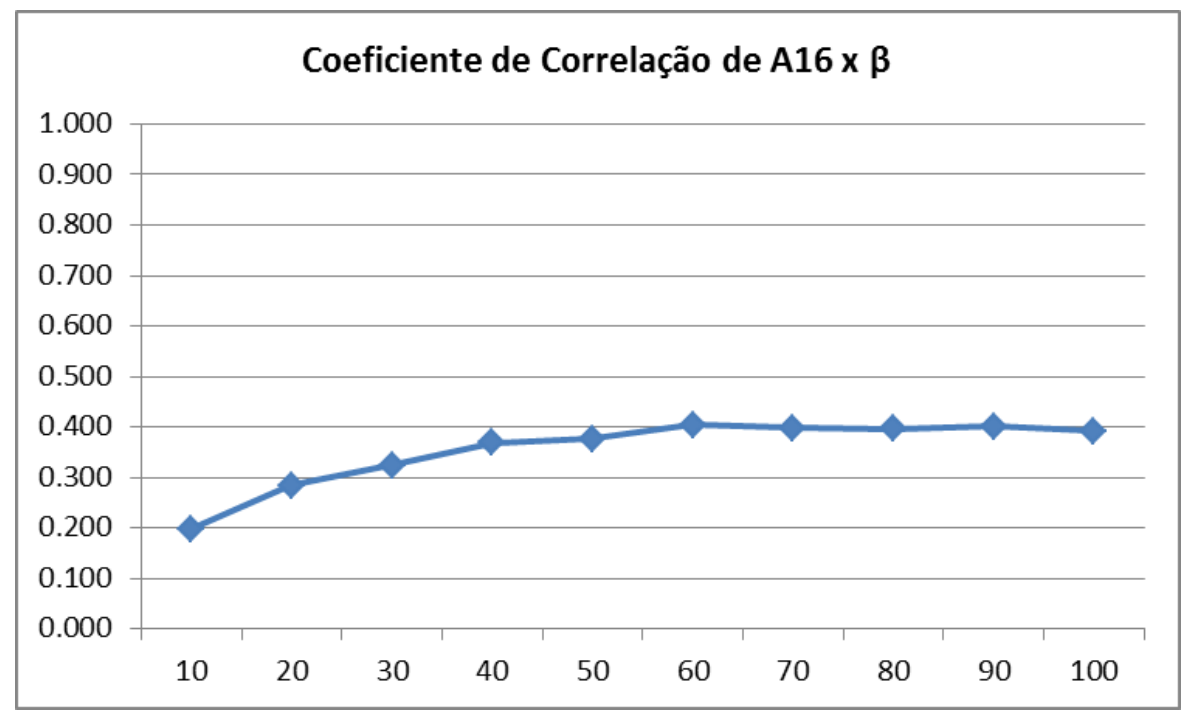

Figura 60: Coeficiente de Correlação (em módulo) do atributo A16 para cada $\beta$.

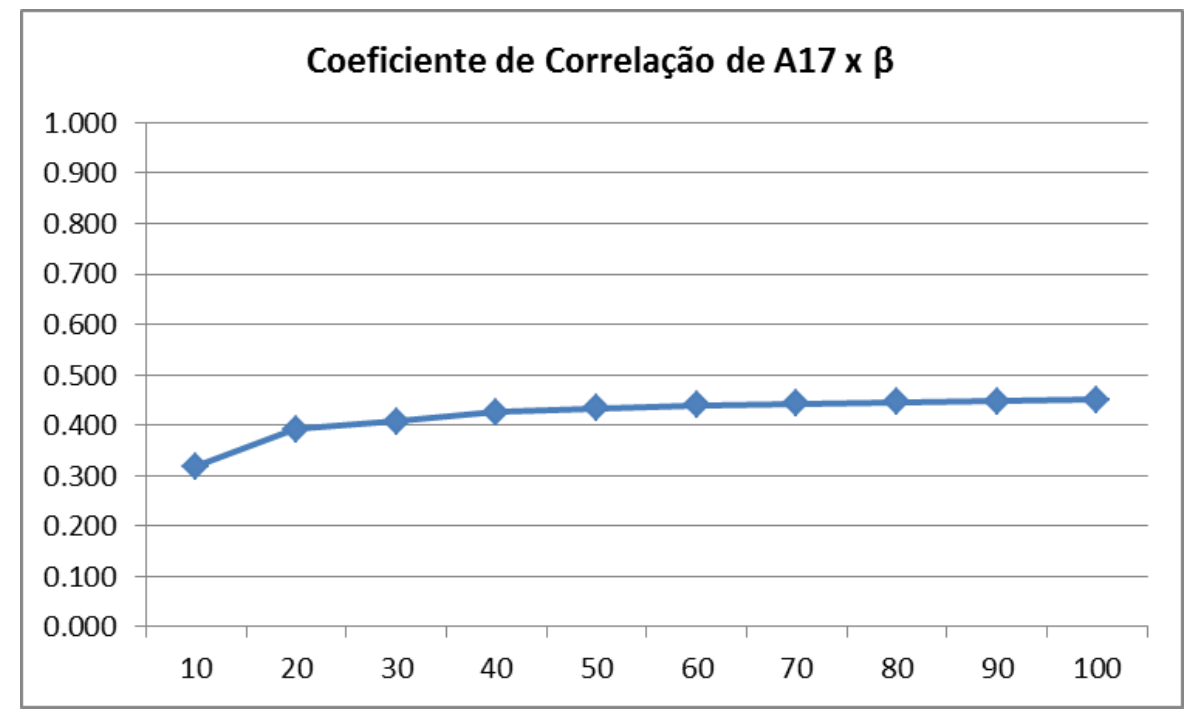

Figura 61: Coeficiente de Correlação (em módulo) do atributo A17 para cada $\beta$. 


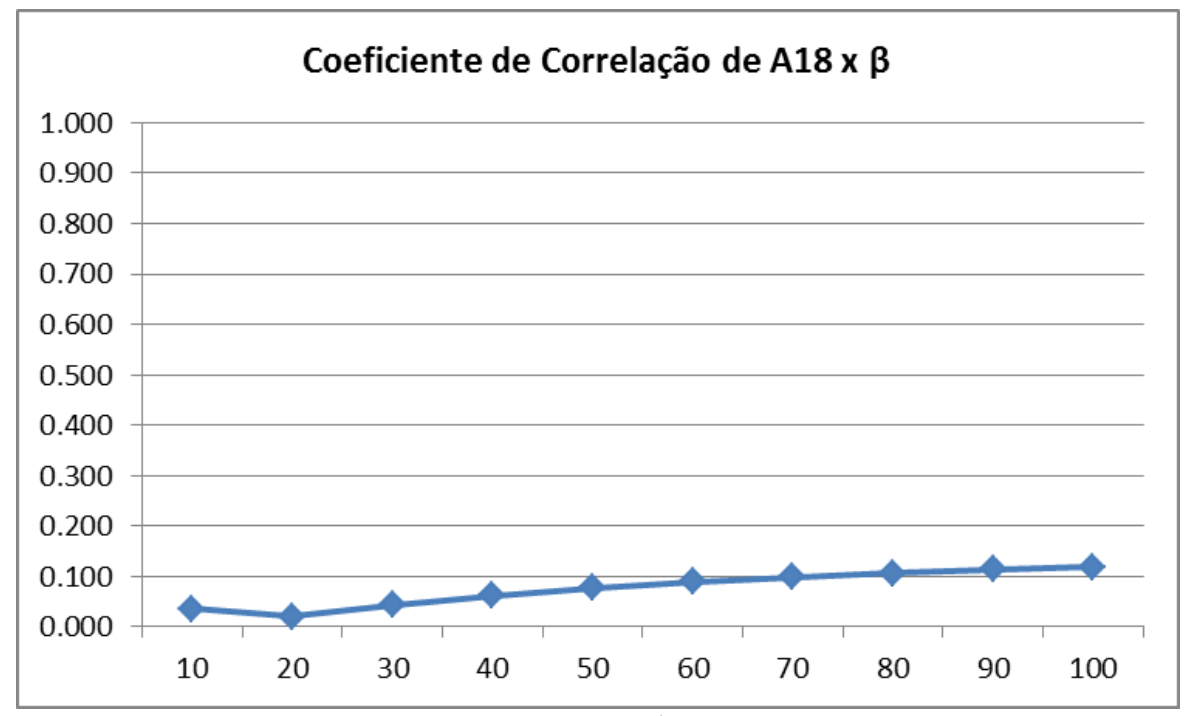

Figura 62: Coeficiente de Correlação (em módulo) do atributo A18 para cada $\beta$.

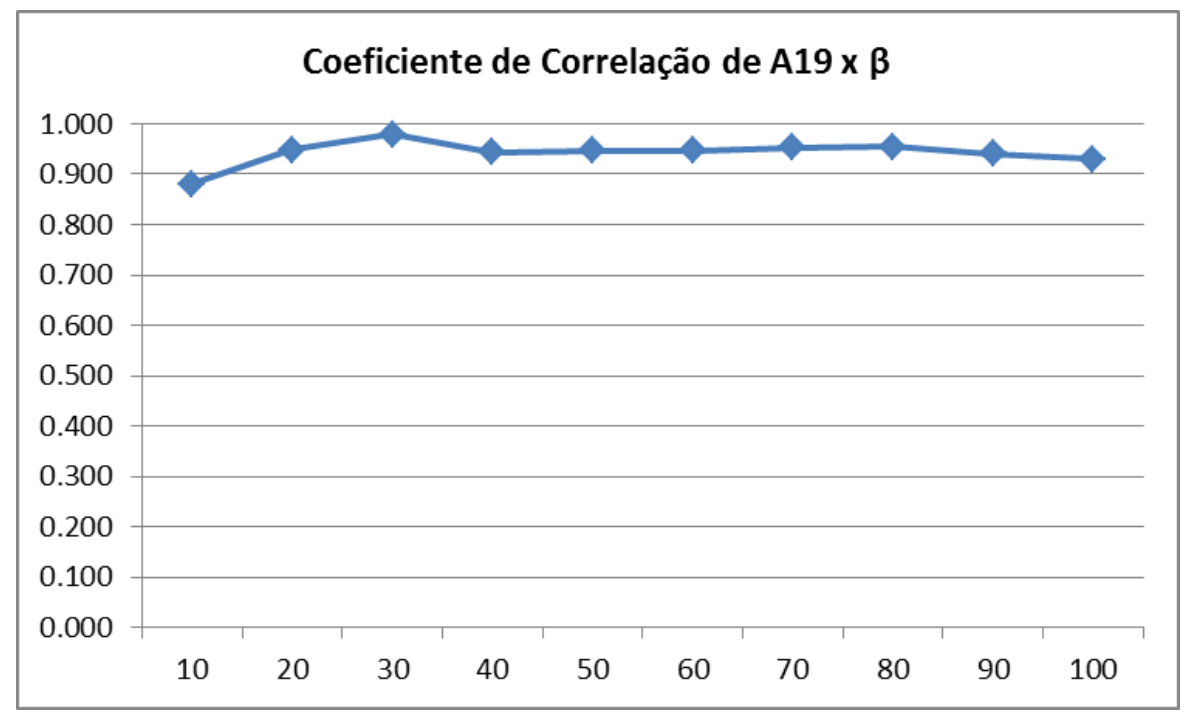

Figura 63: Coeficiente de Correlação (em módulo) do atributo A19 para cada $\beta$.

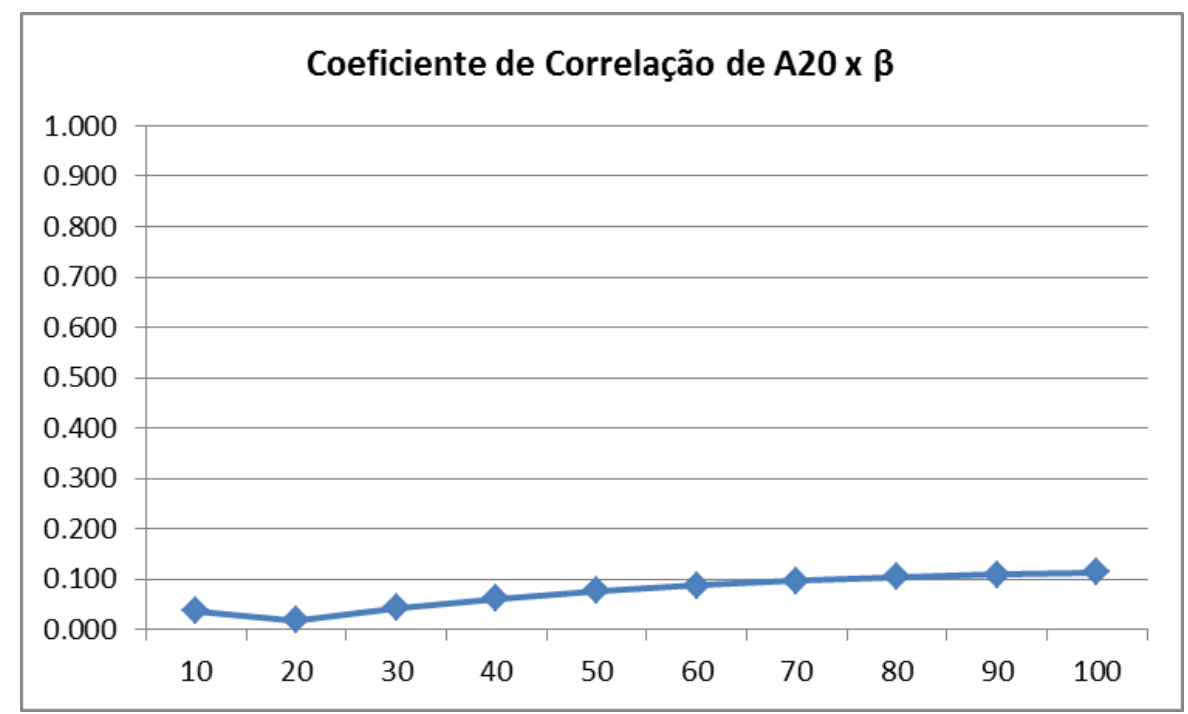

Figura 64: Coeficiente de Correlação (em módulo) do atributo A20 para cada $\beta$. 
Calculando-se o valor médio entre todos os atributos para cada valor de $\beta$ tem-se:

Tabela 18: Valor médio dos módulos dos Coeficientes de Correlação com a saída para cada $\beta$.

\begin{tabular}{cc}
$\boldsymbol{\beta}$ & MÉDIA \\
\hline $\mathbf{1 0}$ & 0,2901 \\
\hline $\mathbf{2 0}$ & 0,3355 \\
\hline $\mathbf{3 0}$ & 0,3542 \\
\hline $\mathbf{4 0}$ & 0,3660 \\
\hline $\mathbf{5 0}$ & 0,3674 \\
\hline $\mathbf{6 0}$ & 0,3657 \\
\hline $\mathbf{7 0}$ & 0,3661 \\
\hline $\mathbf{8 0}$ & 0,3627 \\
\hline $\mathbf{9 0}$ & 0,3592 \\
\hline $\mathbf{1 0 0}$ & 0,3543 \\
\hline
\end{tabular}

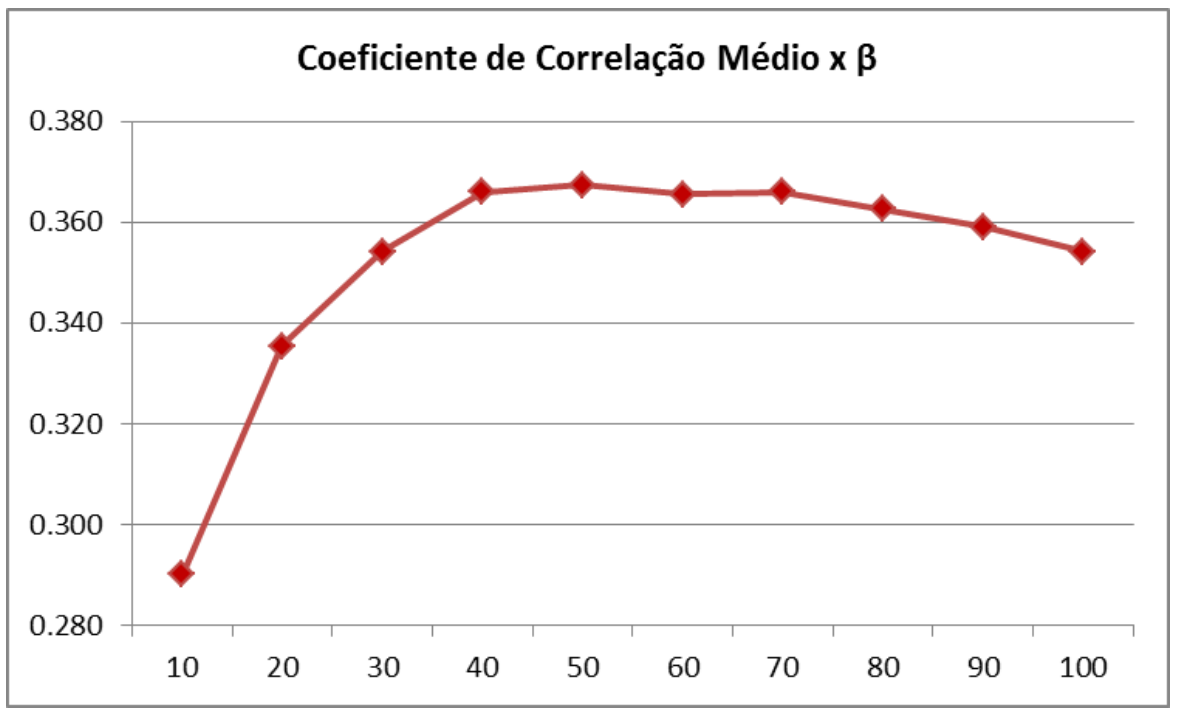

Figura 65: Valor médio dos módulos dos Coeficientes de Correlação com a saída para cada $\beta$.

Analisando-se a Tabela 18 e da Figura 65 constata-se que o valor de $\beta$ que implica em um maior valor médio do Coeficiente de Correlação dos atributos com a saída é o valor 50. Portanto, esse valor foi o escolhido para a sequência das análises.

Os gráficos a seguir (Figura 66 a Figura 145) ilustram o comportamento de cada atributo listado na Tabela 15 em relação ao fluxo de pacotes capturados para cada cenário de teste com o parâmetro $\beta$ igual a 50 pacotes e normalizado entre 0 e 1 .

Apenas para propósitos ilustrativos, plotou-se também os gráficos para os valores de $\beta$ iguais a 20 e 100 pacotes. Estes gráficos podem ser visualizados no APÊNDICE A. 


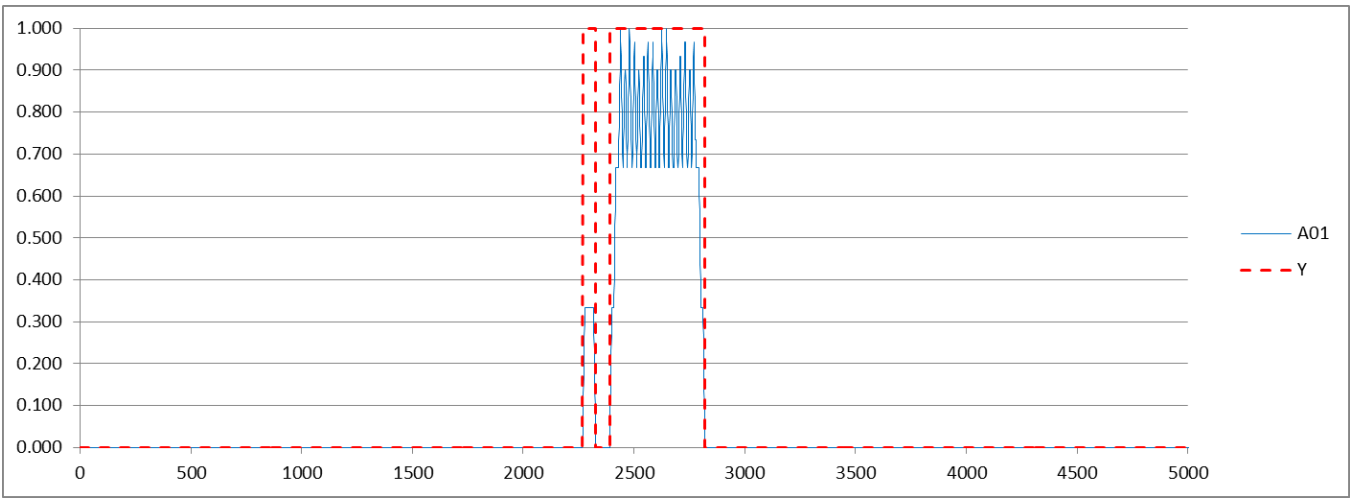

Figura 66: Atributo A01 - Cenário 1.

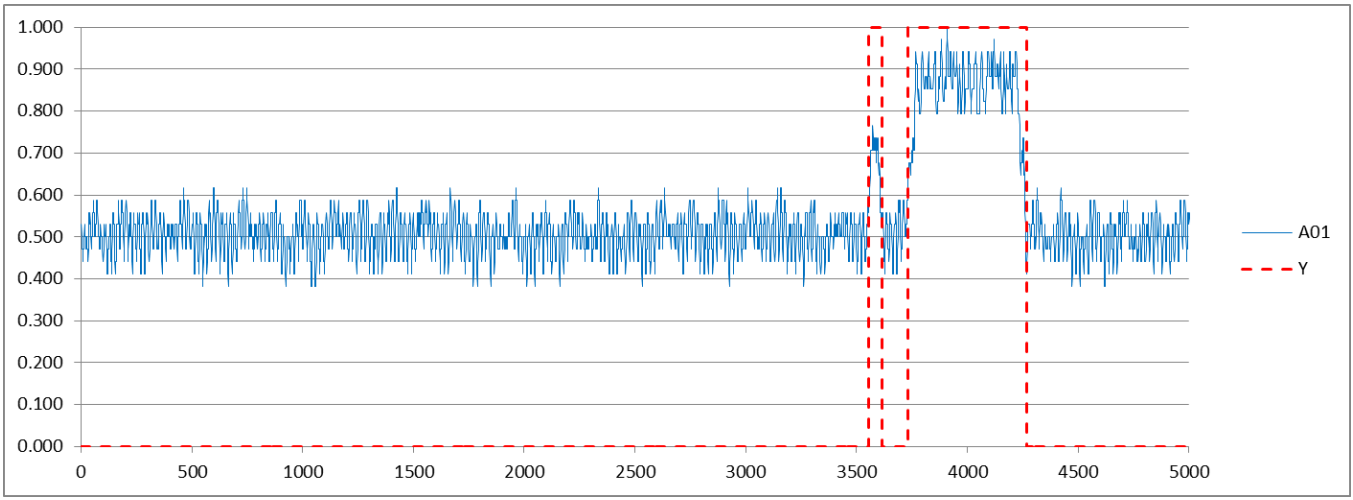

Figura 67: Atributo A01 - Cenário 2.

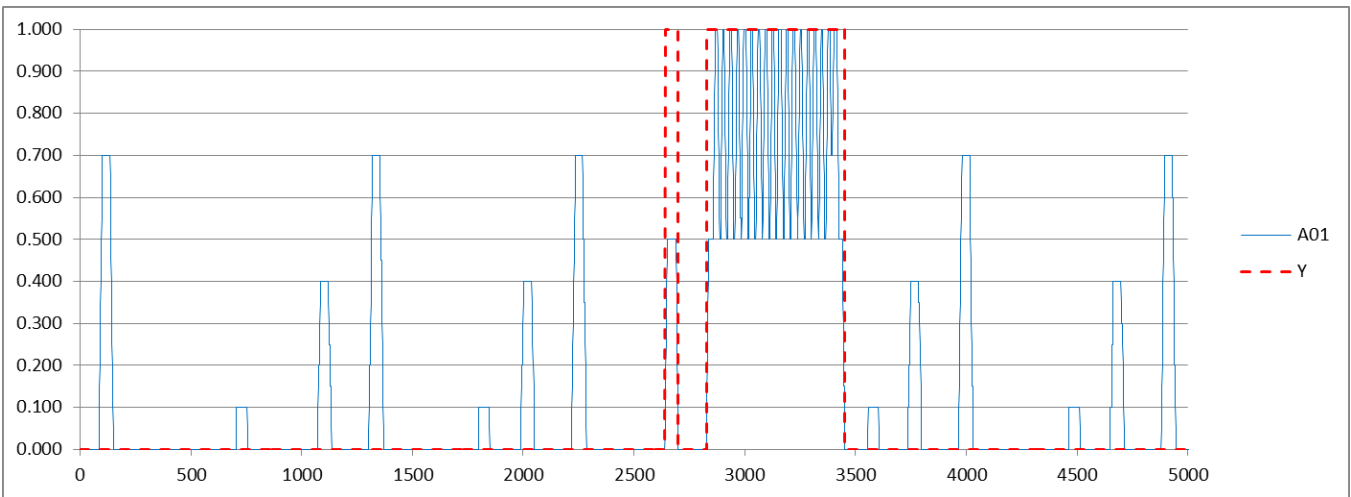

Figura 68: Atributo A01 - Cenário 3.

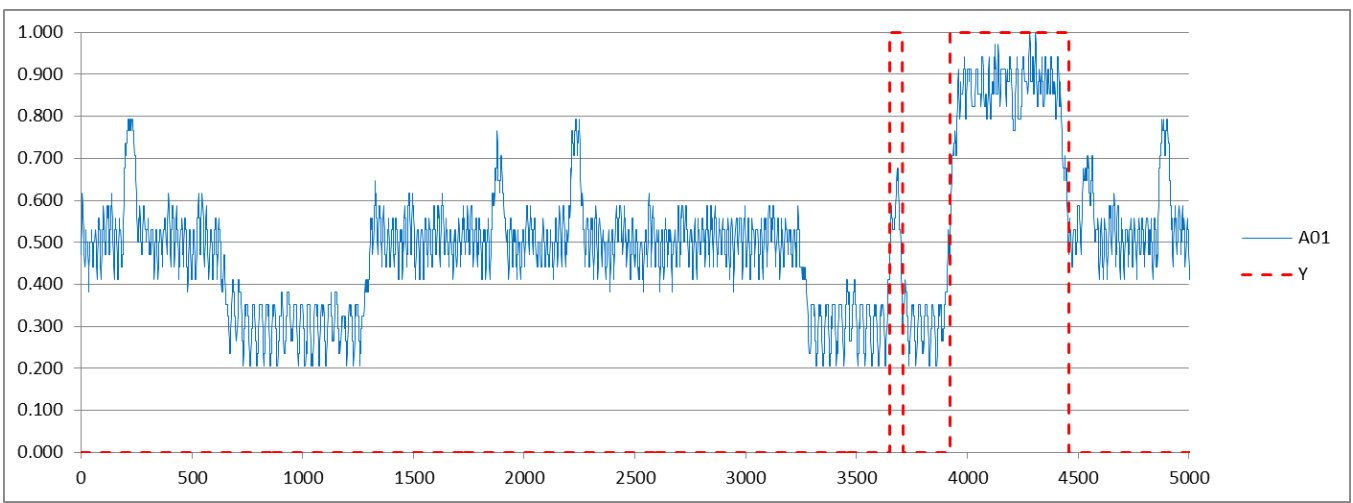

Figura 69: Atributo A01 - Cenário 4. 


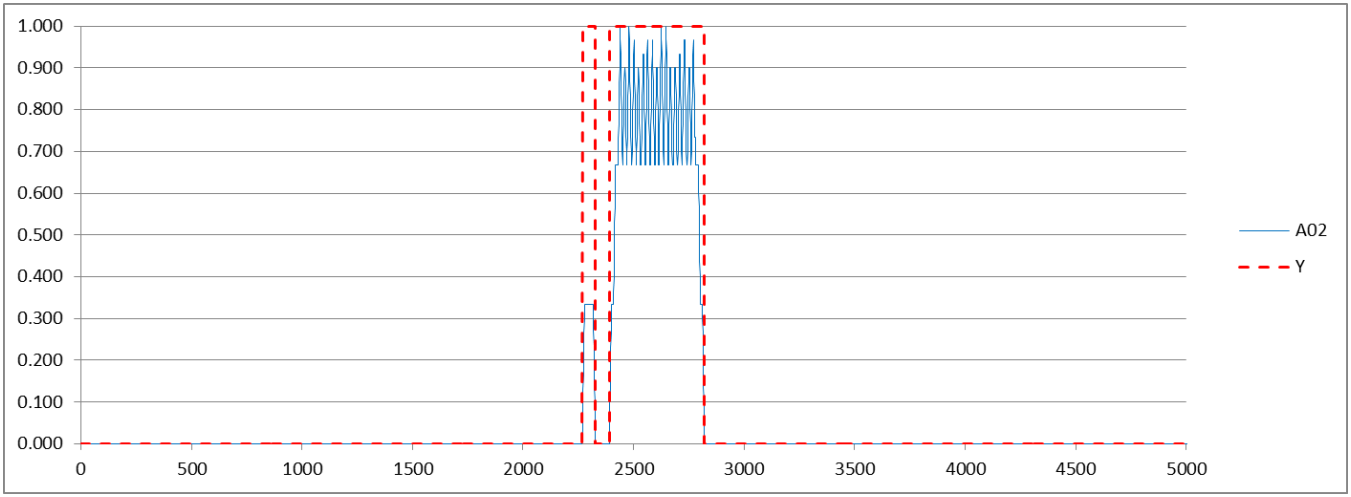

Figura 70: Atributo A02 - Cenário 1.

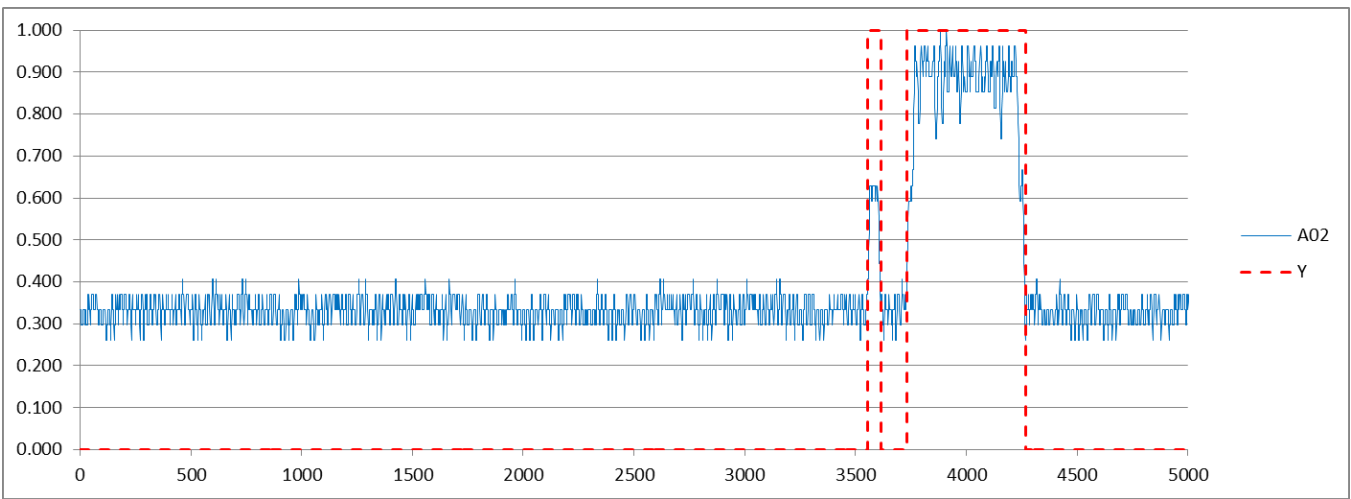

Figura 71: Atributo A02 - Cenário 2.

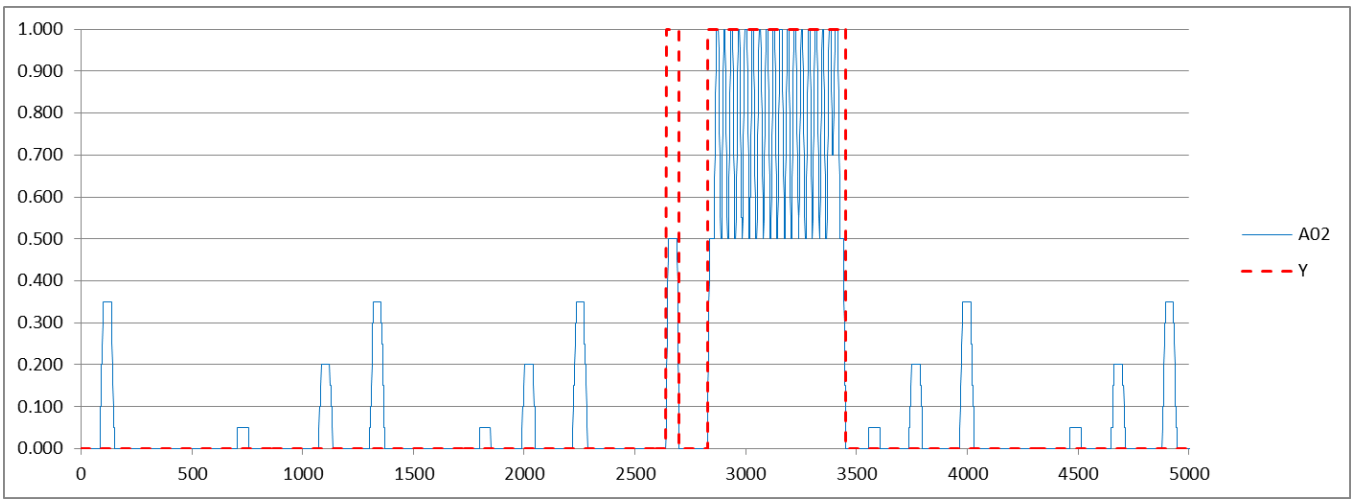

Figura 72: Atributo A02 - Cenário 3.

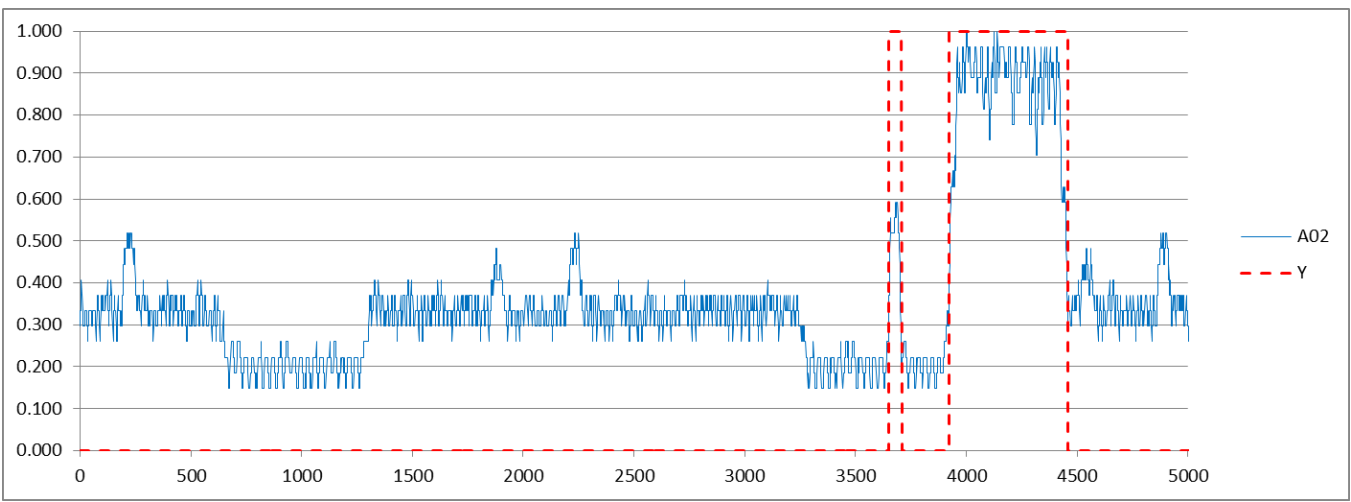

Figura 73: Atributo A02 - Cenário 4. 


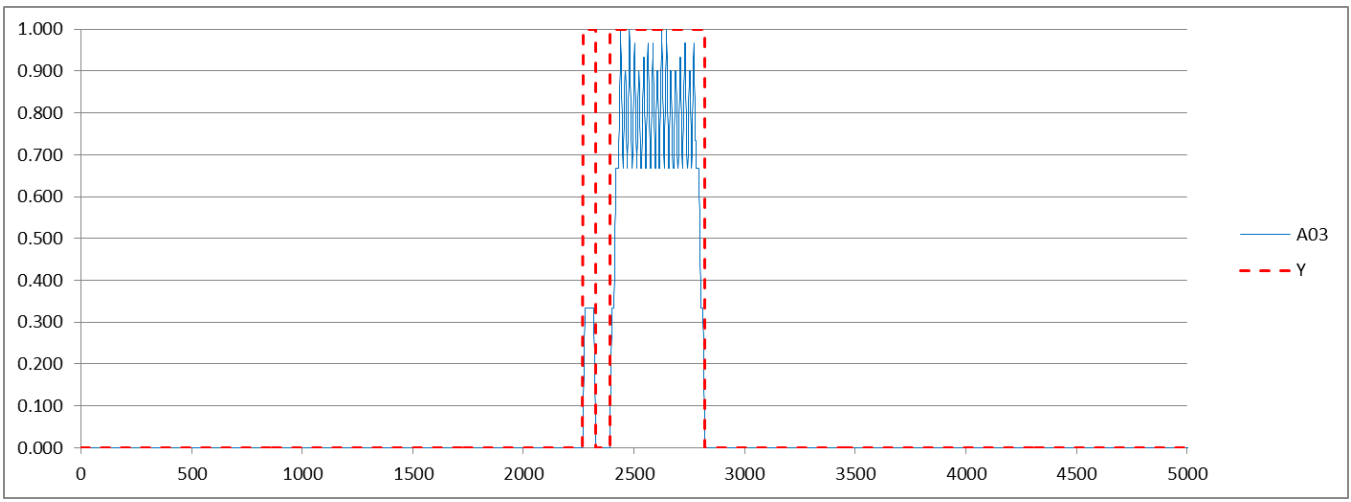

Figura 74: Atributo A03 - Cenário 1.

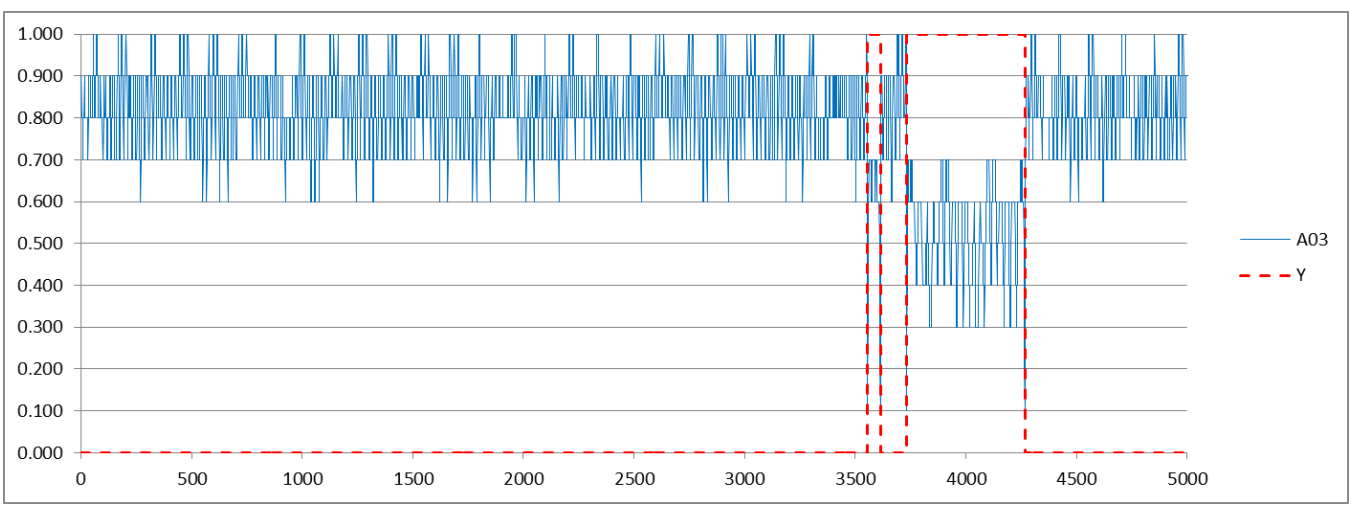

Figura 75: Atributo A03 - Cenário 2.

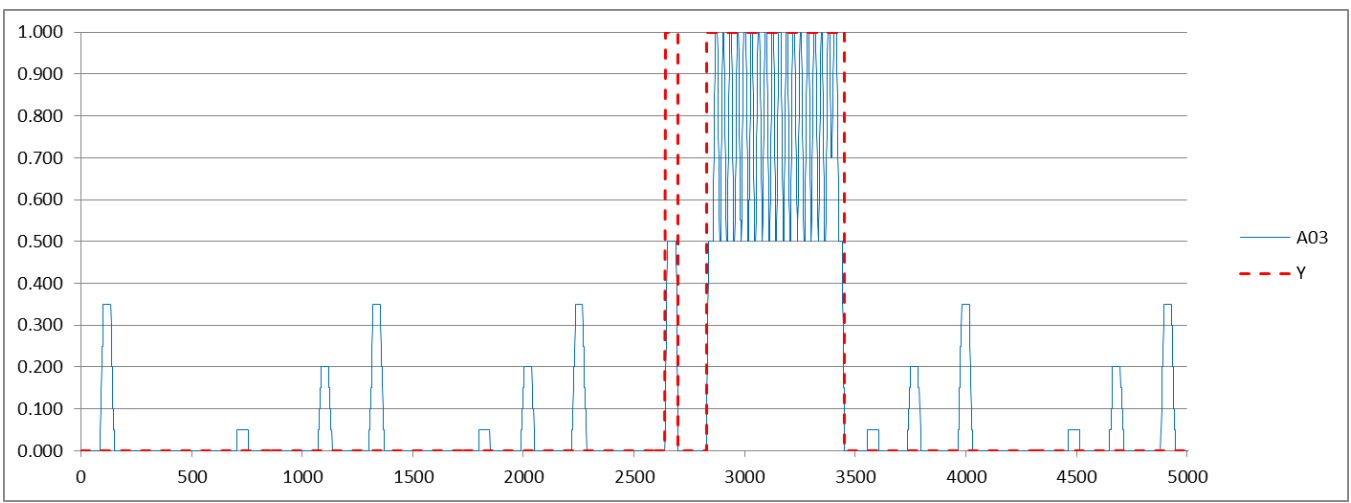

Figura 76: Atributo A03 - Cenário 3.

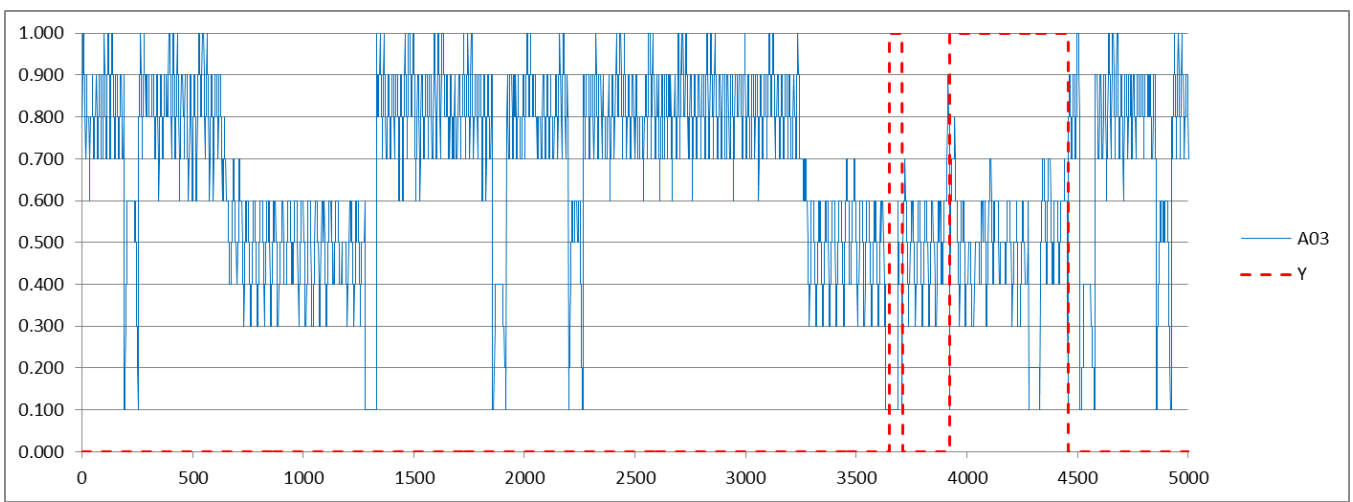

Figura 77: Atributo A03 - Cenário 4. 


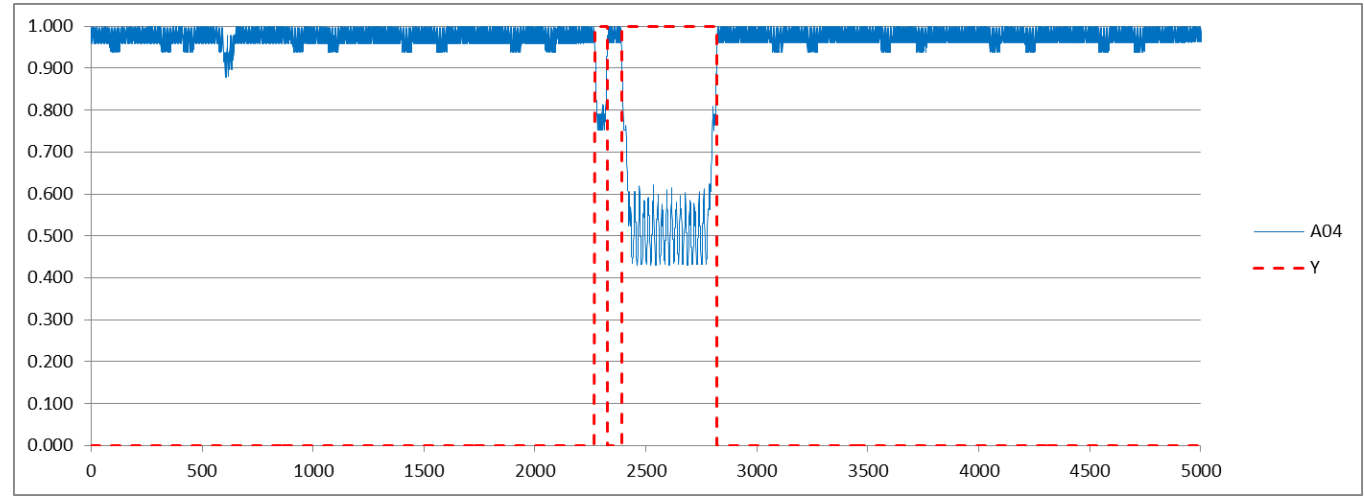

Figura 78: Atributo A04 - Cenário 1.

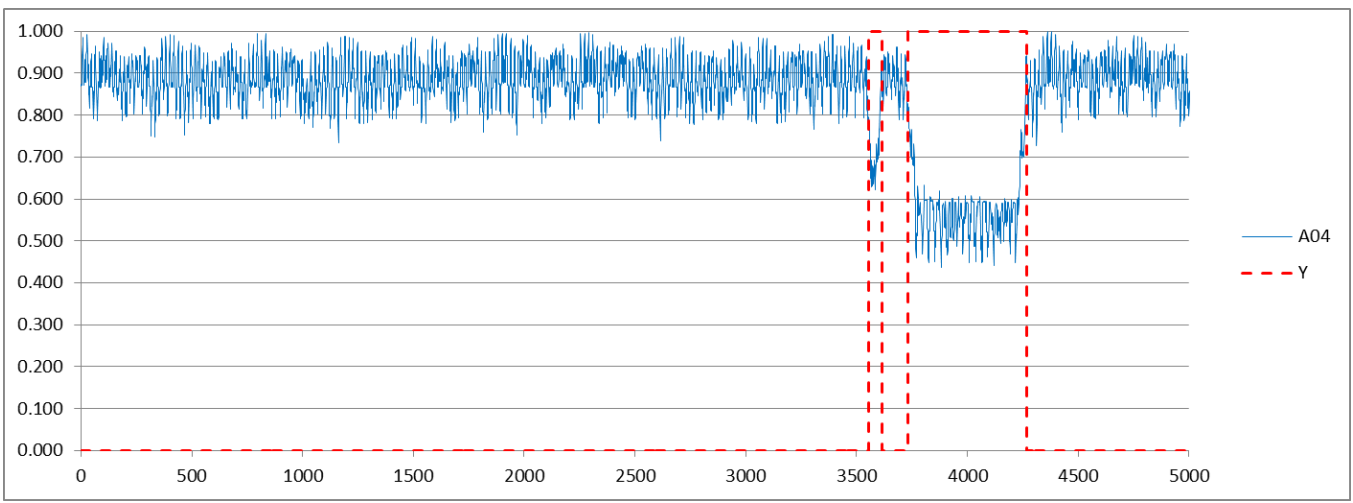

Figura 79: Atributo A04 - Cenário 2.

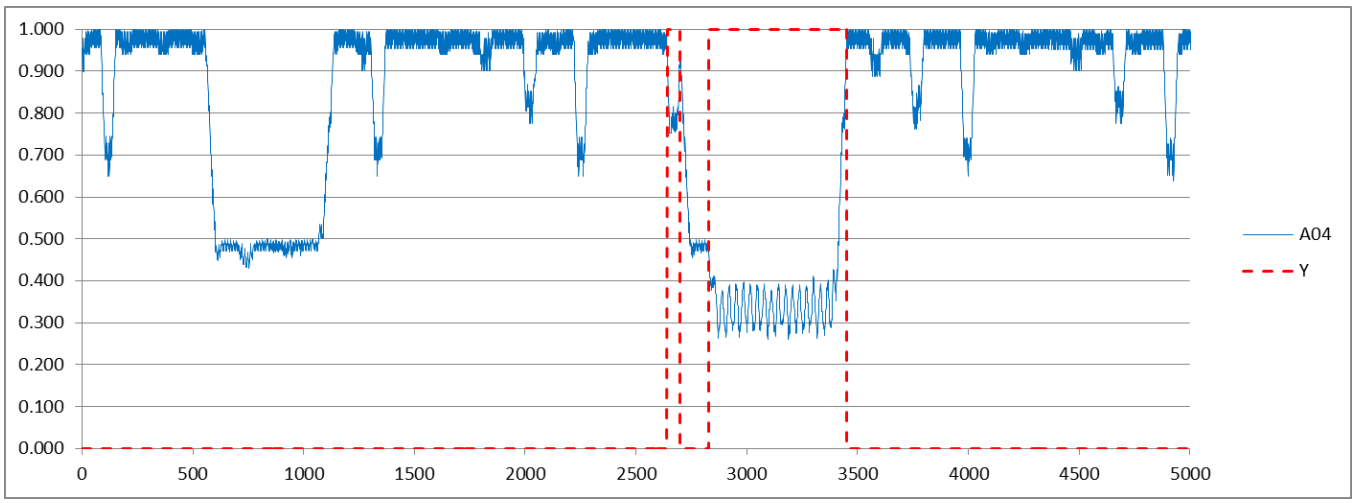

Figura 80: Atributo A04 - Cenário 3.

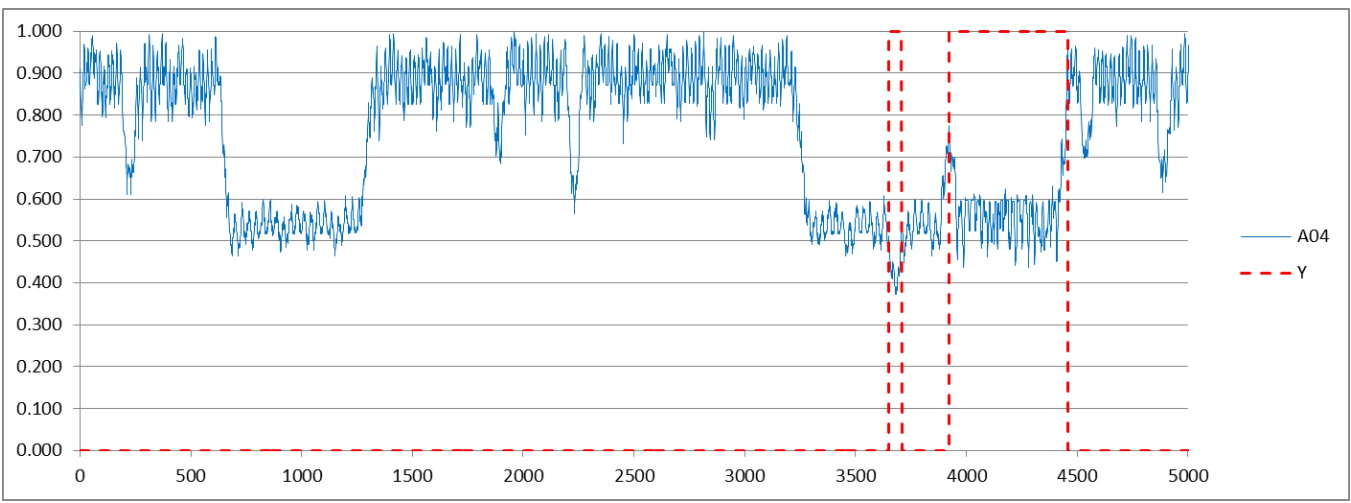

Figura 81: Atributo A04 - Cenário 4. 


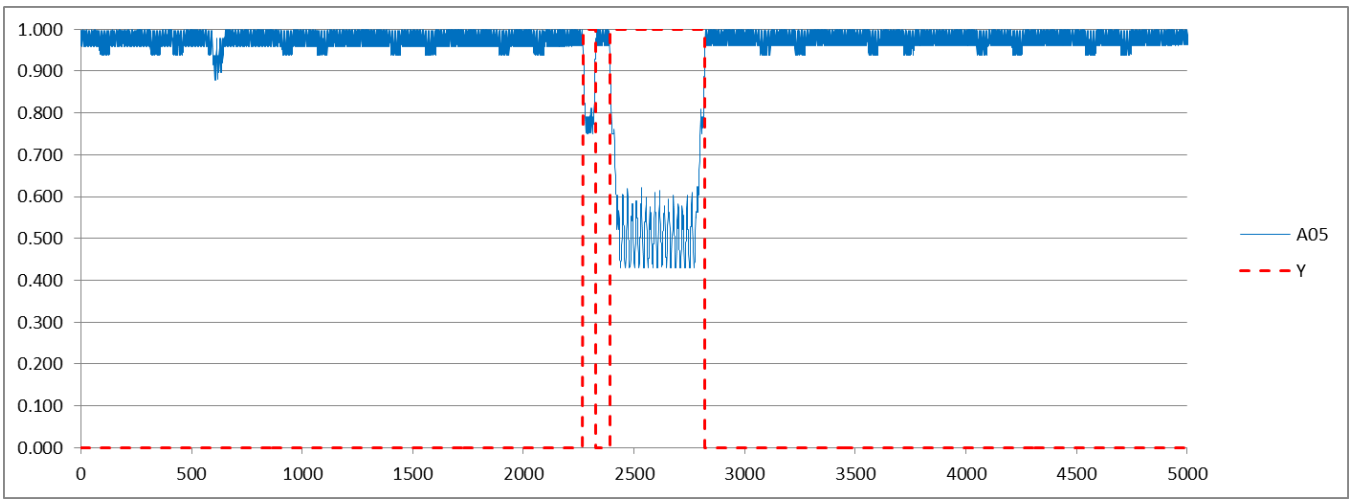

Figura 82: Atributo A05 - Cenário 1.

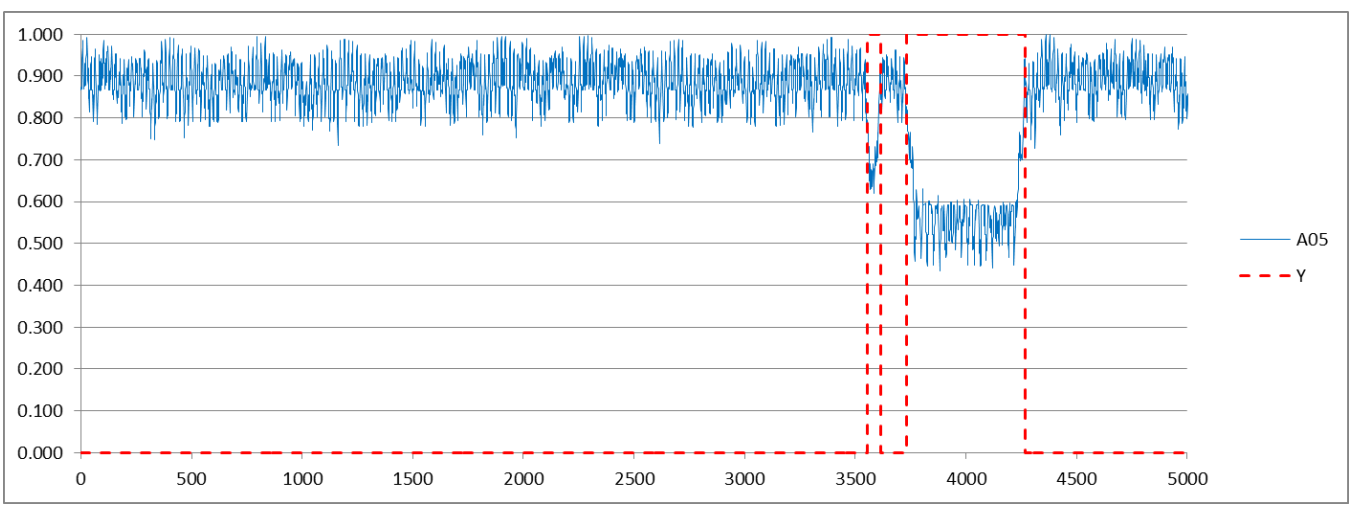

Figura 83: Atributo A05 - Cenário 2.

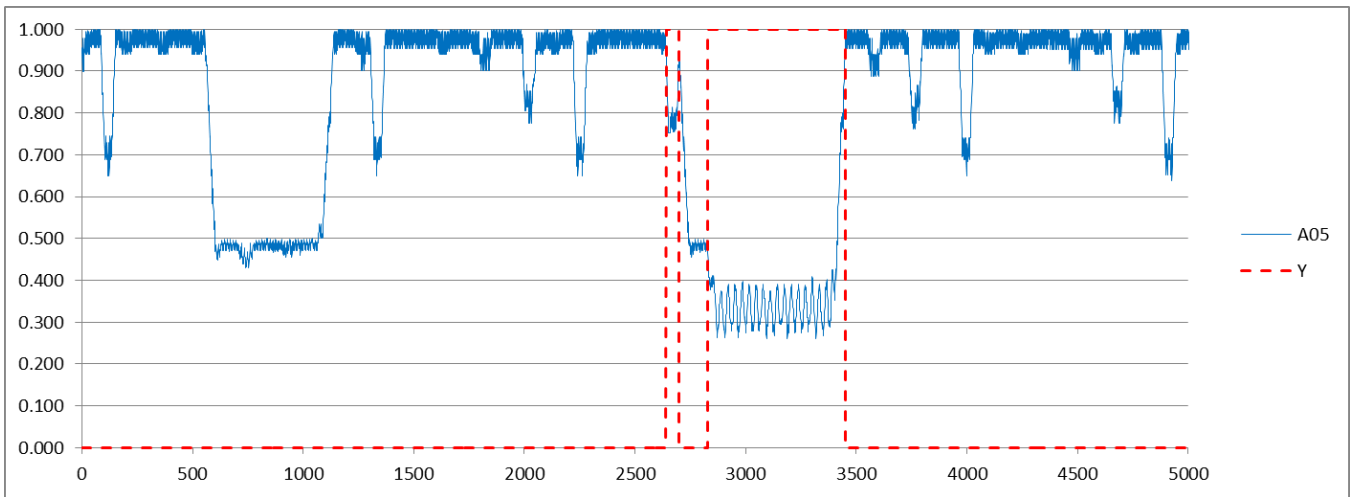

Figura 84: Atributo A05 - Cenário 3.

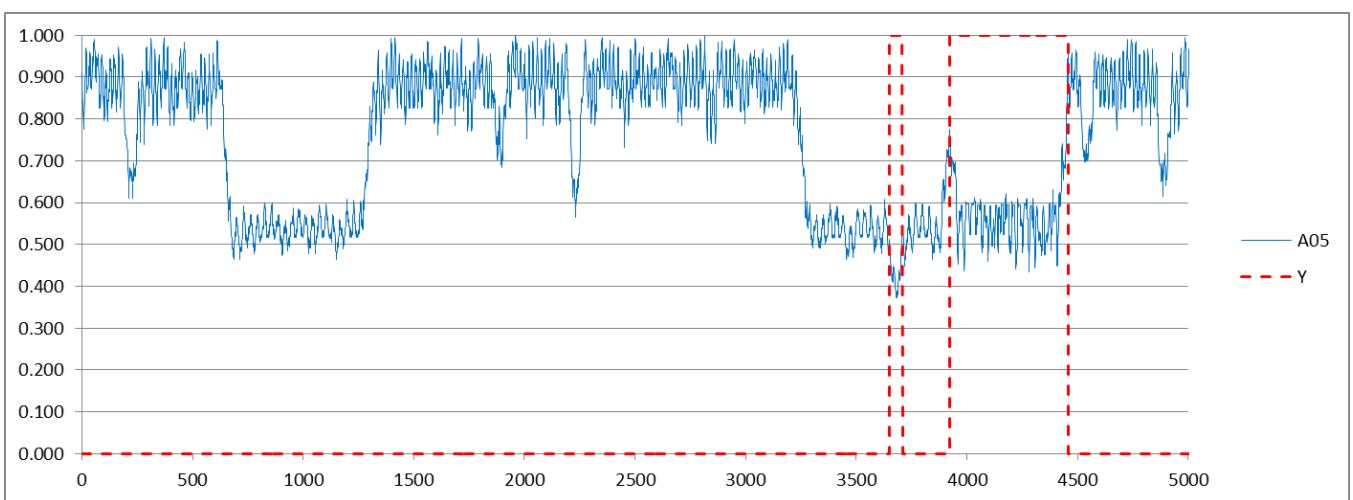

Figura 85: Atributo A05 - Cenário 4. 


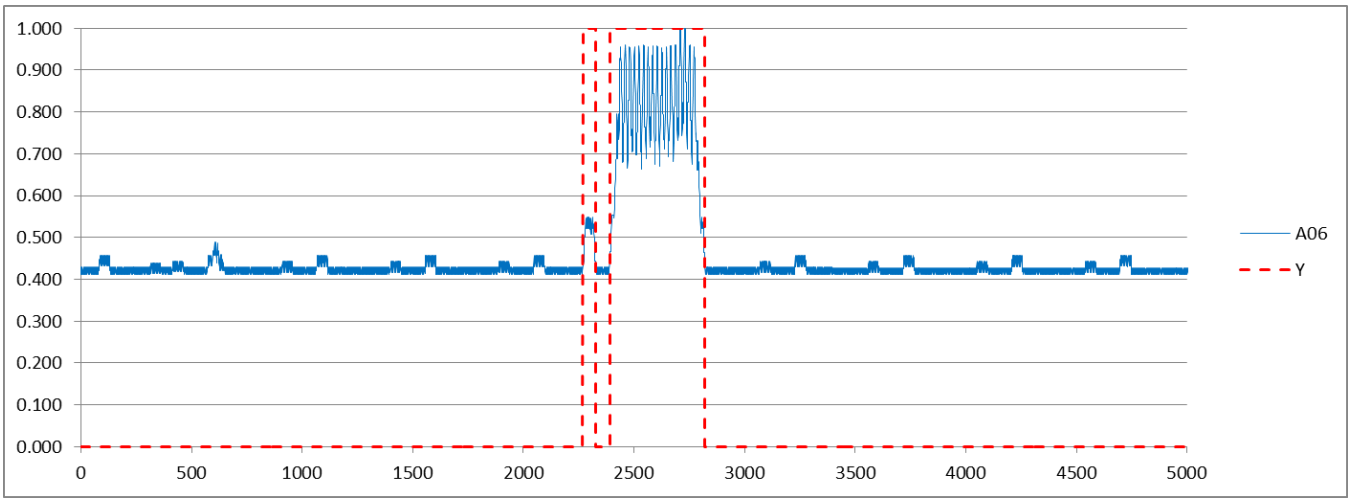

Figura 86: Atributo A06 - Cenário 1.

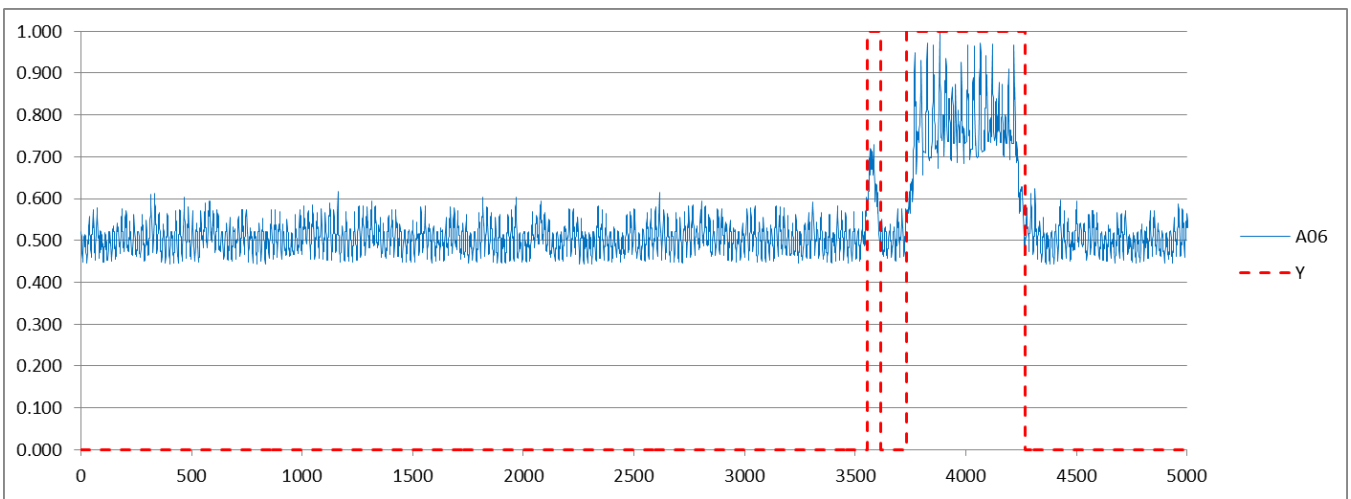

Figura 87: Atributo A06 - Cenário 2.

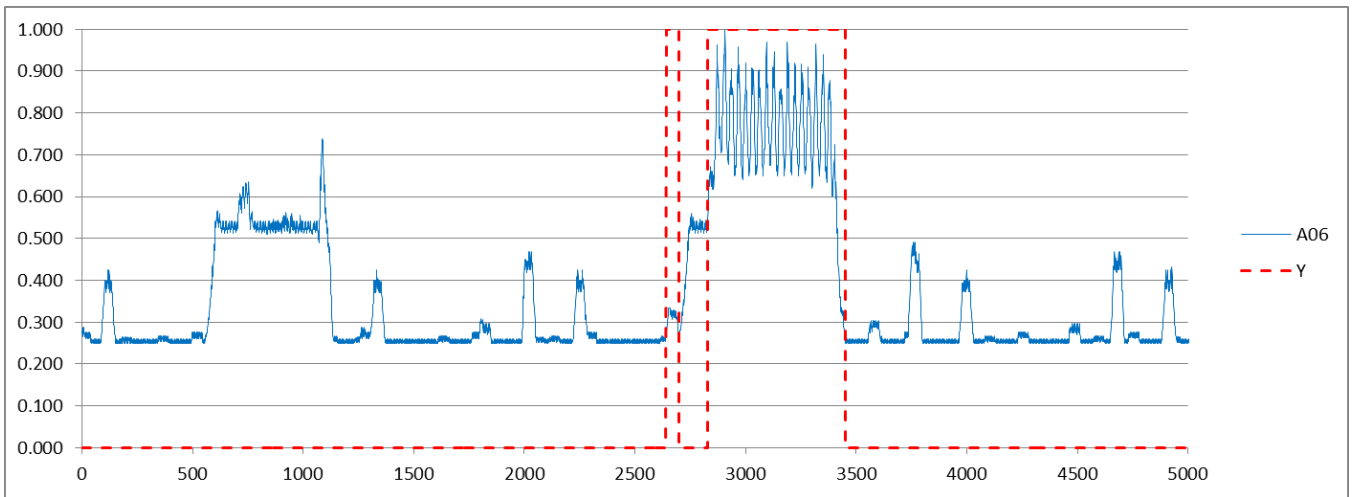

Figura 88: Atributo A06 - Cenário 3.

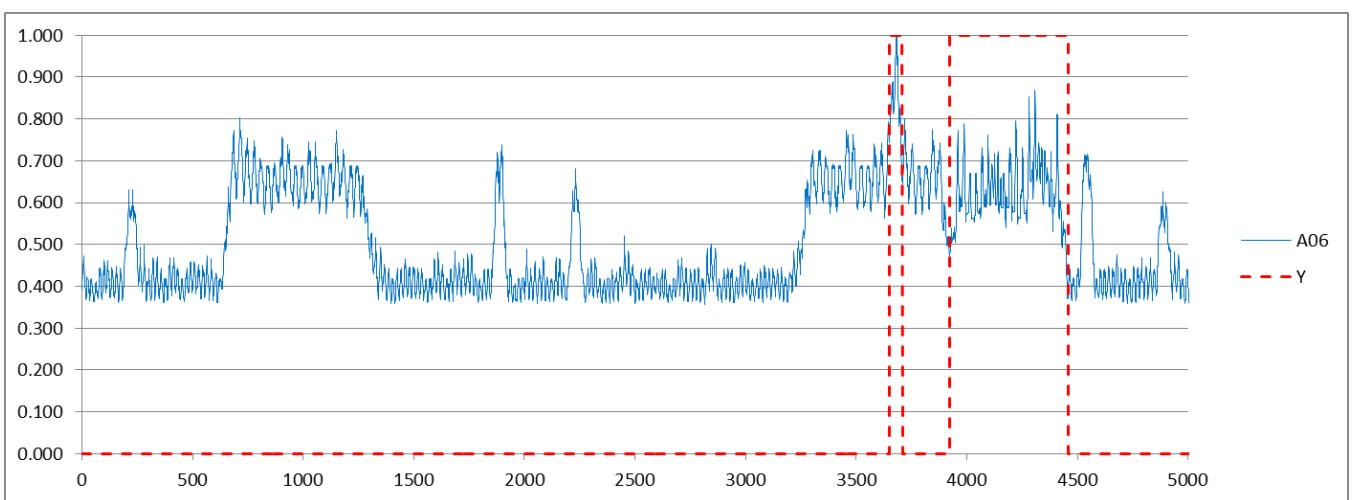

Figura 89: Atributo A06 - Cenário 4. 


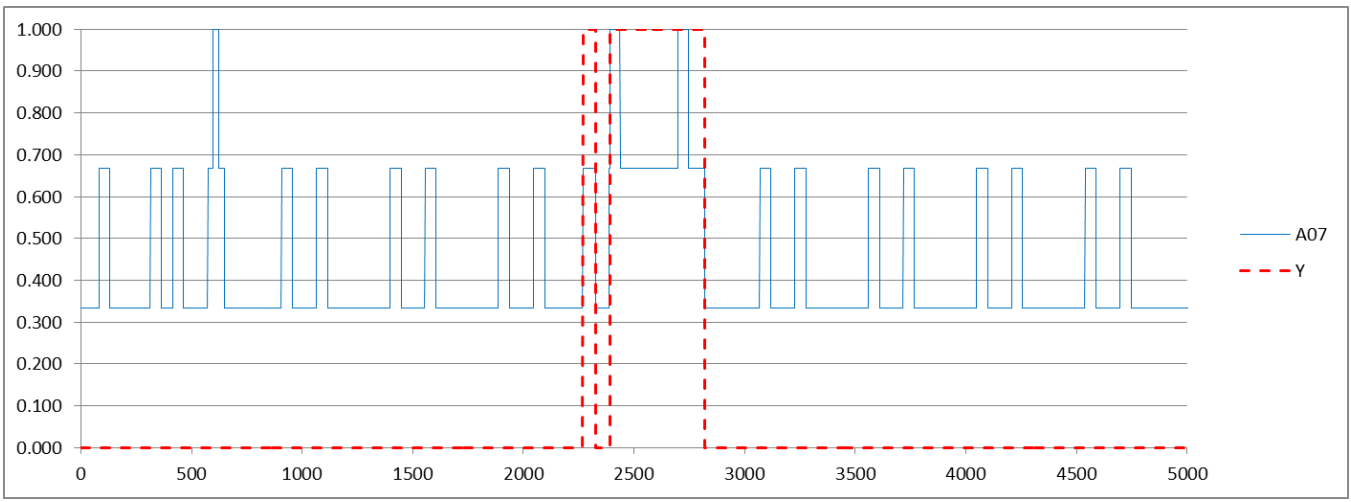

Figura 90: Atributo A07 - Cenário 1.

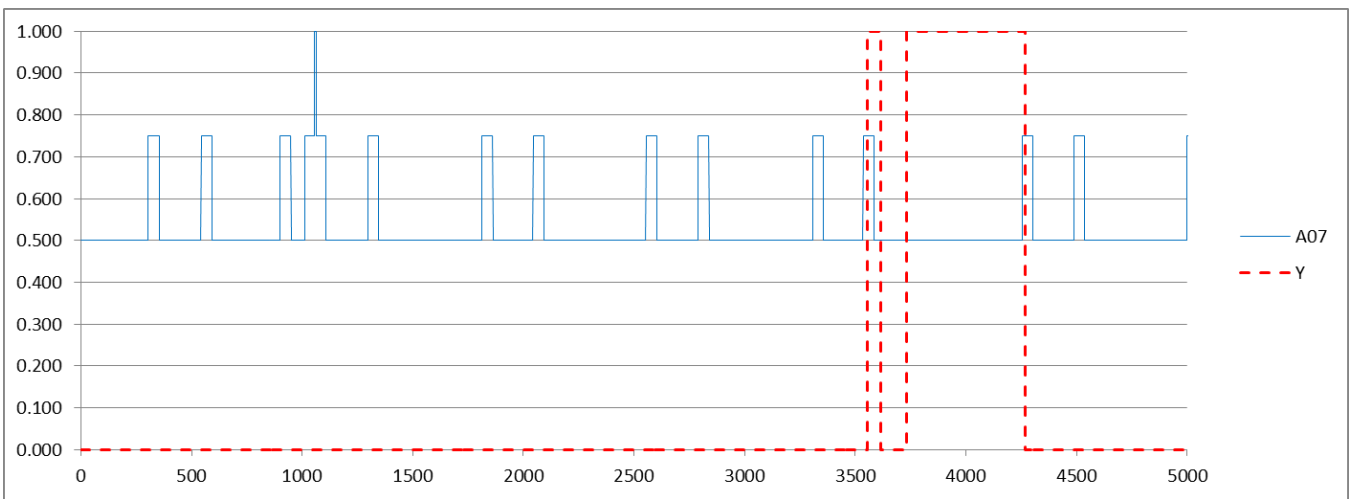

Figura 91: Atributo A07 - Cenário 2.

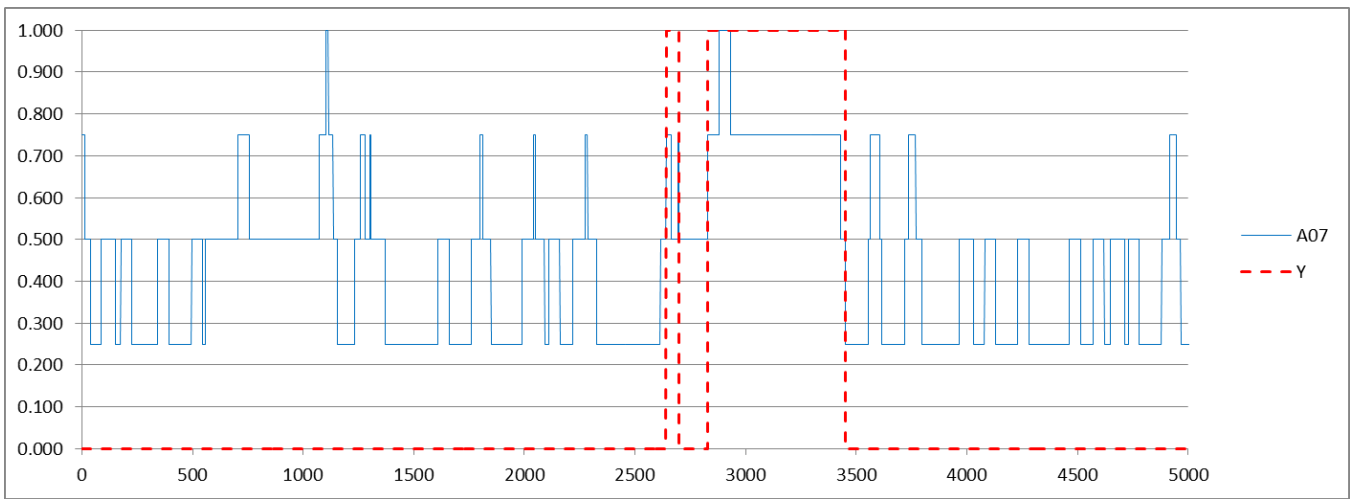

Figura 92: Atributo A07 - Cenário 3.

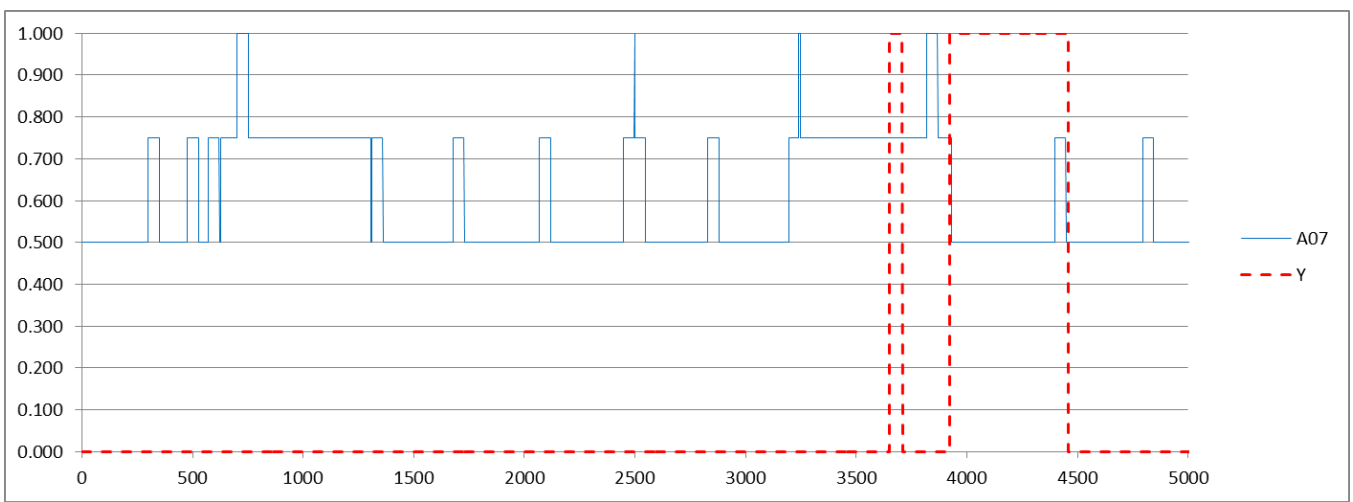

Figura 93: Atributo A07 - Cenário 4. 


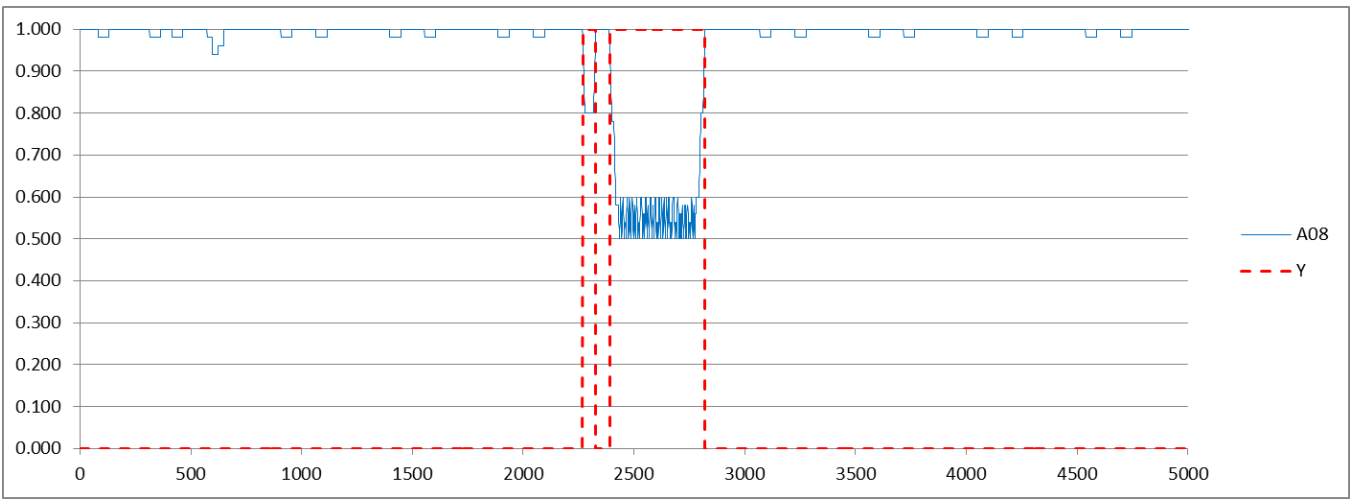

Figura 94: Atributo A08 - Cenário 1.

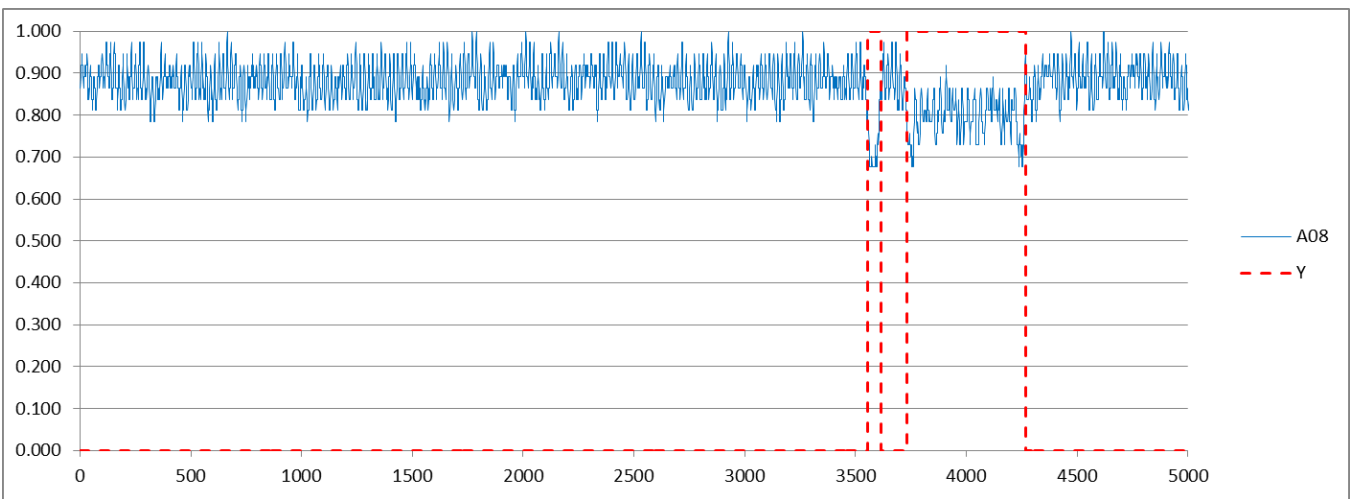

Figura 95: Atributo A08 - Cenário 2.

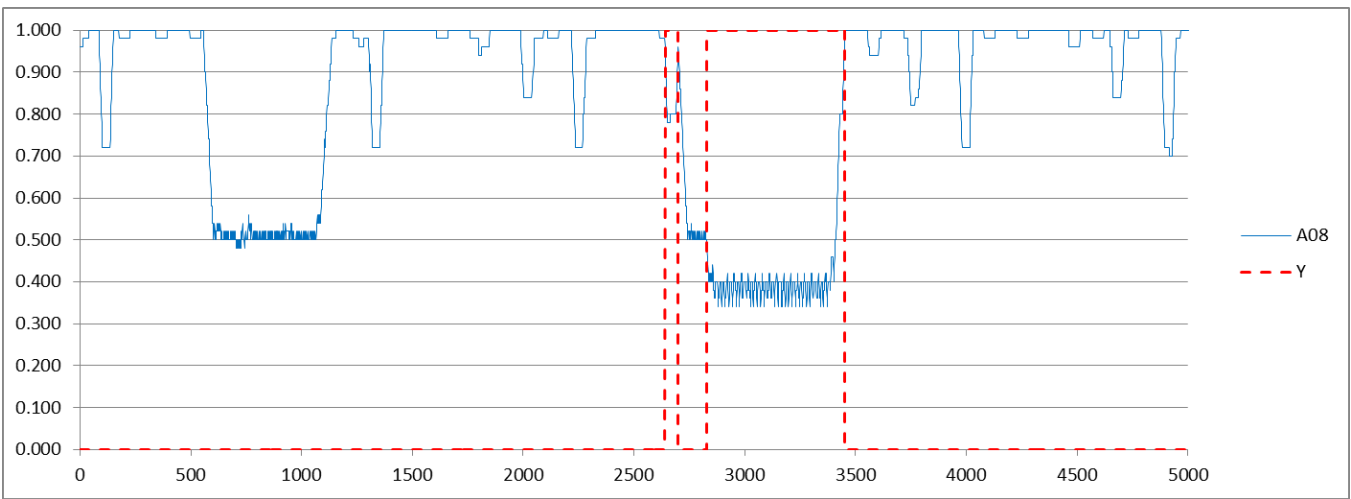

Figura 96: Atributo A08 - Cenário 3.

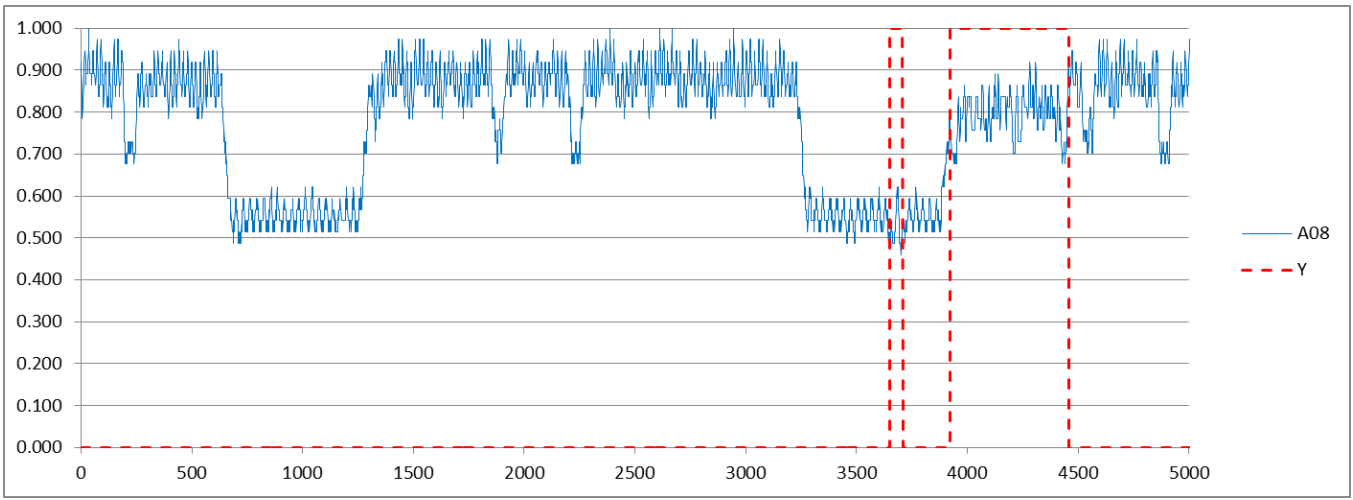

Figura 97: Atributo A08 - Cenário 4. 


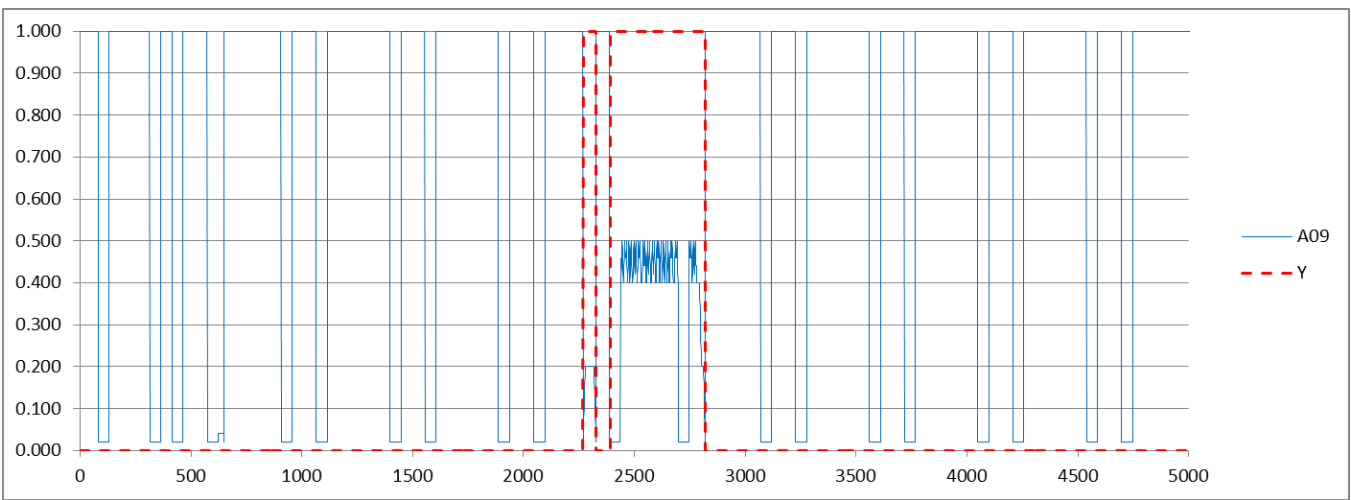

Figura 98: Atributo A09 - Cenário 1.

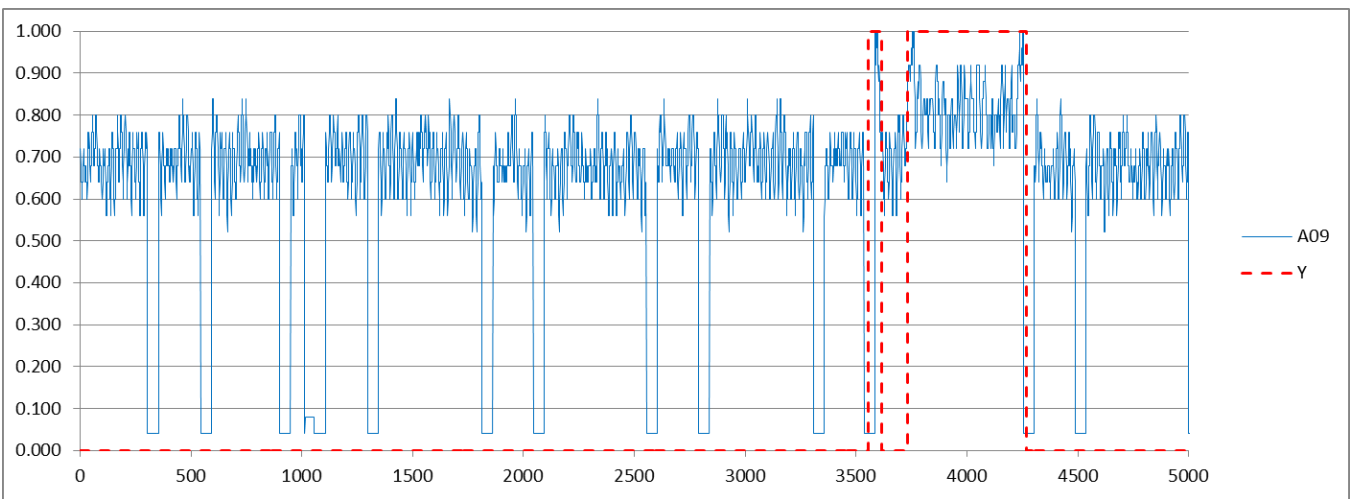

Figura 99: Atributo A09 - Cenário 2.

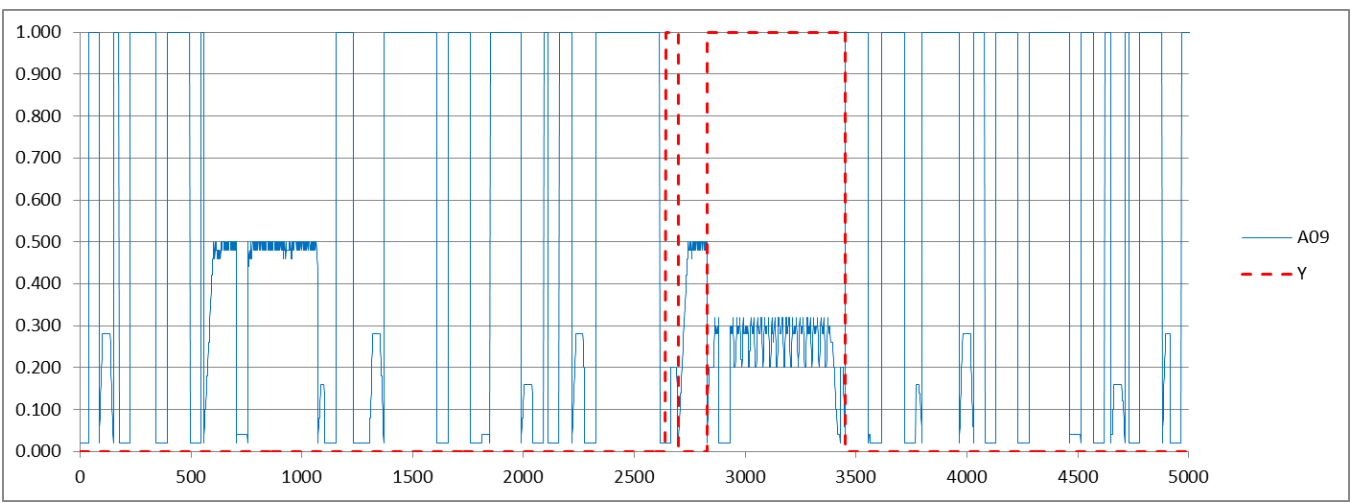

Figura 100: Atributo A09 - Cenário 3.

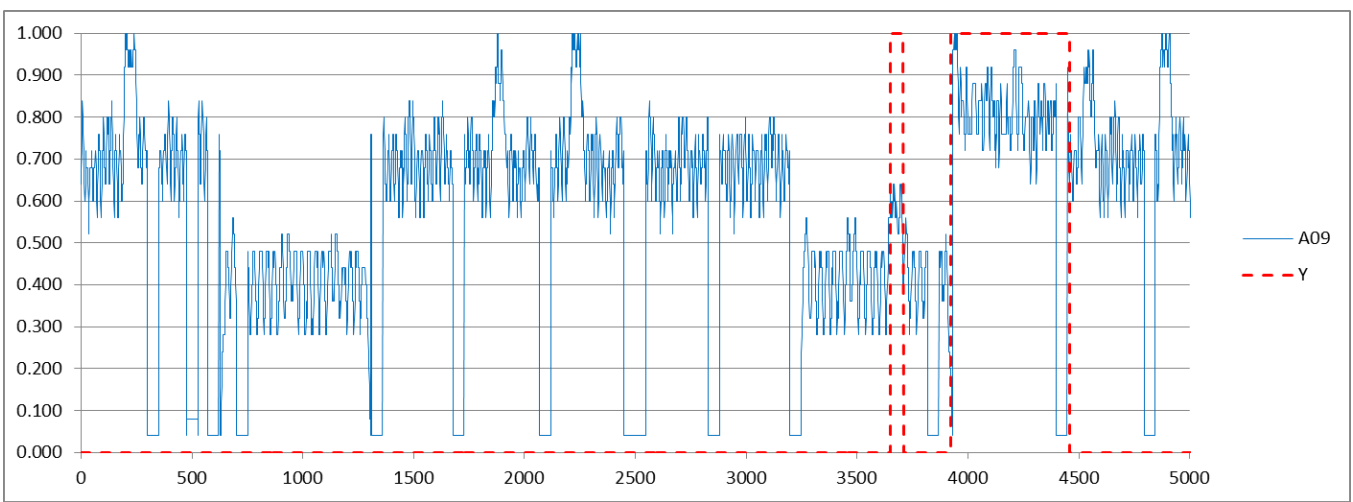

Figura 101: Atributo A09 - Cenário 4. 


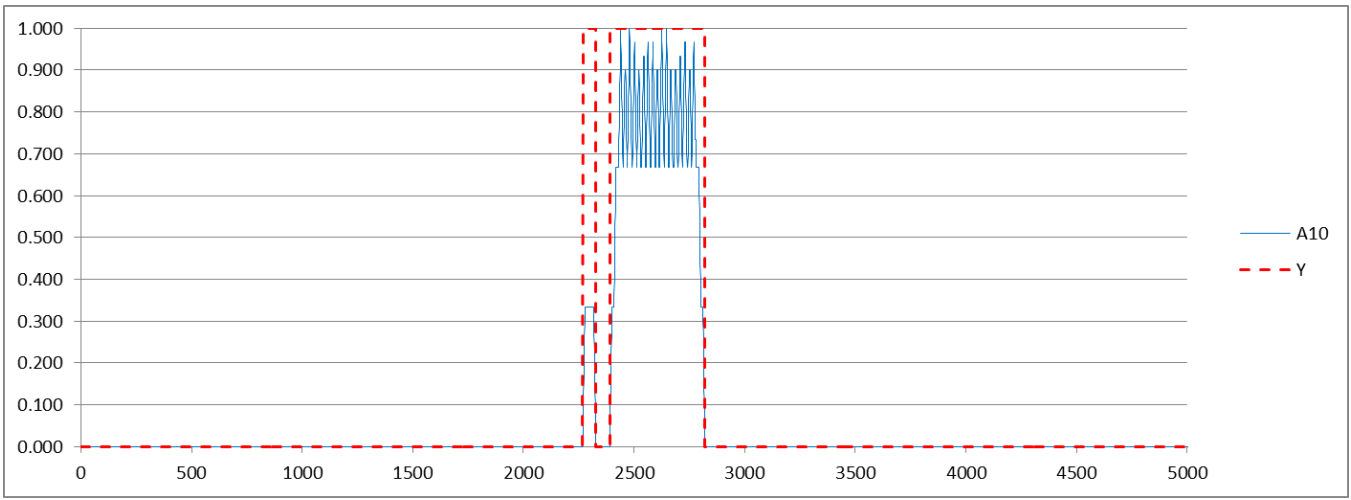

Figura 102: Atributo A10 - Cenário 1.

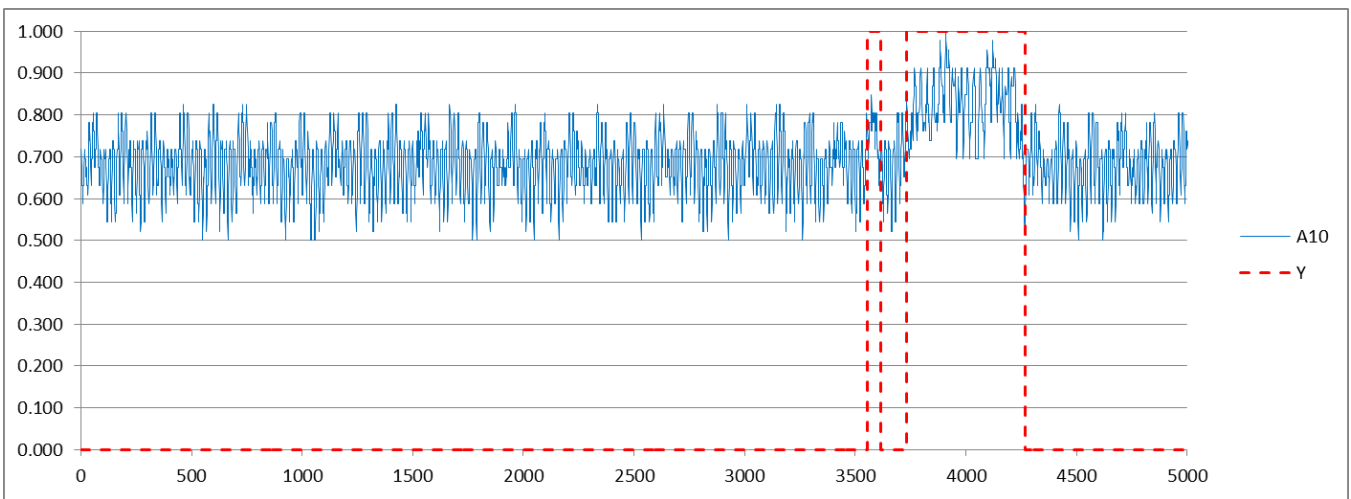

Figura 103: Atributo A10 - Cenário 2.

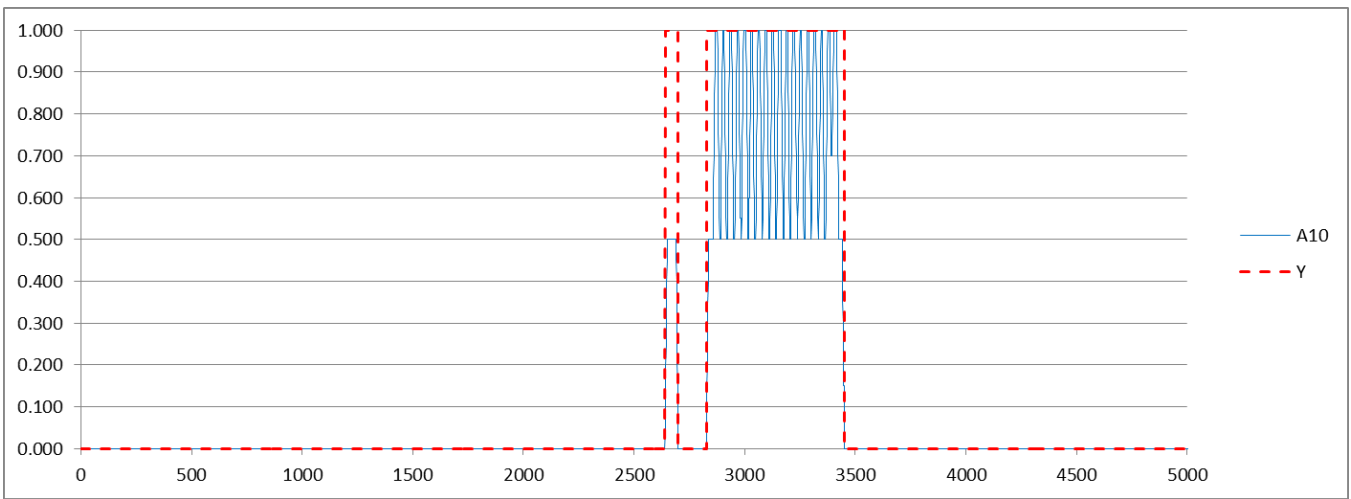

Figura 104: Atributo A10 - Cenário 3.

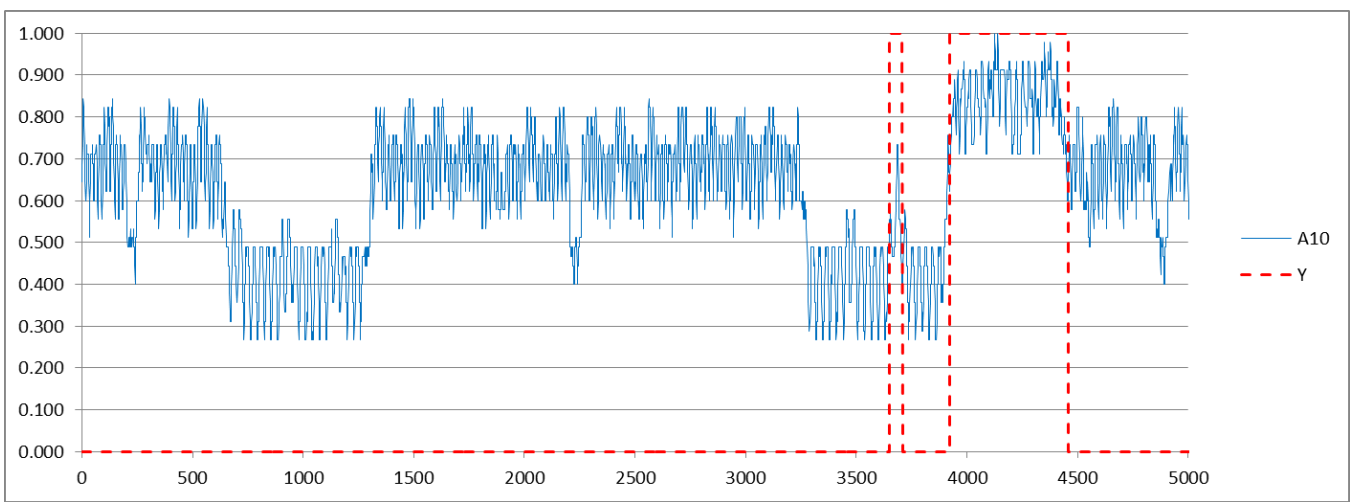

Figura 105: Atributo A10 - Cenário 4. 


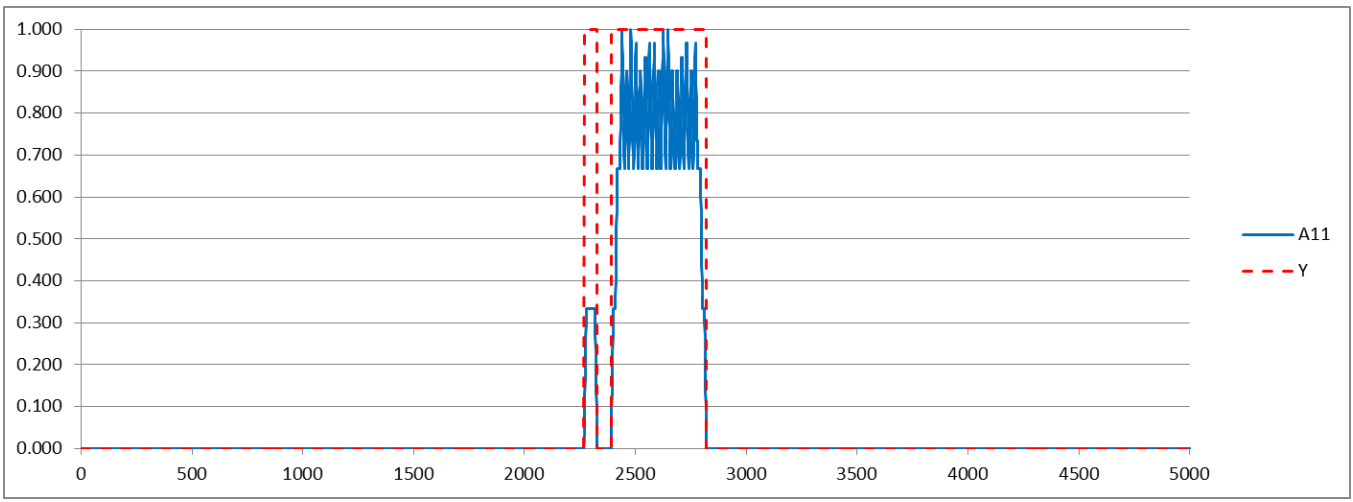

Figura 106: Atributo A11 - Cenário 1.

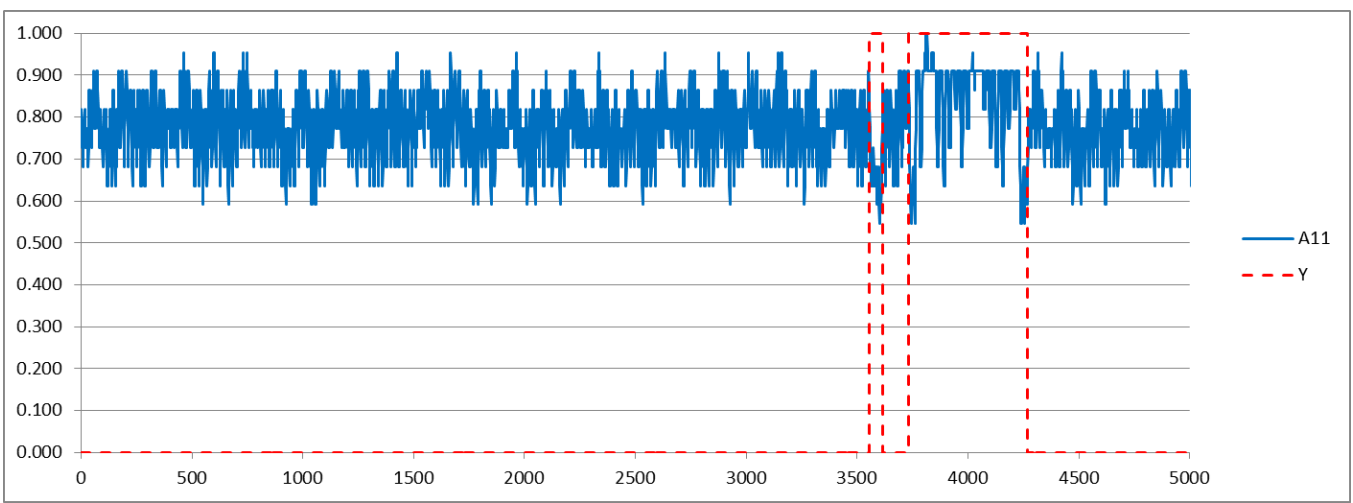

Figura 107: Atributo A11 - Cenário 2.

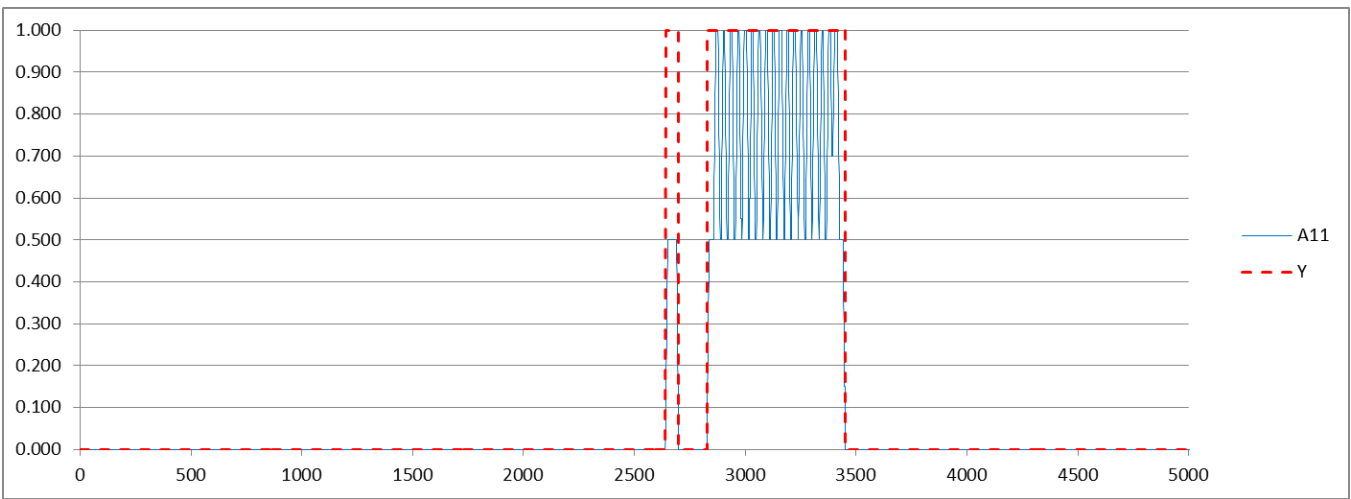

Figura 108: Atributo A11 - Cenário 3.

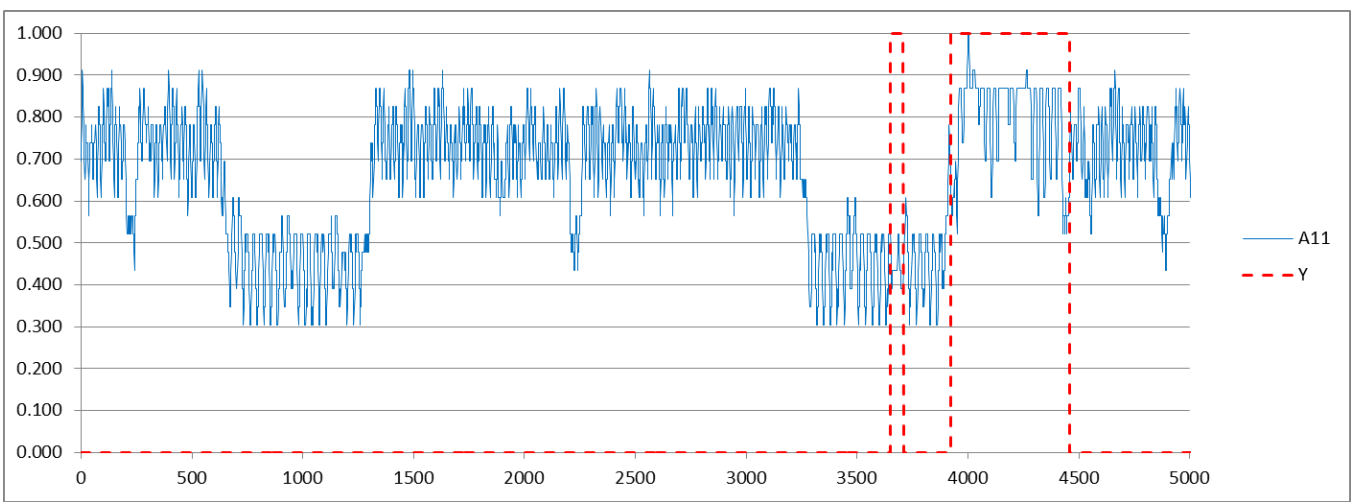

Figura 109: Atributo A11 - Cenário 4. 


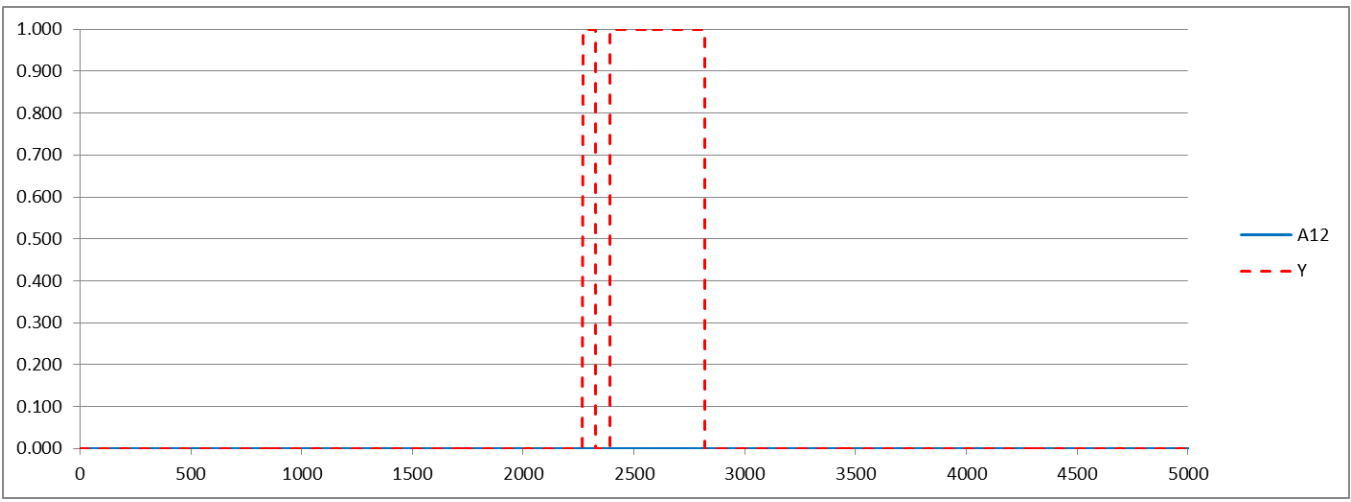

Figura 110: Atributo A12 - Cenário 1.

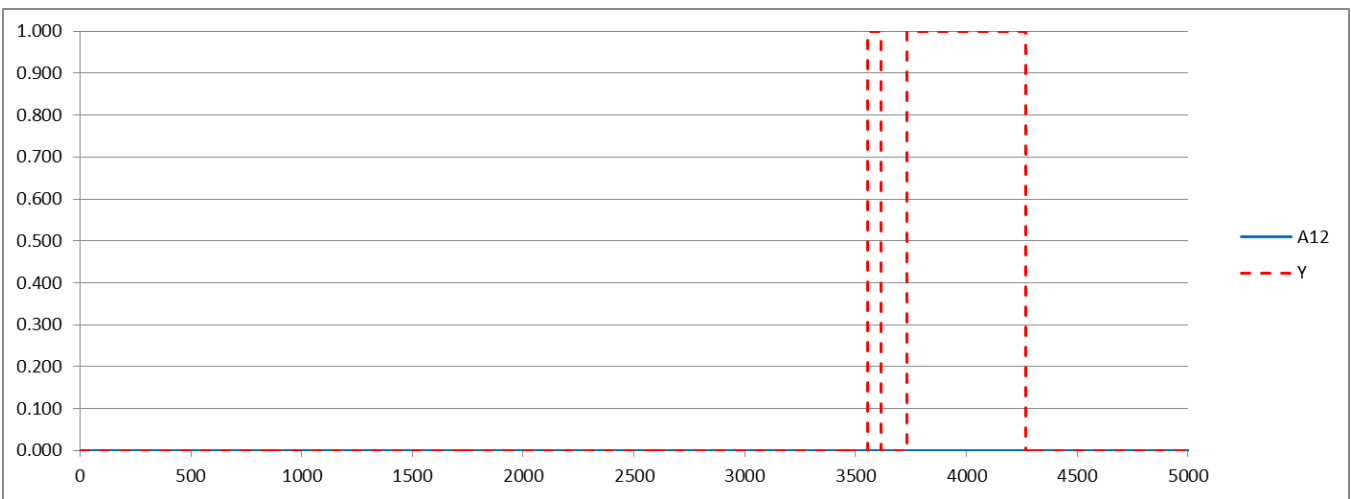

Figura 111: Atributo A12 - Cenário 2.

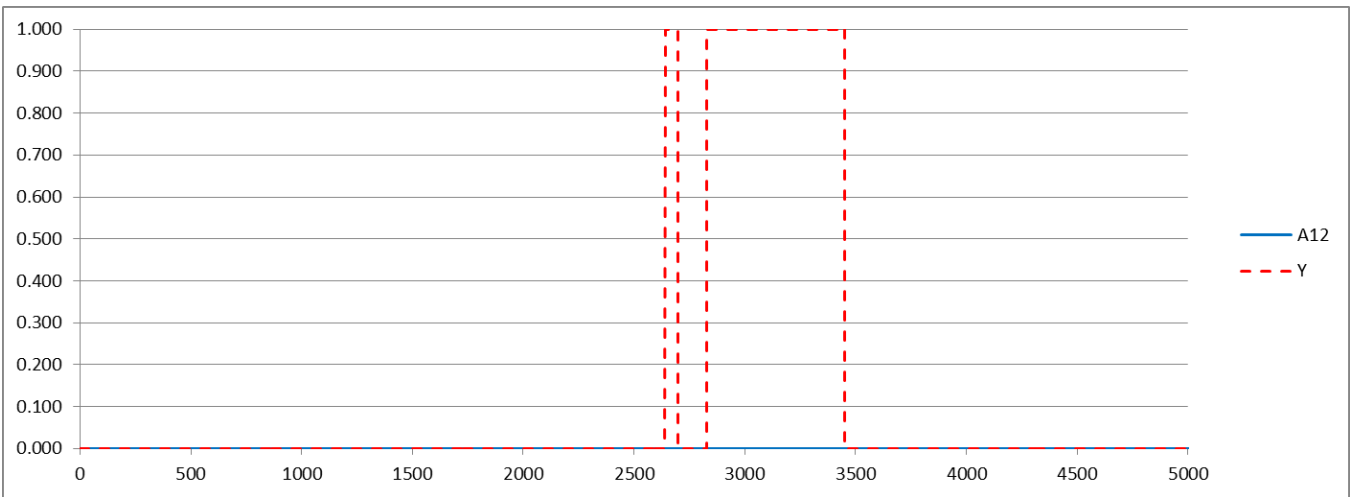

Figura 112: Atributo A12 - Cenário 3.

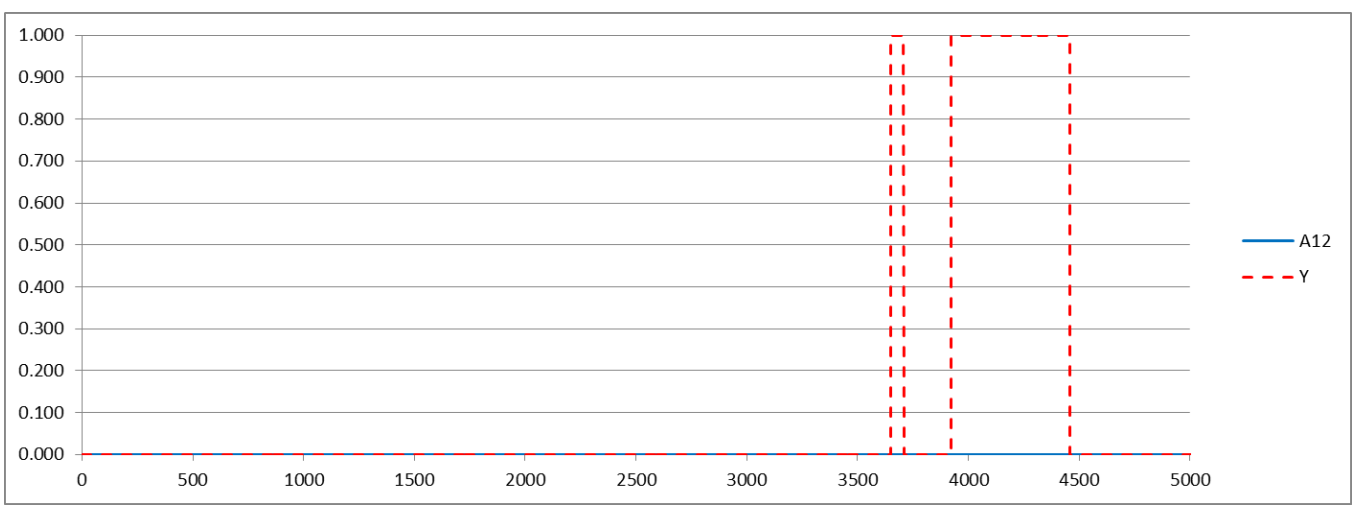

Figura 113: Atributo A12 - Cenário 4. 


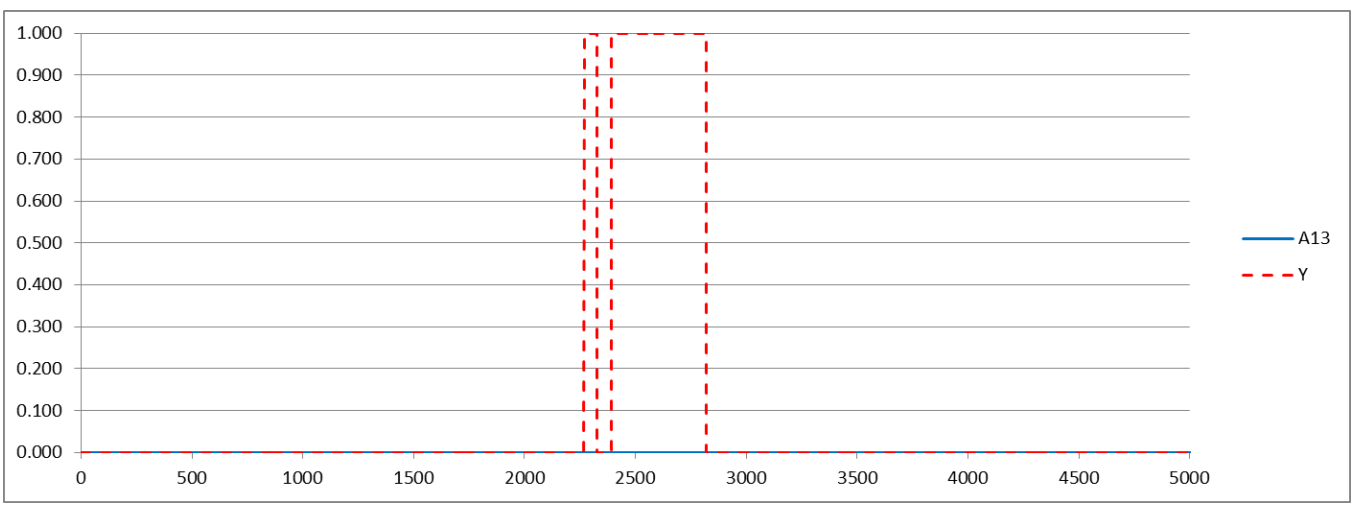

Figura 114: Atributo A13 - Cenário 1.

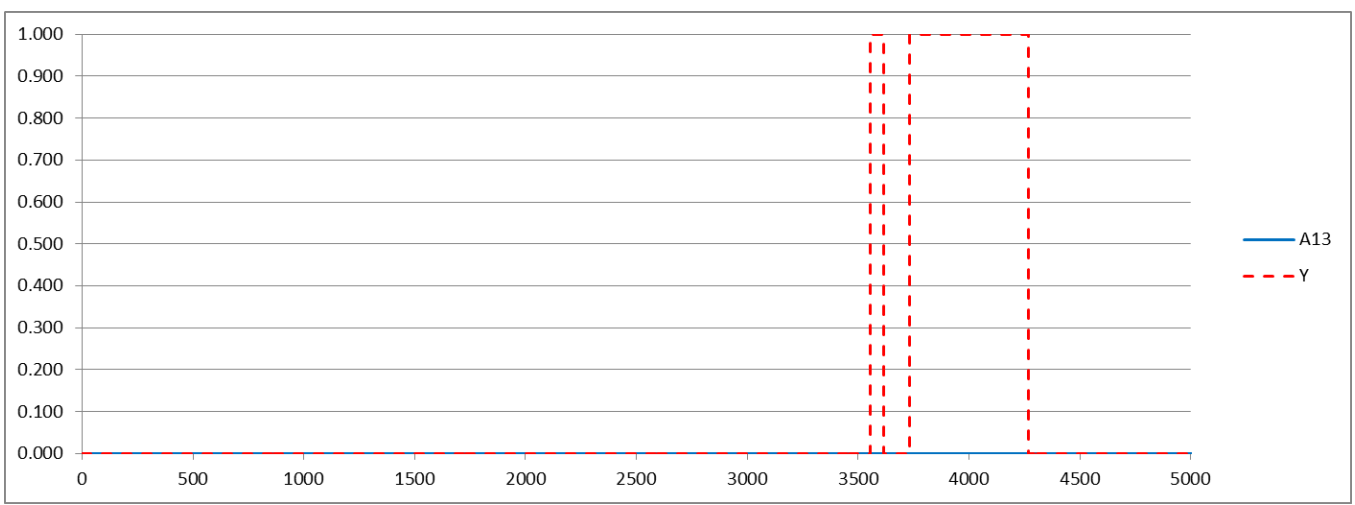

Figura 115: Atributo A13 - Cenário 2.

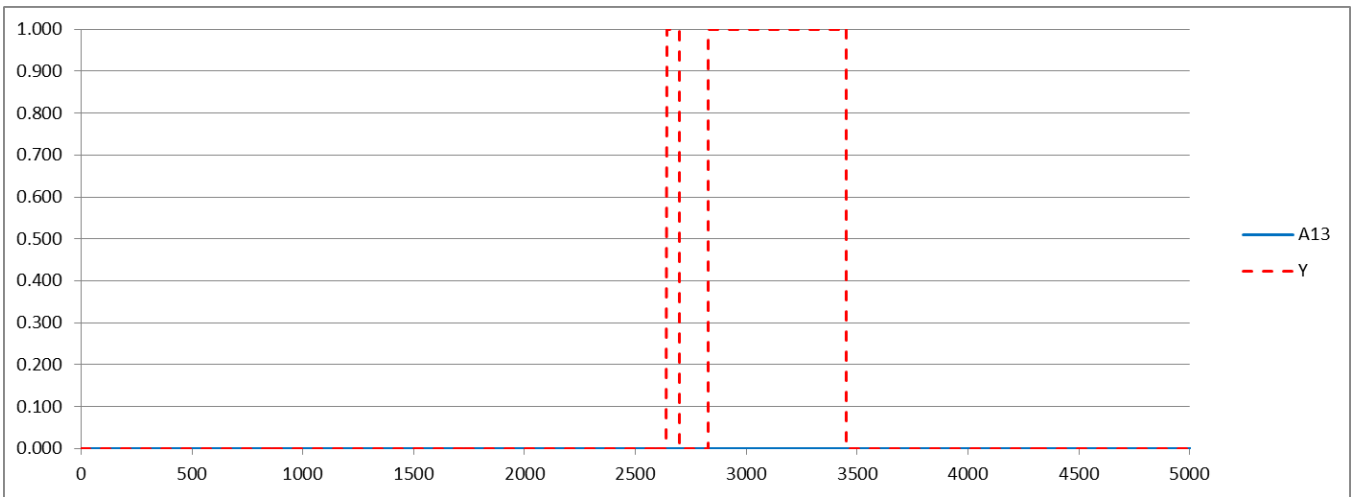

Figura 116: Atributo A13 - Cenário 3.

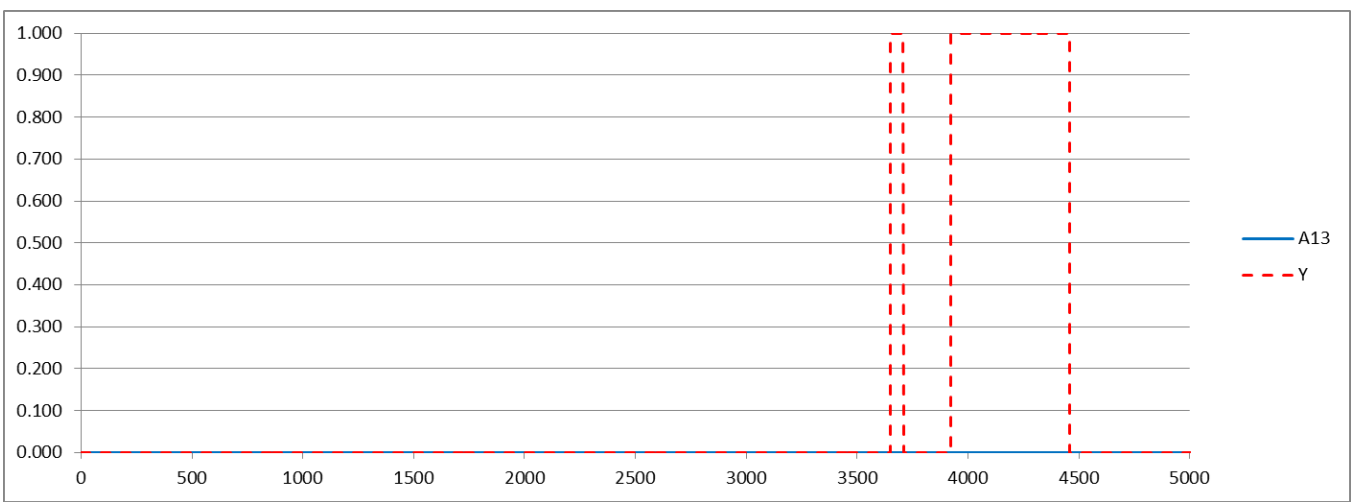

Figura 117: Atributo A13 - Cenário 4. 


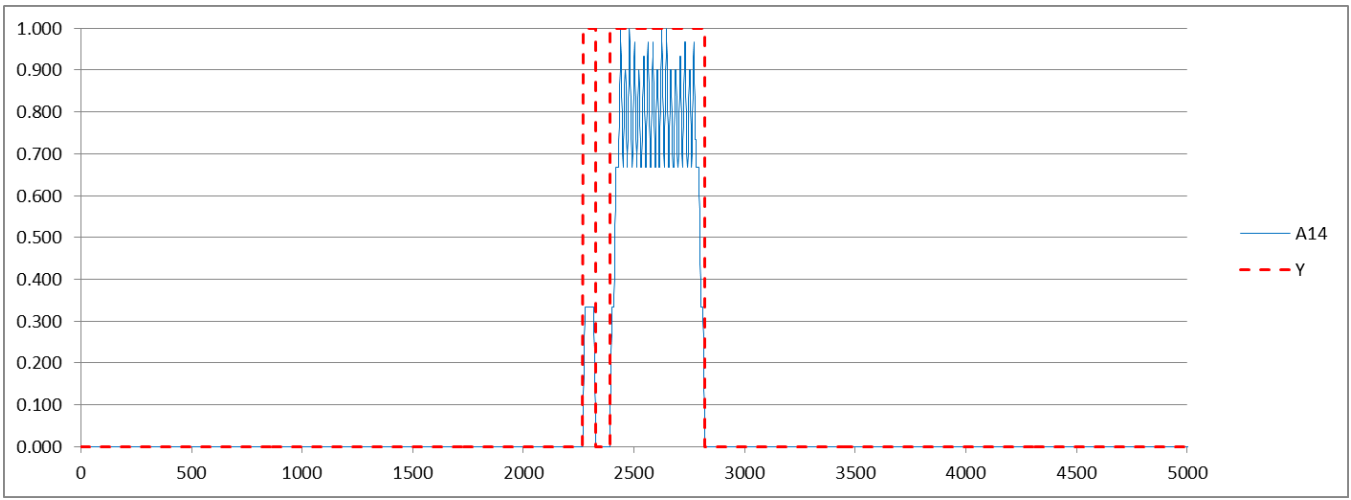

Figura 118: Atributo A14 - Cenário 1.

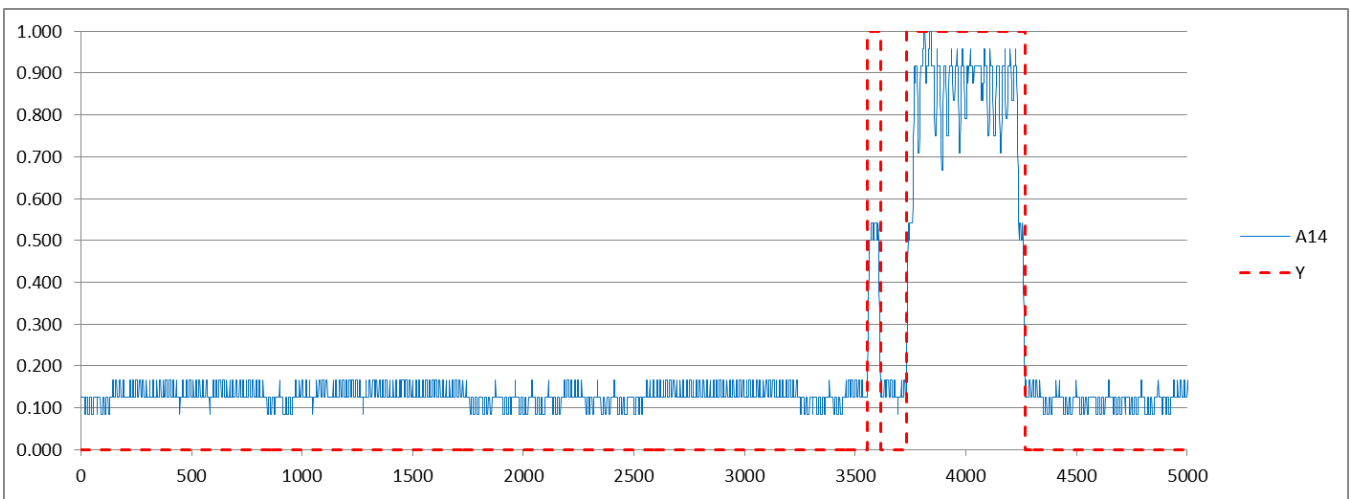

Figura 119: Atributo A14 - Cenário 2.

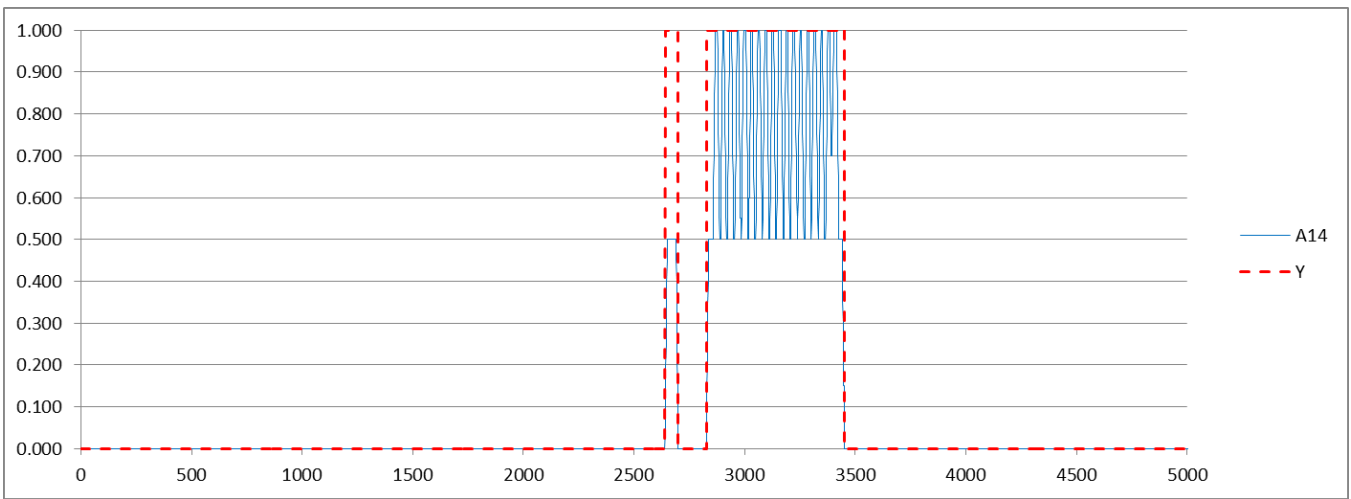

Figura 120: Atributo A14 - Cenário 3.

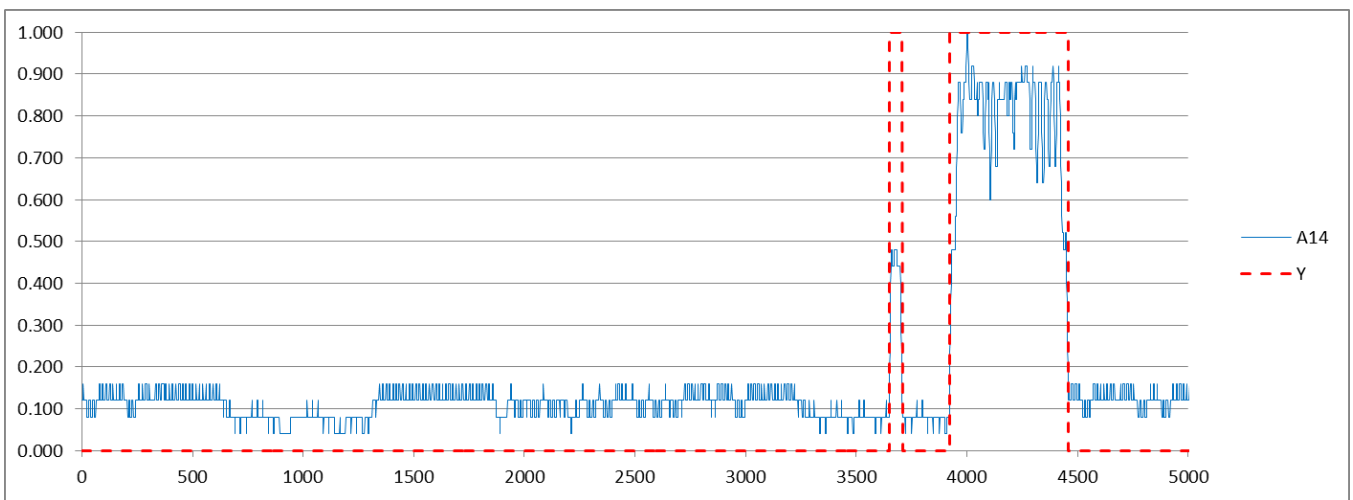

Figura 121: Atributo A14 - Cenário 4. 


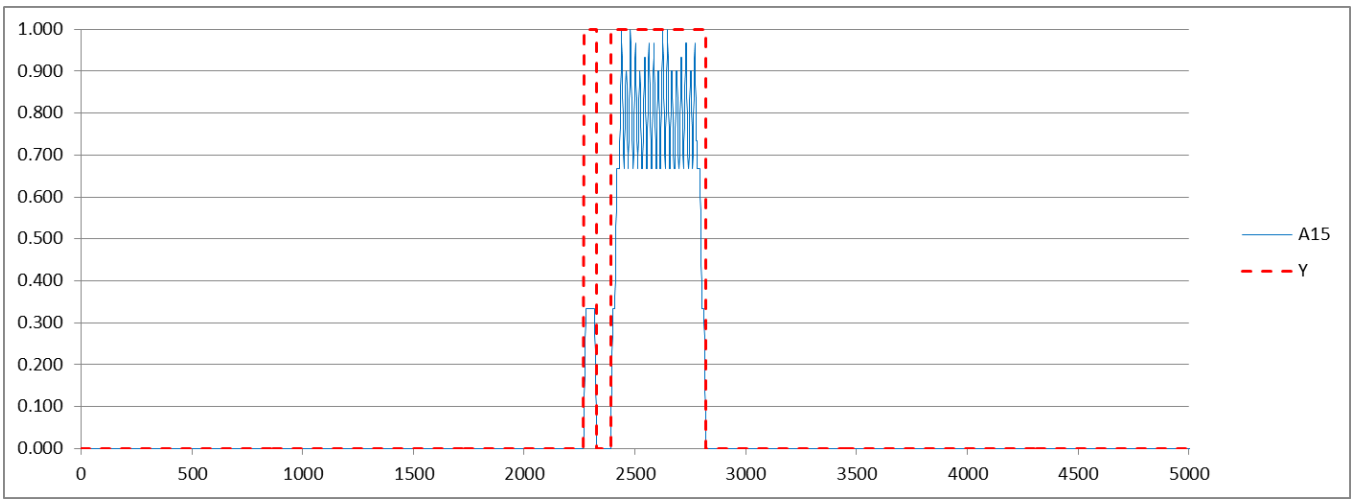

Figura 122: Atributo A15 - Cenário 1.

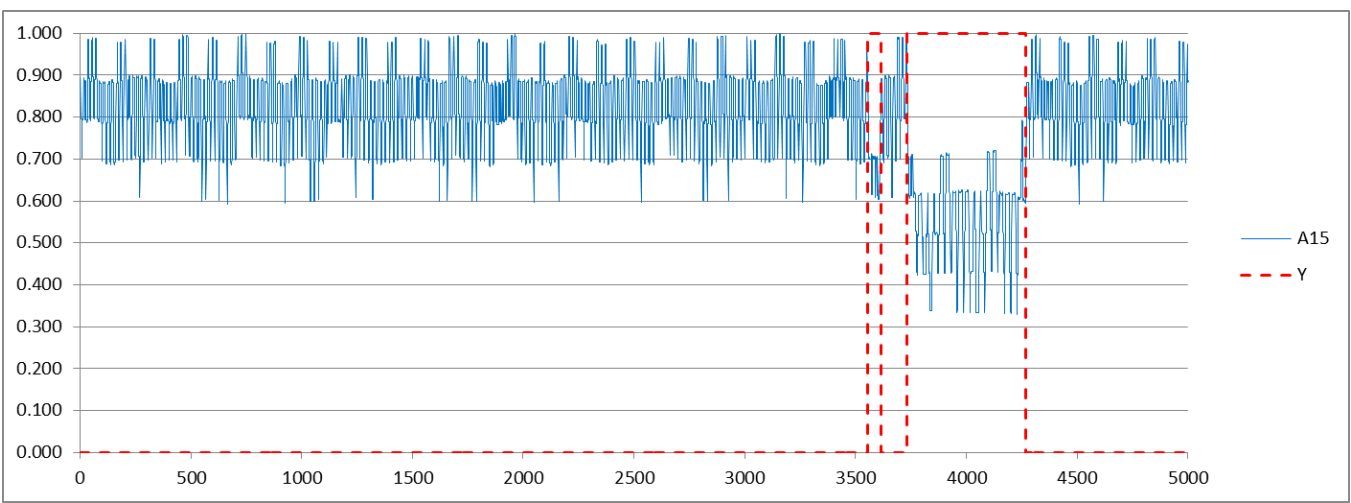

Figura 123: Atributo A15 - Cenário 2.

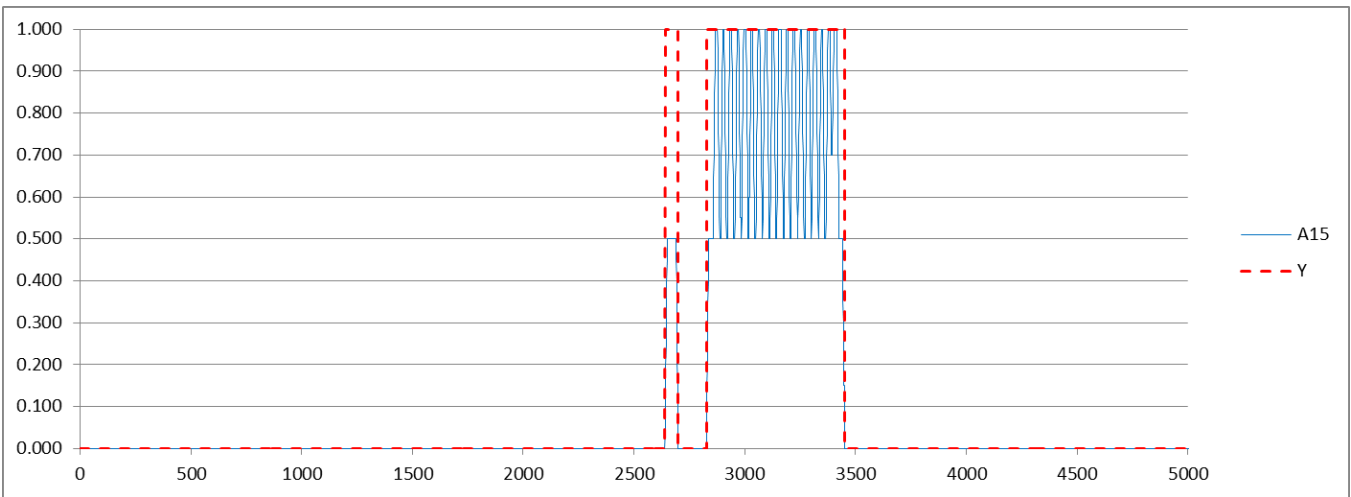

Figura 124: Atributo A15 - Cenário 3.

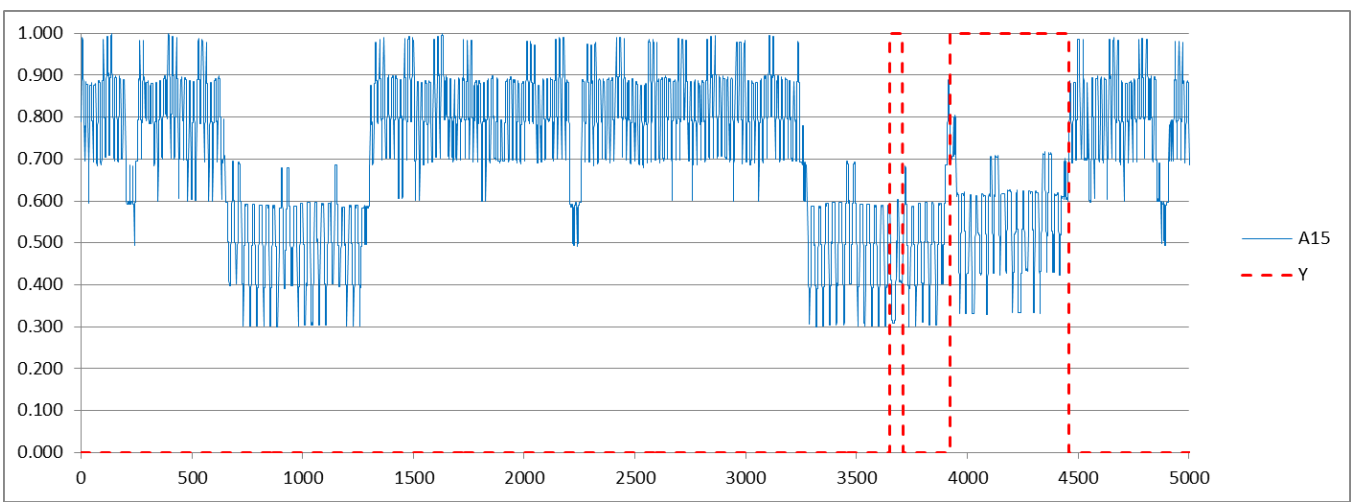

Figura 125: Atributo A15 - Cenário 4. 


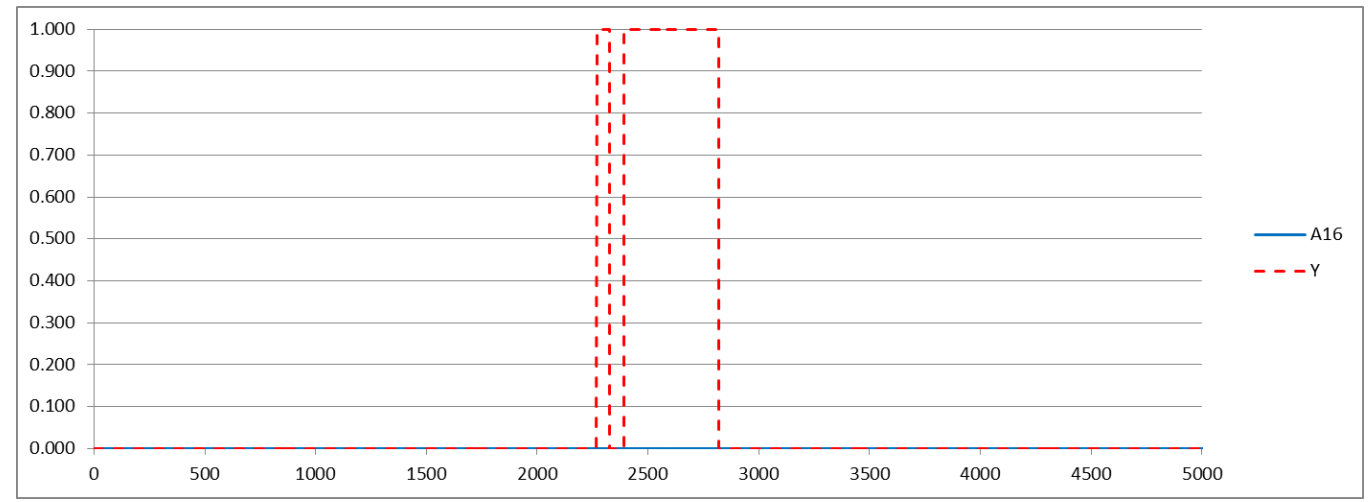

Figura 126: Atributo A16 - Cenário 1.

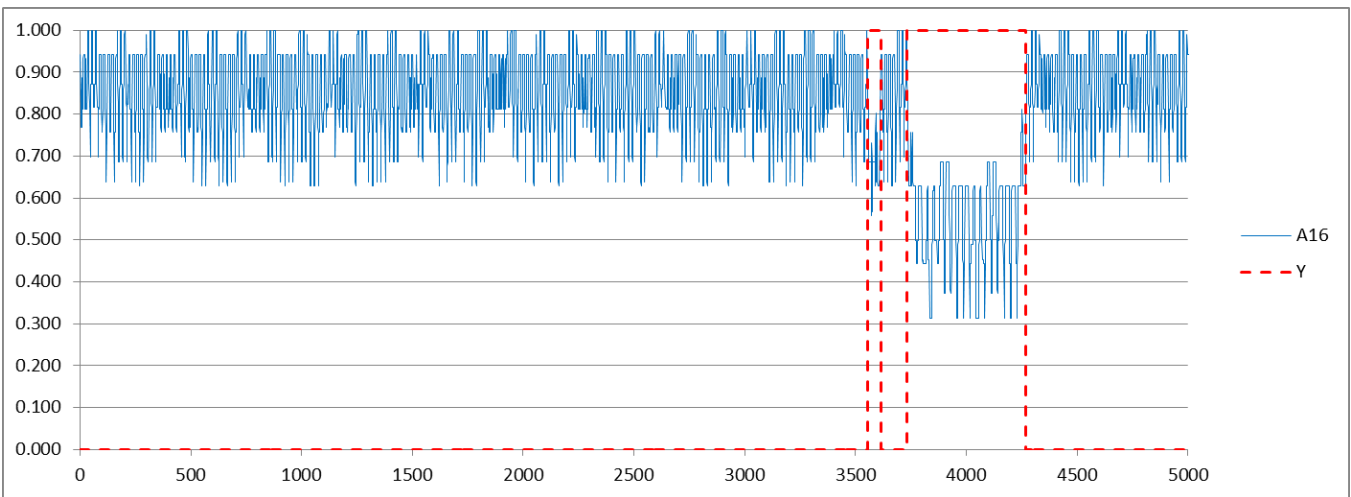

Figura 127: Atributo A16 - Cenário 2.

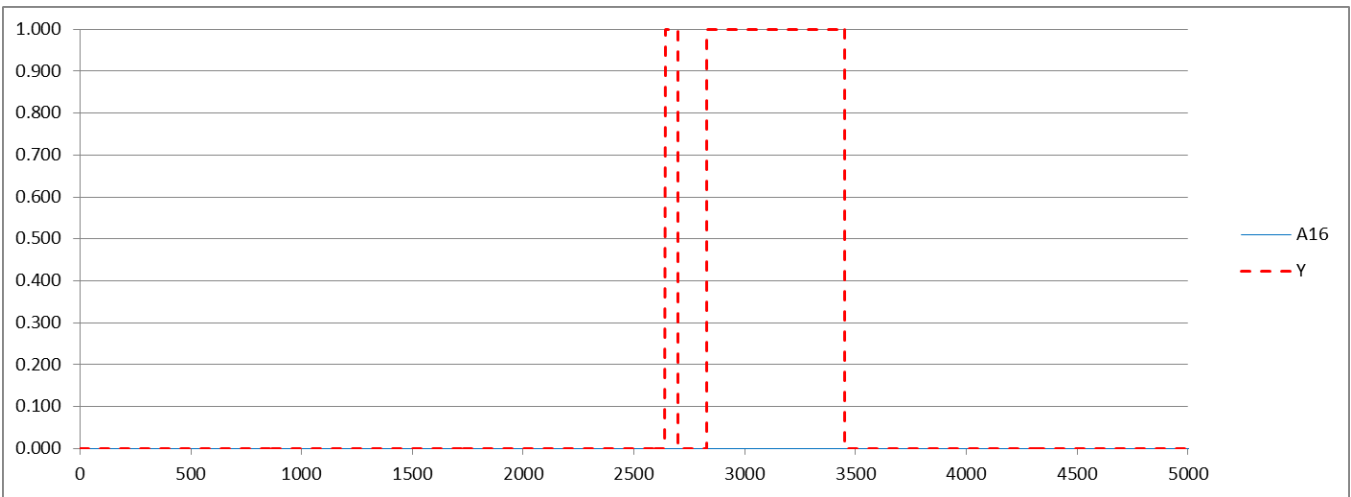

Figura 128: Atributo A16 - Cenário 3.

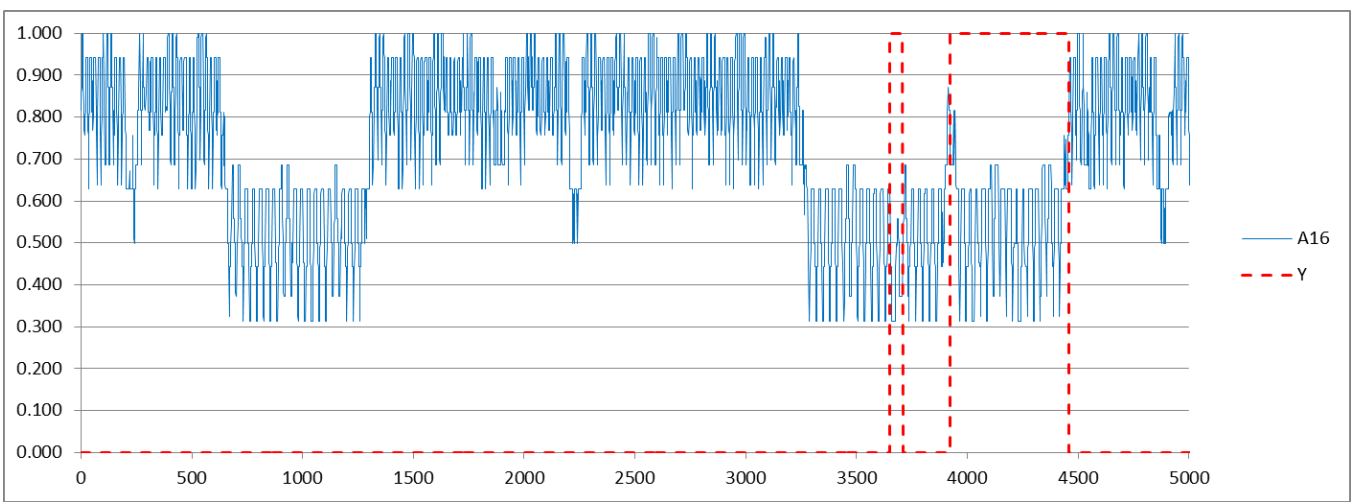

Figura 129: Atributo A16 - Cenário 4. 


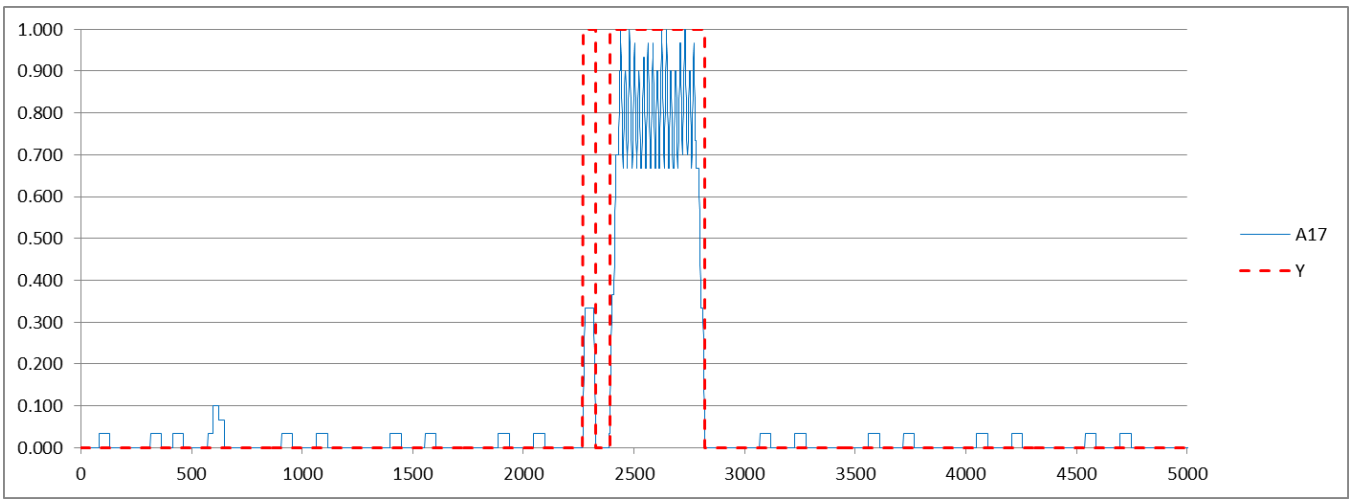

Figura 130: Atributo A17 - Cenário 1.

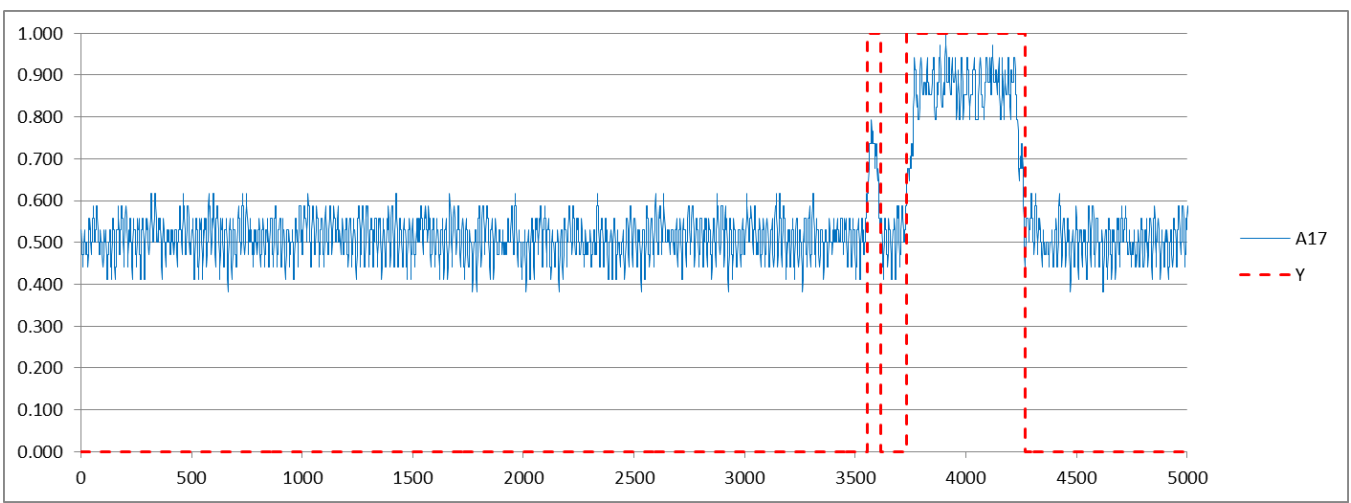

Figura 131: Atributo A17 - Cenário 2.

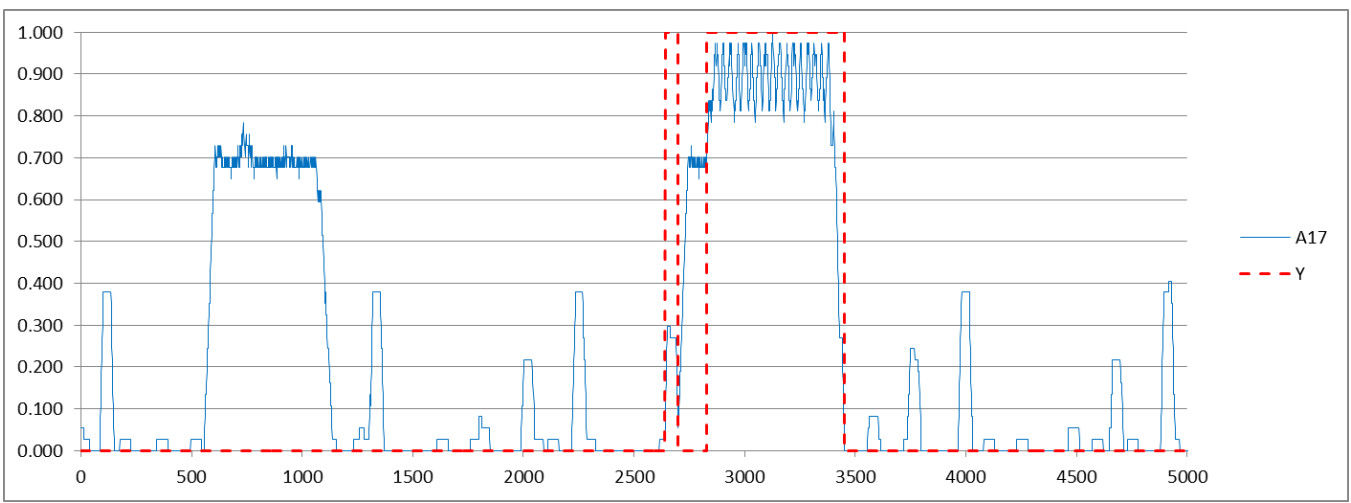

Figura 132: Atributo A17 - Cenário 3.

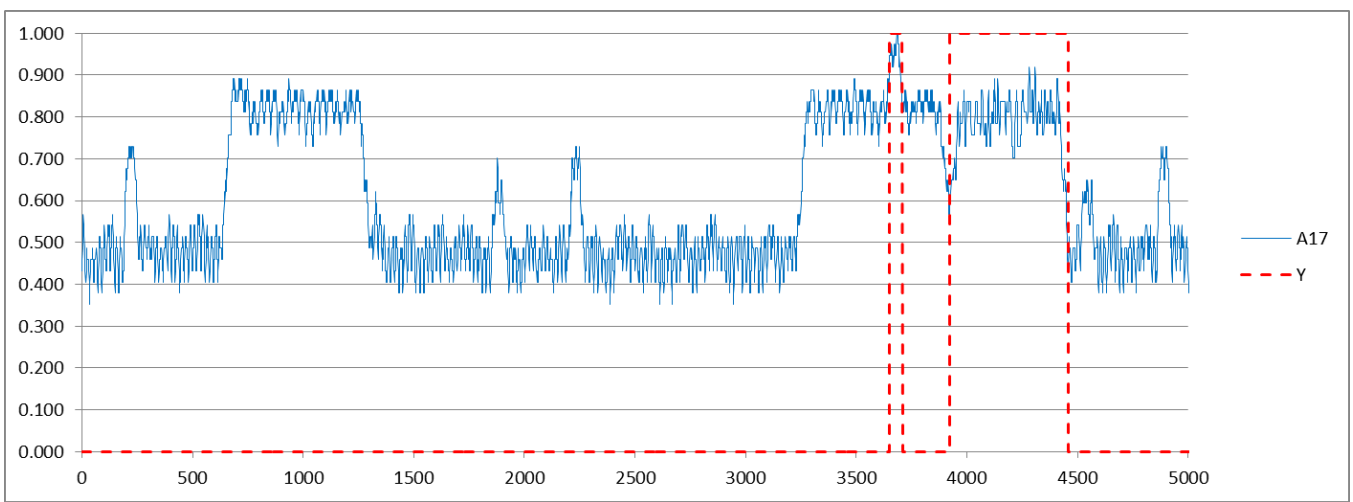

Figura 133: Atributo A17 - Cenário 4. 


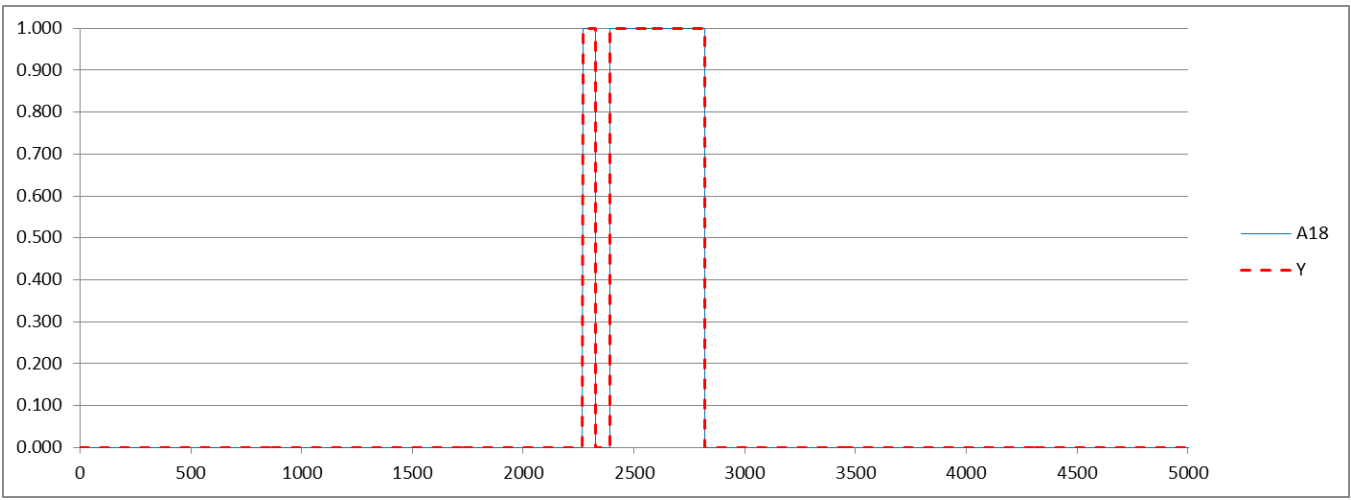

Figura 134: Atributo A18 - Cenário 1.

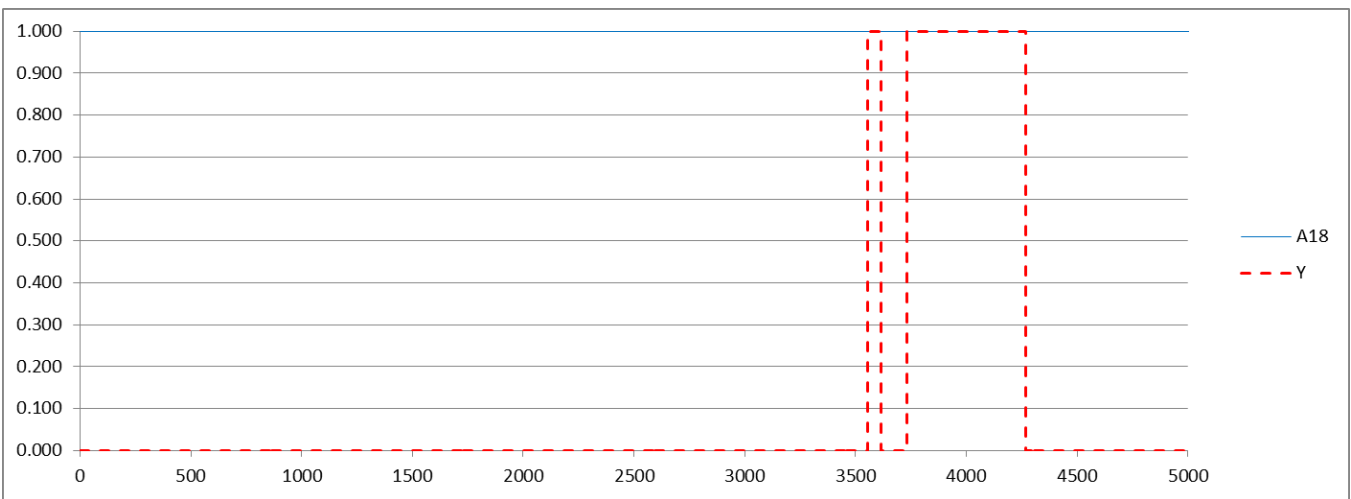

Figura 135: Atributo A18 - Cenário 2.

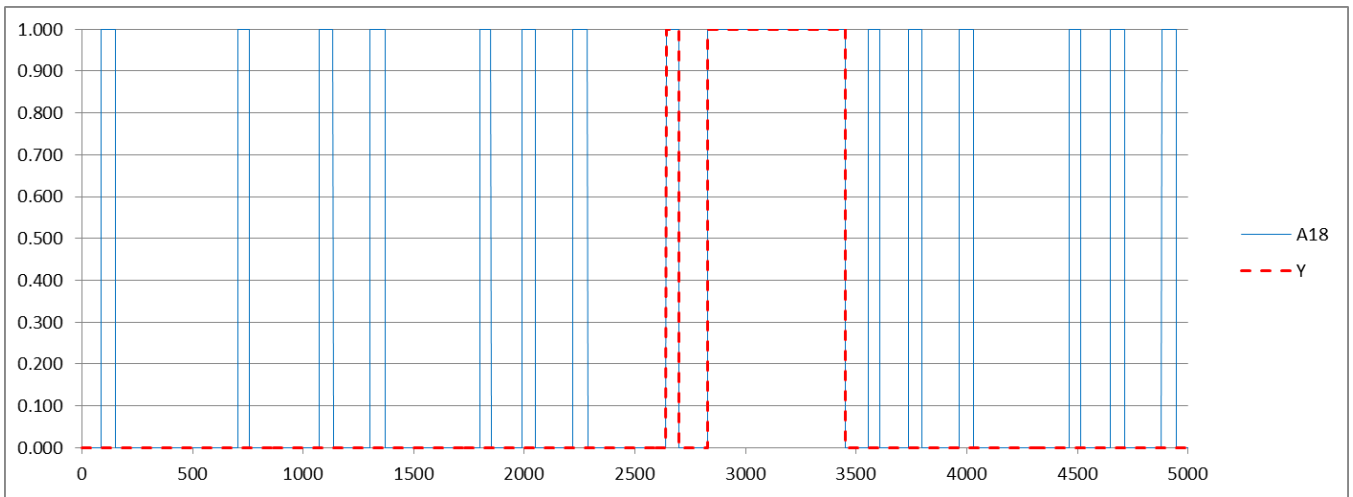

Figura 136: Atributo A18 - Cenário 3.

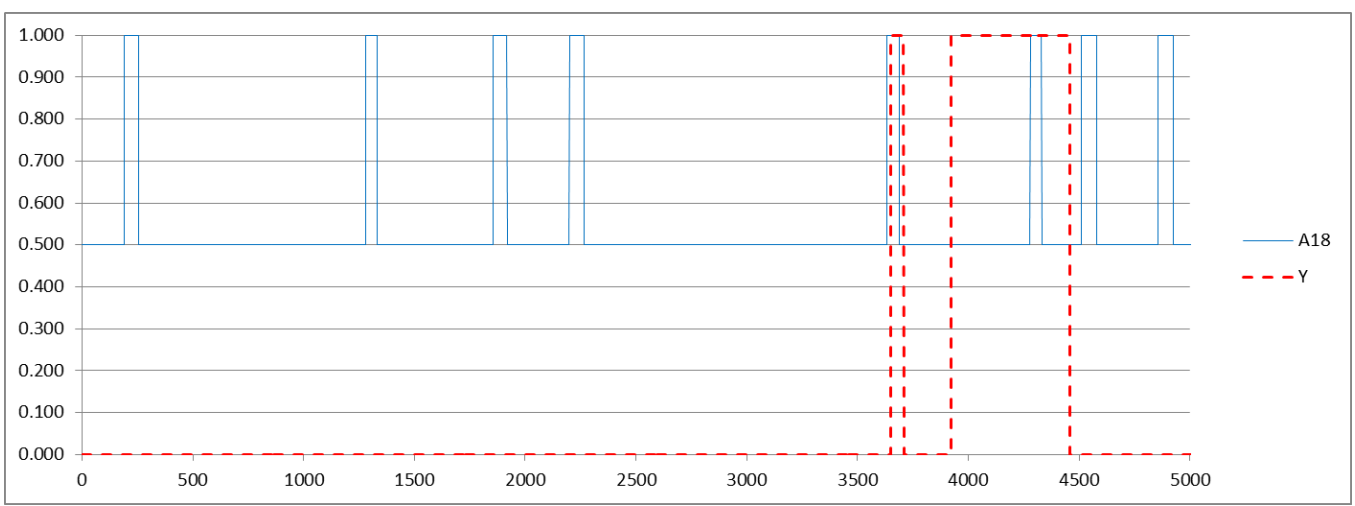

Figura 137: Atributo A18 - Cenário 4. 


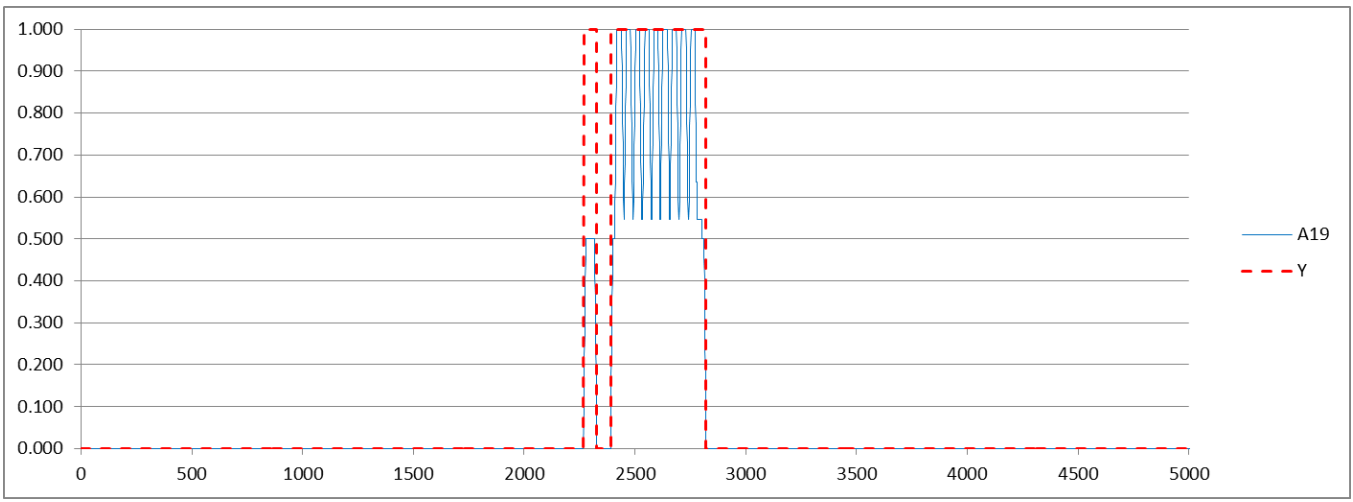

Figura 138: Atributo A19 - Cenário 1.

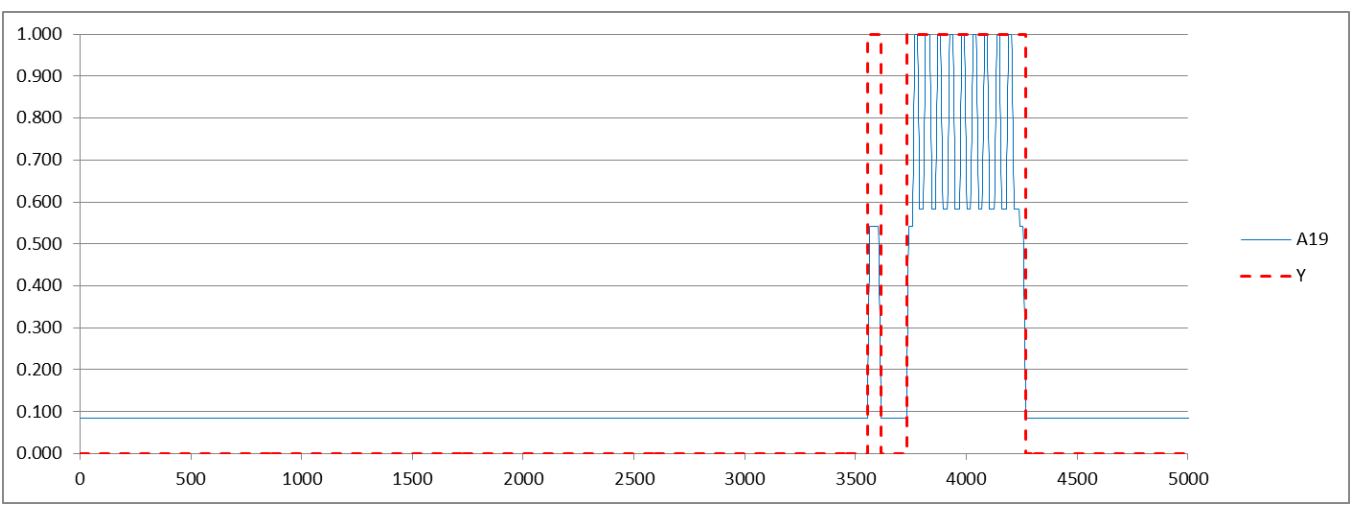

Figura 139: Atributo A19 - Cenário 2.

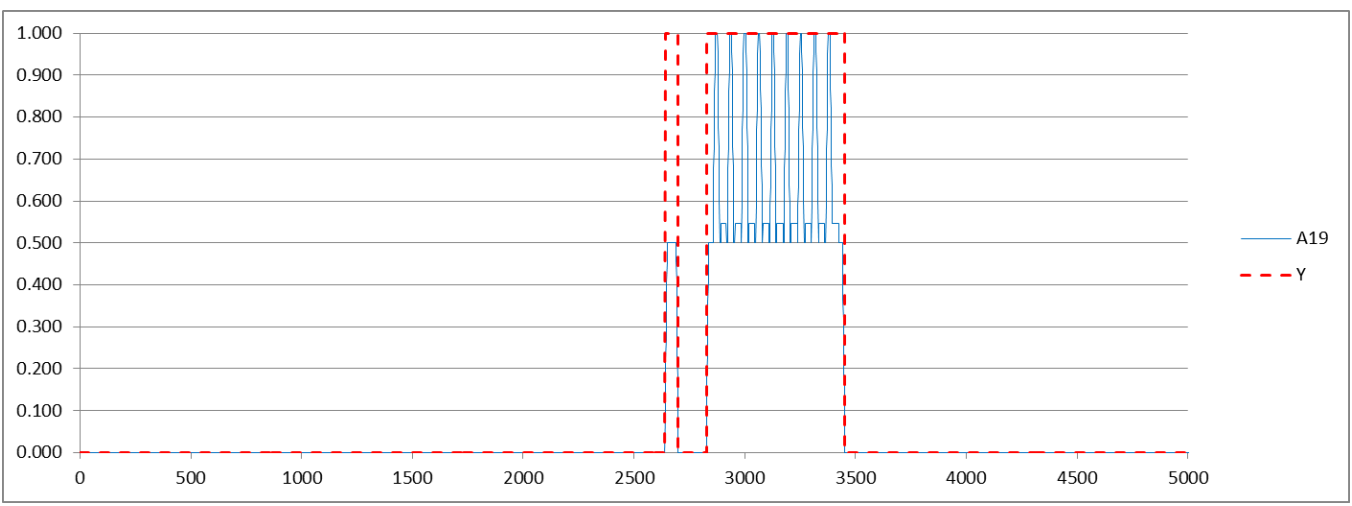

Figura 140: Atributo A19 - Cenário 3.

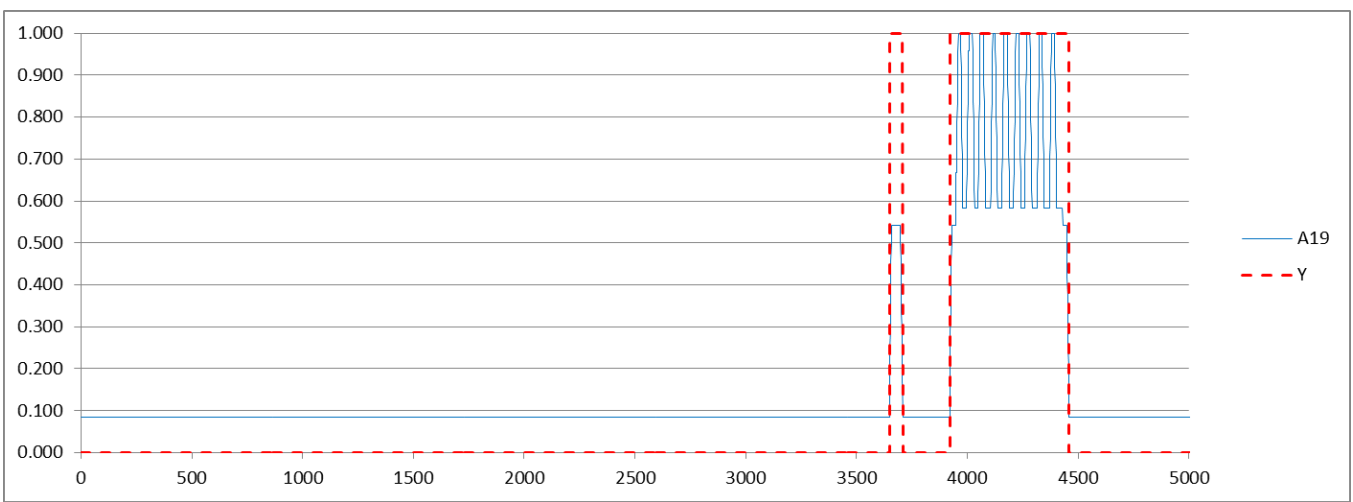

Figura 141: Atributo A19 - Cenário 4. 


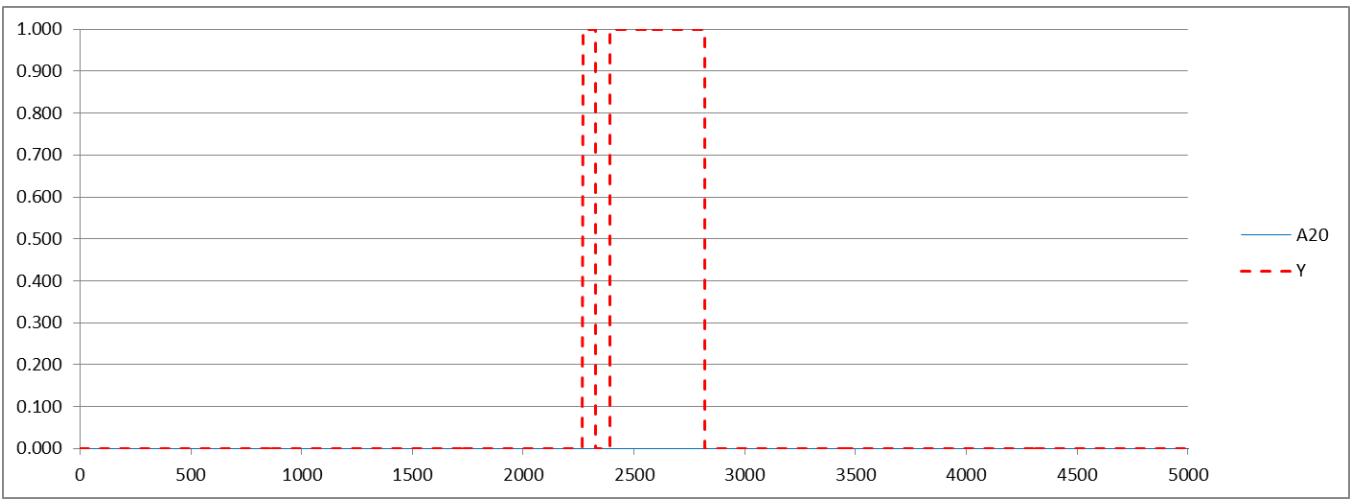

Figura 142: Atributo A20 - Cenário 1.

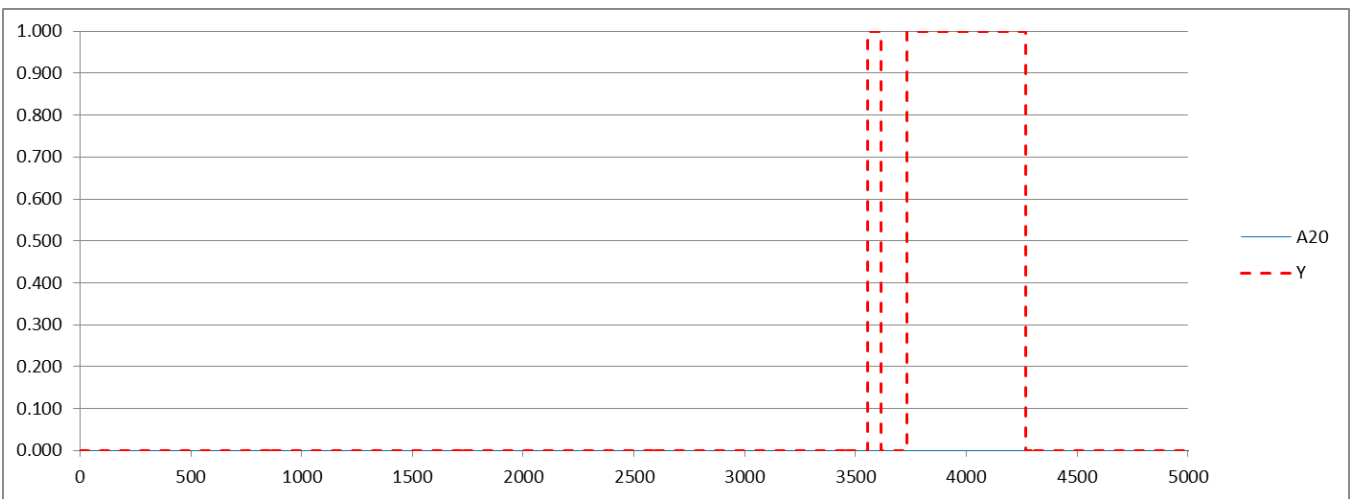

Figura 143: Atributo A20 - Cenário 2.

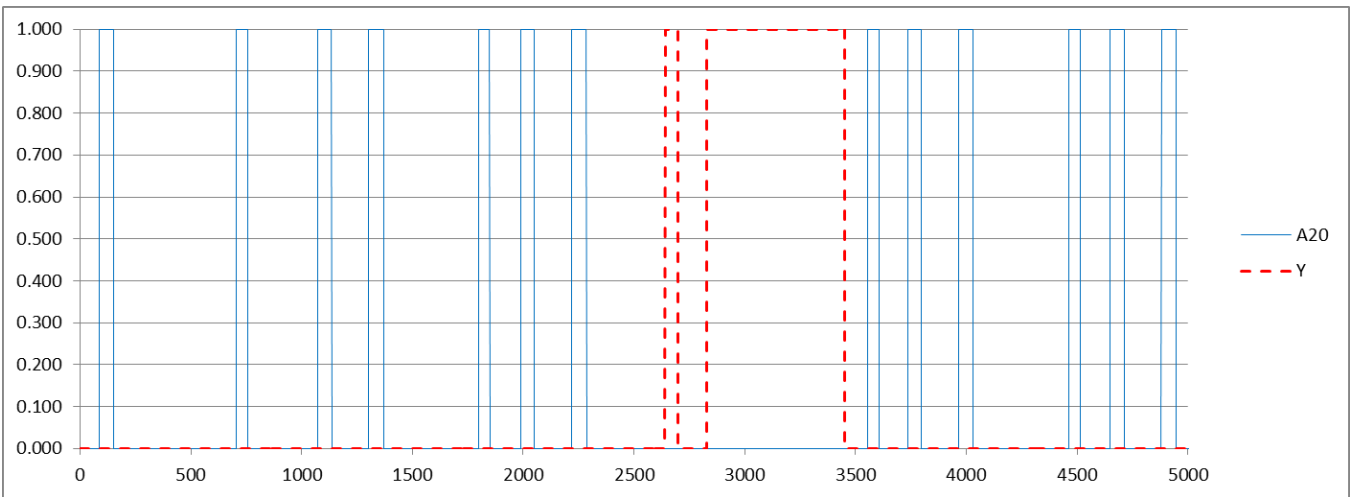

Figura 144: Atributo A20 - Cenário 3.

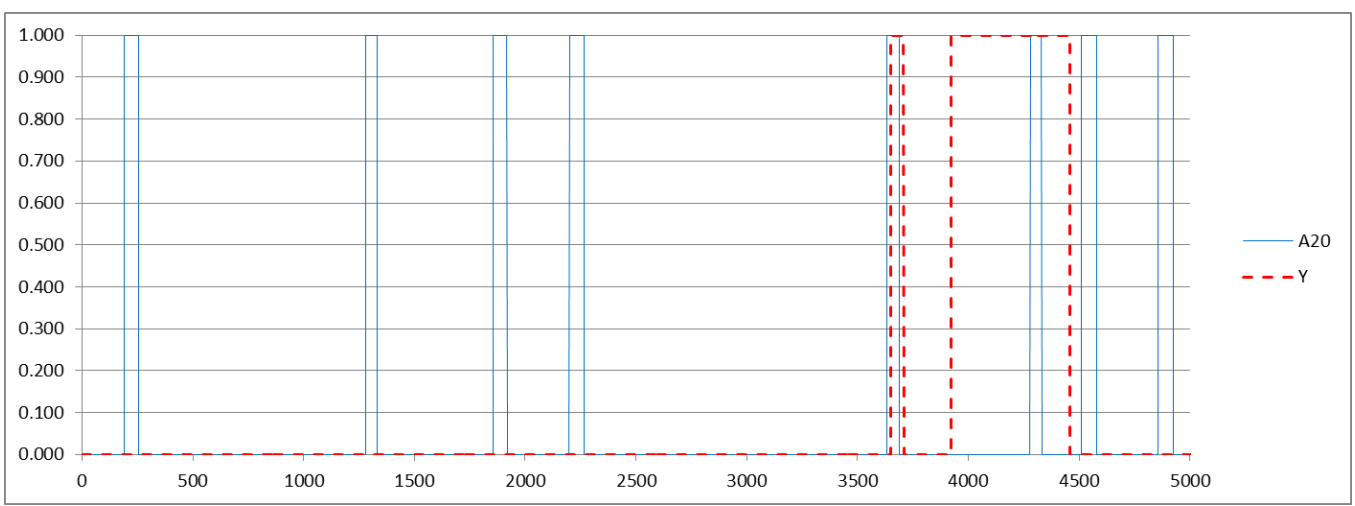

Figura 145: Atributo A20- Cenário 4. 


\subsection{Análise e seleção dos principais atributos}

Na maioria dos IDS existentes, os atributos são escolhidos manualmente, com base na análise de tipos de ataques existentes, análise estatística e visualização de dados (SILVA, 2008).

No caso de uso dos atributos como entrada para classificadores inteligentes, a recomendação é não selecionar muitos atributos, pois podem invalidar os resultados do classificador.

Uma linha de trabalho conduzida por W. Lee e colaboradores (LEE; STOLFO, 1998) tenta abordar a construção de atributos e data mining sistematicamente. O principal foco está na aprendizagem baseada em regras. Já nos trabalhos conduzidos por Lazarevic (LAZAREVIC et al., 2003), os dados são previamente filtrados para remover sessões não interessantes para análise (tráfego de fontes confiáveis ou comportamento de rede não usual ou anômalo que é sabidamente livre de intrusão) e pré-processados para coletar atributos derivados e atributos característicos.

Esforços de seleção de atributos relacionados a métodos de aprendizagem de máquina são realizados por Mukkamala e Sung (MUKKAMALA; SUNG, 2003). Estes autores utilizam a abordagem denominada wrapper, onde os atributos são removidos um por vez e, para cada conjunto restante de atributos, é avaliado o desempenho dos modelos de detecção de intrusão utilizando SVMs (Support Vector Machines).

Neste trabalho, o método utilizado para escolha dos melhores atributos baseia-se no cálculo do Coeficiente de Correlação Cruzada dos atributos. Método similar foi utilizado por Flauzino (2007) e Sestito (2014) para a definição das melhores variáveis de entrada. Detalhes acerca deste processo serão apresentados a seguir.

\subsubsection{Análise de Correlação Cruzada}

Uma simples observação visual de como o valor dos atributos se porta frente às condições normais ou anômalas não constitui em uma metodologia científica para inferir sobre quais desses atributos diretamente colaboram para a identificação da ocorrência de uma anomalia tal como se almeja por meio dessa metodologia.

Partindo-se dessa impossibilidade de inferência, foram então analisados todos os atributos tanto diante dos instantes de tráfego normal, quanto frente às condições de 
tráfego anômalo. A referida análise contemplou o cálculo da correlação entre o valor de cada atributo com as condições de tráfego normal e tráfego anômalo.

Ao se buscar um modelo para um classificador inteligente capaz de relacionar dinamicamente, duas ou mais entradas e uma única saída, parte-se do pressuposto de que existe correlação entre as variáveis de entrada e saída que justifique o modelo, além de fraca ou nula correlação entre as entradas.

Assim, no intuito de colaborar com a interpretação dos resultados obtidos, foram calculados os coeficientes de correlação (CC) de cada atributo com a saída desejada do classificador, conforme Tabela 19, Figura 146 e Figura 147.

Tabela 19: Coeficiente de correlação de cada atributo com a saída.

\begin{tabular}{ccccc} 
ATRIBUTO & CENÁRIO 1 & CENÁRIO 2 & CENÁRIO 3 & CENÁRIO 4 \\
\hline $\mathbf{A 0 1}$ & 0,9418 & 0,8831 & 0,7951 & 0,6872 \\
\hline $\mathbf{A 0 2}$ & 0,9418 & 0,9412 & 0,9032 & 0,8772 \\
\hline $\mathbf{A 0 3}$ & 0,9418 & $-0,7113$ & 0,9055 & $-0,3592$ \\
\hline $\mathbf{A 0 4}$ & $-0,9317$ & $-0,8664$ & $-0,6646$ & $-0,4266$ \\
\hline $\mathbf{A 0 5}$ & $-0,9318$ & $-0,8671$ & $-0,6652$ & $-0,4282$ \\
\hline $\mathbf{A 0 6}$ & 0,8954 & 0,8594 & 0,7431 & 0,4020 \\
\hline $\mathbf{A 0 7}$ & 0,5565 & $-0,0714$ & 0,6247 & $-0,1251$ \\
\hline $\mathbf{A 0 8}$ & $-0,9481$ & $-0,5534$ & $-0,6536$ & $-0,0465$ \\
\hline $\mathbf{A 0 9}$ & $-0,3378$ & 0,2249 & $-0,2879$ & 0,2076 \\
\hline $\mathbf{A 1 0}$ & 0,9418 & 0,5210 & 0,9496 & 0,3970 \\
\hline $\mathbf{A 1 1}$ & 0,9418 & 0,1303 & 0,9496 & 0,1980 \\
\hline $\mathbf{A 1 2}$ & - & - & - & - \\
\hline $\mathbf{A 1 3}$ & - & - & - & - \\
\hline $\mathbf{A 1 4}$ & 0,9418 & 0,9552 & 0,9496 & 0,9469 \\
\hline $\mathbf{A 1 5}$ & 0,9418 & $-0,6661$ & 0,9496 & $-0,3393$ \\
\hline $\mathbf{A 1 6}$ & - & $-0,6873$ & - & $-0,3765$ \\
\hline $\mathbf{A 1 7}$ & 0,9396 & 0,8845 & 0,6659 & 0,4332 \\
\hline $\mathbf{A 1 8}$ & 1,0000 & - & 0,6223 & 0,0763 \\
\hline $\mathbf{A 1 9}$ & 0,9498 & 0,9458 & 0,9481 & 0,9459 \\
\hline $\mathbf{A 2 0}$ & - & - & $-0,1557$ & 0,0763 \\
\hline & & & & \\
\hline & - & - & - & - \\
\hline
\end{tabular}




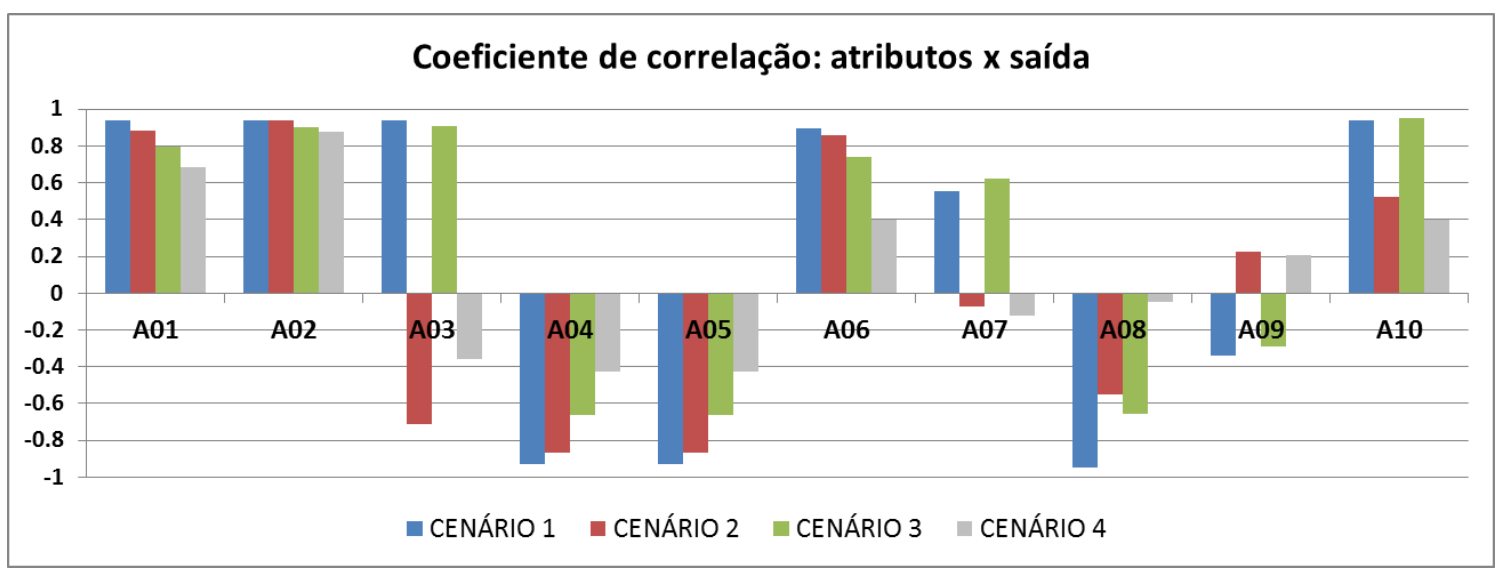

Figura 146: Coeficiente de correlação de cada atributo com a saída (A01 - A10)

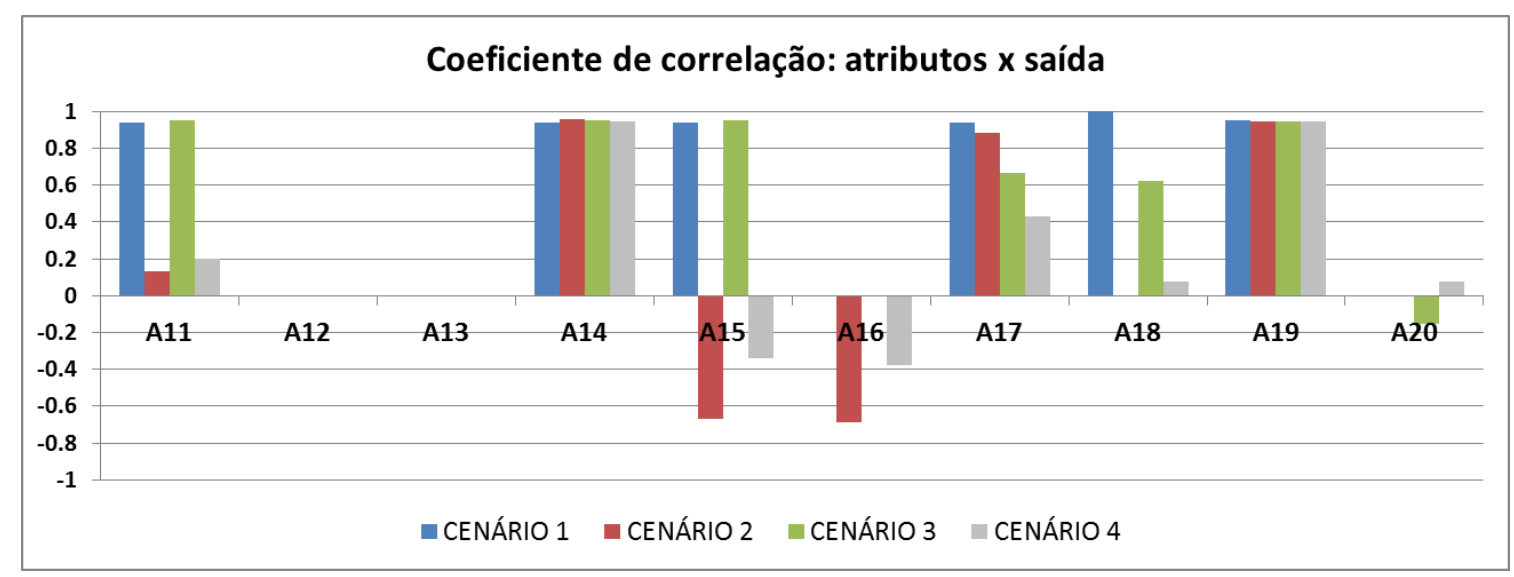

Figura 147: Coeficiente de correlação de cada atributo com a saída (A11 - A20)

O coeficiente de correlação $(\mathrm{CC})$ varia de -1 a +1 . O sinal indica direção positiva ou negativa do relacionamento e seu valor sugere a força da relação entre as variáveis. Uma correlação perfeita $(-1$ e +1$)$ indica que o escore de uma variável pode ser determinado exatamente ao se saber o escore da outra. Em contrapartida, uma correlação de valor zero indica que não há relação entre as variáveis. O valor, em módulo, situado entre 0.10 e 0.39 indica uma dependência fraca entre as variáveis, valores situados entre 0.40 e 0.69 indicam dependência moderada e o valor entre 0.70 e 1 pode ser interpretado como dependência forte (COHEN, 1988).

A fim de se estabelecer um modelo de classificador inteligente independente dos cenários de tráfego, calculou-se a correlação entre o valor de cada atributo com as condições de tráfego normal e tráfego anômalo considerando-se os dados capturados em todos os cenários de teste. 
Tabela 20: Valor dos Coeficientes de Correlação para todos os cenários.

\begin{tabular}{cc} 
ATRIBUTO & CC \\
\hline $\mathbf{A 0 1}$ & 0,5432 \\
\hline $\mathbf{A 0 2}$ & 0,7525 \\
\hline $\mathbf{A 0 3}$ & 0,1345 \\
\hline $\mathbf{A 0 4}$ & $-0,6242$ \\
\hline $\mathbf{A 0 5}$ & $-0,6253$ \\
\hline $\mathbf{A 0 6}$ & 0,6149 \\
\hline $\mathbf{A 0 7}$ & 0,2743 \\
\hline $\mathbf{A 0 8}$ & $-0,4611$ \\
\hline $\mathbf{A 0 9}$ & $-0,0971$ \\
\hline $\mathbf{A 1 0}$ & 0,3753 \\
\hline $\mathbf{A 1 1}$ & 0,2985 \\
\hline $\mathbf{A 1 2}$ & - \\
\hline $\mathbf{A 1 3}$ & - \\
\hline $\mathbf{A 1 4}$ & 0,9198 \\
\hline $\mathbf{A 1 5}$ & 0,1583 \\
\hline $\mathbf{A 1 6}$ & $-0,1479$ \\
\hline $\mathbf{A 1 7}$ & 0,4779 \\
\hline $\mathbf{A 1 8}$ & 0,3114 \\
\hline $\mathbf{A 1 9}$ & 0,9298 \\
\hline $\mathbf{A 2 0}$ & $-0,0393$ \\
\hline &
\end{tabular}

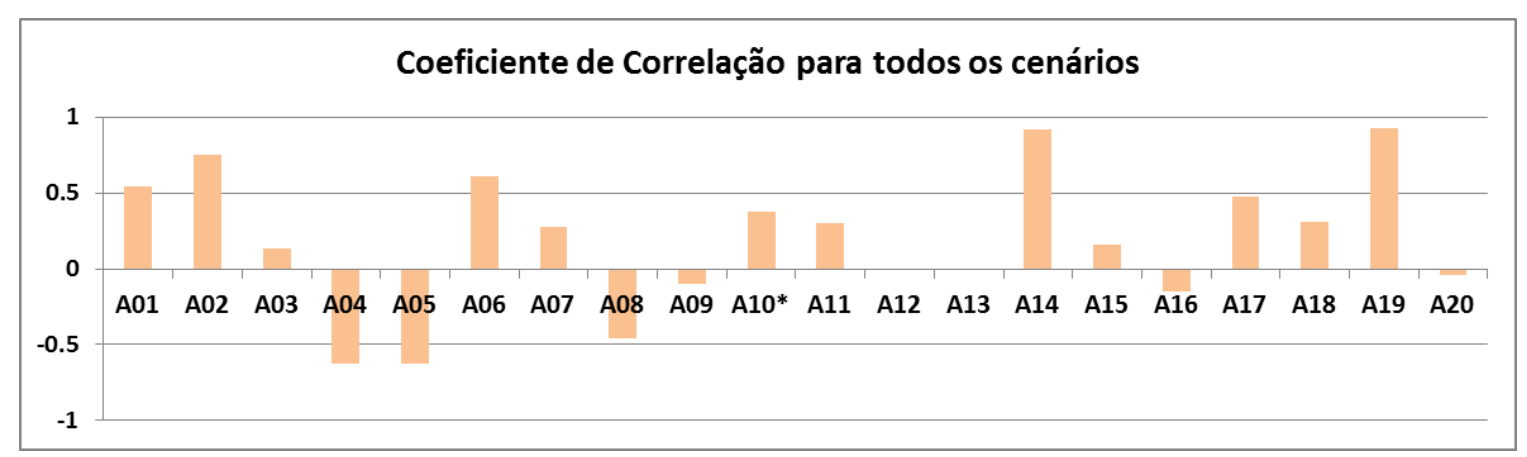

Figura 148: Valor dos Coeficientes de Correlação para todos os cenários.

De posse dos resultados, constata-se que os atributos A02, A14 e A19 possuem dependência forte com a saída. Já os atributos A01, A04, A05, A06, A08 e A17 possuem dependência moderada e os atributos A03, A07, A09, A10, A11, A15, A16, A18 e A20 possuem dependência fraca com a saída. Os atributos A12 e A13, não apresentaram variação de seus valores com relação à saída (conforme Tabela 19), então foram descartados.

Assim, os atributos mais pertinentes (com dependência forte e moderada) foram pré-selecionados, sendo eles: 
Tabela 21: Lista dos atributos pré-selecionados.

\begin{tabular}{|c|c|c|}
\hline ATRIBUTO & $\mathrm{CC}$ & Dependência \\
\hline A02 & 0,7525 & \multirow{3}{*}{ FORTE } \\
\hline A14 & 0,9198 & \\
\hline A19 & 0,9298 & \\
\hline A01 & 0,5432 & \multirow{6}{*}{ - MODERADA } \\
\hline A04 & $-0,6242$ & \\
\hline A05 & $-0,6253$ & \\
\hline A06 & 0,6149 & \\
\hline A08 & $-0,4611$ & \\
\hline A17 & 0,4779 & \\
\hline
\end{tabular}

A seguir, a fim de retirar possíveis redundâncias nas entradas do classificador, verificou-se a existência de possíveis correlações entre as entradas pré-selecionadas.

Tabela 22: Correlação Cruzada dos atributos pré-selecionados para todos os cenários.

\begin{tabular}{cccccccccc} 
& A01 & A02 & A04 & A05 & A06 & A08 & A14 & A17 & A19 \\
\hline A01 & 1,000 & 0,951 & $-0,499$ & $-0,500$ & 0,648 & $-0,451$ & 0,740 & 0,805 & 0,672 \\
\hline A02 & 0,951 & 1,000 & $-0,600$ & $-0,601$ & 0,720 & $-0,490$ & 0,909 & 0,784 & 0,850 \\
\hline A04 & $-0,499$ & $-0,600$ & 1,000 & 1,000 & $-0,819$ & 0,937 & $-0,641$ & $-0,814$ & $-0,642$ \\
\hline A05 & $-0,500$ & $-0,601$ & 1,000 & 1,000 & $-0,819$ & 0,937 & $-0,643$ & $-0,814$ & $-0,643$ \\
\hline A06 & 0,648 & 0,720 & $-0,819$ & $-0,819$ & 1,000 & $-0,742$ & 0,705 & 0,820 & 0,691 \\
\hline A08 & $-0,451$ & $-0,490$ & 0,937 & 0,937 & $-0,742$ & 1,000 & $-0,475$ & $-0,810$ & $-0,481$ \\
\hline A14 & 0,740 & 0,909 & $-0,641$ & $-0,643$ & 0,705 & $-0,475$ & 1,000 & 0,632 & 0,960 \\
\hline A17 & 0,805 & 0,784 & $-0,814$ & $-0,814$ & 0,820 & $-0,810$ & 0,632 & 1,000 & 0,593 \\
\hline A19 & 0,672 & 0,850 & $-0,642$ & $-0,643$ & 0,691 & $-0,481$ & 0,960 & 0,593 & 1,000 \\
\hline
\end{tabular}

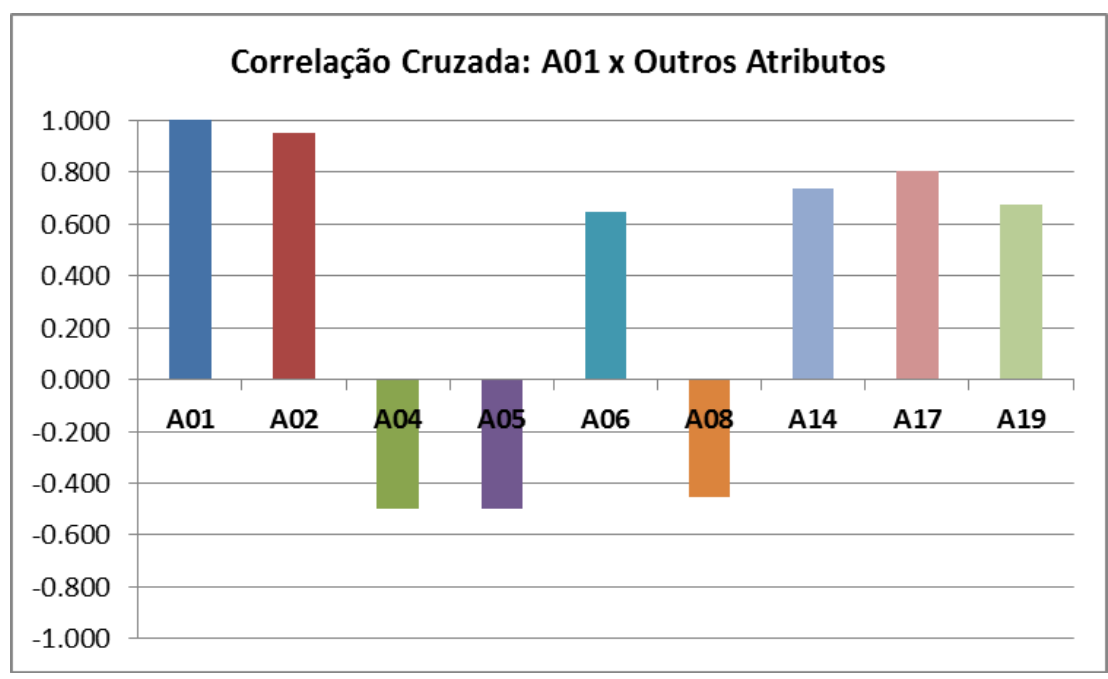

Figura 149: Coeficiente de Correlação Cruzada do atributo A01. 


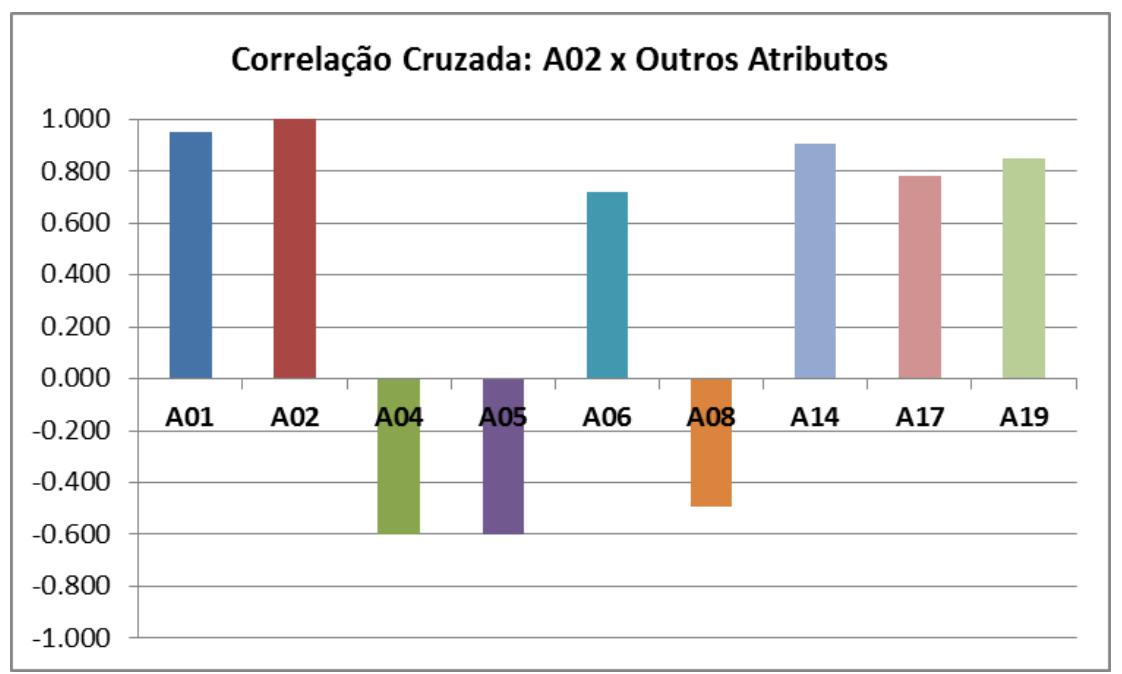

Figura 150: Coeficiente de Correlação Cruzada do atributo A02.

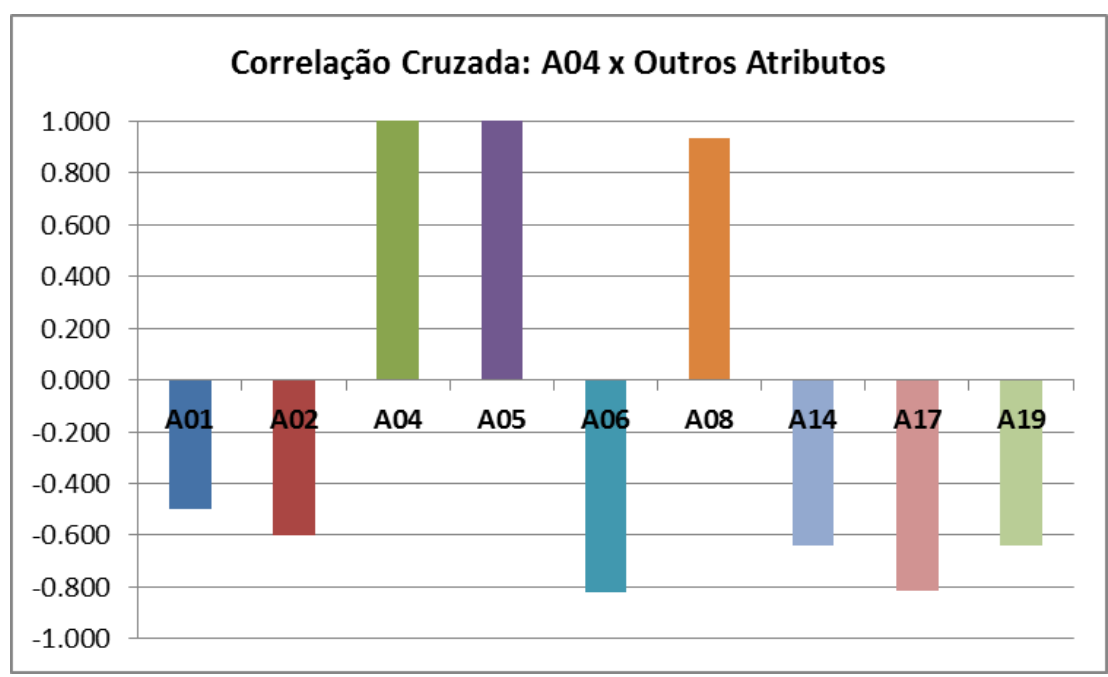

Figura 151: Coeficiente de Correlação Cruzada do atributo A04.

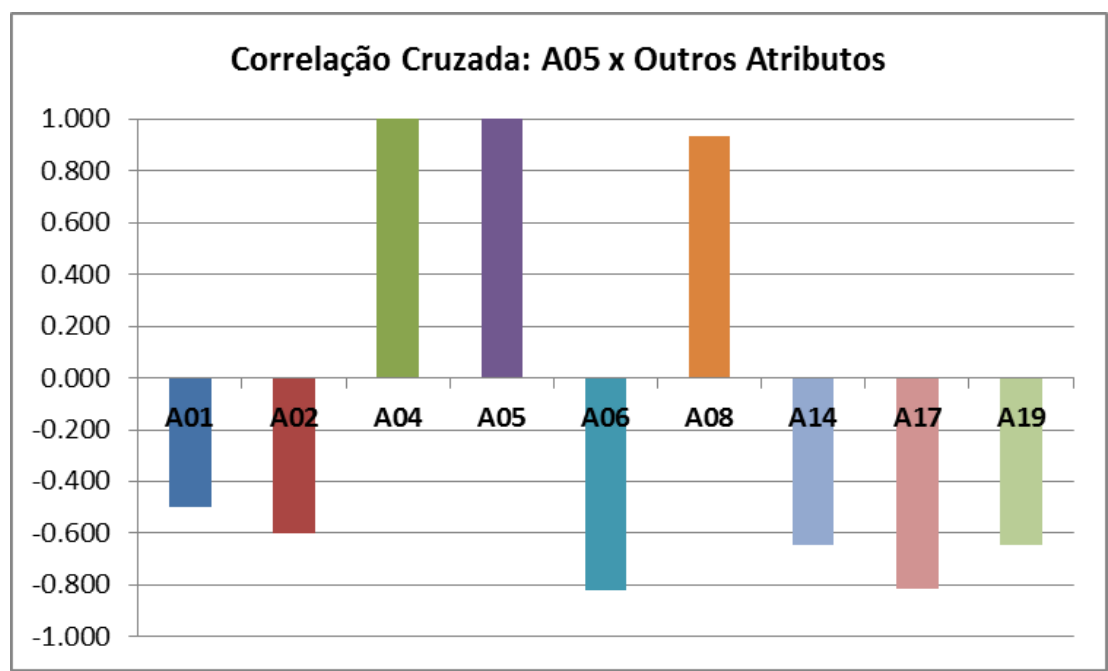

Figura 152: Coeficiente de Correlação Cruzada do atributo A05. 


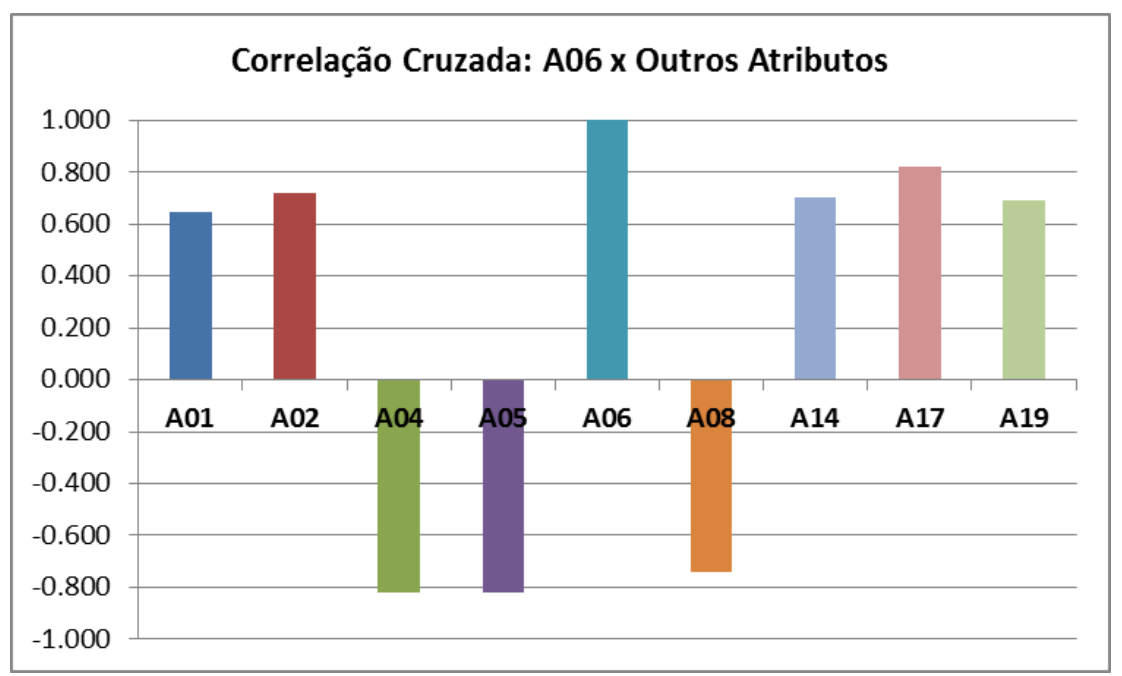

Figura 153: Coeficiente de Correlação Cruzada do atributo A06.

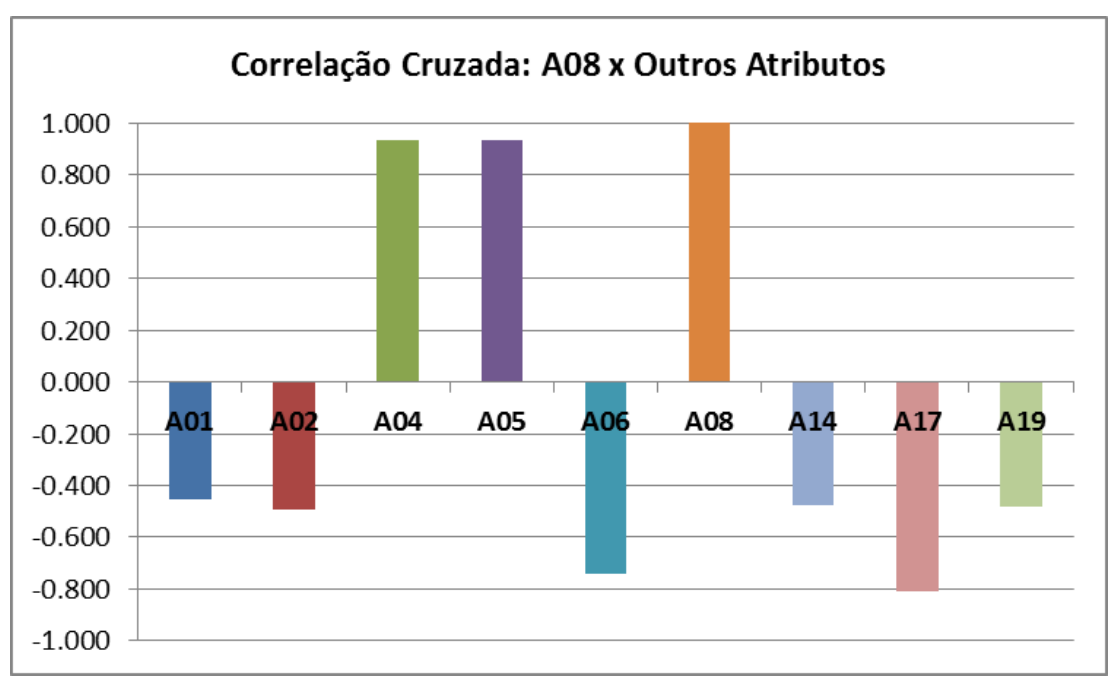

Figura 154: Coeficiente de Correlação Cruzada do atributo A08.

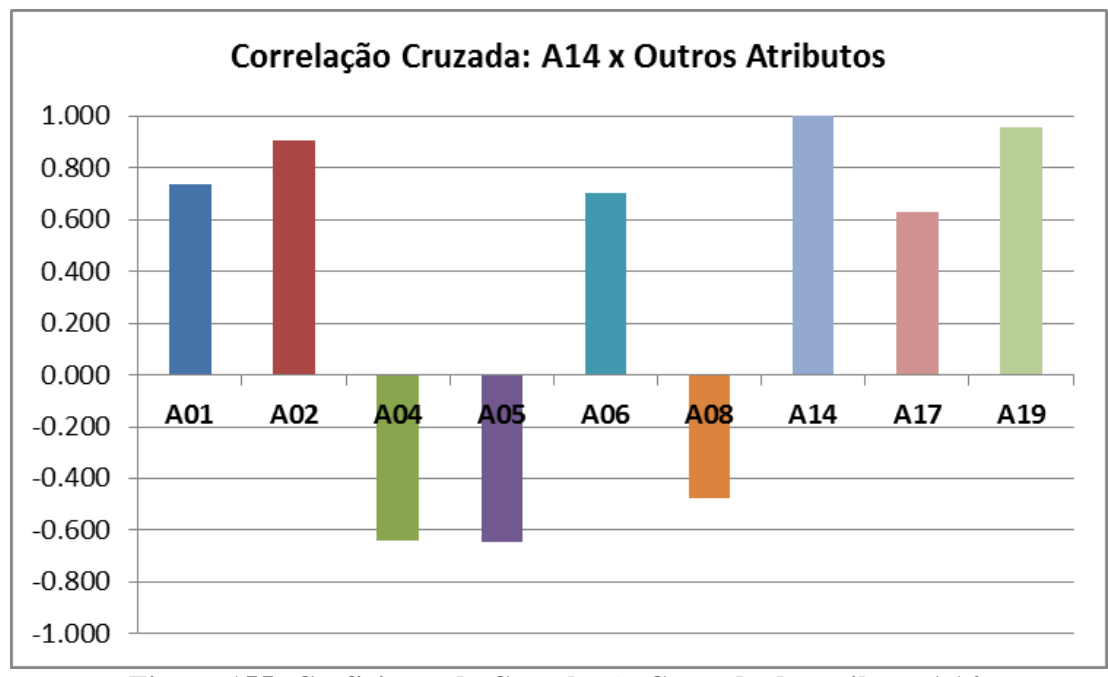

Figura 155: Coeficiente de Correlação Cruzada do atributo A14. 


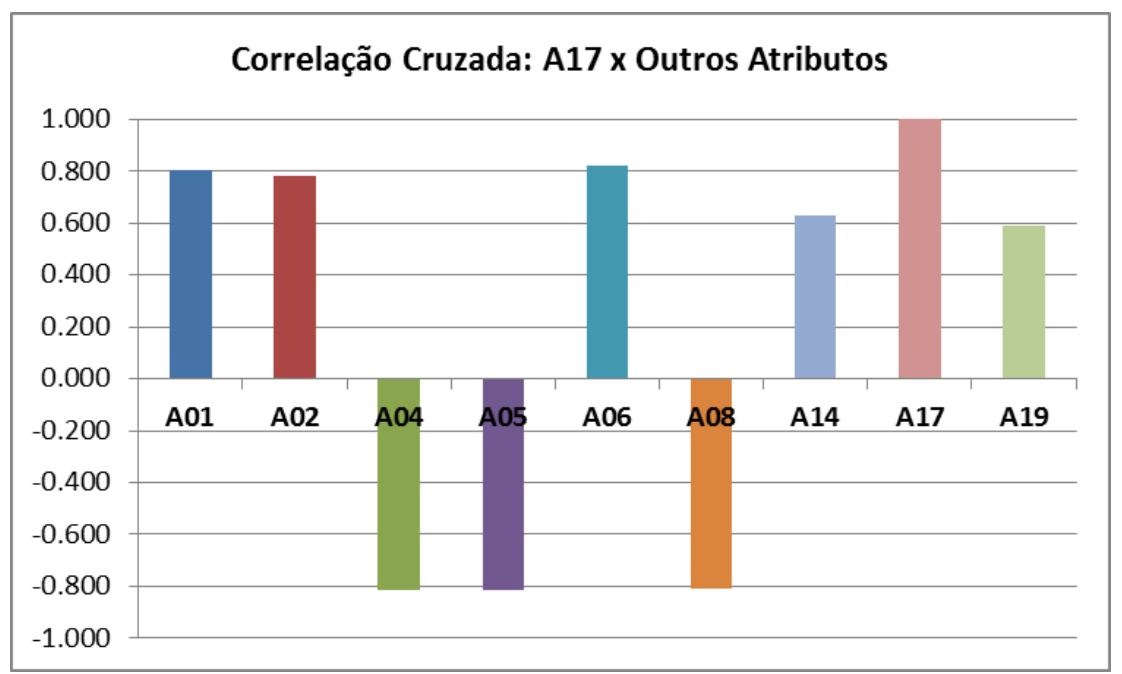

Figura 156: Coeficiente de Correlação Cruzada do atributo A17.

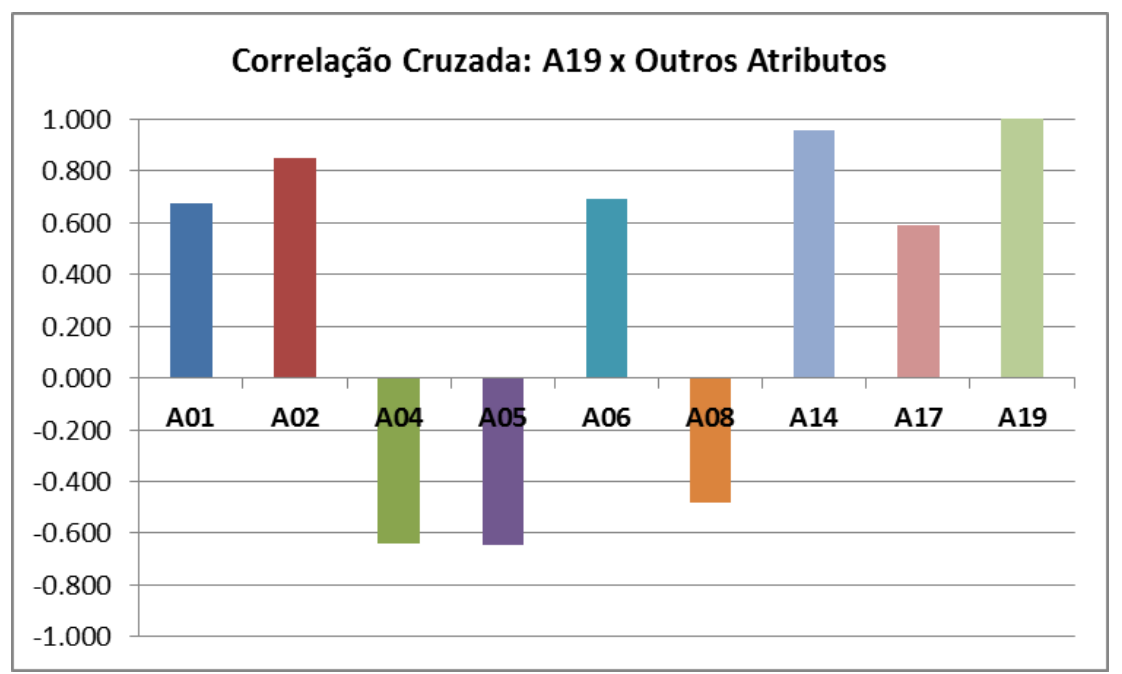

Figura 157: Coeficiente de Correlação Cruzada do atributo A19.

A fim de efetuar uma redução da dimensionalidade através da análise do coeficiente de correlação entre os atributos (previamente selecionados), optou-se por verificar os atributos que possuem coeficiente de correlação mútua maior ou igual a $\underline{0,95}$ (valor de limiar adotado).

Desta forma, por meio da análise da Tabela 22 e dos gráficos de coeficientes de correlação cruzada, é possível identificar quais atributos possuem alto valor de coeficiente de correlação mútua e, desta forma, inserem redundância de informação na entrada do classificador. Por exemplo, analisando a tabela, verifica-se que os atributos A01 e o A02 possuem coeficiente de correlação mútua de 0.951 (maior que o valor de limiar) e, portanto, um deles deve ser eliminado. Sendo que, o critério de eliminação adotado foi o de eliminar aquele atributo que possuir menor coeficiente de correlação, em módulo, com a saída. 
Em uma primeira análise, ao percorrer a Tabela 22, linha por linha, constata-se que o primeiro valor, maior que o valor de limiar encontrado, refere-se ao índice de correlação mútua entre os atributos A01 e A02. Adotando-se o critério mencionado acima, verifica-se que o atributo A02 possui maior coeficiente de correlação com a saída (através da Tabela 21) e, portanto, o A01 deve ser eliminado. Assim, após essa primeira eliminação, restam para análise os atributos A02, A04, A05, A06, A08, A14, A17, A19.

Continuando a percorrer a tabela resultante, constata-se que o próximo valor encontrado, maior que o valor de limiar adotado, é o índice de correlação mútua entre os atributos A04 e A05. Adotando-se o mesmo critério, elimina-se o A04. Continuando o processo até chegar ao ponto em que não há nenhum índice de correlação mútua entre os atributos maior ou igual ao valor de limiar, o algoritmo se encerra. Ao final, restam somente os atributos A02, A05, A06, A08, A17 e A19 que são, então, os atributos selecionados para comporem as entradas da rede neural.

Veja nas tabelas abaixo a sequência de eliminação dos atributos, um a um, conforme o algoritmo utilizado.

Tabela 23: Primeira análise: atributos A01 e A02.

\begin{tabular}{cccccccccc}
$\underline{\mathbf{1}} \mathbf{\underline { }}$ & $\mathbf{A 0 1}$ & $\mathbf{A 0 2}$ & $\mathbf{A 0 4}$ & $\mathbf{A 0 5}$ & $\mathbf{A 0 6}$ & $\mathbf{A 0 8}$ & $\mathbf{A 1 4}$ & $\mathbf{A 1 7}$ & $\mathbf{A 1 9}$ \\
\hline $\mathbf{A 0 1}$ & 1,000 & $\mathbf{0 , 9 5 1}$ & $-0,499$ & $-0,500$ & 0,648 & $-0,451$ & 0,740 & 0,805 & 0,672 \\
\hline $\mathbf{A 0 2}$ & 0,951 & 1,000 & $-0,600$ & $-0,601$ & 0,720 & $-0,490$ & 0,909 & 0,784 & 0,850 \\
\hline $\mathbf{A 0 4}$ & $-0,499$ & $-0,600$ & 1,000 & 1,000 & $-0,819$ & 0,937 & $-0,641$ & $-0,814$ & $-0,642$ \\
\hline $\mathbf{A 0 5}$ & $-0,500$ & $-0,601$ & 1,000 & 1,000 & $-0,819$ & 0,937 & $-0,643$ & $-0,814$ & $-0,643$ \\
\hline $\mathbf{A 0 6}$ & 0,648 & 0,720 & $-0,819$ & $-0,819$ & 1,000 & $-0,742$ & 0,705 & 0,820 & 0,691 \\
\hline $\mathbf{A 0 8}$ & $-0,451$ & $-0,490$ & 0,937 & 0,937 & $-0,742$ & 1,000 & $-0,475$ & $-0,810$ & $-0,481$ \\
\hline $\mathbf{A 1 4}$ & 0,740 & 0,909 & $-0,641$ & $-0,643$ & 0,705 & $-0,475$ & 1,000 & 0,632 & 0,960 \\
\hline $\mathbf{A 1 7}$ & 0,805 & 0,784 & $-0,814$ & $-0,814$ & 0,820 & $-0,810$ & 0,632 & 1,000 & 0,593 \\
\hline $\mathbf{A 1 9}$ & 0,672 & 0,850 & $-0,642$ & $-0,643$ & 0,691 & $-0,481$ & 0,960 & 0,593 & 1,000 \\
\hline
\end{tabular}

Tabela 24: Segunda análise: atributos A04 e A05.

\begin{tabular}{ccccccccc}
$\underline{\mathbf{2}} \mathbf{a}$ & $\mathbf{A 0 2}$ & $\mathbf{A 0 4}$ & $\mathbf{A 0 5}$ & $\mathbf{A 0 6}$ & $\mathbf{A 0 8}$ & $\mathbf{A 1 4}$ & $\mathbf{A 1 7}$ & $\mathbf{A 1 9}$ \\
\hline A02 & 1,000 & $-0,600$ & $-0,601$ & 0,720 & $-0,490$ & 0,909 & 0,784 & 0,850 \\
\hline A04 & $-0,600$ & 1,000 & $\mathbf{1 , 0 0 0}$ & $-0,819$ & 0,937 & $-0,641$ & $-0,814$ & $-0,642$ \\
\hline A05 & $-0,601$ & 1,000 & 1,000 & $-0,819$ & 0,937 & $-0,643$ & $-0,814$ & $-0,643$ \\
\hline A06 & 0,720 & $-0,819$ & $-0,819$ & 1,000 & $-0,742$ & 0,705 & 0,820 & 0,691 \\
\hline A08 & $-0,490$ & 0,937 & 0,937 & $-0,742$ & 1,000 & $-0,475$ & $-0,810$ & $-0,481$ \\
\hline A14 & 0,909 & $-0,641$ & $-0,643$ & 0,705 & $-0,475$ & 1,000 & 0,632 & 0,960 \\
\hline A17 & 0,784 & $-0,814$ & $-0,814$ & 0,820 & $-0,810$ & 0,632 & 1,000 & 0,593 \\
\hline A19 & 0,850 & $-0,642$ & $-0,643$ & 0,691 & $-0,481$ & 0,960 & 0,593 & 1,000 \\
\hline
\end{tabular}


Tabela 25: Terceira análise: atributos A14 e A19.

\begin{tabular}{cccccccc}
$\underline{\mathbf{3}}$ & $\mathbf{A 0 2}$ & $\mathbf{A 0 5}$ & $\mathbf{A 0 6}$ & $\mathbf{A 0 8}$ & $\mathbf{A 1 4}$ & $\mathbf{A 1 7}$ & $\mathbf{A 1 9}$ \\
\hline $\mathbf{A 0 2}$ & 1,000 & $-0,601$ & 0,720 & $-0,490$ & 0,909 & 0,784 & 0,850 \\
\hline $\mathbf{A 0 5}$ & $-0,601$ & 1,000 & $-0,819$ & 0,937 & $-0,643$ & $-0,814$ & $-0,643$ \\
\hline $\mathbf{A 0 6}$ & 0,720 & $-0,819$ & 1,000 & $-0,742$ & 0,705 & 0,820 & 0,691 \\
\hline $\mathbf{A 0 8}$ & $-0,490$ & 0,937 & $-0,742$ & 1,000 & $-0,475$ & $-0,810$ & $-0,481$ \\
\hline $\mathbf{A 1 4}$ & 0,909 & $-0,643$ & 0,705 & $-0,475$ & 1,000 & 0,632 & $\mathbf{0 , 9 6 0}$ \\
\hline $\mathbf{A 1 7}$ & 0,784 & $-0,814$ & 0,820 & $-0,810$ & 0,632 & 1,000 & 0,593 \\
\hline $\mathbf{A 1 9}$ & 0,850 & $-0,643$ & 0,691 & $-0,481$ & 0,960 & 0,593 & 1,000 \\
\hline
\end{tabular}

Tabela 26: Resultado final: atributos restantes A02, A05, A06, A08, A17 e A19.

\begin{tabular}{ccccccc} 
& $\mathbf{A 0 2}$ & $\mathbf{A 0 5}$ & $\mathbf{A 0 6}$ & $\mathbf{A 0 8}$ & $\mathbf{A 1 7}$ & $\mathbf{A 1 9}$ \\
\hline $\mathbf{A 0 2}$ & 1,000 & $-0,601$ & 0,720 & $-0,490$ & 0,784 & 0,850 \\
\hline $\mathbf{A 0 5}$ & $-0,601$ & 1,000 & $-0,819$ & 0,937 & $-0,814$ & $-0,643$ \\
\hline $\mathbf{A 0 6}$ & 0,720 & $-0,819$ & 1,000 & $-0,742$ & 0,820 & 0,691 \\
\hline $\mathbf{A 0 8}$ & $-0,490$ & 0,937 & $-0,742$ & 1,000 & $-0,810$ & $-0,481$ \\
\hline $\mathbf{A 1 7}$ & 0,784 & $-0,814$ & 0,820 & $-0,810$ & 1,000 & 0,593 \\
\hline $\mathbf{A 1 9}$ & 0,850 & $-0,643$ & 0,691 & $-0,481$ & 0,593 & 1,000 \\
\hline
\end{tabular}

A Tabela 27 sumariza os valores de correlação dos atributos eleitos como parâmetros no processo de identificação de anomalias na rede.

Tabela 27: Relação dos atributos eleitos como parâmetros no processo de identificação de anomalias.

\begin{tabular}{cc} 
ATRIBUTO & CC \\
\hline A02 & 0,7525 \\
\hline A05 & $-0,6253$ \\
\hline A06 & 0,6149 \\
\hline A08 & $-0,4611$ \\
\hline A17 & 0,4779 \\
\hline A19 & 0,9298 \\
\hline
\end{tabular}

\subsection{Preparação dos dados para o treinamento das RNAs}

O pré-processamento dos dados é etapa fundamental para reduzir erros inerentes à aquisição de dados. Nesta etapa é realizada uma análise criteriosa sobre os dados coletados buscando minimizar ambiguidades e possíveis erros associados à etapa de aquisição de dados. Na prática, dois procedimentos foram realizados: o primeiro referese a uma filtragem dos dados capturados eliminando-se os pacotes oriundos da própria estação de captura e o segundo, refere-se à equalização do tamanho do conjunto de 
dados capturados em cada cenário para que estejam todos com a mesma ordem de grandeza. Assim, estabeleceu-se o tamanho de 5500 pacotes para os conjuntos de dados de captura para cada cenário de teste (veja Seção 6.2).

Os dados coletados foram divididos em três conjuntos: Conjunto de Treinamento que é utilizado para o treinamento da rede neural, Conjunto de Validação que é utilizado para verificar a eficiência da rede quanto a sua capacidade de generalização durante o treinamento e utilizado com critério de parada do treinamento, e Conjunto de Teste que é utilizado para testar e validar a rede treinada, dessa maneira verifica-se seu desempenho em condições reais de utilização.

Conforme visto na Seção 6.3, os atributos (entradas da RNA) possuem diferentes ordens de grandeza. Porém, um dos requisitos para se trabalhar com redes neurais é utilizar entradas com a mesma ordem de grandeza (normalizadas) e, portanto, para contornar esse problema, os valores de todas as entradas e saídas foram normalizados para o intervalo $[-1,1]$ levando-se em conta os valores máximos e mínimos de cada atributo. A normalização dos dados faz com que os valores apresentados à RNA não se afastem dos limites dinâmicos da função de ativação, além de aproximar a faixa de variação dos dados de entrada com a dos pesos iniciais, o que contribui para a convergência do algoritmo de treinamento (ZHANG; PATUWO; HU, 1998). Além disso, outro pré-processamento realizado nessa etapa foi a remoção do valor médio do conjunto de dados. Todas essas operações foram realizadas com o uso do software Matlab utilizando-se as funções: impordata(), mapminmax() e nprtool.

A divisão do conjunto de amostras para todos os cenários de teste, conforme mencionado acima, é representada na Tabela 28.

Uma característica peculiar deste trabalho refere-se à forma que são construídos os conjuntos de treinamento, validação e teste. Como um dos objetivos deste trabalho é demonstrar que o conjunto de treinamento pode ser formado por uma combinação entre casos normais, capturados de um fluxo real da rede Profinet, e os casos de intrusão, gerados artificialmente, os conjuntos de treinamento, validação e teste foram compostos por duas metades bem distintas: a primeira metade é formada pela captura de tráfego real em condições "normais" e a segunda metade, por dados gerados aleatoriamente representando o tráfego "anômalo". 
O desempenho do sistema é então testado em uma etapa posterior denominada 'Teste Adicional'. Nesta etapa, apresentam-se dados inéditos à rede (dados não utilizados durante a fase de treinamento, validação e teste) utilizando-se dados capturados de tráfego real em condições de ataque, ou seja, tráfego "anômalo".

Tabela 28: Divisão do conjunto de amostras para a RNA.

\begin{tabular}{cllc} 
CENÁRIOS & \multicolumn{3}{c}{ AMOSTRAS } \\
\hline \multirow{3}{*}{$\mathbf{1}$} & Total & $100 \%$ & 6519 \\
\cline { 2 - 4 } & Treinamento & $70 \%$ & 4563 \\
\cline { 2 - 4 } & Validação & $15 \%$ & 978 \\
\cline { 2 - 4 } & Teste & $15 \%$ & 978 \\
\hline \multirow{2}{*}{$\mathbf{2}$} & Total & $100 \%$ & 8003 \\
\cline { 2 - 4 } & Treinamento & $70 \%$ & 5603 \\
\cline { 2 - 4 } & Validação & $15 \%$ & 1200 \\
\cline { 2 - 4 } & Teste & $15 \%$ & 1200 \\
\hline \multirow{3}{*}{3} & Total & $100 \%$ & 7522 \\
\cline { 2 - 4 } & Treinamento & $70 \%$ & 5266 \\
\cline { 2 - 4 } & Validação & $15 \%$ & 1128 \\
\cline { 2 - 4 } & Teste & $15 \%$ & 1128 \\
\hline \multirow{3}{*}{4} & Total & $100 \%$ & 8882 \\
\cline { 2 - 4 } & Treinamento & $70 \%$ & 6218 \\
\cline { 2 - 4 } & Validação & $15 \%$ & 1332 \\
\cline { 2 - 4 } & Teste & $15 \%$ & 1332 \\
\hline
\end{tabular}

\subsection{Treinamento das RNAs}

Conforme apresentado anteriormente, a rede neural a ser utilizada é a PMC com seis neurônios na camada de entrada (atributos do tráfego A02, A05, A06, A08, A17 e A19) e apenas um neurônio na camada de saída. Para definição da quantidade de neurônios $\mathrm{da}(\mathrm{s})$ camada(s) escondida(s) (N, N1 e N2), foram feitos diversos experimentos alterando-se esses valores utilizando-se o toolbox Pattern Recognition Tool (nprtool) do software Matlab.

Os algoritmos utilizados pelo toolbox são:

- Divisão dos Dados:

- Treinamento:

- Desempenho:

- Derivada:
Random (dividerand)

Levenberg-Marquardt (trainlm)

Mean Squared Error (mse)

Default (defaultderiv) 
Nesta etapa de definição da Topologia mais adequada, foram utilizados apenas os dados referentes ao Cenário 4 por se tratar do conjunto de dados mais abrangente, heterogêneo e que de certa forma engloba o tráfego de todos os outros cenários.

\section{PMC com uma camada escondida:}

A topologia de rede avaliada está ilustrada na Figura 158.

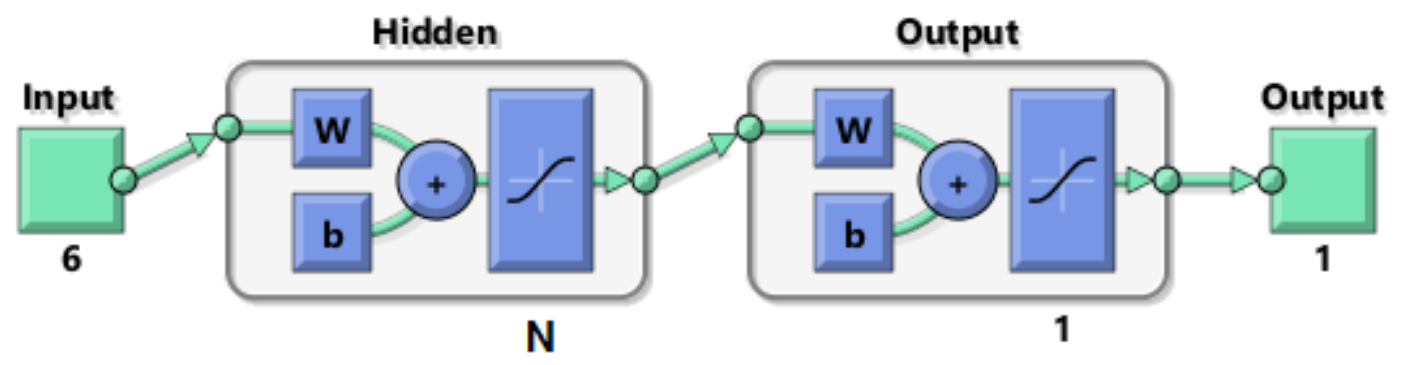

Figura 158: Rede PMC com uma camada escondida.

Os resultados estão sumarizados na Tabela 29.

Tabela 29: Treinamentos realizados com vários valores de $\mathbf{N}$.

\begin{tabular}{|c|c|c|c|c|c|}
\hline \multirow[t]{2}{*}{$\mathbf{N}$} & \multirow[t]{2}{*}{ Rede } & \multirow[t]{2}{*}{ Épocas } & \multirow[t]{2}{*}{ Tempo } & \multicolumn{2}{|c|}{$\begin{array}{l}\text { EP - Erro } \\
\text { Percentual }\end{array}$} \\
\hline & & & & Validacão & Teste \\
\hline \multirow{3}{*}{5} & 05.1 & 15 & $4 s$ & $0,00 \%$ & $0,40 \%$ \\
\hline & 05.2 & 15 & $4 \mathrm{~s}$ & $0,60 \%$ & $0,50 \%$ \\
\hline & 05.3 & 13 & $4 s$ & $0,20 \%$ & $0,10 \%$ \\
\hline \multirow{3}{*}{10} & 10.1 & 14 & $5 s$ & $0,10 \%$ & $0,10 \%$ \\
\hline & 10.2 & 12 & $4 s$ & $0,00 \%$ & $0,10 \%$ \\
\hline & 10.3 & 14 & $6 s$ & $0,20 \%$ & $0,20 \%$ \\
\hline \multirow{3}{*}{15} & 15.1 & 12 & $5 s$ & $0,10 \%$ & $0,20 \%$ \\
\hline & 15.2 & 14 & $5 s$ & $0,20 \%$ & $0,20 \%$ \\
\hline & 15.3 & 15 & $6 s$ & $0,00 \%$ & $0,20 \%$ \\
\hline \multirow{3}{*}{20} & 20.1 & 15 & $7 \mathrm{~s}$ & $0,00 \%$ & $0,00 \%$ \\
\hline & 20.2 & 13 & $6 s$ & $0,00 \%$ & $0,30 \%$ \\
\hline & 20.3 & 17 & $8 \mathrm{~s}$ & $0,20 \%$ & $0,00 \%$ \\
\hline \multirow{3}{*}{25} & 25.1 & 11 & $6 s$ & $0,20 \%$ & $0,20 \%$ \\
\hline & 25.2 & 11 & $6 s$ & $0,20 \%$ & $0,20 \%$ \\
\hline & 25.3 & 13 & $7 \mathrm{~s}$ & $0,10 \%$ & $0,10 \%$ \\
\hline \multirow{3}{*}{30} & 30.1 & 12 & $8 \mathrm{~s}$ & $0,20 \%$ & $0,10 \%$ \\
\hline & 30.2 & 13 & $8 s$ & $0,20 \%$ & $0,10 \%$ \\
\hline & 30.3 & 12 & $8 \mathrm{~s}$ & $0,10 \%$ & $0,10 \%$ \\
\hline
\end{tabular}

\section{PMC com duas camadas escondidas}

A topologia de rede avaliada está ilustrada na Figura 159. 


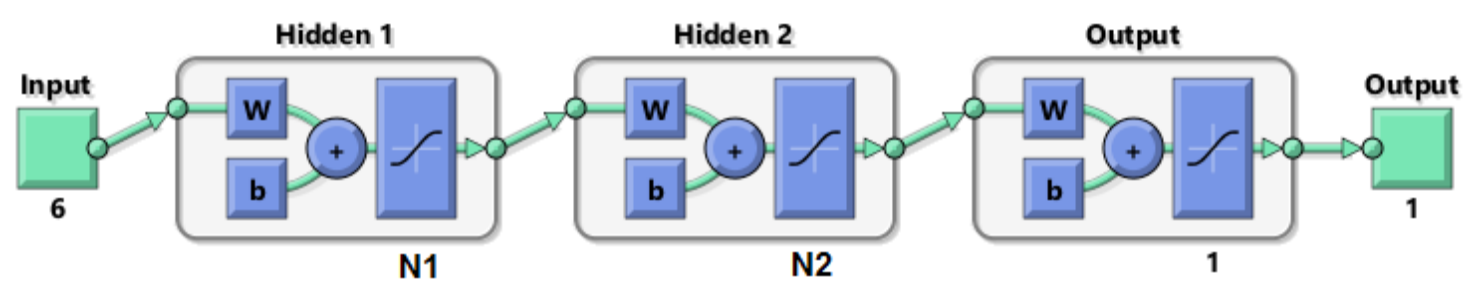

Figura 159: Rede PMC com duas camadas escondidas.

Os resultados estão sumarizados na Tabela 30.

Tabela 30: Treinamentos realizados com vários valores de $\mathrm{N}$.

\begin{tabular}{|c|c|c|c|c|c|c|}
\hline \multirow{2}{*}{ N1 } & \multirow{2}{*}{$\mathbf{N} 2$} & \multirow{2}{*}{ Rede } & \multirow{2}{*}{ Épocas } & \multirow{2}{*}{ Tempo } & \multicolumn{2}{|c|}{ EP - Erro Percentual } \\
\hline & & & & & Validação & Teste \\
\hline \multirow{3}{*}{8} & \multirow{3}{*}{4} & 0804.1 & 22 & $8 \mathrm{~s}$ & $0,30 \%$ & $0,30 \%$ \\
\hline & & 0804.2 & 22 & $8 \mathrm{~s}$ & $0,20 \%$ & $0,50 \%$ \\
\hline & & 0804.3 & 15 & $6 s$ & $0,10 \%$ & $0,30 \%$ \\
\hline \multirow{3}{*}{10} & \multirow{3}{*}{6} & 1006.1 & 11 & $6 s$ & $0,10 \%$ & $0,20 \%$ \\
\hline & & 1006.2 & 17 & $7 \mathrm{~s}$ & $0,20 \%$ & $0,00 \%$ \\
\hline & & 1006.3 & 12 & $5 s$ & $0,20 \%$ & $0,10 \%$ \\
\hline \multirow{3}{*}{15} & \multirow{3}{*}{10} & 1510.1 & 15 & $10 \mathrm{~s}$ & $0,00 \%$ & $0,20 \%$ \\
\hline & & 1510.2 & 20 & $13 \mathrm{~s}$ & $0,20 \%$ & $0,10 \%$ \\
\hline & & 1510.3 & 15 & $9 \mathrm{~s}$ & $0,10 \%$ & $0,20 \%$ \\
\hline \multirow{3}{*}{20} & \multirow{3}{*}{15} & 2015.1 & 14 & $13 \mathrm{~s}$ & $0,40 \%$ & $0,20 \%$ \\
\hline & & 2015.2 & 18 & $19 \mathrm{~s}$ & $0,10 \%$ & $0,00 \%$ \\
\hline & & 2015.3 & 21 & $23 \mathrm{~s}$ & $0,10 \%$ & $0,20 \%$ \\
\hline \multirow{3}{*}{20} & \multirow{3}{*}{20} & 2020.1 & 14 & $19 \mathrm{~s}$ & $0,00 \%$ & $0,10 \%$ \\
\hline & & 2020.2 & 12 & $16 \mathrm{~s}$ & $0,20 \%$ & $0,10 \%$ \\
\hline & & 2020.3 & 14 & $19 \mathrm{~s}$ & $0,10 \%$ & $0,10 \%$ \\
\hline \multirow{3}{*}{20} & \multirow{3}{*}{25} & 2025.1 & 19 & $29 \mathrm{~s}$ & $0,00 \%$ & $0,20 \%$ \\
\hline & & 2025.2 & 28 & $43 \mathrm{~s}$ & $0,10 \%$ & $0,30 \%$ \\
\hline & & 2025.3 & 22 & $34 \mathrm{~s}$ & $0,00 \%$ & $0,00 \%$ \\
\hline \multirow{3}{*}{20} & \multirow{3}{*}{30} & 2030.1 & 18 & $37 \mathrm{~s}$ & $0,10 \%$ & $0,10 \%$ \\
\hline & & 2030.2 & 13 & $27 \mathrm{~s}$ & $0,30 \%$ & $0,00 \%$ \\
\hline & & 2030.3 & 20 & $46 s$ & $0,10 \%$ & $0,10 \%$ \\
\hline \multirow{3}{*}{25} & \multirow{3}{*}{15} & 2515.1 & 14 & $18 \mathrm{~s}$ & $0,00 \%$ & $0,20 \%$ \\
\hline & & 2515.2 & 18 & $23 \mathrm{~s}$ & $0,60 \%$ & $0,20 \%$ \\
\hline & & 2515.3 & 13 & $20 \mathrm{~s}$ & $0,40 \%$ & $0,00 \%$ \\
\hline \multirow{3}{*}{25} & \multirow{3}{*}{20} & 2520.1 & 15 & $24 \mathrm{~s}$ & $0,20 \%$ & $0,20 \%$ \\
\hline & & 2520.2 & 10 & $16 \mathrm{~s}$ & $0,20 \%$ & $0,20 \%$ \\
\hline & & 2520.3 & 14 & $22 \mathrm{~s}$ & $0,20 \%$ & $0,20 \%$ \\
\hline \multirow{3}{*}{25} & \multirow{3}{*}{25} & 2525.1 & 14 & $34 \mathrm{~s}$ & $0,20 \%$ & $0,00 \%$ \\
\hline & & 2525.2 & 12 & $28 \mathrm{~s}$ & $0,20 \%$ & $0,10 \%$ \\
\hline & & 2525.3 & 21 & $50 \mathrm{~s}$ & $0,10 \%$ & $0,20 \%$ \\
\hline \multirow{3}{*}{25} & & 2530.1 & 14 & $38 \mathrm{~s}$ & $0,00 \%$ & $0,10 \%$ \\
\hline & 30 & 2530.2 & 14 & $38 \mathrm{~s}$ & $0,20 \%$ & $0,10 \%$ \\
\hline & & 2530.3 & 13 & $35 \mathrm{~s}$ & $0,00 \%$ & $0,30 \%$ \\
\hline & & 3030.1 & 20 & $68 \mathrm{~s}$ & $0,10 \%$ & $0,00 \%$ \\
\hline 30 & 30 & 3030.2 & 12 & $42 \mathrm{~s}$ & $0,10 \%$ & $0,10 \%$ \\
\hline & & 3030.3 & 18 & $69 \mathrm{~s}$ & $0,20 \%$ & $0,20 \%$ \\
\hline
\end{tabular}


Para avaliação de qual a topologia de rede neural mais adequada, foram calculados os valores de erro percentual médio para cada treinamento realizado. Esses valores estão descritos na tabela abaixo.

A análise da tabela acima permite constatar que a rede que apresentou o menor erro total na classificação foi a rede 20 (considerando-se o dados do conjunto de Validação e Teste).

Tabela 31: Valores Médios de EP para diversas redes considerando os três treinamentos.

\begin{tabular}{cccc}
\multirow{2}{*}{ Rede } & \multicolumn{3}{c}{ EP - Médio } \\
\cline { 2 - 4 } & Validação & Teste & Total \\
\hline 20 & $0,07 \%$ & $0,10 \%$ & $0,17 \%$ \\
\hline 2020 & $0,10 \%$ & $0,10 \%$ & $0,20 \%$ \\
\hline 2025 & $0,03 \%$ & $0,17 \%$ & $0,20 \%$ \\
\hline 3030 & $0,13 \%$ & $0,10 \%$ & $0,23 \%$ \\
\hline 10 & $0,10 \%$ & $0,13 \%$ & $0,23 \%$ \\
\hline 2030 & $0,17 \%$ & $0,07 \%$ & $0,23 \%$ \\
\hline 2530 & $0,07 \%$ & $0,17 \%$ & $0,23 \%$ \\
\hline 30 & $0,17 \%$ & $0,10 \%$ & $0,27 \%$ \\
\hline 2525 & $0,17 \%$ & $0,10 \%$ & $0,27 \%$ \\
\hline 1006 & $0,17 \%$ & $0,10 \%$ & $0,27 \%$ \\
\hline 1510 & $0,10 \%$ & $0,17 \%$ & $0,27 \%$ \\
\hline 15 & $0,10 \%$ & $0,20 \%$ & $0,30 \%$ \\
\hline 2015 & $0,20 \%$ & $0,13 \%$ & $0,33 \%$ \\
\hline 25 & $0,17 \%$ & $0,17 \%$ & $0,33 \%$ \\
\hline 2520 & $0,20 \%$ & $0,20 \%$ & $0,40 \%$ \\
\hline 2515 & $0,33 \%$ & $0,13 \%$ & $0,47 \%$ \\
\hline 0804 & $0,20 \%$ & $0,37 \%$ & $0,57 \%$ \\
\hline 05 & $0,27 \%$ & $0,33 \%$ & $0,60 \%$ \\
\hline
\end{tabular}

\subsection{Análise dos resultados}

O sistema de detecção proposto consiste em uma rede neural PMC com seis entradas (atributos do tráfego A02, A05, A06, A08, A17 e A19), uma camada escondida com vinte neurônios e apenas uma saída, conforme Figura 160. 


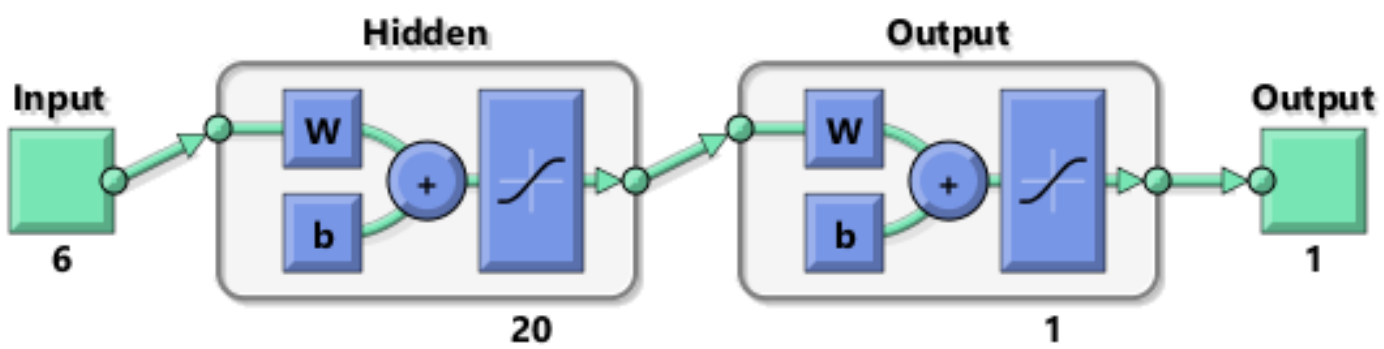

Figura 160: Rede PMC com 20 neurônios na camada escondida.

Para validar a utilização desta topologia e dos atributos de tráfego selecionados, foi calculado a Taxa de Detecção (TD) e a Taxa de Alarmes Falsos (TAF) do IDS constituído por esses elementos. Esses valores foram calculados conforme expressões apresentadas na Seção 4.3.2 e estão apresentados na Tabela 33. Esta etapa refere-se à etapa 'Teste Adicional' descrita na Seção 6.5.

Tabela 32: Taxa de Detecção (TD) e Taxa de Alarmes-Falsos (TAF) para cada cenário.

\begin{tabular}{|c|c|c|c|c|c|c|c|}
\hline CENÁRIO & TESTE & NA & NTA & TD & NNI & NTN & TAF \\
\hline \multirow{6}{*}{1} & 1.1 & 478 & 479 & $99,79 \%$ & 0 & 514 & $0,00 \%$ \\
\hline & 1.2 & 475 & 479 & $99,16 \%$ & 0 & 510 & $0,00 \%$ \\
\hline & 1.3 & 473 & 479 & $98,75 \%$ & 0 & 527 & $0,00 \%$ \\
\hline & 1.4 & 472 & 479 & $98,54 \%$ & 0 & 489 & $0,00 \%$ \\
\hline & 1.5 & 475 & 479 & $99,16 \%$ & 0 & 514 & $0,00 \%$ \\
\hline & Média & - & - & $99,08 \%$ & - & - & $0,00 \%$ \\
\hline \multirow{6}{*}{2} & 2.1 & 586 & 593 & $98,82 \%$ & 0 & 673 & $0,00 \%$ \\
\hline & 2.2 & 593 & 593 & $100,00 \%$ & 1 & 687 & $0,15 \%$ \\
\hline & 2.3 & 585 & 593 & $98,65 \%$ & 1 & 668 & $0,15 \%$ \\
\hline & 2.4 & 589 & 593 & $99,33 \%$ & 0 & 679 & $0,00 \%$ \\
\hline & 2.5 & 587 & 593 & $98,99 \%$ & 0 & 653 & $0,00 \%$ \\
\hline & Média & - & - & $99,16 \%$ & - & - & $0,06 \%$ \\
\hline \multirow{6}{*}{3} & 3.1 & 671 & 674 & $99,55 \%$ & 1 & 553 & $0,18 \%$ \\
\hline & 3.2 & 671 & 674 & $99,55 \%$ & 1 & 537 & $0,19 \%$ \\
\hline & 3.3 & 674 & 674 & $100,00 \%$ & 0 & 571 & $0,00 \%$ \\
\hline & 3.4 & 670 & 674 & $99,41 \%$ & 2 & 556 & $0,36 \%$ \\
\hline & 3.5 & 673 & 674 & $99,85 \%$ & 0 & 557 & $0,00 \%$ \\
\hline & Média & - & - & $99,67 \%$ & - & - & $0,15 \%$ \\
\hline \multirow{6}{*}{4} & 4.1 & 589 & 592 & $99,49 \%$ & 4 & 721 & $0,55 \%$ \\
\hline & 4.2 & 588 & 592 & $99,32 \%$ & 1 & 695 & $0,14 \%$ \\
\hline & 4.3 & 583 & 592 & $98,48 \%$ & 2 & 671 & $0,30 \%$ \\
\hline & 4.4 & 589 & 592 & $99,49 \%$ & 1 & 690 & $0,14 \%$ \\
\hline & 4.5 & 588 & 592 & $99,32 \%$ & 1 & 702 & $0,14 \%$ \\
\hline & Média & - & - & $99,22 \%$ & - & - & $0,26 \%$ \\
\hline
\end{tabular}

A fim de validar o desempenho do IDS proposto, uma comparação com os resultados obtidos por outros pesquisadores, em trabalho correlacionado a este, foi feita. 
Os valores encontrados por Linda et al. (2009) foram uma taxa de detecção (TD) de $66,06 \%$ e taxa de alarmes falsos (TAF) de $0,38 \%$ utilizando uma rede neural com uma camada escondida e dezesseis entradas, $\mathrm{TD}=85,08 \%$ e $\mathrm{TAF}=0 \%$ para uma rede neural com uma camada escondida e oito entradas, $\mathrm{TD}=78,64 \%$ e $\mathrm{TAF}=0 \%$ utilizando uma rede neural com duas camadas escondidas e dezesseis entradas e TD = $100 \%$ e $\mathrm{TAF}=0 \%$ para uma rede neural com duas camadas escondidas e oito entradas.

Ressalta-se que, no estudo realizado por esses pesquisadores, foi considerada a avaliação de apenas um cenário de teste bem simplificado, cuja rede era composta por apenas um controlador (fabricante Allen Bradley, modelo PLC5 e protocolo de rede não informado) e uma estação de controle (PC), o que torna o tráfego de pacotes mais homogêneo e, consequentemente, atinge-se taxas superiores de detecção por parte do IDS.

Já o IDS proposto por Silva (2008) apresentou uma taxa de detecção média de 85,54\% e uma taxa média de alarmes-falsos de 25,8\%. Já em Onut e Ghorbani (2007) foi encontrada uma TD média de $31,5 \%$ e uma TAF média de $22,22 \%$. No trabalho de Souza e Monteiro (2009), a TD encontrada para ataque tipo Probing foi de $72,44 \%$. O trabalho de Shum e Malki (2008) apresentou uma TD para ataques desconhecidos de $76 \%$.

Considerando-se os valores encontrados nos trabalhos correlatos citados acima, conclui-se que os valores de TD e TAF apresentados pelo IDS proposto neste trabalho, na Tabela 32, são superiores aos valores encontrados pelos outros pesquisadores. Devese ter em mente a diversidade de opções e análises possíveis que podem resultar em valores muito diferentes e, portanto, uma análise comparativa ampla e contextualizada sempre deve ser realizada. 


\section{Capítulo 7}

\section{Conclusões Gerais e Trabalhos Futuros}

O trabalho aqui apresentado visou desenvolver e avaliar uma metodologia a ser utilizada na identificação de anomalias em redes de comunicação Profinet, por meio da aplicação de redes neurais artificias como classificador de padrões.

\subsection{Conclusões}

Os ensaios realizados mostraram a factibilidade da metodologia desenvolvida para detecção de ataques em redes Profinet em modo off-line. Sendo que, aparentemente, poucas alterações podem ser realizadas a fim de se realizar uma análise online do tráfego da rede.

É pertinente destacar que esta metodologia pode ser também aplicada para a análise do tráfego de outras redes baseadas no protocolo Ethernet com pouquíssimas alterações/ajustes. A Seção 2.3 apresenta a lista dos protocolos industriais derivados do protocolo Ethernet.

As anomalias foram identificadas por meio da análise do tráfego da rede Profinet em sua fase de operação. Anomalias estas que podem ser desde defeitos comuns apresentados pelos equipamentos da rede e/ou tentativas de ataques externos a esta, que por sua vez, podem gerar instabilidade e mau funcionamento da unidade industrial que fazem parte.

No desenvolvimento deste trabalho, foi feita uma profunda revisão bibliográfica acerca dos trabalhos científicos referentes ao detalhamento do protocolo Profinet, sobre os principais mecanismos de segurança em redes, os métodos tradicionais de captura de tráfego e sobre os principais tipos de ataques às redes de comunicação conhecidos na literatura e como estes podem ser classificados. Foi também realizada uma investigação sobre as possíveis vulnerabilidades do protocolo e, embora, o trabalho tenha sido focado apenas no protocolo Profinet, estima-se que os resultados possam ser extrapolados para outros protocolos que também possam ter suas vulnerabilidades exploradas para fins maliciosos. 
Desta forma, constatou-se que com esse trabalho, muito conteúdo sobre o tema 'segurança em redes industriais' foi adquirido e, certamente será utilizado em outros trabalhos científicos envolvidos com temas de pesquisa correlatos.

Conclui-se que este trabalho tem grande contribuição pela teoria apresentada obtida por meio de normas internacionais e, também, pela proposta metodológica que se provou ser factível e passível de ser implementada como uma função adicional a ser incorporada em analisadores de redes de comunicação digital.

\subsection{Trabalhos futuros}

Durante o desenvolvimento deste trabalho, observou-se que algumas análises importantes poderiam ter sido feitas, mas que demandavam um tempo adicional não disponível. Assim, decidiu-se mantê-las como sugestões de trabalhos futuros.

São elas:

- Avaliar os resultados desta metodologia alterando-se o tipo da RNA utilizado. Por exemplo, utilizar redes tipo RBF (Radial Basis Function), SOM (Self Organizing Map) e LVQ (Learning Vector Quantization).

- Testar a metodologia desenvolvida neste trabalho com outros valores de 'tamanho da janela' $(\beta)$ do algoritmo de extração de atributos, assim como efetuar testes adicionais utilizando outros atributos.

- Avaliar a utilização de outros métodos para a redução da dimensionalidade do conjunto de dados, tais como SVM (Support Vector Machines) e PCA (Principal Component Analysis).

- Expandir o tamanho da rede (aumentar a quantidade de equipamentos $I O$ Controller, IO-Supervisor e IO-Devices) e verificar o desempenho do sistema de detecção proposto.

- Validar a metodologia através da utilização de um conjunto de dados obtidos de uma rede submetida a outros tipos de anomalias/ataques não consideradas neste trabalho.

- Testar a metodologia desenvolvida com dados provenientes de uma rede com PROFIsafe e/ou com comunicação IRT. 
Dentre os futuros trabalhos que poderão ser desenvolvidos, correlacionados aos temas focados nessa Dissertação, pontuam-se os seguintes:

- Utilizar outras técnicas do campo da Inteligência Computacional para detecção de intrusão tais como: Sistemas Imunológicos Artificiais, Algoritmos Genéticos, Regras de Associação e Lógica Nebulosa (fuzzy).

- Aplicar outras técnicas do campo da Estatística para a identificação de intrusão, tais como as técnicas de mineração de dados: detecção de outliers e cadeia de Markov e tratamento de sinais como as transformadas Wavelets.

- Avaliar a utilização de um sistema adaptativo para cálculo do melhor parâmetro $\beta$ a ser utilizado no processo de extração de atributos, tais como a utilização de sistemas híbridos: Neuro-Fuzzy, Fuzzy-Genético e NeuroGenético.

- Desenvolver uma ferramenta de software que incorpore essa metodologia para análise em tempo real (online) do tráfego da rede e integrá-lo nas ferramentas dedicadas de análise de rede tais como Wireshark (Wireshark, 2015), o Netilities (NETILITIES - PROFINET diagnostics and engineering tool, 2015).

- Implementação de um equipamento eletrônico (appliance) para aquisição online do tráfego da rede, extração dos atributos e identificação das anomalias em um único equipamento dedicado a essa tarefa. 


\section{Referências Bibliográficas}

ABDOLLAH, M. F. et al. Revealing the Influence of Feature Selection for Fast Attack Detection. International Journal of Computer Science and Network Security (IJCSNS), Skudai Johor, Malasia, v. 8, n. 8, p. 107-115, 2008. Disponível em: <http://paper.ijcsns.org/07_book/200808/20080816.pdf>. Acesso em: Jan 2015.

AKERBERG, J. et al. Integration of WirelessHART networks in Distributed Control Systems using PROFINET IO. 8th IEEE International Conference on Industrial Informatics (INDIN), Jul 2010. Disponível em: $<$ http://ieeexplore.ieee.org/stamp/stamp.jsp?tp=\&arnumber=5549444\&isnumber=55493 $88>$.

AKERBERG, J.; BJORKMAN, M. Exploring Network Security in PROFIsafe. Computer Safety, Reliability, and Security Lecture Notes in Computer Science, v. 5775, p. 67-80, 2009a. Disponível em: <http://link.springer.com/chapter/10.1007\%2F978-3-642-04468-7_7>. Acesso em: 10 Out 2014.

AKERBERG, J.; BJORKMAN, M. Exploring Security in PROFINET IO. 33rd Annual IEEE International Computer Software and Applications Conference, 2009. COMPSAC '09, Jul 2009b. 406-412. Disponível em: $<\mathrm{http}$ ://ieeexplore.ieee.org/stamp/stamp.jsp?tp=\&arnumber=5254232\&isnumber $=52541$ 61>. Acesso em: 10 Out 2014.

AKERBERG, J.; BJORKMAN, M. Introducing Security Modules in Profinet IO. IEEE Conference on Emerging Technologies \& Factory Automation, 2009. ETFA 2009., Set 2009c. 1,8,22-25. Disponível em: $<$ http://ieeexplore.ieee.org/stamp/stamp.jsp?tp=\&arnumber=5347205\&isnumber=53469 87>. Acesso em: 10 Dez 2014.

ANDERSON, J. P. Computer security threat monitoring and surveillance, 1980. Disponível em: <http://csrc.nist.gov/publications/history/ande80.pdf>. Acesso em: 10 Out 2014.

BARFORD, P. et al. A Signal Analysis of Network Traffic Anomalies. IN PROCEEDINGS OF ACM SIGCOMM INTERNET MEASUREMENT WORKSHOP 2002, 2002. 12.2 Disponível em: <http://pages.cs.wisc.edu/ pb/paper_imw_02.pdf>. Acesso em: 27 Jan 2015.

BARFORD, P.; PLONKA, D. Characteristics of Network Traffic Flow Anomalies. ACM SIGCOMM INTERNET MEASUREMENT WORKSHOP. San Francisco, CA: NY: ACM Press. 2001. p. 69-73.

BAUD, M.; FELSER, M. Profinet IO-Device Emulator based on the Man-in-the-middle Attack. ETFA '06. IEEE Conference on Emerging Technologies and Factory Automation, 2006, Set 2006. Disponível em: $<$ http://ieeexplore.ieee.org/stamp/stamp.jsp?tp=\&arnumber=4178343\&isnumber $=41781$ $71>$.

BERTHOLDO, L. M.; ANDREOLI, A. V.; TAROUCO, L. M. R. Compreendendo Ataques Denial of Services. UFRGS. Porto Alegre, RS. 2003. 
CERT - Estatísticas do CERT.br - Incidências. CERT - Centro de Estudos, Resposta e Tratamento de Incidentes de Segurança no Brasil, 2015. Disponível em: <http://www.cert.br/stats/incidentes/\#2013>. Acesso em: 27 Jan 2015.

CHOU, T. S.; YEN, K. K.; LUO, J. Network Intrusion Detection Design Using Feature Selection of Soft Computing Paradigms. International Journal of Computational Intelligence, v. 4, n. 3, p. 196-208, Jan 2008. Disponível em: $<$ http://citeseerx.ist.psu.edu/viewdoc/download?doi=10.1.1.105.5592\&rep=rep1\&type= pdf>. Acesso em: 25 Jan 2015.

CISCO. Internet Protocol Security (IPSec). In: MANSON, A. Cisco Secure Virtual Private Networks. 1. ed. [S.1.]: Cisco Press, 2002. Cap. 2, p. 416. Disponível em: <http://www.ciscopress.com/articles/article.asp? $\mathrm{p}=24833 \&$ seqNum=3>. Acesso em: 22 Jan 2015.

CISCO. Cut-Through and Store-and-Forward Ethernet Switching for Low-Latency Environments, 2008. Disponível em: $<$ http://www.cisco.com/c/en/us/products/collateral/switches/nexus-5020switch/white_paper_c11-465436.html>. Acesso em: 10 Out 2014.

CISCO. IPv4 Multicast IGMP Snooping, 2008. Disponível em: $<$ http://www.cisco.com/c/en/us/td/docs/switches/lan/catalyst6500/ios/12-

2SY/configuration/guide/sy_swcg/ipv4_igmp_snooping.html>. Acesso em: 20 jan. 2015.

CISCO. Configuring ACLs. Cisco Nexus 5000 Series NX-OS Software Configuration Guide, 2014. Disponível em: $<$ http://www.cisco.com/c/en/us/td/docs/switches/datacenter/nexus5000/sw/configuratio n/guide/cli_rel_4_0_1a/CLIConfigurationGuide/sec_ipacls.html>. Acesso em: 21 jan. 2015.

COHEN, J. Statistical power analysis for behavioral sciences. Hillsdale, NJ: Erlbaum, 1988.

DECOTIGNIE, J. D. Ethernet-Based Real-Time and Industrial Communications. Proceedings of the IEEE, 93, n. 6, Junho 2005. 1102-1117. Disponível em: $<$ http://ieeexplore.ieee.org/stamp/stamp.jsp?tp=\&arnumber=1435741\&isnumber=30937 >. Acesso em: 10 Out 2014.

DEMIRAY, S. Improving Misuse Detection with Neural Networks. Tese de Doutorado. The Graduate School of Engineering and Sciences of Izmir Institute of Technology, IZMIR, 2005.

DENNING, D. E. An Intrusion-Detection Model. IEEE Transactions on Software Engineering, Fev $1987.222-232 . \quad$ Disponível em: $<$ http://ieeexplore.ieee.org/stamp/stamp.jsp?tp=\&arnumber=1702202\&isnumber=35884 >. Acesso em: 10 Out 2014.

DUERKOP, L. et al. Towards autoconfiguration of industrial automation systems: A case study using Profinet IO. 2012 IEEE 17th Conference on Emerging Technologies \& Factory Automation (ETFA), Set 2012. Disponível em: $<$ http://ieeexplore.ieee.org/stamp/stamp.jsp?tp=\&arnumber=6489654\&isnumber=64895 $22>$. 
FERRARI, P.; FLAMMINI, A.; VITTURI, S. Response Times Evaluation of PROFINET Networks. Industrial Electronics, 2005. ISIE 2005. Proceedings of the IEEE International Symposium on, 2005. 1371-1376. Disponível em: $<$ http://ieeexplore.ieee.org/stamp/stamp.jsp?tp=\&arnumber $=1529132 \&$ isnumber $=32655$ $>$. Acesso em: 10 Out 2014.

FLAUZINO, R. A. Identificação e Localização de Faltas de Alta Impedância em Sistemas de Distribuição Baseadas em Decomposição por Componentes Ortogonais e Inferência Fuzzy. [S.1.]: [s.n.], 2007.

GHALI, N. I. Feature Selection for Effective Anomaly-Based Intrusion Detection. IJCSNS International Journal of Computer Science and Network Security, v. 9, n. 3, p. 285-289, Mar 2009. Disponível em: <http://paper.ijcsns.org/07_book/200903/20090339.pdf>. Acesso em: 28 Jan 2015.

GHOSH, A. K.; SCHWARTZBARD, A.; SCHATZ, M. Learning Program Behavior Profiles for Intrusion Detection. Proceedings of the 1st USENIX Workshop on Intrusion Detection and Network Monitoring, Santa Clara, CA, Abril 1999. 51-62. Disponível em: <https://www.usenix.org/legacy/event/detection99/full_papers/ghosh/ghosh.pdf >. Acesso em: 10 Out 2014.

GRANZER, W.; REINISCH, C.; KASTNER, W. Denial-of-service in automation systems. IEEE International Conference on Emerging Technologies and Factory Automation, 2008. ETFA 2008, Set 2008. 468-471. Disponível em: $<$ http://ieeexplore.iee.. rg/stamp/stamp.jsp?tp=\&arnumber=4638438\&isnumber $=46383$ 43>. Acesso em: 10 Dez 2014.

GUANGMIN, L. Modeling Unknown Web Attacks in Network Anomaly Detection. Third International Conference on Convergence and Hybrid Information Technology, 2008. ICCIT '08, Nov 2008. 112-116. Disponível em: $<$ http://ieeexplore.ieee.org/stamp/stamp.jsp?tp=\&arnumber $=4682223 \&$ isnumber $=46821$ 95>. Acesso em: 27 Jan 2015.

HAGAN, M. T.; MENHAJ, M. B. Training feedforward networks with the Marquardt algorithm. IEEE Transactions on Neural Networks, 5, n. 6, Nov 1994. 989-993. Disponível em: <http://ieeexplore.ieee.org/stamp/stamp.jsp?tp=\&arnumber=329697\&isnumber=7801 >. Acesso em: 10 Out 2014.

HAHN, J.; GUILLEN, D. P.; ANDERSON, T. Process Control Systems in the Chemical Industry: Safety x Security. 20th Annual CCPS International Conference, Abr 2005. Disponível em: <http://www5vip.inl.gov/technicalpublications/Documents/3169874.pdf>. Acesso em: 8 Abr 2015.

HOPFIELD, J. J. Neural Network and Physical Systems with Emergent Collective Computational Abilities. Proceedings of the National Academy do Sciences of the United States of America, v. 79, n. 8, p. 2554-2558, Abr 1982. Disponível em: <http://www.dna.caltech.edu/courses/cs191/paperscs191/Hopfield82.pdf>. Acesso em: 28 Jan 2015. 
HOST Definition. The Linux Information Project, 2005. Disponível em: <http://www.linfo.org/host.html>. Acesso em: 01 Jan 2015.

IANA.ORG - Protocol Numbers. Assigned Internet Protocol Numbers, 2015. Disponível em: <http://www.iana.org/assignments/protocol-numbers/protocolnumbers.xhtml>. Acesso em: 26 Mar 2015.

IEEE Xplore Digital Library. IEEE Xplore Digital Library, 2015. Disponível em: <http://ieeexplore.ieee.org/Xplore/home.jsp>. Acesso em: 27 Jan 2015.

IMS RESEARCH. The EMEA Market for Industrial Ethernet. [S.1.]. 2011.

INTERNATIONAL ELECTROTECHNICAL COMISSION. IEC 61784-2 Ed.2.0: industrial communication networks-profiles-part 2: additional fieldbus profiles for real-time networks based on ISO/IEC 8802 -3. International Electrotechnical Comission. Geneva. 2010.

INTERNATIONAL ELECTROTECHNICAL COMISSION. IEC 62443-2-1 Ed.1.0: Industrial communication networks - Network and system security - Part 2-1: Establishing an industrial automation and control system security program. International Electrotechnical Comission. [S.1.]. 2010. (978-2-88912-206-6).

INTERNATIONAL ELECTROTECHNICAL COMISSION. IEC 61158-2 Ed.6.0: Industrial communication networks - Fieldbus specifications - Part 2: Physical layer specification and service definition. International Electrotechnical Comission. [S.1.], p. 470. 2014. (978-2-8322-1747-4).

INTERNATIONAL ELECTROTECHNICAL COMMISSION. IEC 61784-3-3: Industrial Communication Networks - Profiles - Part 3-3: Functional Safety Fieldbuses - Aditional Specifications for CPF 3. International Electrotechnical Commission. [S.1.]. 2007.

JASPERNEITE, J.; FELD, J. PROFINET: an integration platform for heterogeneous industrial communication systems. 10th IEEE Conference on Emerging Technologies and Factory Automation, 2005. ETFA 2005, 1, Set 2005. 8,822. Disponível em: $<$ http://ieeexplore.ieee.org/stamp/stamp.jsp?tp=\&arnumber=1612610\&isnumber $=33857$ $>$. Acesso em: 10 Out 2014.

KIM, H. S. et al. Design of networks for distributed digital control systems in nuclear power plants. IntI. Topical Meeting on Nuclear Plant Instrumentation, Controls, and Human-Machine Interface Technologies (NPIC\&HMIT 2000), Washington DC, Nov 2000. Disponível em: <http://www.researchgate.net/publication/2475021_Design_Of_Networks_For_Distribu ted_Digital_Control_Systems_In_Nuclear_Power_Plants>. Acesso em: 10 Out 2014.

KIM, S. S.; REDDY, A. L. N. Statistical Techniques for Detecting Traffic Anomalies Through Packet Header Data. IEEE/ACM Transactions on Networking, v. 16, n. 3, p. 562-575, Jun 2008. Disponível em: $<$ http://ieeexplore.ieee.org/stamp/stamp.jsp?tp=\&arnumber=4460526\&isnumber $=45428$ 18>. Acesso em: 27 Jan 2015.

KIZZA, J. M. Guide to Computer Network Security. New York, NY: Springer, 2005. 
KLASEN, F.; OESTREICH, V.; VOLZ, M. Security for Ethernet Systems. Industrial Communication with Fieldbus and Ethernet. Berlin: VDE Verlag. 2010. p. 271-279.

KLEINES, H. et al. Performance Aspects of PROFINET IO. Real-Time Conference, 2007 15th IEEE-NPSS, 2007. 1-5. Disponível em: $<$ http://ieeexplore.ieee.org/stamp/stamp.jsp?tp=\&arnumber $=4382777 \&$ isnumber $=43827$ 26>. Acesso em: 2014 Out 10.

KOHAVI, R. A study of cross-validation and bootstrap for accuracy estimation and model selection. International joint Conference on artificial intelligence, 1995. 1137-1145. Disponível em: <http://www.cs.iastate.edu/ jtian/cs573/Papers/KohaviIJCAI-95.pdf >. Acesso em: 01 Jan 2015.

KRUEGEL, C.; VIGNA, G. Anomaly detection of web-based attacks. 10th ACM conference on Computer and communications security, New York, NY, USA, 2003. 251-261. Disponível em: $<$ https://www.cs.ucsb.edu/ vigna/publications/2003_kruegel_vigna_ccs03.pdf $>$. Acesso em: 27 Jan 2015.

LAKHINA, A.; CROVELlA, M.; DIOT, C. Diagnosing Network-Wide Traffic Anomalies. ACM SIGCOMM 2004 CONFERENCE ON APPLICATIONS, TECHNOLOGIES, ARCHITECTURES, AND PROTOCOLS FOR COMPUTER COMMUNICATION (ACM'2004). Portland, Oregon, USA: NY: ACM Press. 2004. p. 219-230.

LAZAREVIC, A. et al. A Comparative Study of Anomaly Detection Schemes in Network Intrusion Detection. SIAM INTERNATIONAL CONFERENCE ON DATA MINING (SDM' 2003), San Francisco, CA, 2003. Disponível em: <http://wwwusers.cs.umn.edu/ aleks/MINDS/papers/siam2003.pdf>. Acesso em: 03 Mar 2015.

LEE, W.; STOLFO, S. J. Data Mining Approaches for Intrusion Detection. Proceedings of the 7th USENIX Security Symposium, San Antonio, 26 Jan 1998. Disponível em: <http://static.usenix.org/publications/library/proceedings/sec98/full_papers/lee/lee.pdf>. Acesso em: 27 Mar 2015.

LI, L.; LEE, G. DDoS attack detection and wavelets. The 12th International Conference on Computer Communications and Networks, 2003. ICCCN 2003. Proceedings, Out 2003. 421-427. Disponível em: $<$ http://ieeexplore.ieee.org/stamp/stamp.jsp?tp=\&arnumber=1284203\&isnumber=28660 >. Acesso em: 27 Jan 2015.

LINDA, O.; VOLLMER, T.; MANIC, M. Neural Network based Intrusion Detection System for critical infrastructures. IJCNN 2009 International Joint Conference on Neural Networks, Junho 2009. 1827-1834. Disponível em: $<\mathrm{http}$ ://ieeexplore.iee.. rg/stamp/stamp.jsp?tp=\&arnumber $=5178592 \&$ isnumber $=51785$ 57>. Acesso em: 10 Out 2014.

LIU, T. et al. Method for network anomaly detection based on Bayesian statistical model with time slicing. 7th World Congress on Intelligent Control and Automation, 2008, Jun 2008. 3359-3362. Disponível em: $<$ http://ieeexplore.ieee.org/stamp/stamp.jsp?tp=\&arnumber=4593458\&isnumber $=45927$ 80>. Acesso em: 27 Jan 2015. 
LONGCHUPOLE, S.; MANEERAT, N.; VARAKULSIRIPUNTH, R. Anomaly detection through packet header data. 7th International Conference on Information, Communications and Signal Processing, 2009, Dez 2009. 1,4,8-10. Disponível em: $<$ http://ieeexplore.ieee.org/stamp/stamp.jsp?tp=\&arnumber $=5397552 \&$ isnumber $=53974$ 65>. Acesso em: 20 Jan 2015.

LU, W.; TAVAllaEE, M.; GHORBANI, A. A. Detecting Network Anomalies Using Different Wavelet Basis Functions. Communication Networks and Services Research Conference, 2008, Mai 2008. 149-156. Disponível em: $<$ http://ieeexplore.ieee.org/stamp/stamp.jsp?tp=\&arnumber $=4519851 \&$ isnumber $=45198$ 16>. Acesso em: 27 Jan 2015.

LYDON, B. Cyber Attacks on Industrial Systems Increasing Rapidly. Automation.com, Nov 2012. Disponível em: $<$ http://www.automation.com/automation-news/article/cyber-attacks-on-industrialsystems-increasing-rapidly>. Acesso em: 10 Out 2014.

MAFRA, P. M. et al. POLVO-IIDS: Um Sistema de Deteç̧ão de Intrusão Inteligente Baseado em Anomalias. Brazilian Symposium on Information and Computer System Security, Gramado, RS, Set 2008. Disponível em: <http://www.lbd.dcc.ufmg.br/colecoes/sbseg/2008/005.pdf>. Acesso em: 27 Jan 2015.

MCCULLOCH, W. S.; PITTS, W. A logical calculus of the ideas immanent in nervous activity. Bulletin of Mathematical Biophysics, v. 5, n. 4, p. 115-133, 1943. Disponível em: <http://link.springer.com/article/10.1007\%2FBF02478259>. Acesso em: 01 Jan 2015.

METZ CONNECT. METZ CONNECT, 2015. Disponível em: <http://www.metzconnect.com/us>. Acesso em: 30 Jan 2015.

MINSKY, M. L.; PAPERT, S. A. Perceptrons: an introduction to computational geometry. Cambridge, MA, USA: The MIT Press, 1969.

MIYACHI, T. et al. Myth and reality on control system security revealed by Stuxnet. Proceedings of SICE Annual Conference (SICE), Set 2011. 1537-1540. Disponível em:

$<\mathrm{http}: / /$ ieeexplore.ieee.org/stamp/stamp.jsp?tp=\&arnumber=6060208\&isnumber $=60601$ 71>. Acesso em: 27 Jan 2015.

MOYNE, J. R.; TILBURY, D. M. The emergence of industrial control networks for manufacturing control, diagnostics, and safety data. Proceedings of IEEE, New York, 95, n. 1, Janeiro 2007. 29-47. Disponível em: <http://ieeexplore.ieee.org/stamp/stamp.jsp?tp=\&arnumber=4118467\&isnumber $=41184$ 53>. Acesso em: 10 Out 2014.

MUKKAMALA, S.; SUNG, A. H. A comparative study of techniques for intrusion detection. Proceedings. 15th IEEE International Conference on Tools with Artificial Intelligence, 2003. Sacramento, CA, USA: IEEE Computer Society. 2003. p. 570-577.

NETILITIES - PROFINET diagnostics and engineering tool. PROCENTEC web site, 2015. Disponível em: <http://www.procentec.com/netilities/>. Acesso em: 26 Jan 2015. 
NMAP.ORG. Nmap - Free Security Scanner for Network Exploration and Security Audits, 2014. Disponível em: <http://nmap.org/>. Acesso em: 10 Out 2014.

NORTHCUTT, S.; NOVAK, J. Network Intrusion Detection, Third Edition. $3^{\text {a }}$. ed. [S.1.]: New Riders Publishing, 2002.

OJUGO, A. A. et al. Genetic Algorithm Rule-Based Intrusion Detection System (GAIDS). Journal of Emerging Trends in Computing and Information Sciences, v. 3, n. 8, p. 1182-1194, Ago 2012. Disponível em: <http://cisjournal.org/journalofcomputing/archive/vol3no8/vol3no8_6.pdf>. Acesso em: 27 Jan 2015.

ONUT, I.-V.; GHORBANI, A. A. A Feature Classification Scheme for Network Intrusion Detection. International Journal of Network Security, v. 5, n. 1, p. 1-15, Jul 2007. Disponível em: <http://ijns.femto.com.tw/contents/ijns-v5-n1/ijns-2007-v5-n1p1-15.pdf>. Acesso em: 20 Jan 2015.

PANHONG, W. et al. A Method for HMM-Based System Calls Intrusion Detection Based on Hybrid Training Algorithm. Proceedings of the IEEE International Conference on Information and Automation, Shenzhen, Jun 2011. 339-342. Disponível em: $<$ http://ieeexplore.ieee.org/stamp/stamp.jsp?tp=\&arnumber=5949013\&isnumber=59489 53>. Acesso em: 27 Jan 2015.

PEGAIA, D. Tecnologia Profinet. [S.1.]. 2010.

PERLIN, T.; NUNES, R. C.; KOZAKEVICIUS, A. D. J. Detecção de Anomalias em Redes de Computadores através de Transformadas Wavelet. Revista Brasileira de Computação Aplicada, Passo Fundo, v. 3, n. 1, p. 02-15, Mar 2011. ISSN ISSN 21766649. Disponível em: <http://www.upf.br/seer/index.php/rbca/article/view/1313/1067>. Acesso em: 27 Jan 2015.

PNCC BURGDORF. PROFINET IO measurements of telegram sequences with Ethereal. Praga, República Tcheca. 2005.

POPP, M. Industrial communication with PROFINET. Karlsruhe: Profibus International, 2007.

POPP, M.; WEBER, K. The Rapid Way to PROFINET. [S.1.]: PROFIBUS Nutzerorganisation, 2004.

PROFIBUS INTERNATIONAL. PROFINET Design Guideline. Karlsruhe: [s.n.], 2010. Disponível em: <http://www.profibus.com/nc/download/installationguide/downloads/profinet-installation-guide/display/>. Acesso em: 10 Out 2014.

PROFIBUS INTERNATIONAL. PROFINET IO Conformance Classes Guideline for Profinet IO. Karlsruhe: [s.n.], 2011. Disponível em: $<$ http://www.profibus.com/nc/download/supplementary-documents/downloads/profinetioconformance-classes/display/>. Acesso em: 10 Out 2014.

PROFIBUS INTERNATIONAL. PROFINET application layer protocol for descentralized periphery and distributed automation. Karlsruhe: [s.n.], 2012. Disponível em: <http://www.profibus.com/download/specifications-standards/>. Acesso em: 10 Out 2014. 
PROFIBUS INTERNATIONAL. PROFINET Security Guideline. Karlsruhe: [s.n.], 2013. Disponível em: <http://www.profibus.com/nc/download/specificationsstandards/downloads/profinet-security-guideline/display/>. Acesso em: 10 Out 2014.

PROFIBUS INTERNATIONAL. Profinet Tool available free of charge. Profibus International, 2015. Disponível em: <http://www.profibus.com/newsroom/detailview/article/profinet-tools-available-free-of-charge/>. Acesso em: 10 Mar 2015.

QUAN, Q. et al. An Anomaly Intrusion Detection Method Based on PageRank Algorithm. IEEE International Conference on and IEEE Cyber, Physical and Social Computing, Green Computing and Communications (GreenCom), Ago $2013.2226-2230$. Disponível em: $<$ http://ieeexplore.ieee.org/stamp/stamp.jsp?tp=\&arnumber $=6682431 \&$ isnumber $=66820$ 13>. Acesso em: 27 Jan 2015.

ROSENBLATT, F. Principles of Neurodynamics and the Theory of Brain Mechanisms. Washington, DC: Spartan Books, 1959.

RUMELHART, D. E.; HINTON, G. E.; WILLIAMS, R. J. Learning internal representations by error propagation. In: Parallel Distributed Processing. Cambridge, MA, USA: MIT Press, v. 1, 1986. Cap. 8, p. 318-362. Disponível em: <http://psych.stanford.edu/ jlm/papers/PDP/Volume\%201/Chap8_PDP86.pdf>. Acesso em: 28 Jan 2015.

RUNDE, M.; TEBBE, C.; NIEMANN, K. Performance evaluation of an IT security layer in real-time communication. 2013 IEEE 18th Conference on Emerging Technologies \& Factory Automation (ETFA), Set 2013. Disponível em: $<$ http://ieeexplore.ieee.org/stamp/stamp.jsp?tp=\&arnumber=6648104\&isnumber $=66479$ $27>$.

RYAN, J.; LIN, M.; MIIKKULAINEN, R. Intrusion Detection with Neural Networks. ADVANCES IN NEURAL INFORMATION PROCESSING SYSTEMS, Cambridge, MA, 1998. Disponível em: <http://citeseerx.ist.psu.edu/viewdoc/summary?doi=10.1.1.31.3570>. Acesso em: 10 Out 2014.

SAMAAN, N.; KARMOUCH, A. Network anomaly diagnosis via statistical analysis and evidential reasoning. IEEE Transactions on Network and Service Management, v. $5, \quad$ n. 2 , Jun 2008. Disponível em: $<$ http://ieeexplore.ieee.org/stamp/stamp.jsp?tp=\&arnumber=4694132\&isnumber $=46941$ 31>. Acesso em: 27 Jan 2015.

SELVAKANI, S.; RAJESH, R. S. Genetic Algorithm for framing rules for Intrusion Detection. International Journal of Computer Science and Network Security, v. 7, n. 11, 2007. Disponível em: <http://paper.ijcsns.org/07_book/200711/20071144.pdf>. Acesso em: 27 Jan 2015.

SESTITO, G. S. Uma proposta metodológica para a previsão do Throughput durante a inicialização de redes Profinet através de Redes Neurais Artificiais. [S.l.]: [s.n.], 2014.

SHIREY, R. Interney Security Glossary. Faqs.org, 2000. Disponível em: <http://www.faqs.org/rfcs/rfc2828.html>. Acesso em: 27 Jan 2015. 
SHUM, J.; MALKI, H. A. Network Intrusion Detection System Using Neural Networks. Fourth International Conference on Natural Computation, 2008. 242246.

SILVA, I. N.; SPATTI, D. H.; FLAUZINO, R. A. Redes Neurais Artificiais para Engenharia e Ciências Aplicadas. São Paulo: Artliber, 2010.

SILVA, L. D. S. Uma metodologia para detecção de ataques no tráfego de redes baseada em redes neurais. Tese de Doutorado. Instituto de Pesquisas Espaciais INPE. São José dos Campos. 2008.

SILVA, L. D. S. et al. Detecting attack signatures in the real network traffic with ANNIDA. Expert Systems with Applications, Nem York, v. 34, n. 4, p. 2326-2333, Maio 2008. Disponível em: <http://www.sciencedirect.com/science/article/pii/S095741740700125X>. Acesso em: 27 Jan 2015.

SILVA, L. D. S.; SANTOS, A. F.; MONTES, A. A neural network application for attack detection in computer networks. Proceedings. 2004 IEEE International Joint Conference on Neural Networks, 2004. [S.1.]: [s.n.]. 2004. p. 1569-1574.

SITA, I. V. Building Control, Monitoring, Safety and Security Using Collaborative Systems. 2012 4th International Conference on Intelligent Networking and Collaborative Systems (INCoS), Set 2012. Disponível em: $<$ http://ieeexplore.ieee.org/stamp/stamp.jsp?tp=\&arnumber=6338002\&isnumber=63378 94>.

SOUZA, E. P.; MONTEIRO, J. A. S. ESTUDO SOBRE SISTEMA DE DETECÇÃO DE INTRUSÃO POR ANOMALIAS UMA ABORDAGEM UTLIZANDO REDES NEURAIS. 14 $^{\circ}$ Workshop de Gerência e Operação de Redes e Serviços, Recife, 2009. 84-97.

STALLINGS, W. SSL: Foundation for Web Security. The Internet Protocol Journal, San Jose, CA, v. 1, n. 1, p. 20-39, Jun 1998. Disponível em: <http://www.cisco.com/web/about/ac123/ac147/archived_issues/ipj_1-1/ipj_1-1.pdf>. Acesso em: 22 Jan 2015.

SUNG, A. H.; MUKKAMALA, S. Identifying important features for intrusion detection using support vector machines and neural networks. Proceedings. 2003 Symposium on Applications and the Internet, 2003. [S.1.]: [s.n.]. 2003. p. 209-216.

TANENBAUM, A. S. Redes de Computadores. 4a . ed. Rio de Janeiro: Elsevier, 2003.

TENABLE NETWORK SECURITY. Nessus Vulnerability Scanner, 2014. Disponível em: <http://www.tenable.com/products/nessus-vulnerability-scanner>. Acesso em: 10 Out 2014.

THOMAS, P. An Introduction to Profinet Frame Analysis using Wireshark - V1.0, 2013. Disponível em: <https://profibusgroup.files.wordpress.com/2013/01/w4-profinetframe-analysis-peter-thomas.pdf $>$. Acesso em: 10 Out 2013.

TURCATO, A. C. Diagnóstico de redes PROFINET IO utilizando software Wireshark. Saber Eletrônica, São Paulo, n. 464, p. 34-40, Out 2012. Disponível em: <http://sabereletronica.com.br/files/file/SE464_web.pdf>. Acesso em: 10 Out 2014. 
WERBOS, P. J. The Roots of Backpropagation. New York: Johns Wiley \& Sons, 1994.

WIDROW, B.; HOFF, M. E. Adaptive switching circuits. Proceedings of IRE Wescon Convention Record, 1960. 96-104. Disponível em: <http://wwwisl.stanford.edu/ widrow/papers/c1960adaptiveswitching.pdf $>$. Acesso em: 28 Jan 2015.

WIRESHARK. Wireshark.org, 2015. Disponível em: <https://www.wireshark.org/>. Acesso em: 01 Jan 2015.

YANG, D.; USYNIN, A.; HINES, J. W. Anomaly-Based Intrusion Detection for SCADA Systems. 5th Intl. Topical Meeting on Nuclear Plant Instrumentation, Control and Human Machine Interface Technologies (NPIC\&HMIT 05), Albuquerque, Nov 2006. Disponível em: <http://citeseerx.ist.psu.edu/viewdoc/summary?doi=10.1.1.102.1649>. Acesso em: 10 Out 2014.

YAO, L.; ZHITANG, L.; SHUYU, L. A Fuzzy Anomaly Detection Algorithm for IPv6. Second International Conference on Semantics, Knowledge and Grid, 2006. SKG '06, Nov 2006. 67-70. Disponível em: $<$ http://ieeexplore.ieee.org/stamp/stamp.jsp?tp=\&arnumber $=5727704 \&$ isnumber $=40238$ 45>. Acesso em: 27 Jan 2015.

ZAMAN, S.; KARRAY, F. Features Selection for Intrusion Detection Systems Based on Support Vector Machines. 6th IEEE Consumer Communications and Networking Conference, 2009. CCNC 2009, p. 1,8,10-13, Jan 2009. Disponível em: $<$ http://ieeexplore.ieee.org/stamp/stamp.jsp?tp=\&arnumber $=4784780 \& i$ isnumber $=47846$ 84>. Acesso em: 28 Jan 2015.

ZHANG, G.; PATUWO, B. E.; HU, M. Y. Forecasting with artificial neural networks: The state of the art. International Journal of Forecasting, 14, n. 1, 1 Mar 1998. 35-62. Disponível em: <http://www.sciencedirect.com/science/article/pii/S0169207097000447>. Acesso em: 01 Jan 2015.

ZHONG, S.; KHOSHGOFTAAR, T.; SELIYA, N. Clustering-based network intrusion detection. IntI. Journal of Reliability, Quality and Safety, 2007. 169-187. Disponível em: <http://www.worldscientific.com/doi/pdf/10.1142/S0218539307002568>. Acesso em: 10 Out 2014. 


\section{APÊNDICE A}

Gráficos dos atributos com $\beta=20,50$ e 100 pacotes para o Cenário 4.

$\beta=20$

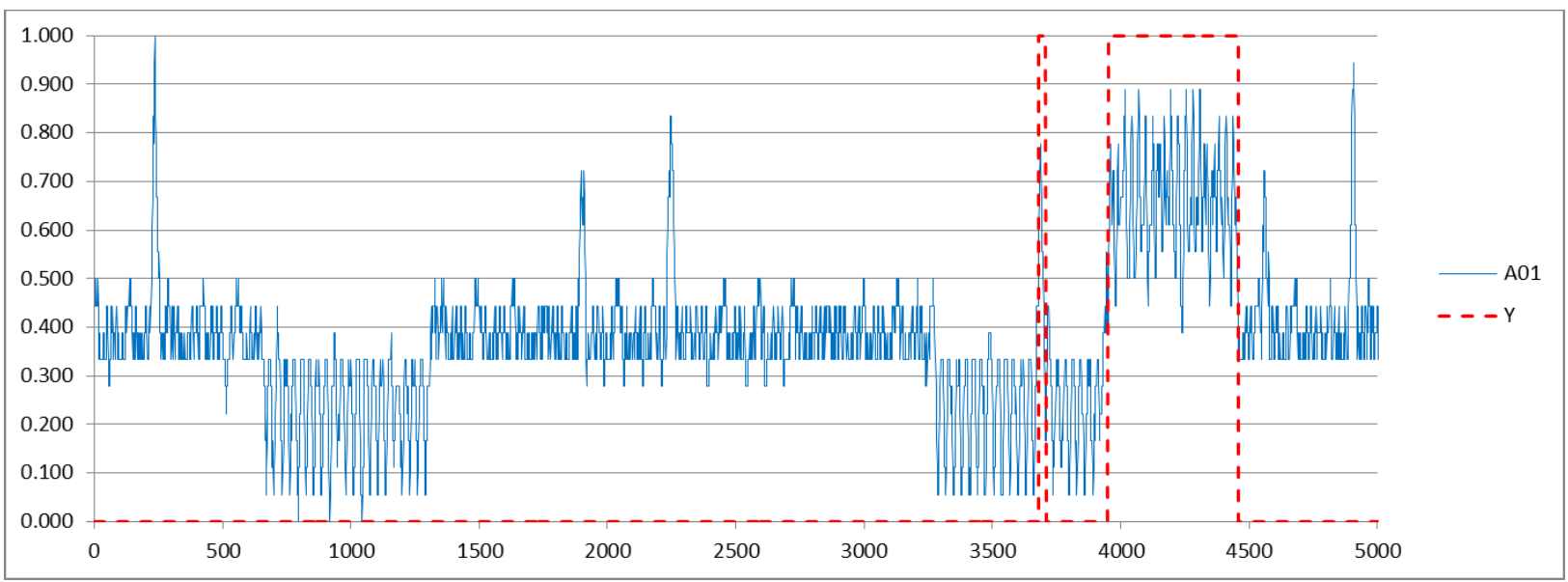

$\beta=50$

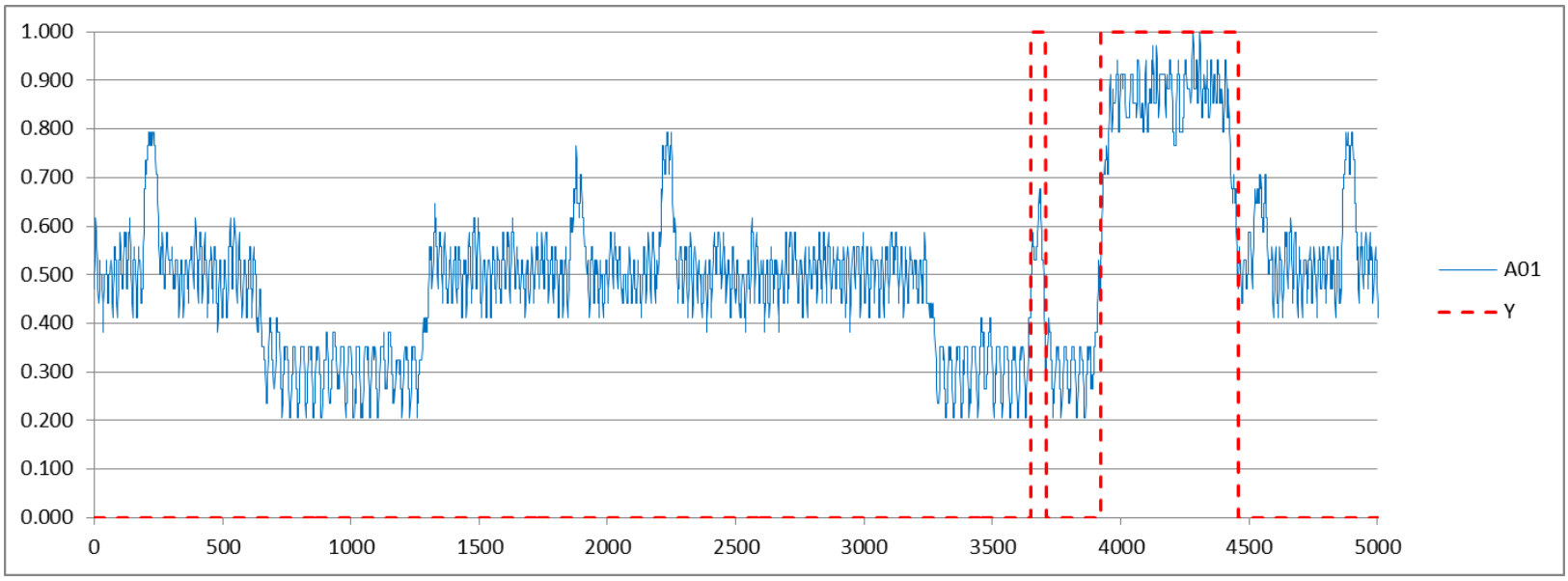

$\beta=100$

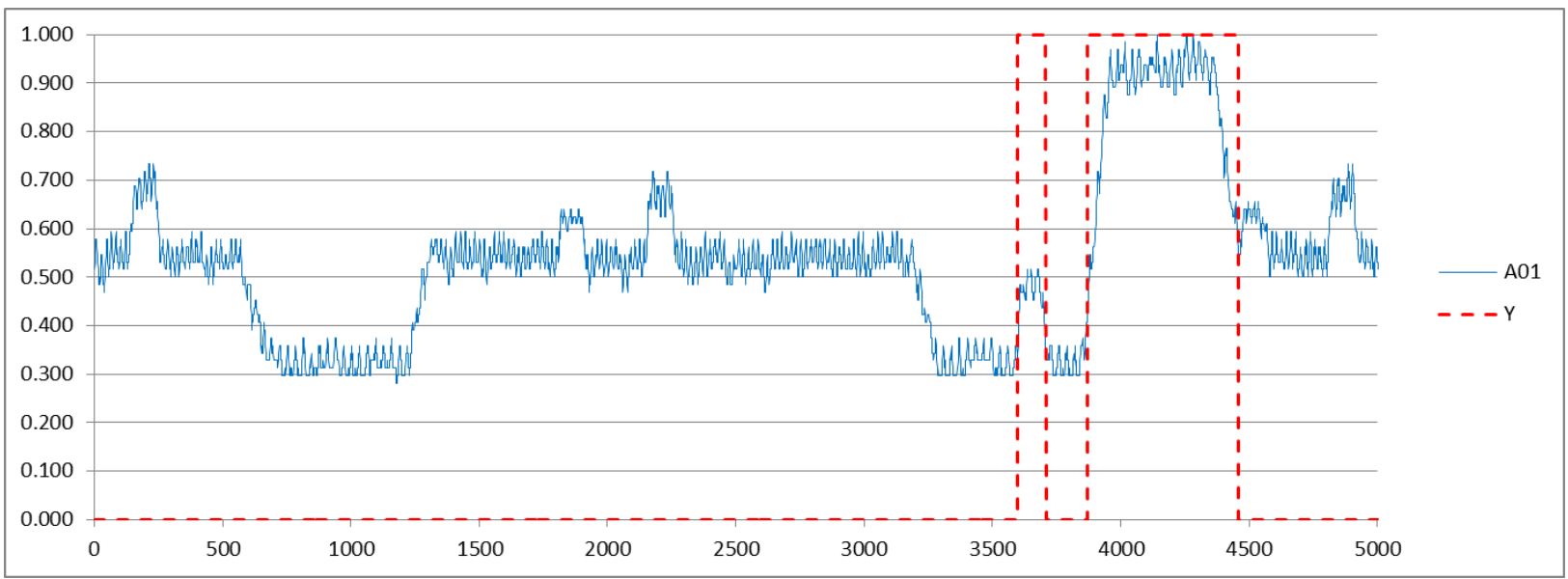

Cenário 04 - Atributo A01 
$\beta=20$

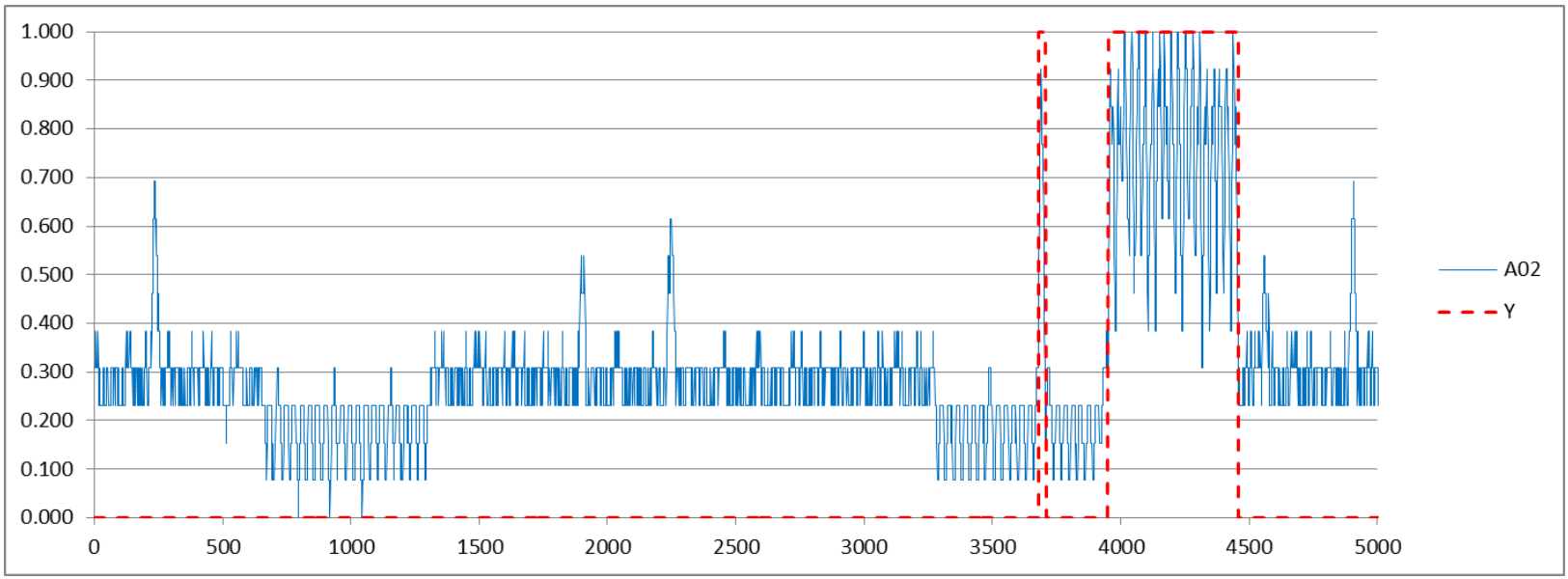

$\beta=50$

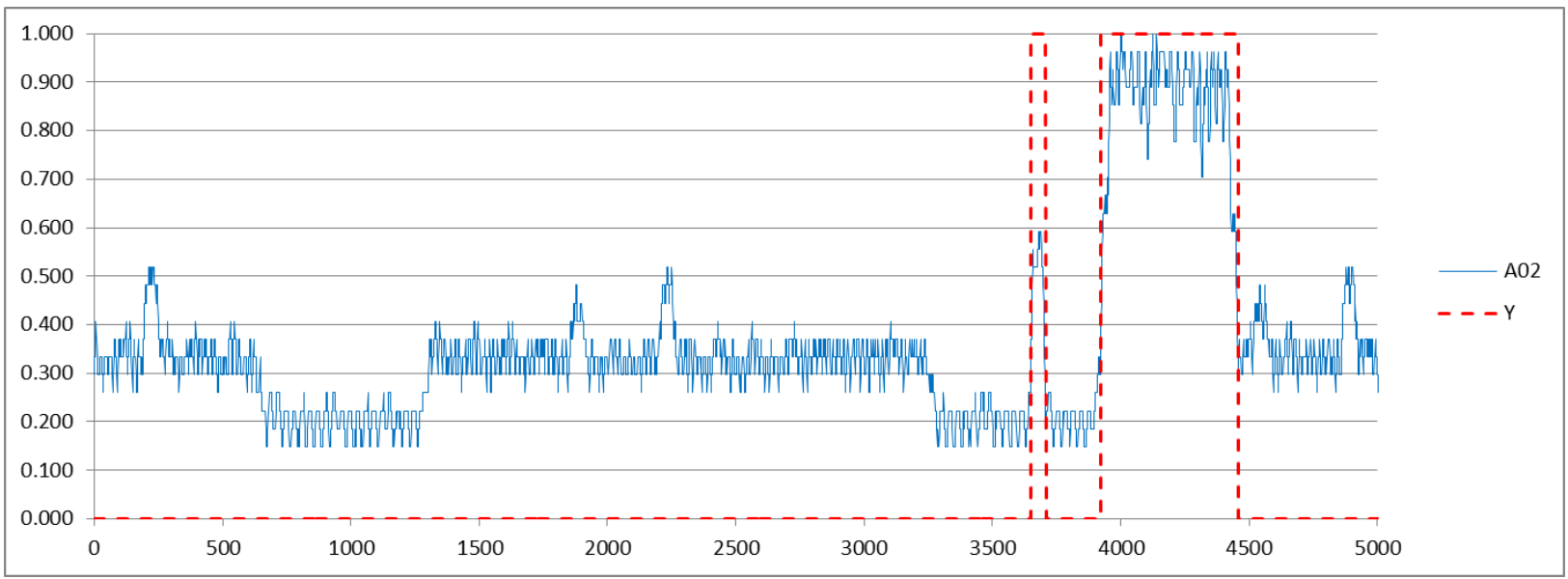

$\beta=100$

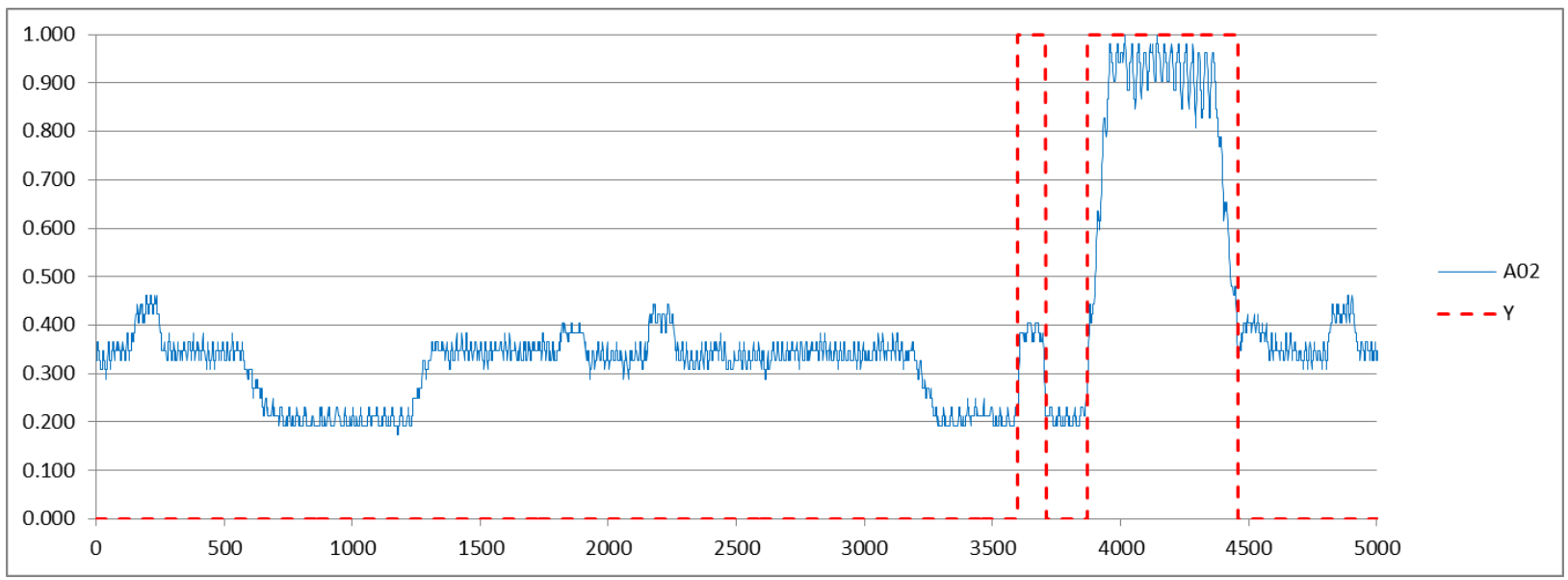

Cenário 04 - Atributo A02 
$\beta=20$

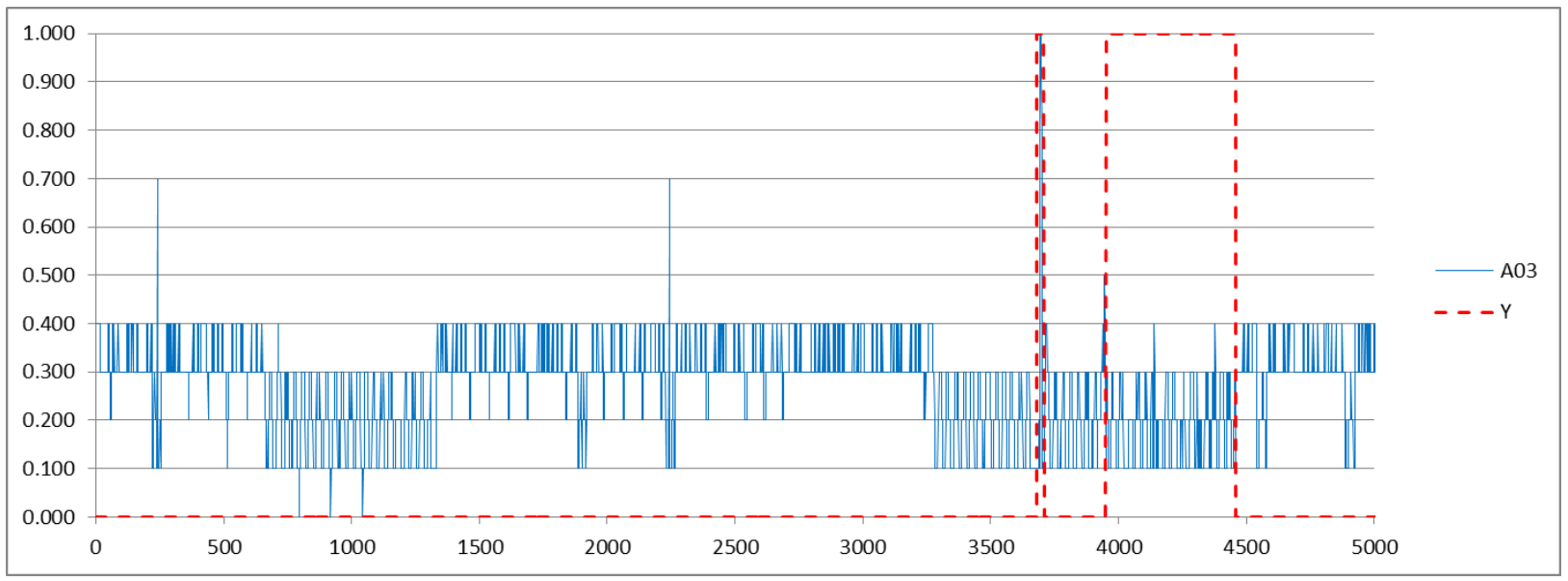

$\beta=50$

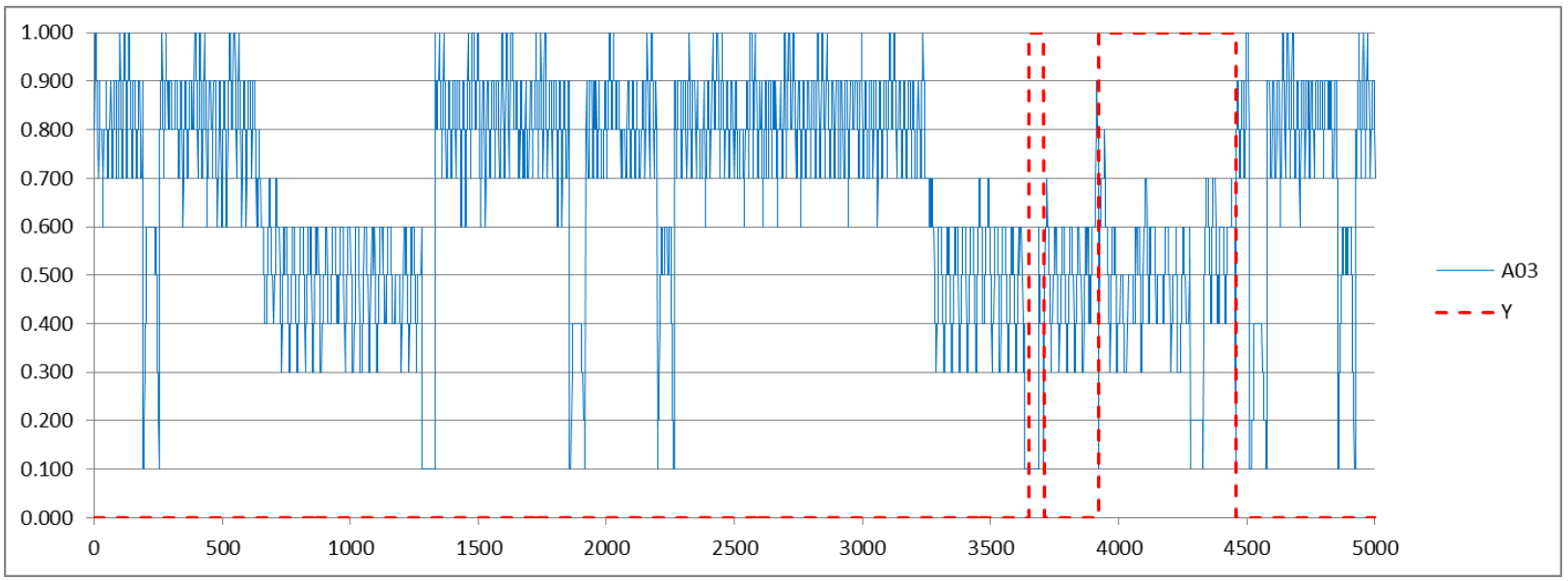

$\beta=100$

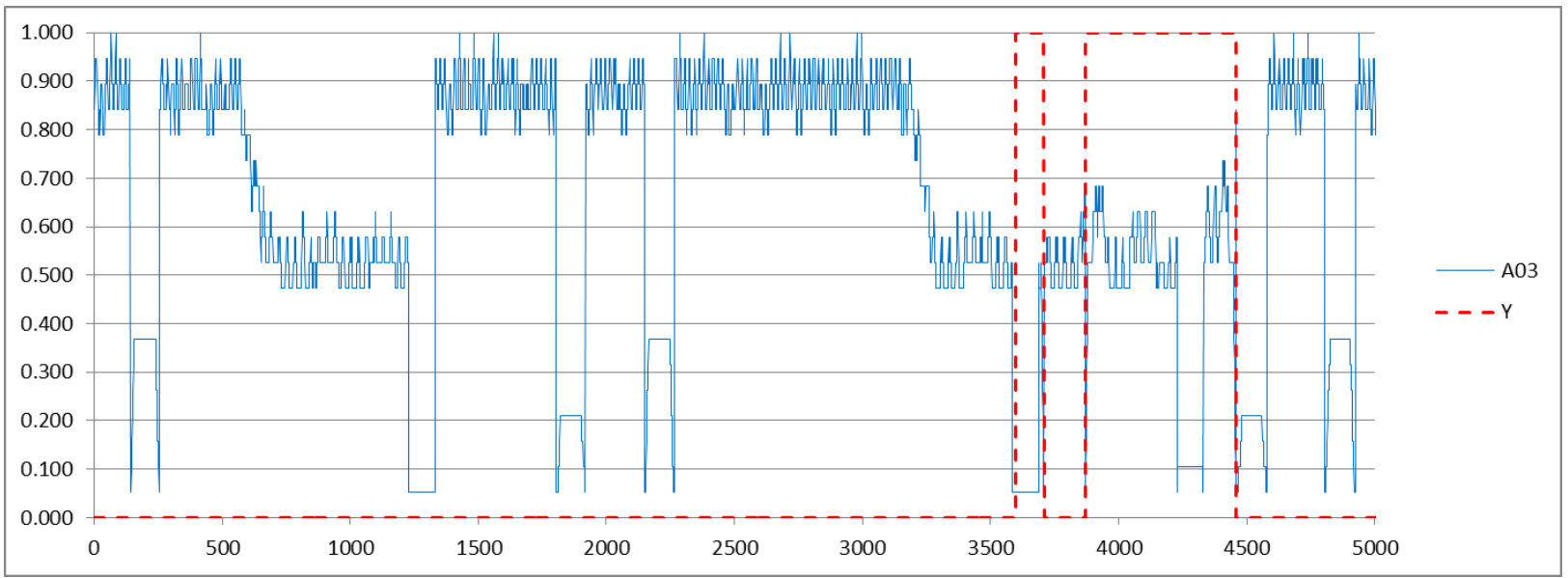

Cenário 04 - Atributo A03 
$\beta=20$

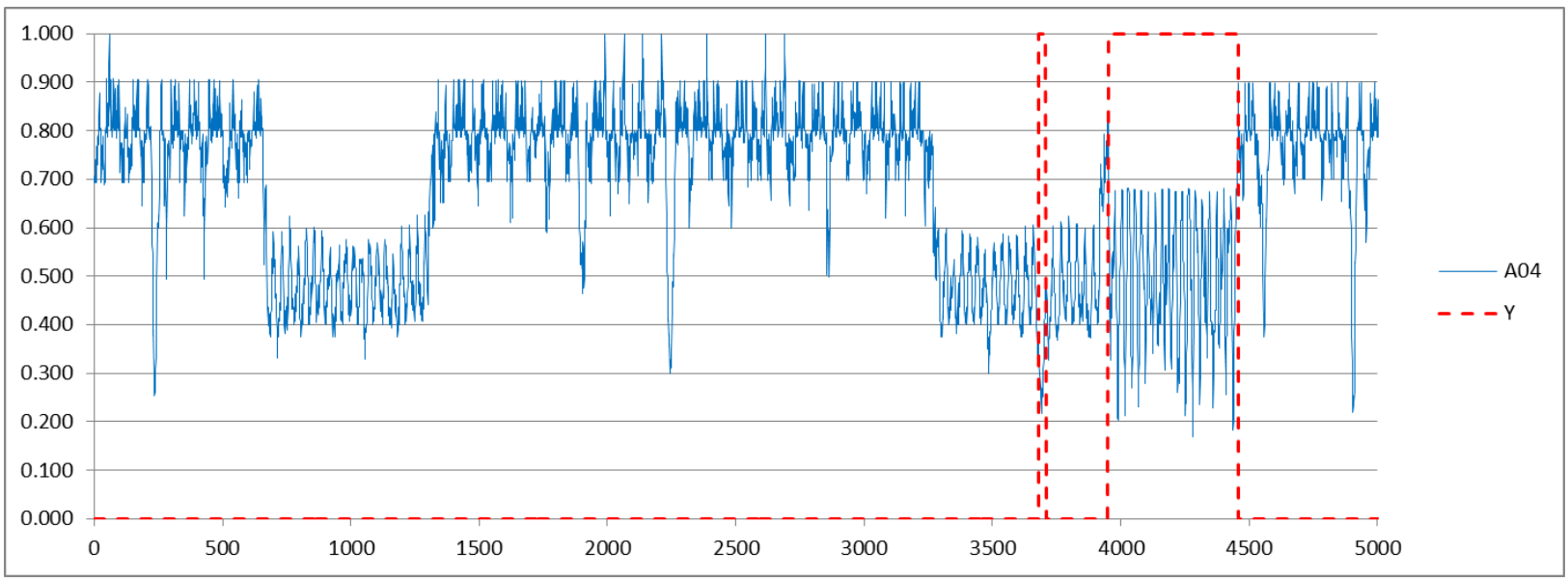

$\beta=50$

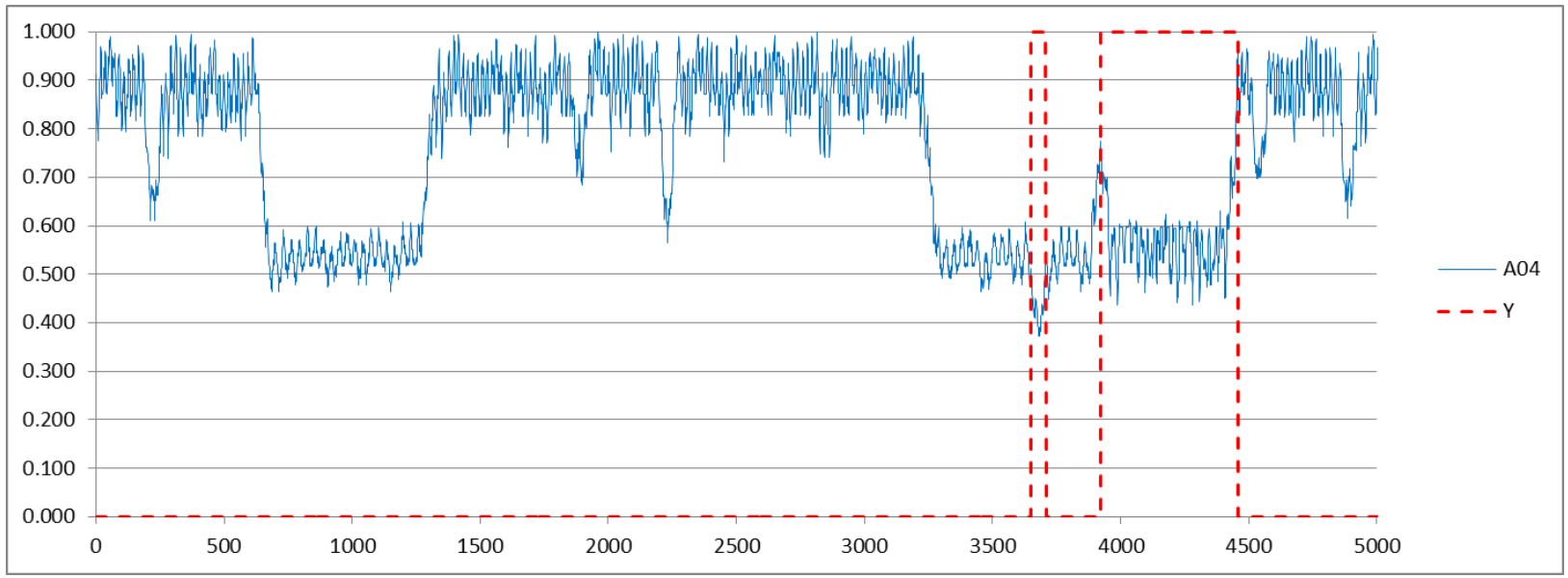

$\beta=100$

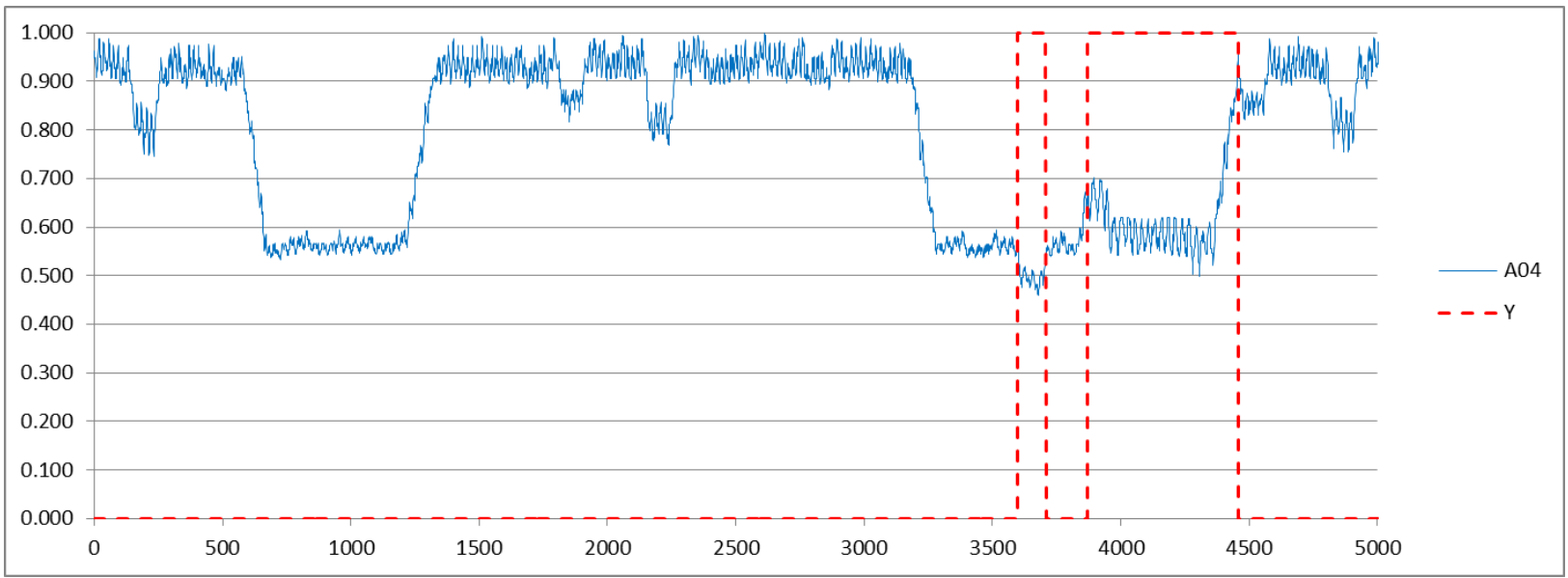

Cenário 04 - Atributo A04 
$\beta=20$

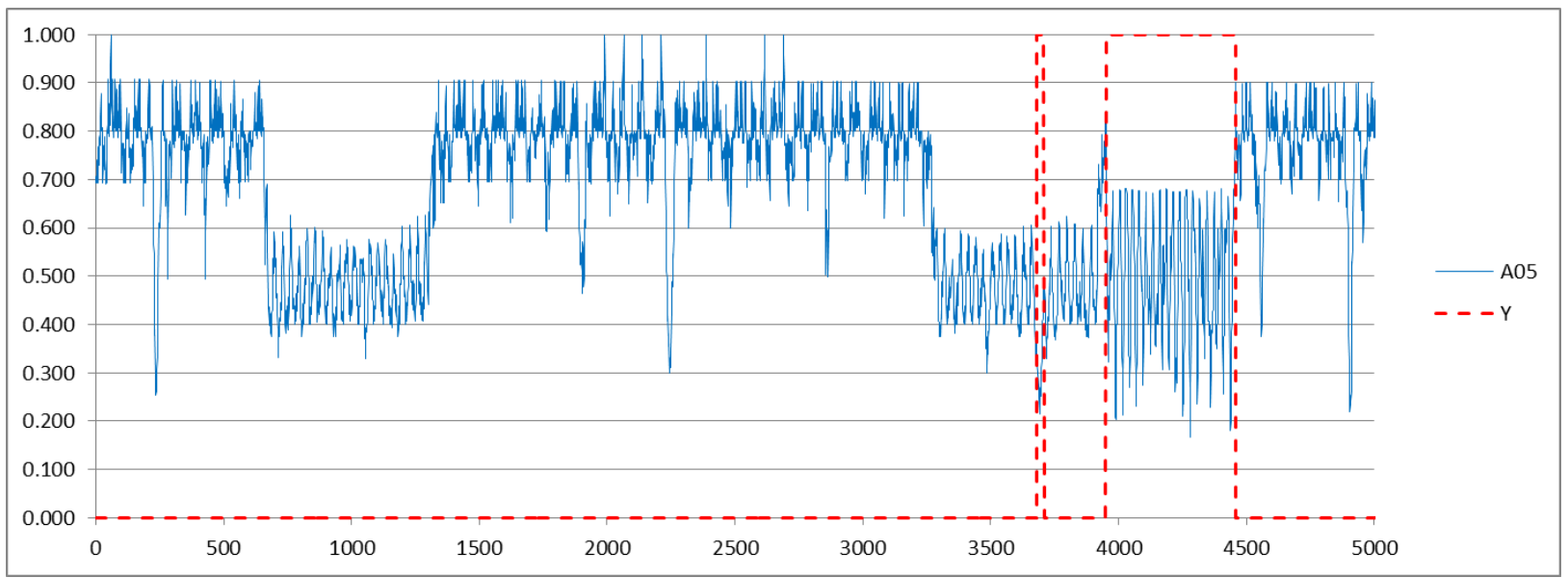

$\beta=50$

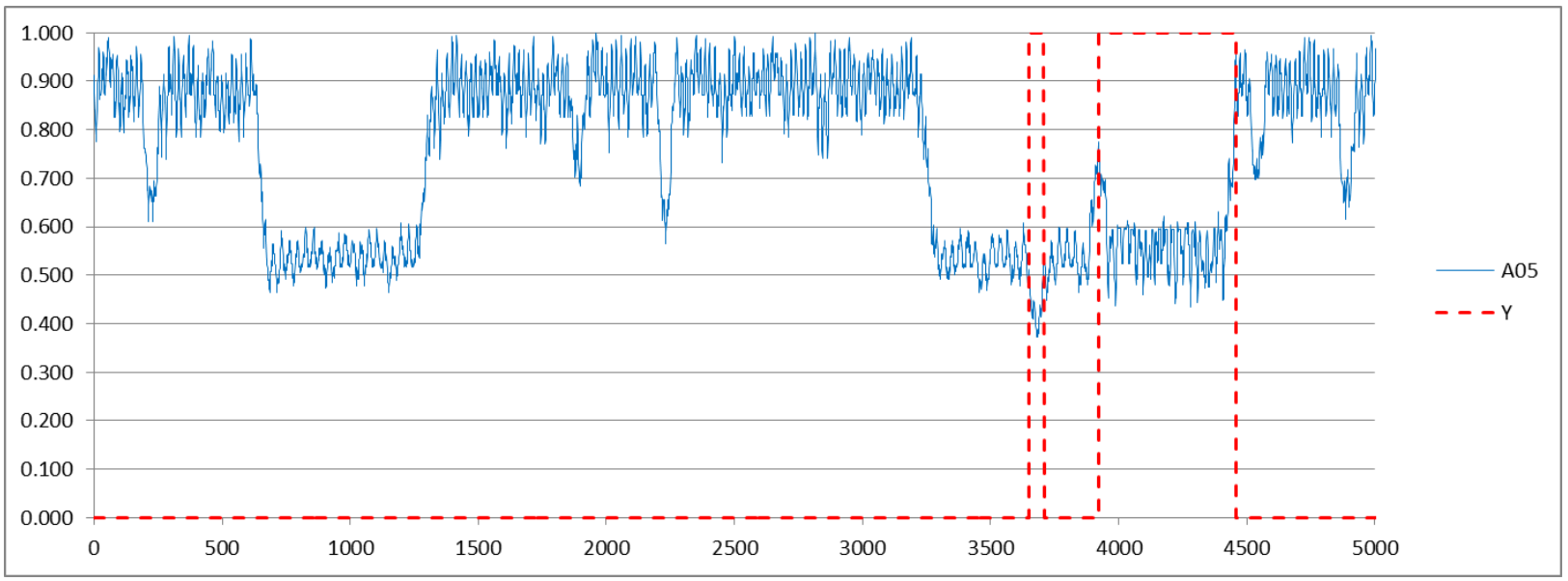

$\beta=100$

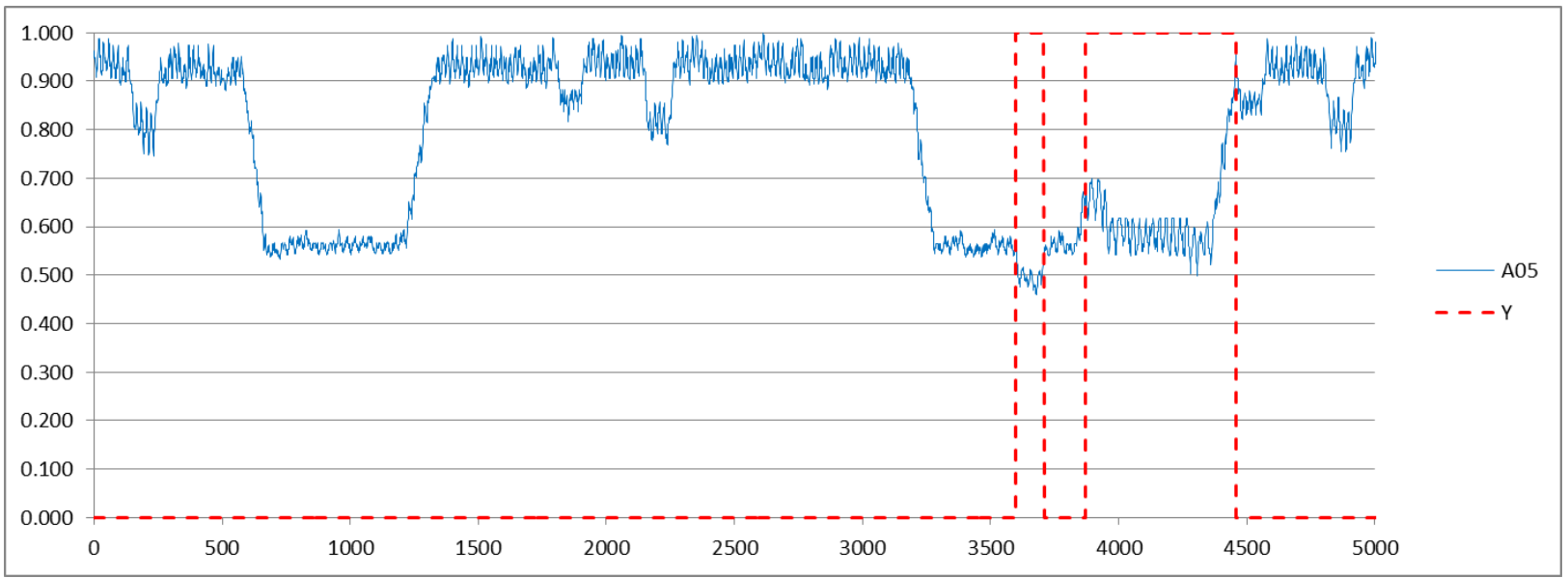

Cenário 04 - Atributo A05 
$\beta=20$

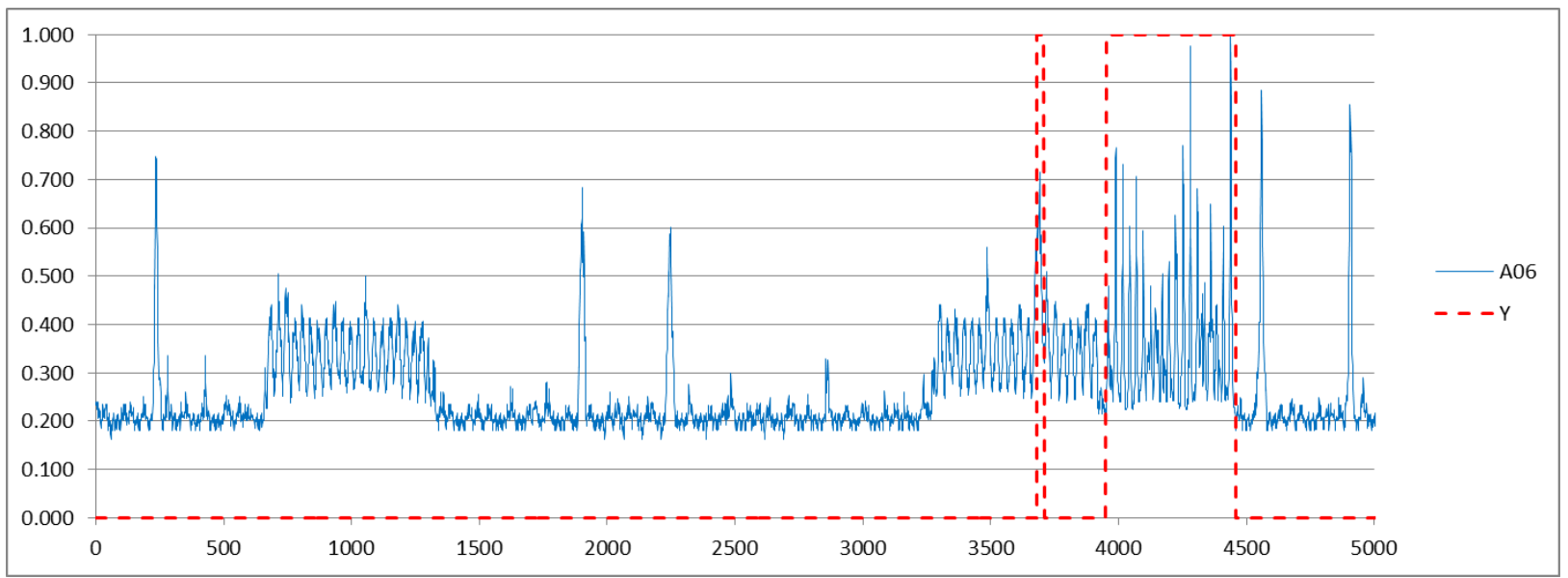

$\beta=50$

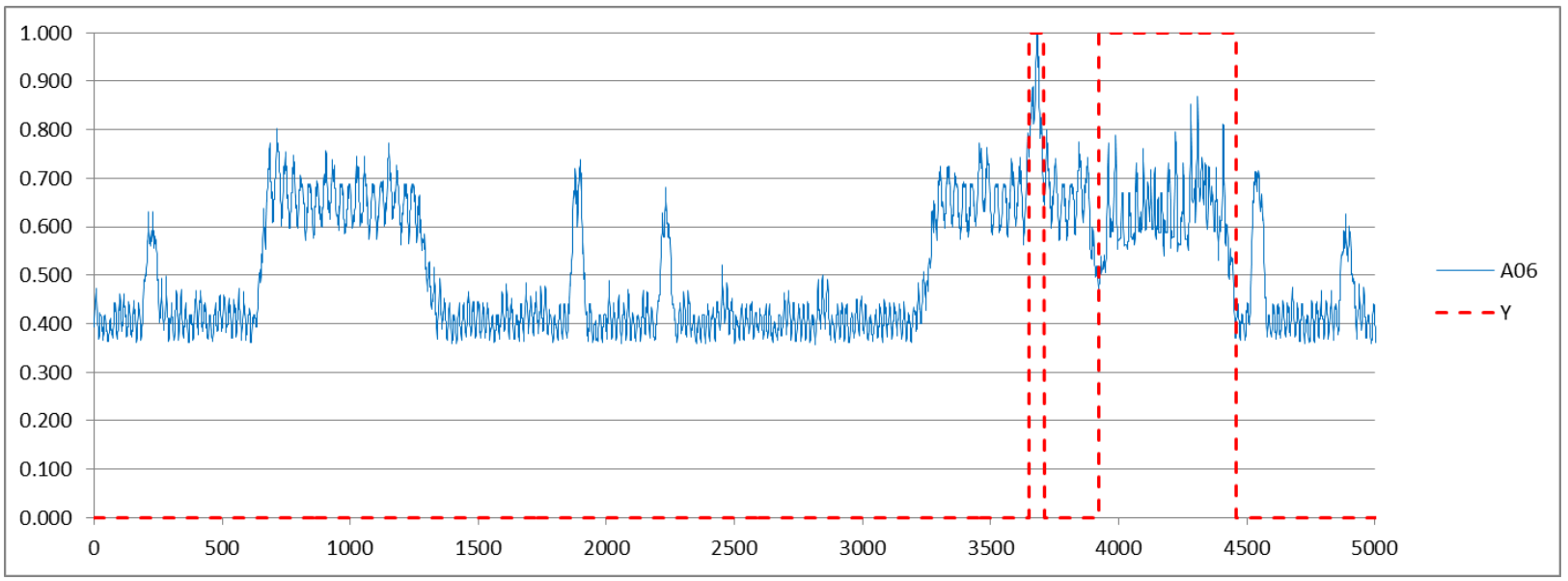

$\beta=100$

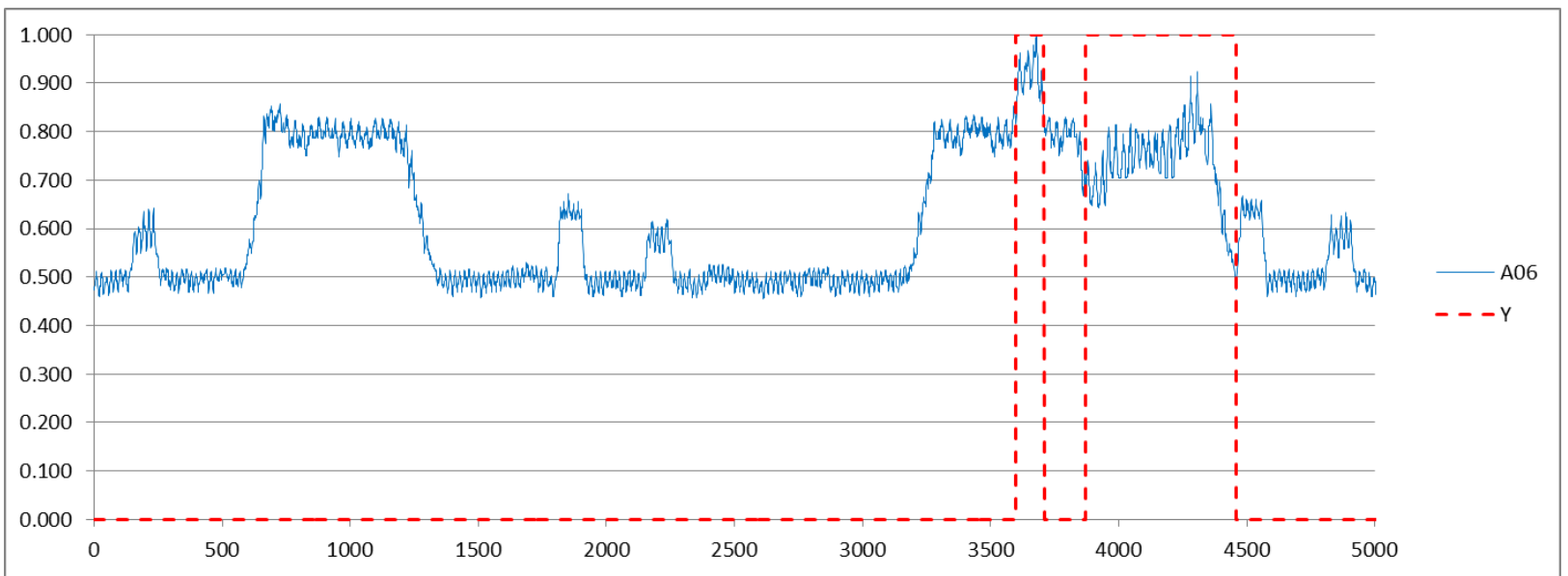

Cenário 04 - Atributo A06 
$\beta=20$

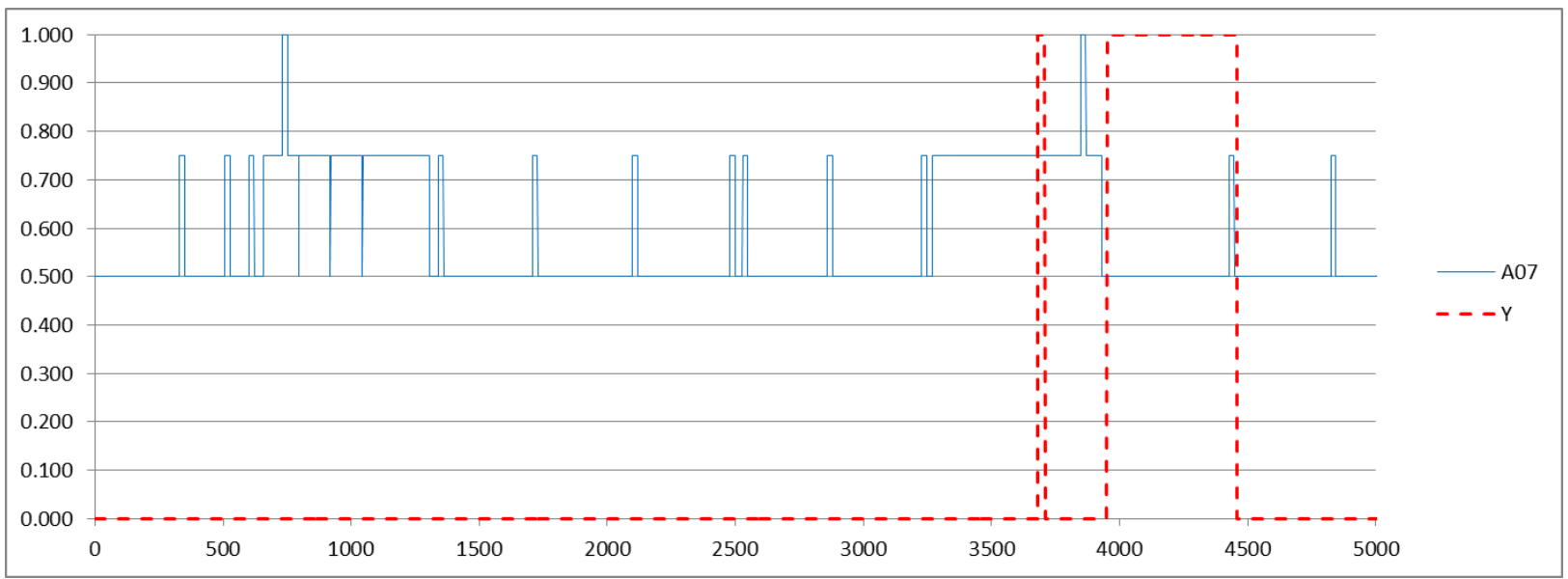

$\beta=50$

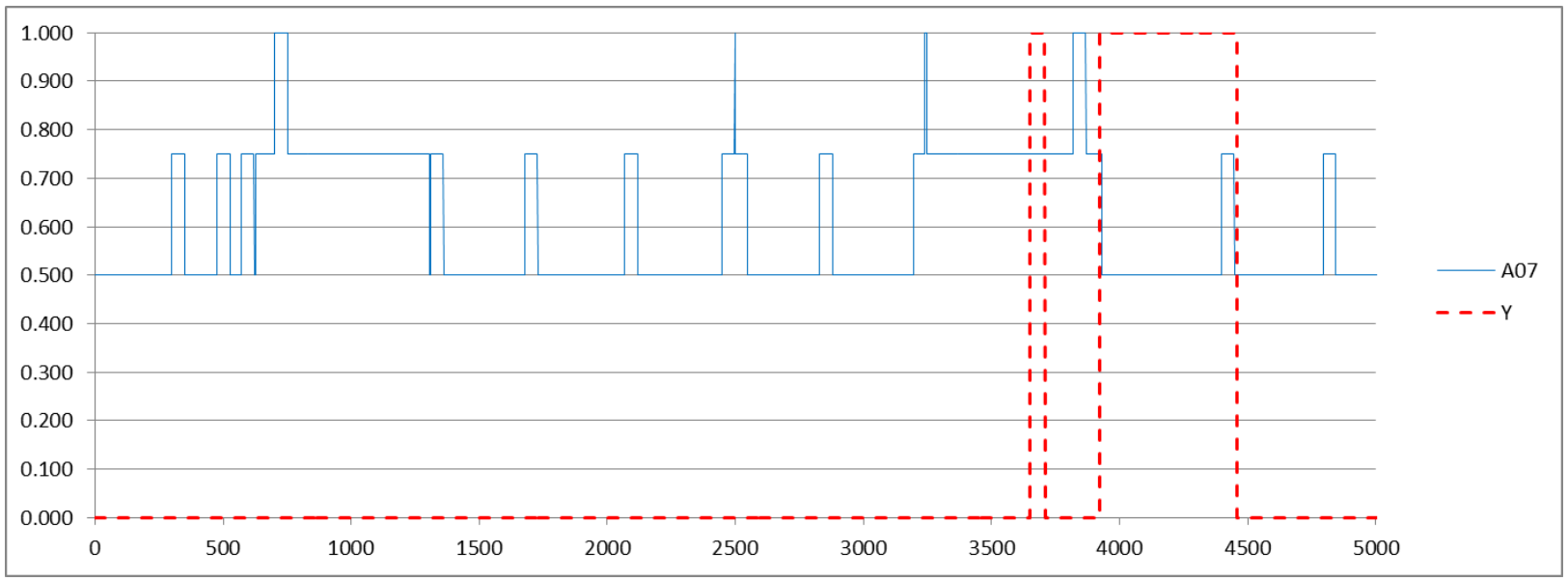

$\beta=100$

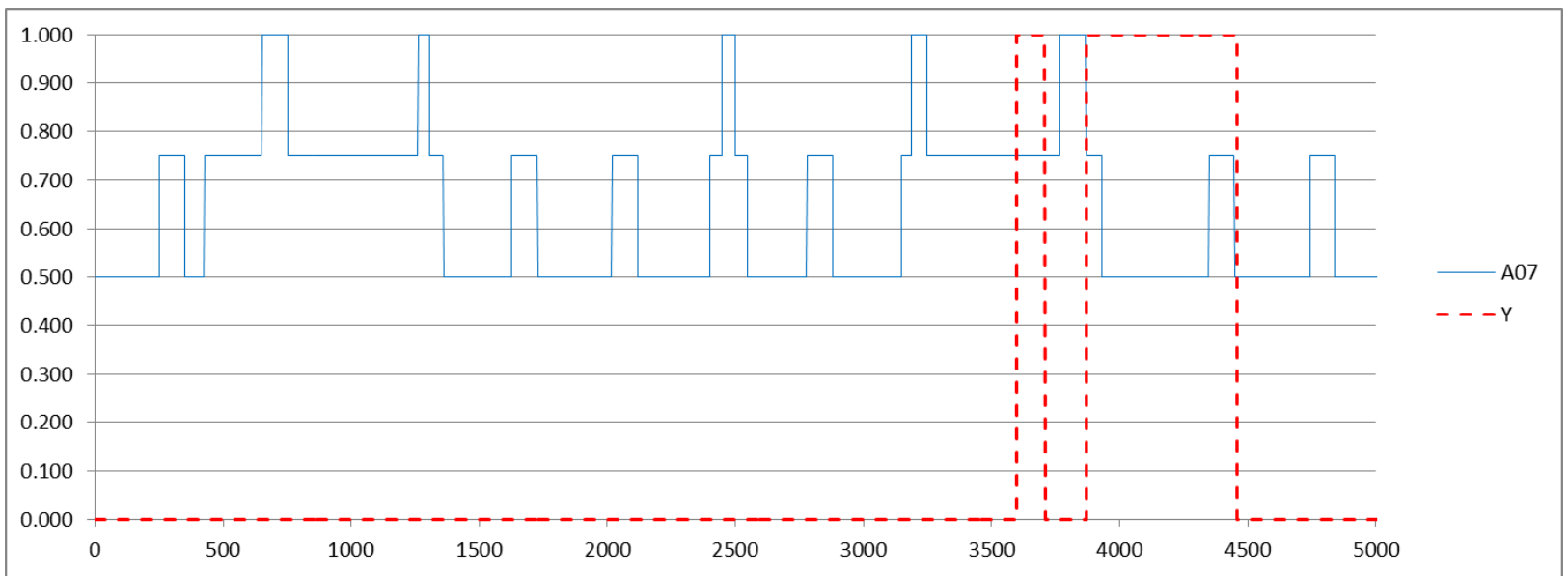

Cenário 04 - Atributo A07 
$\beta=20$

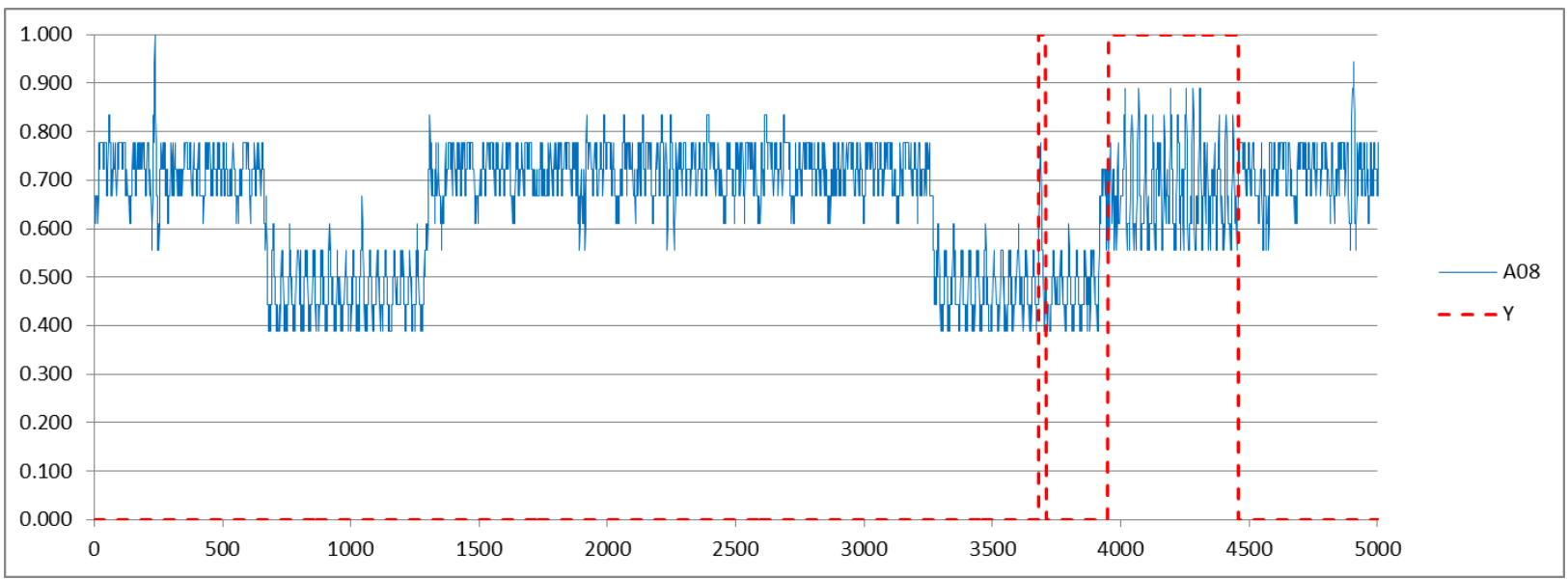

$\beta=50$

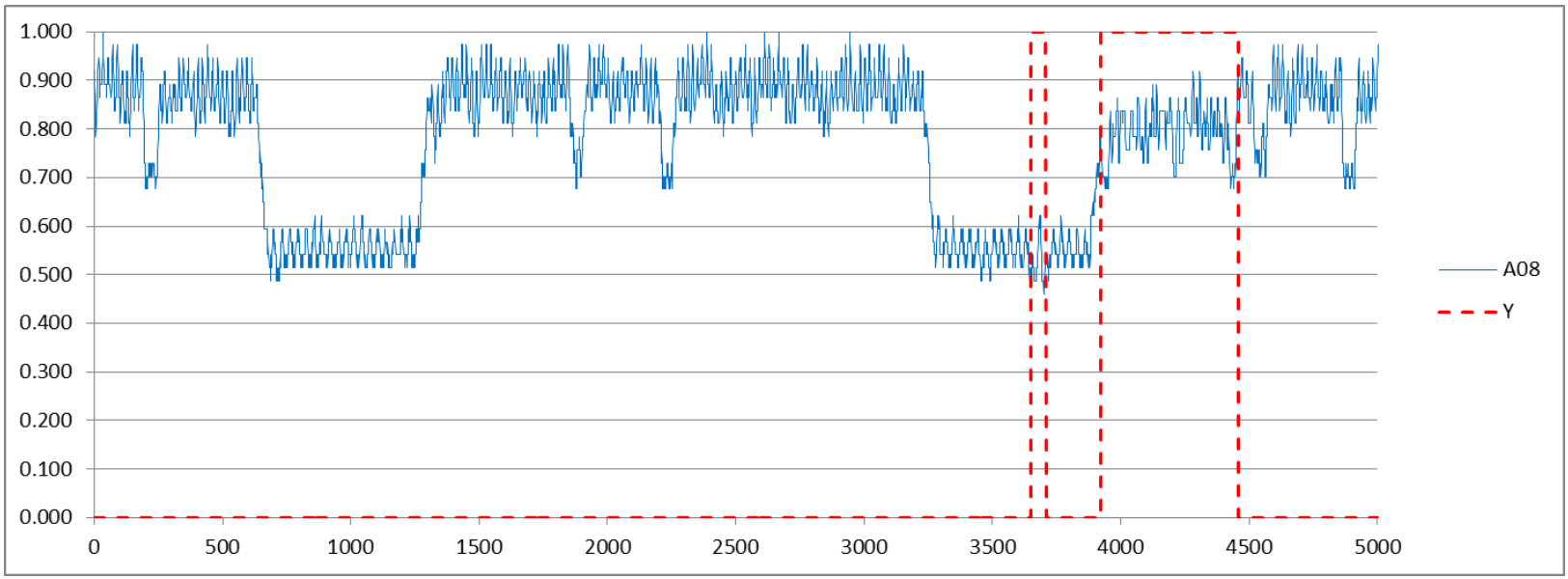

$\beta=100$

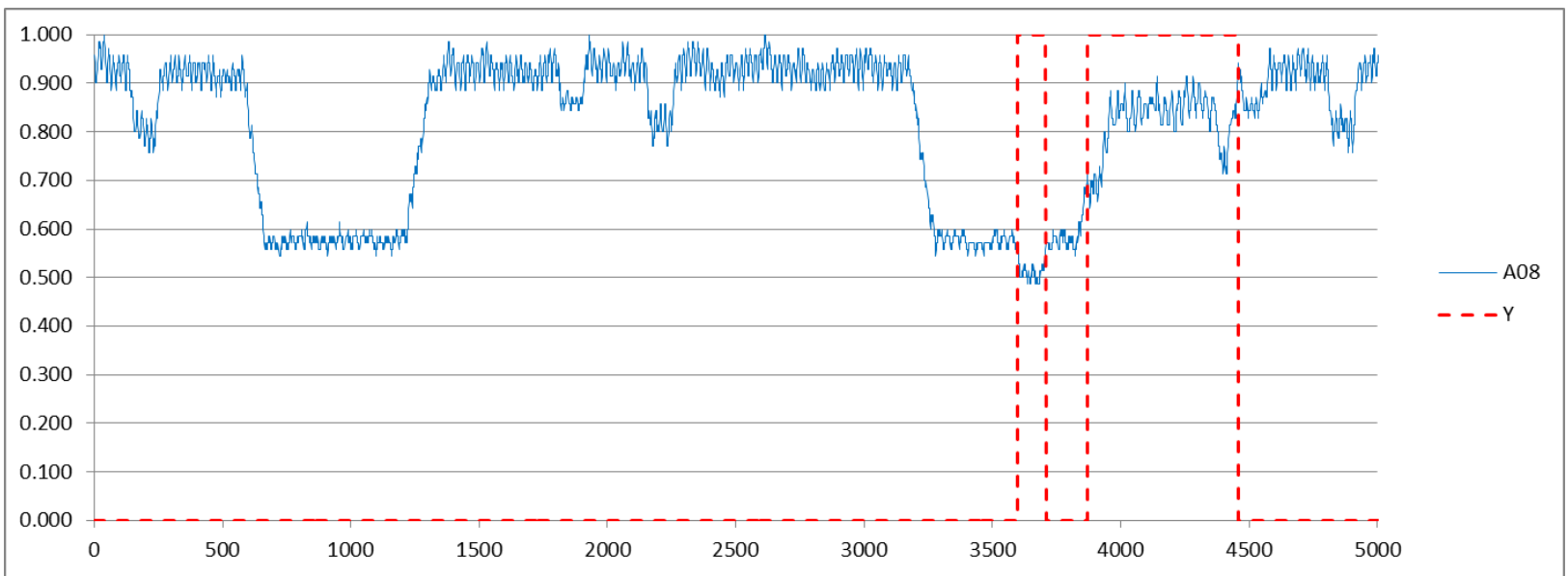

Cenário 04 - Atributo A08 
$\beta=20$

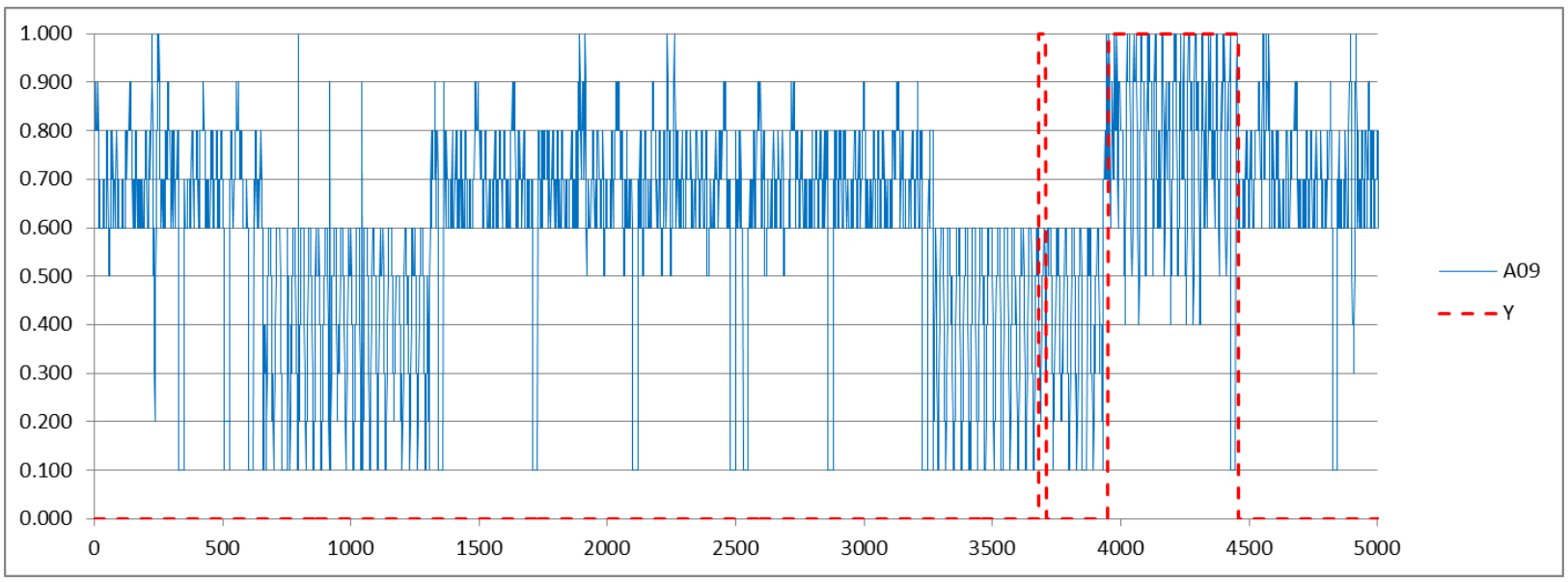

$\beta=50$

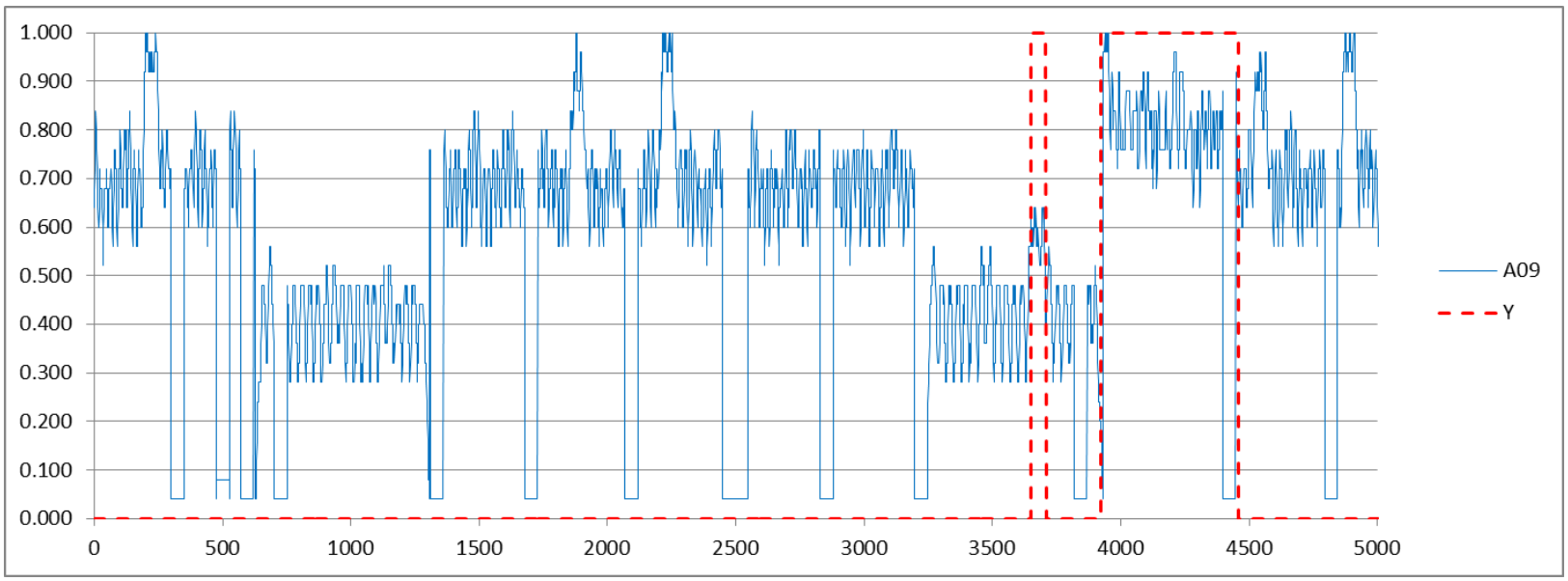

$\beta=100$

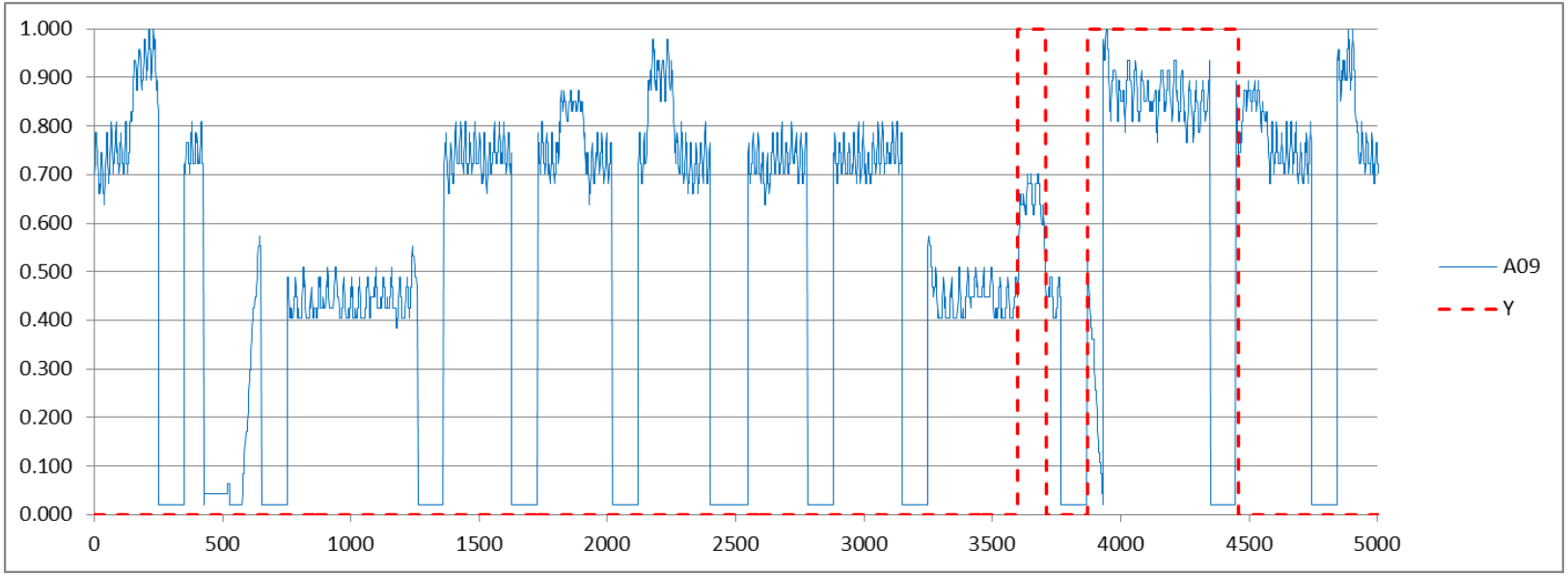

Cenário 04 - Atributo A09 
$\beta=20$

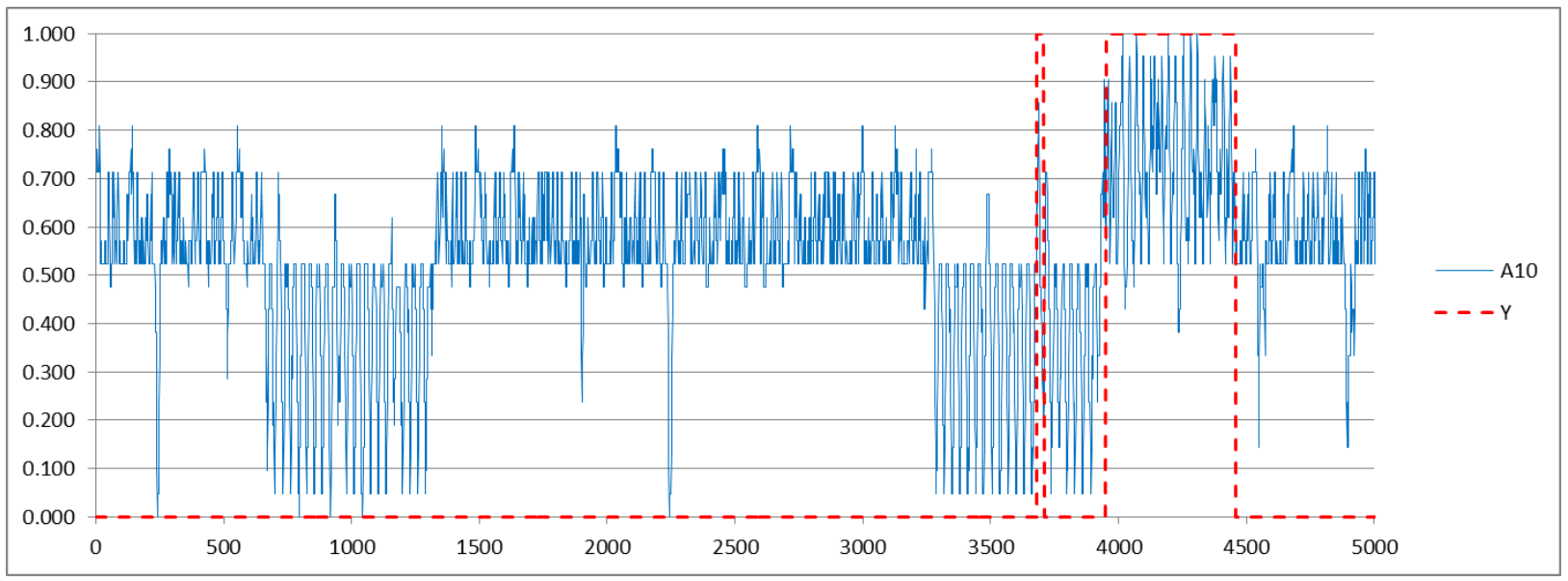

$\beta=50$

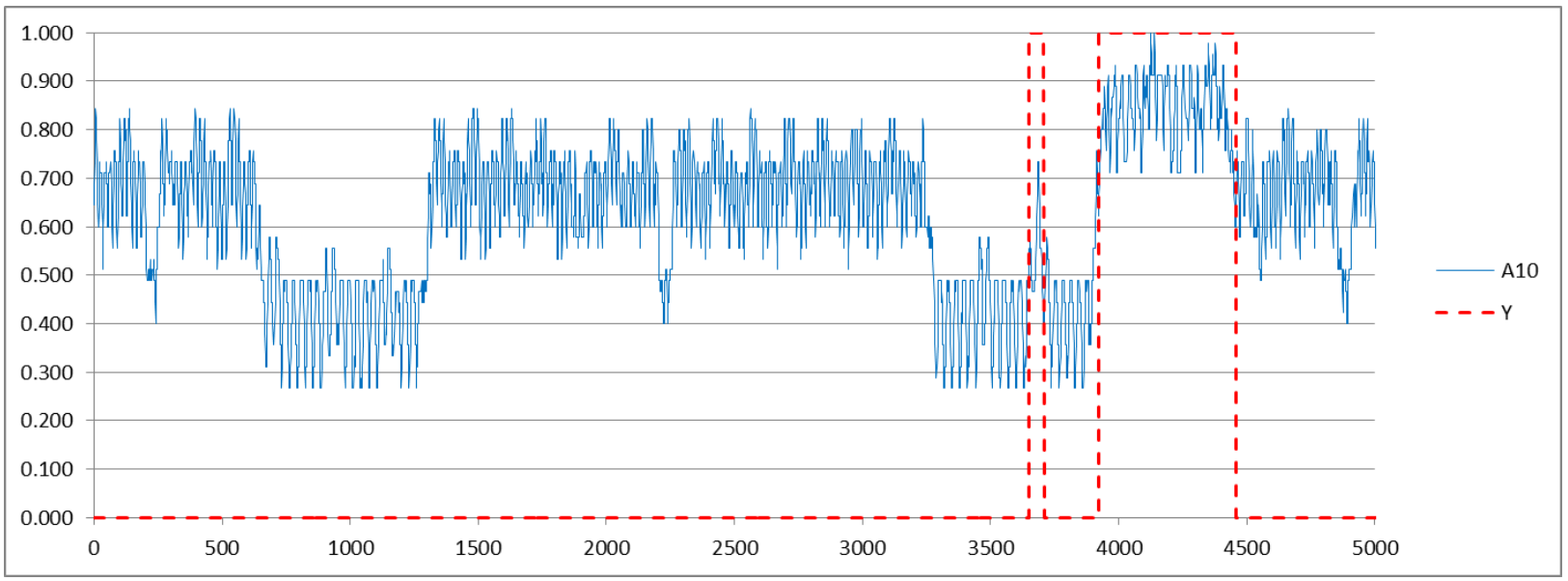

$\beta=100$

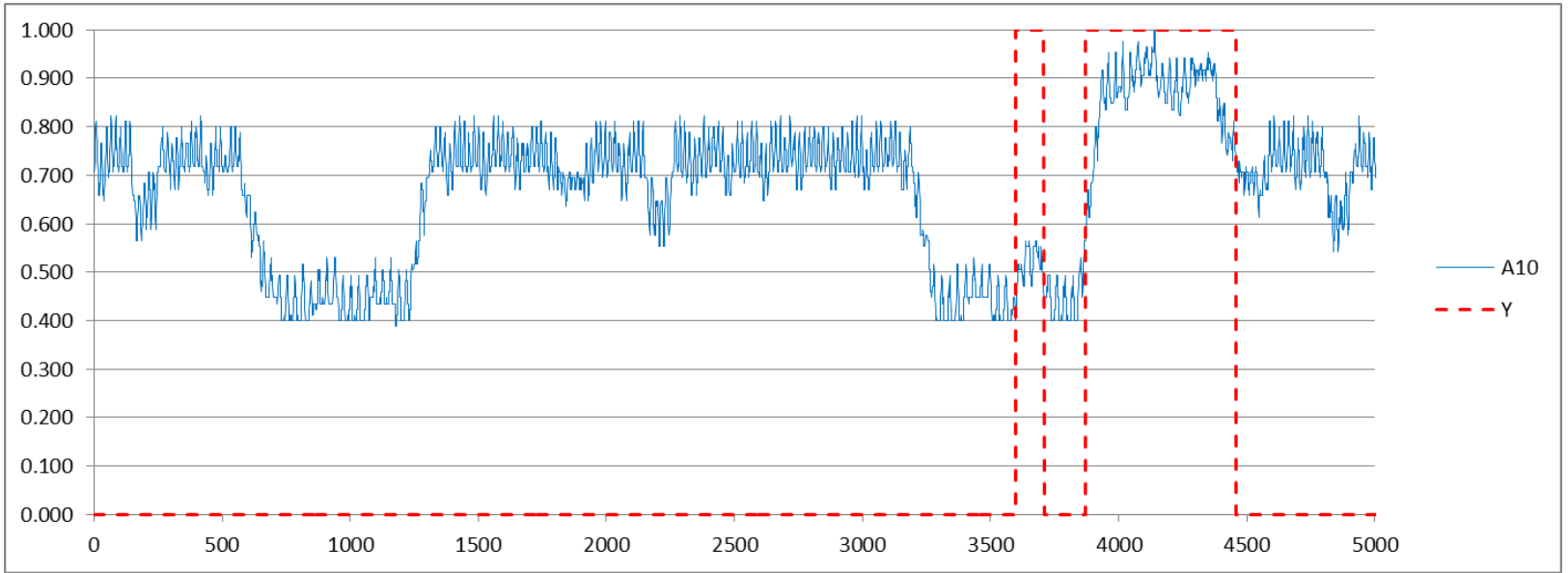

Cenário 04 - Atributo A10 
$\beta=20$

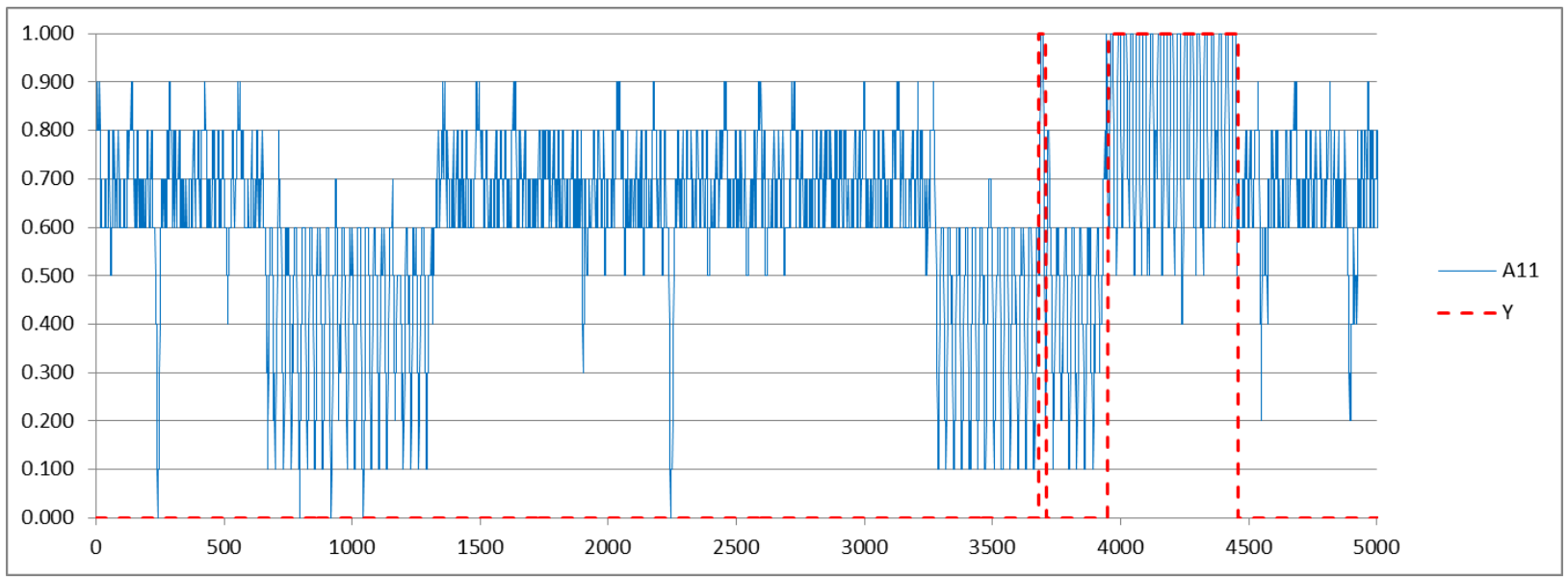

$\beta=50$

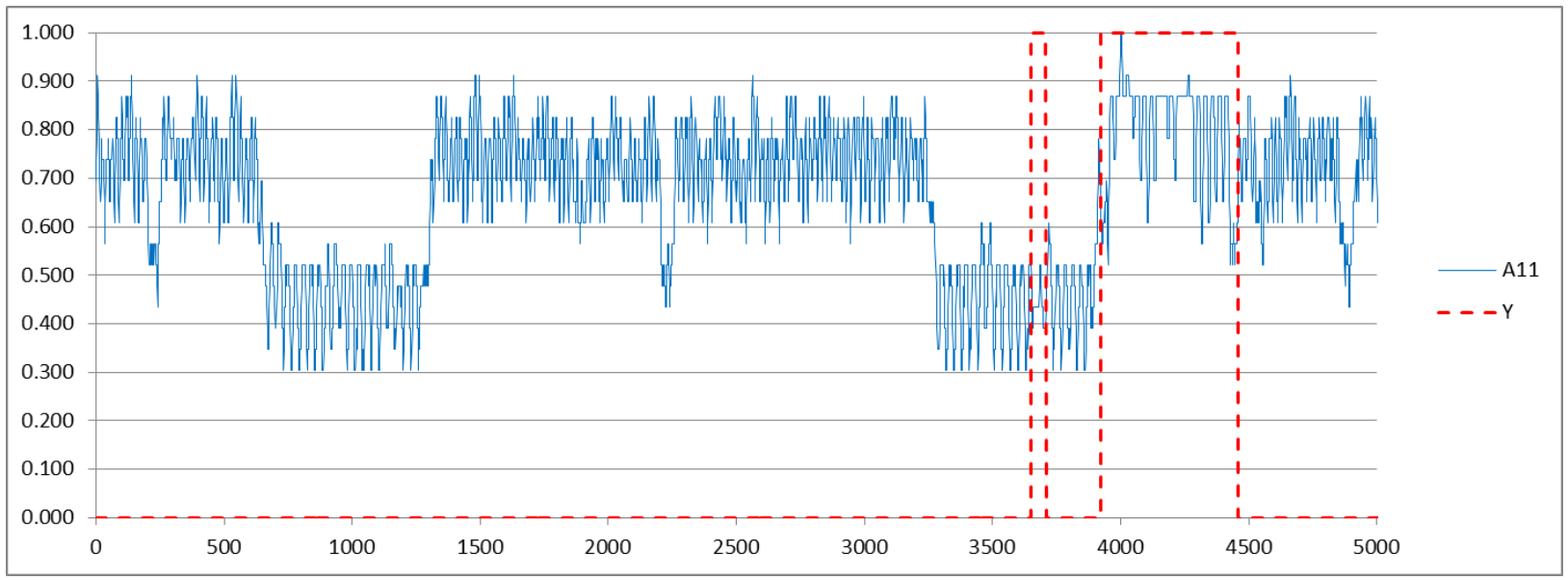

$\beta=100$

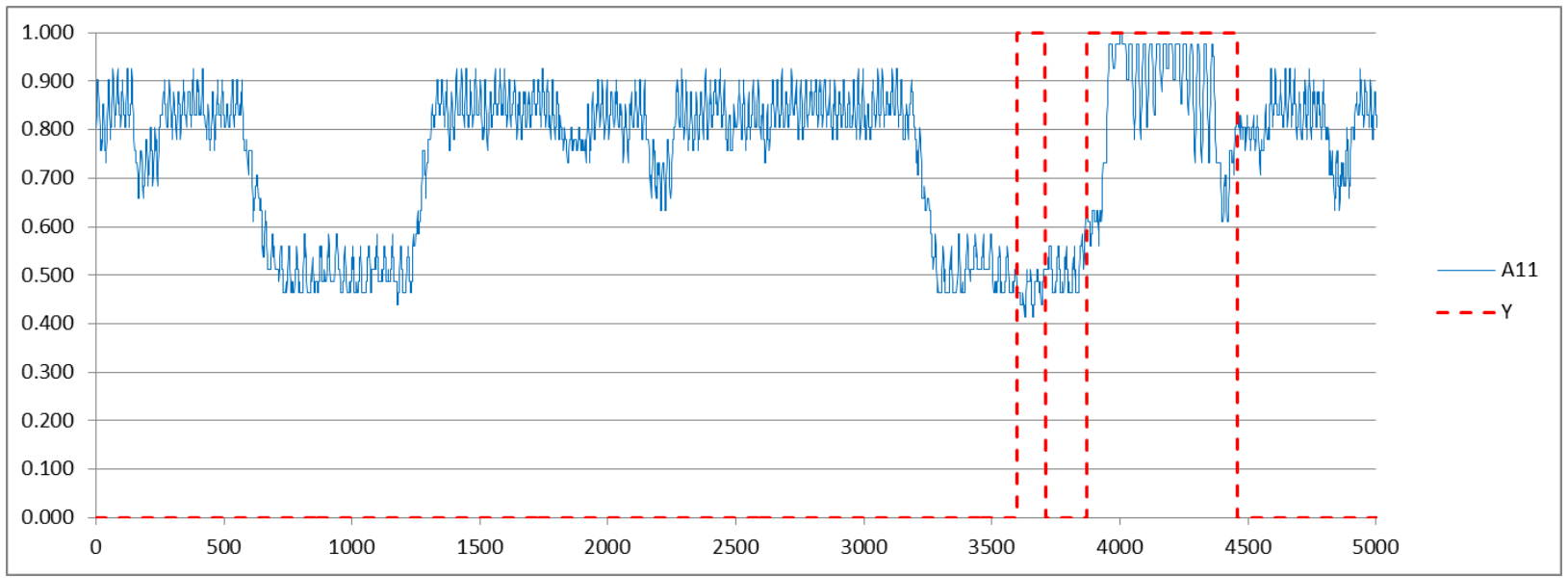

Cenário 04 - Atributo A11 
$\beta=20$

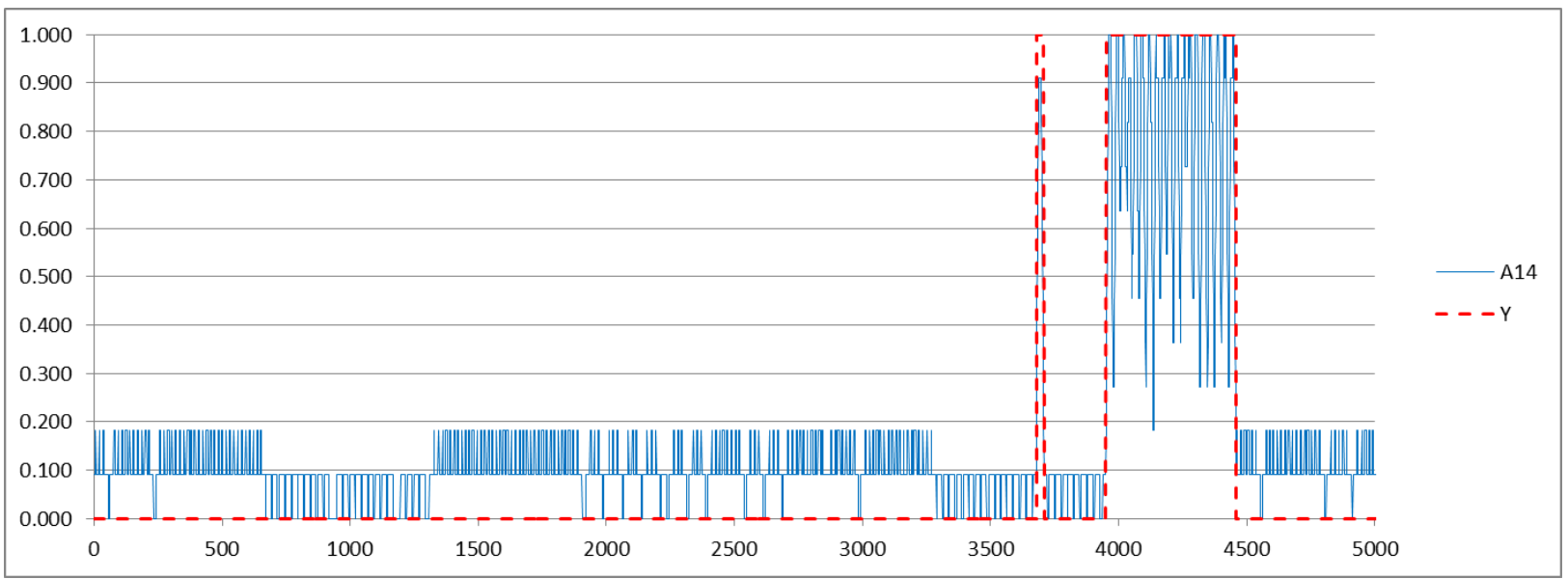

$\beta=50$

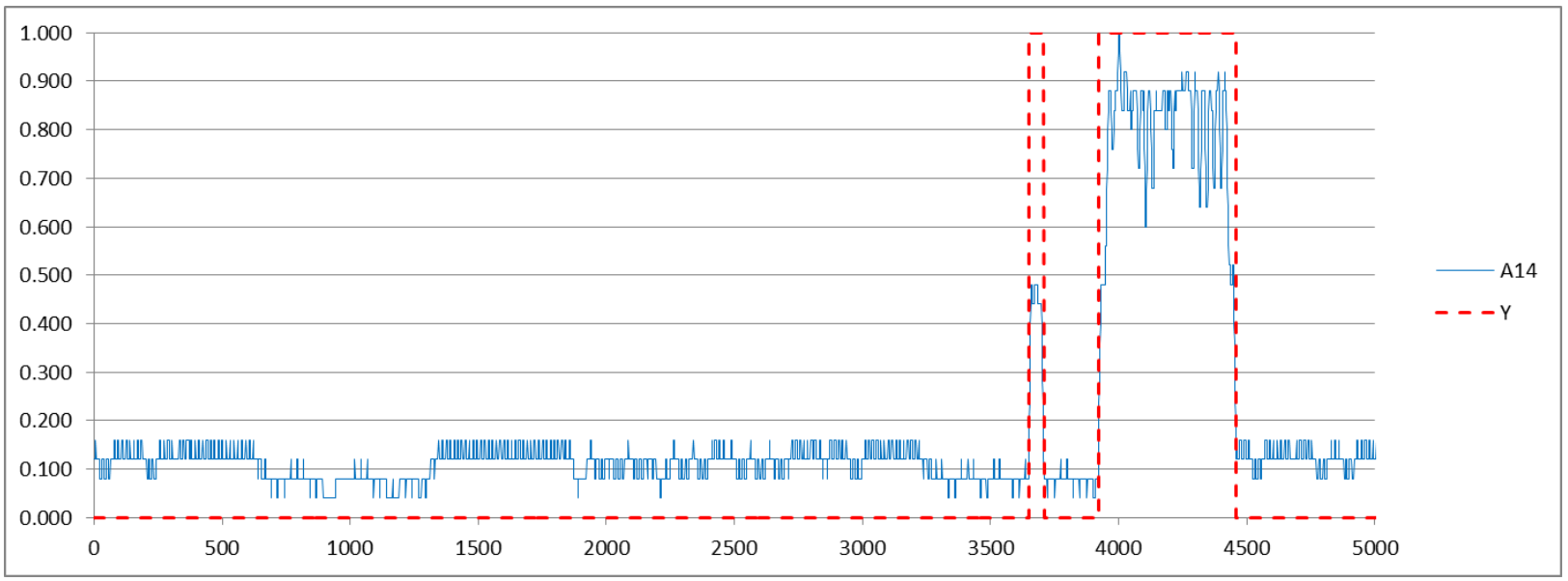

$\beta=100$

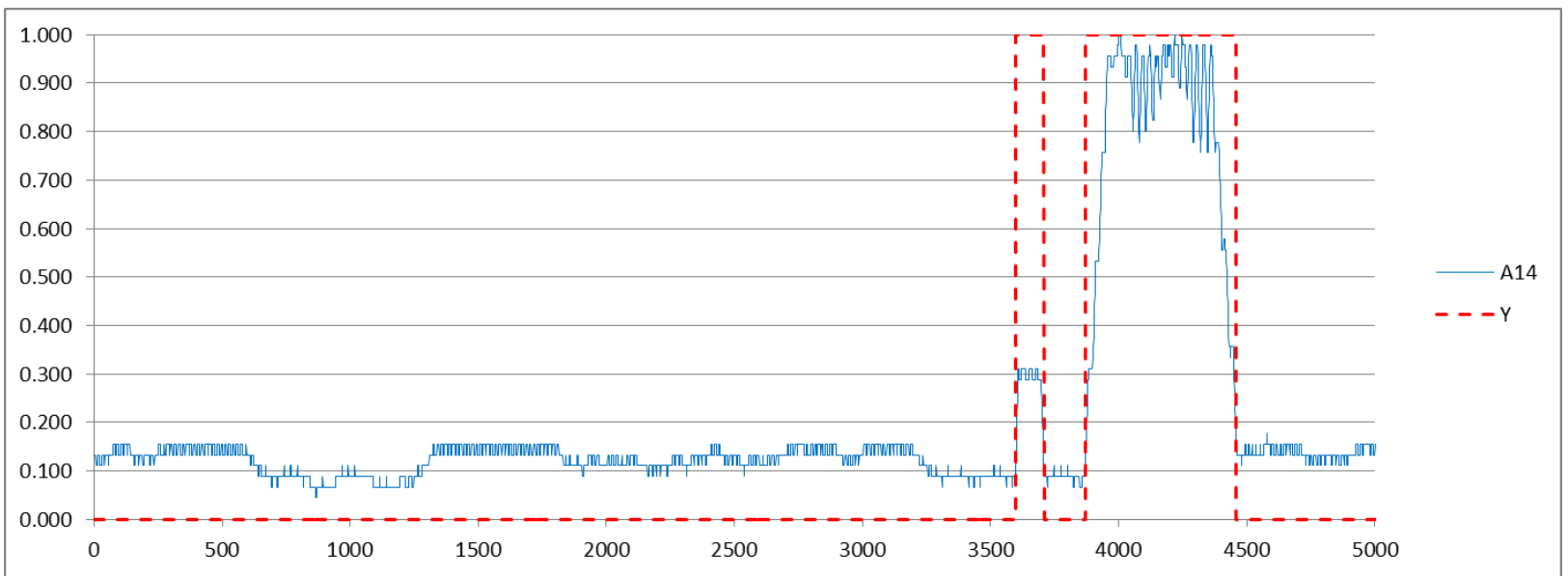

Cenário 04 - Atributo A14 
$\beta=20$

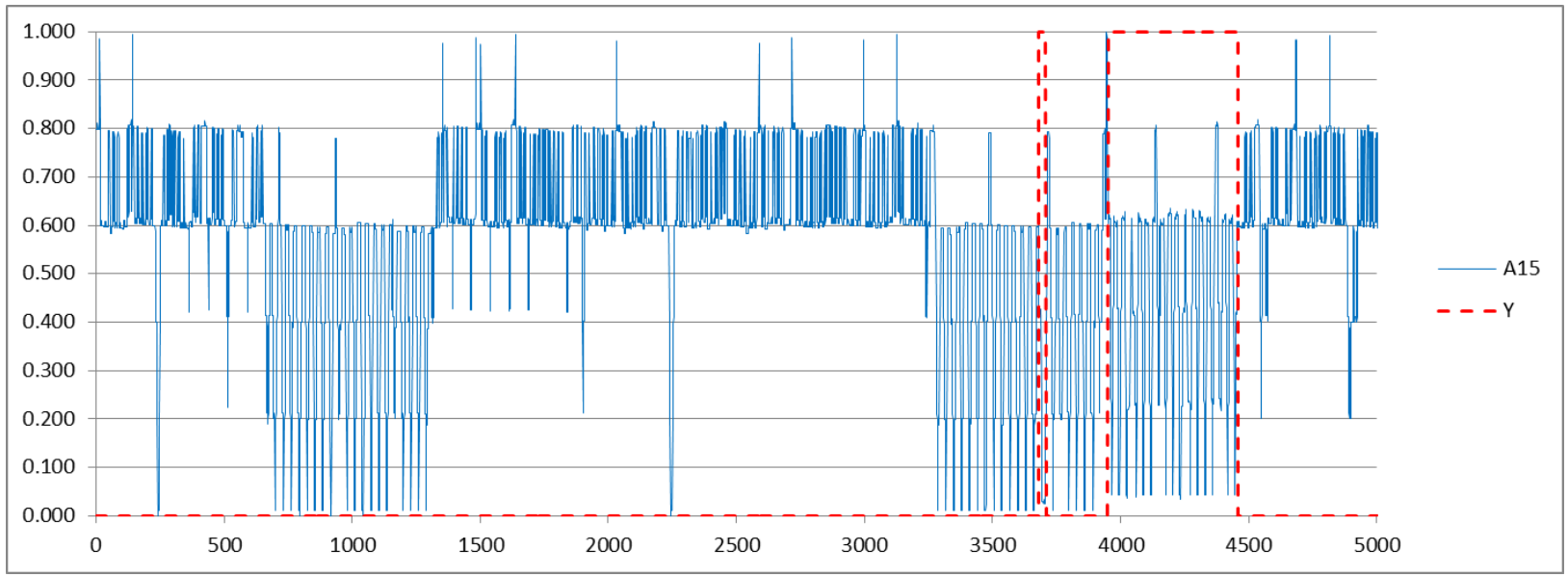

$\beta=50$

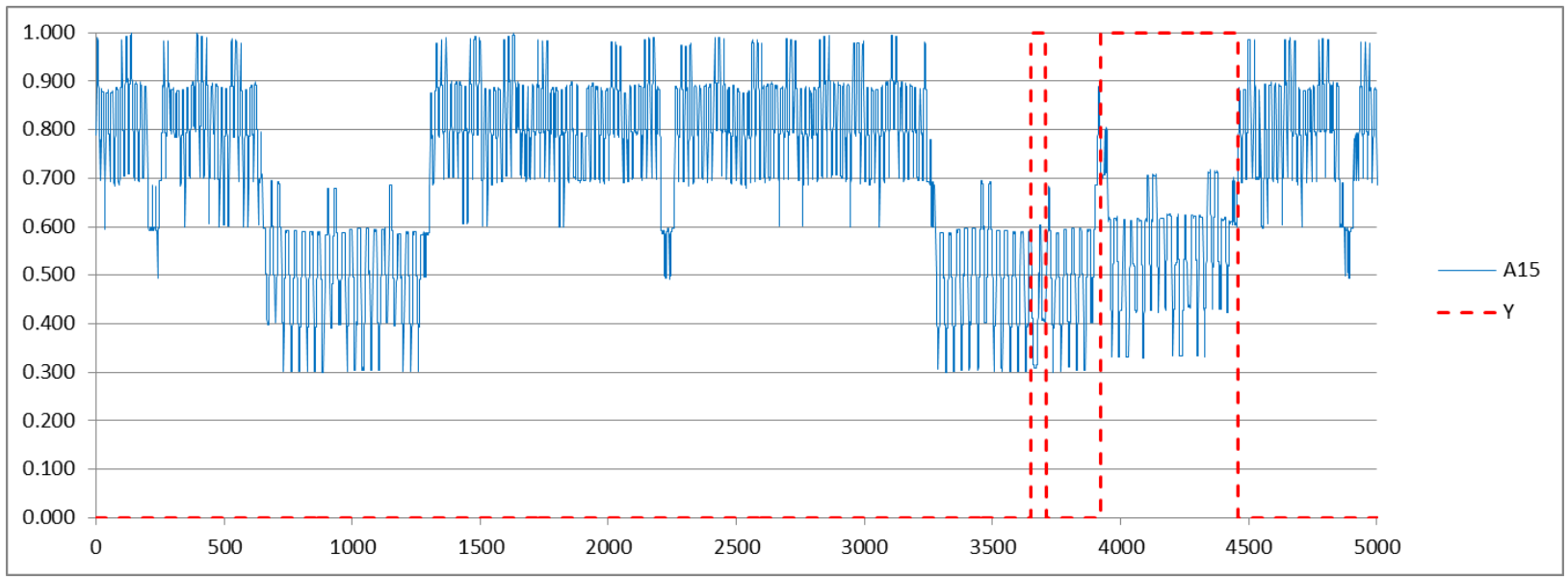

$\beta=100$

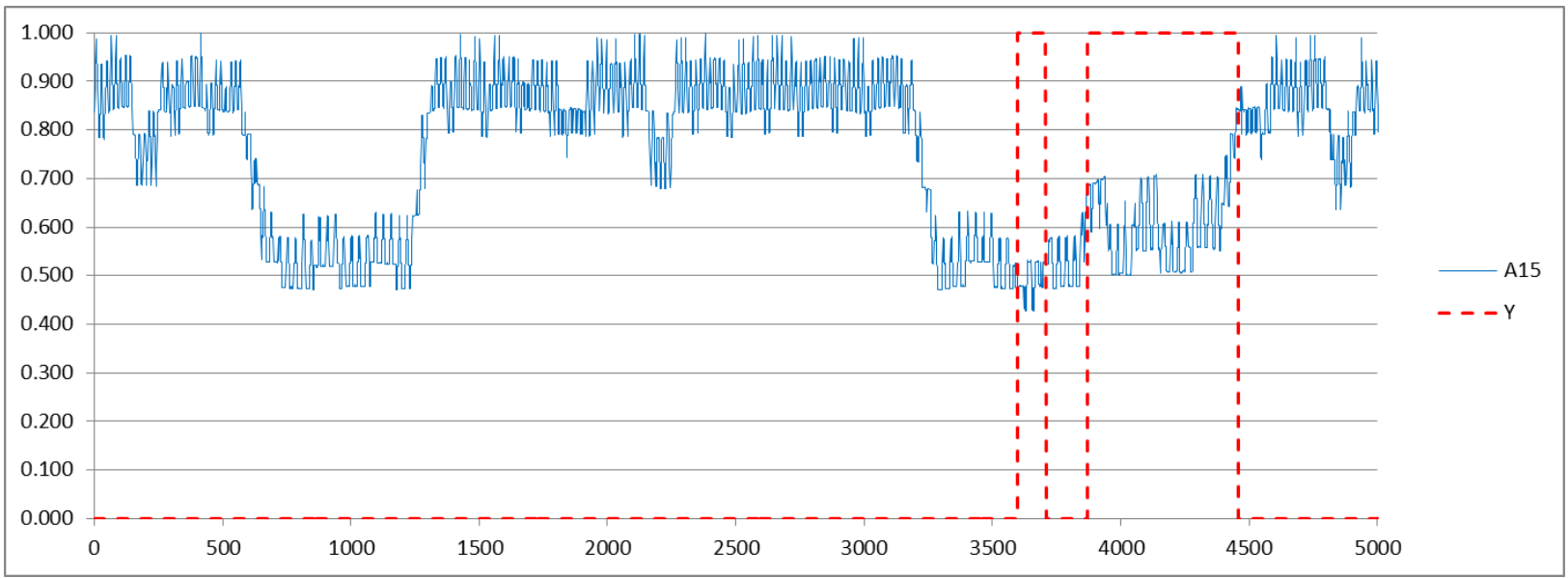

Cenário 04 - Atributo A15 
$\beta=20$

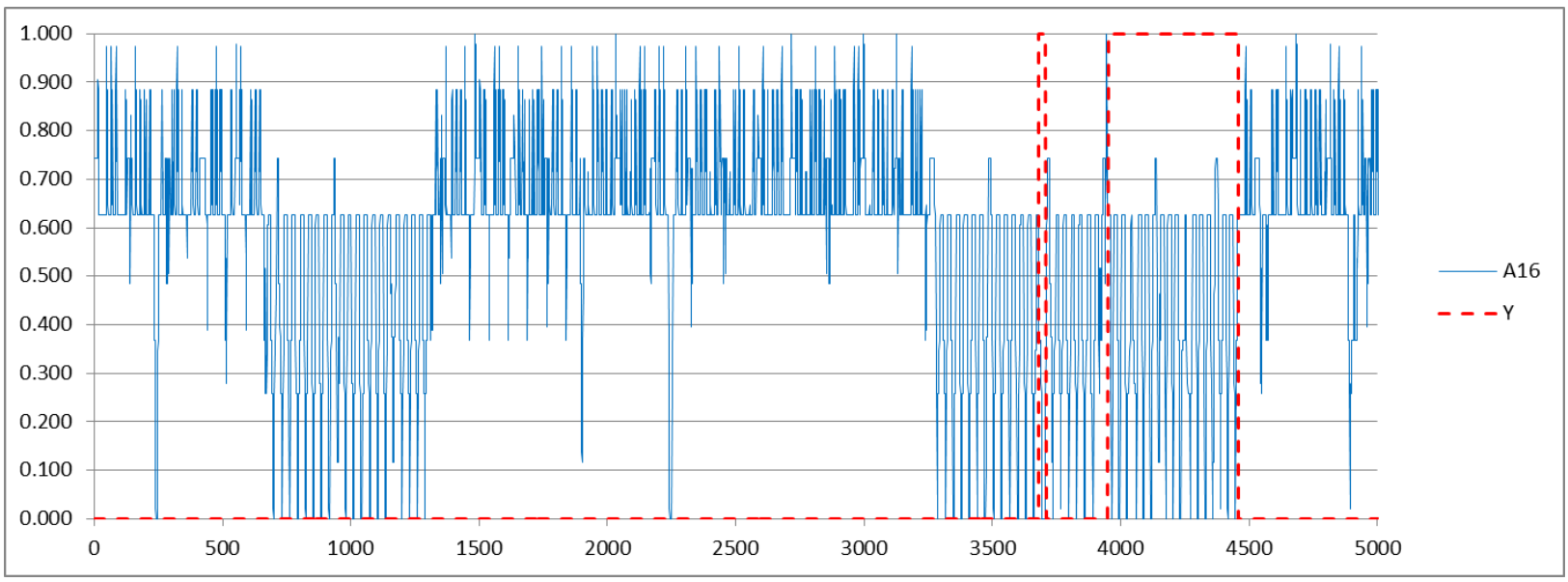

$\beta=50$

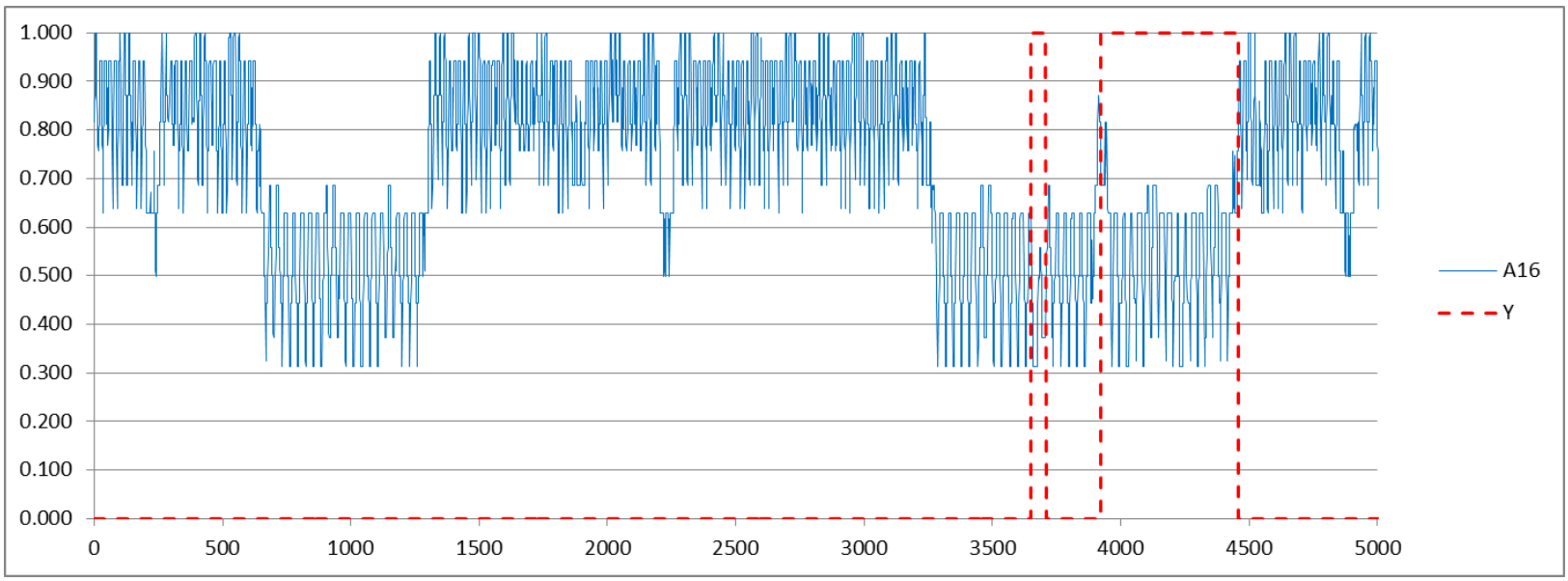

$\beta=100$

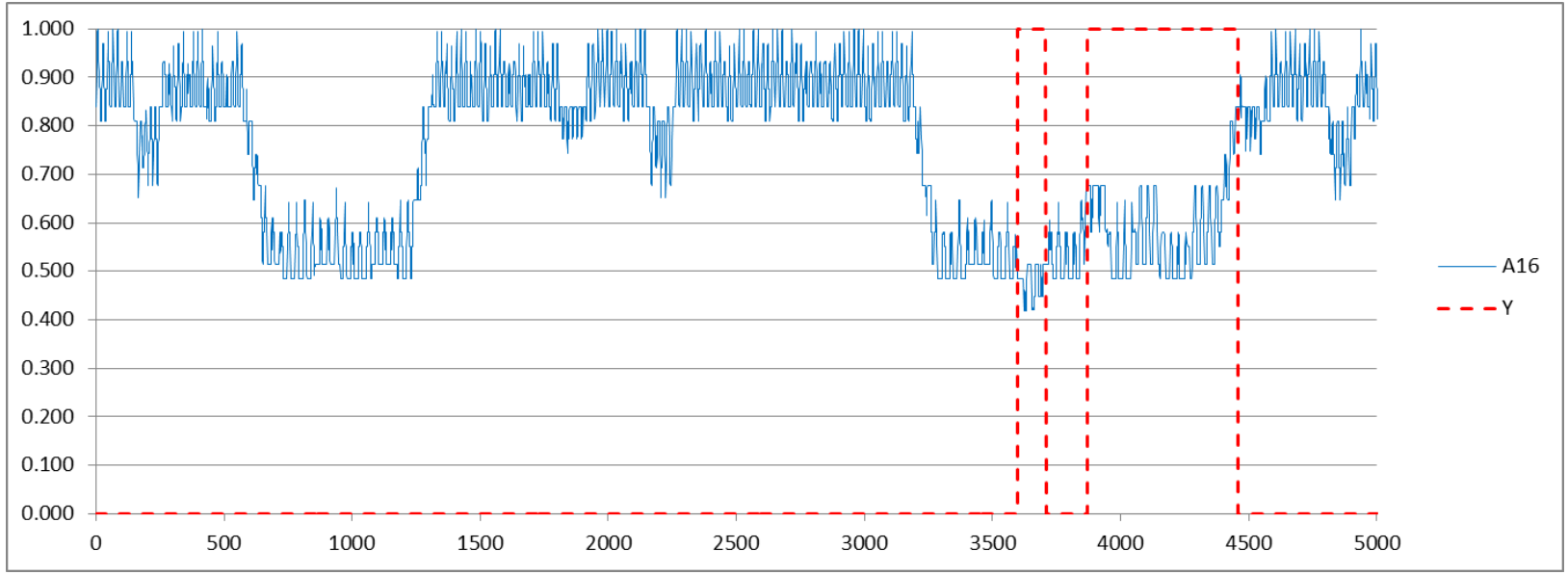

Cenário 04 - Atributo A16 
$\beta=20$

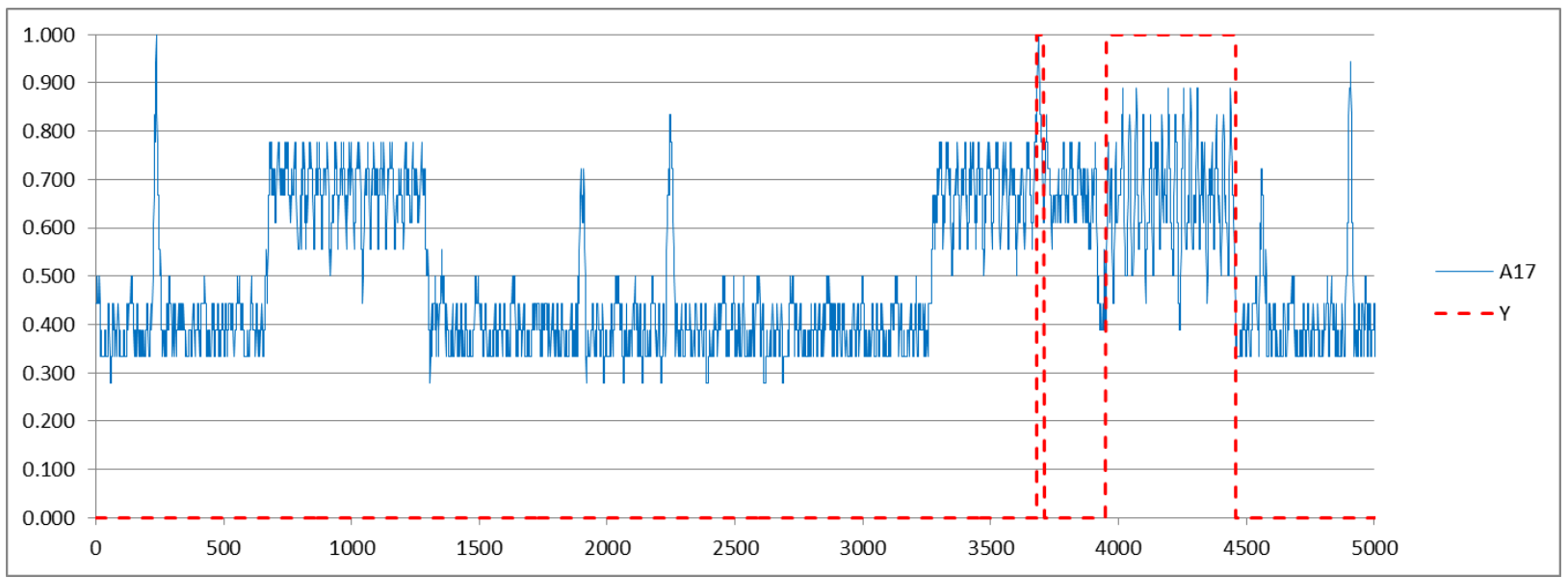

$\beta=50$

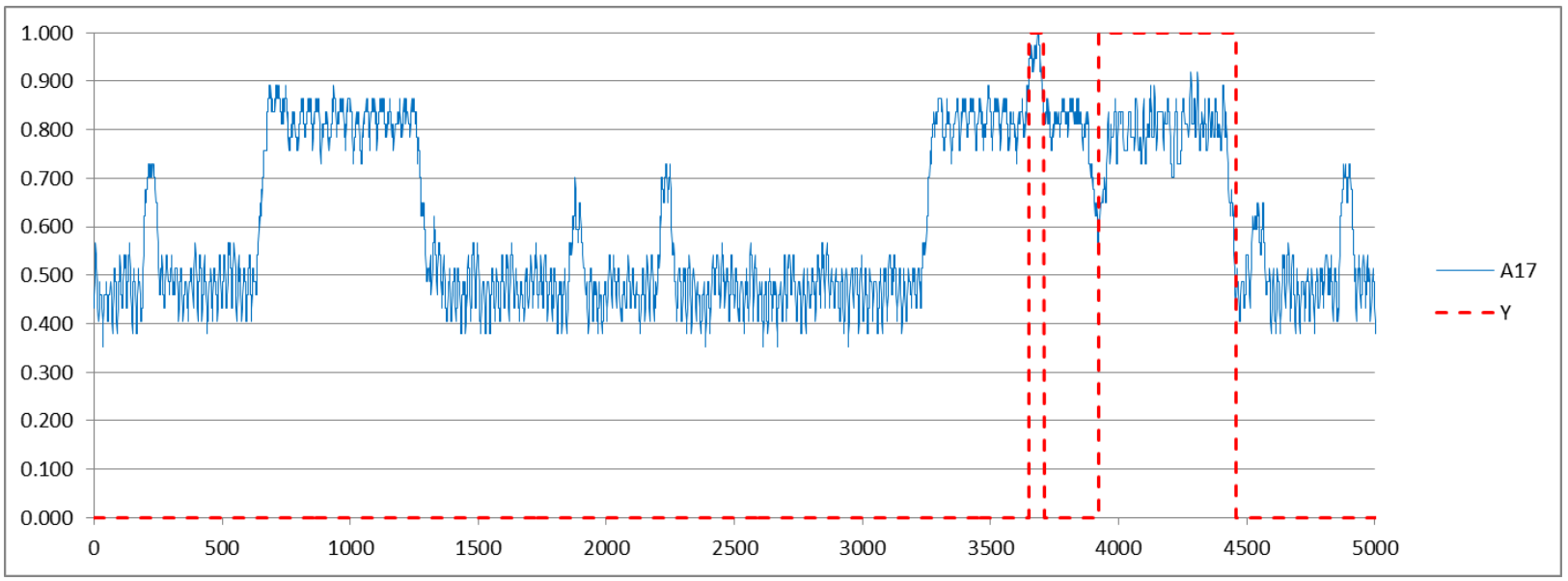

$\beta=100$

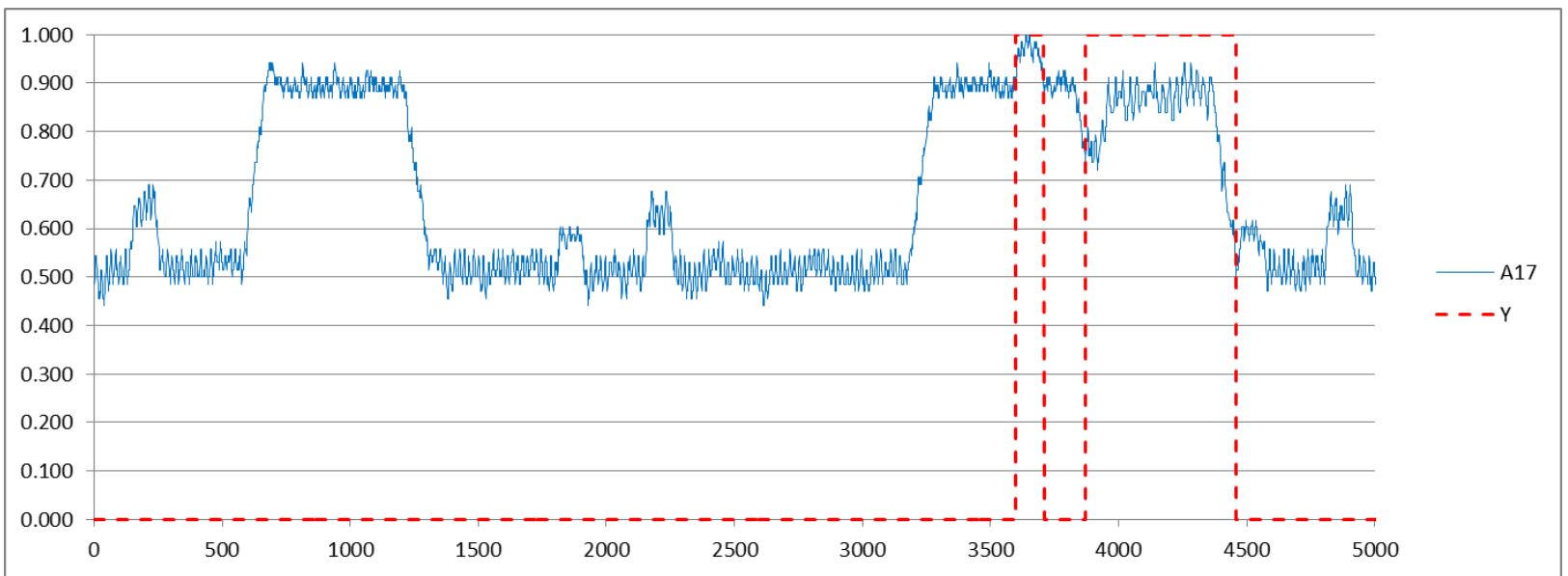

Cenário 04 - Atributo A17 
$\beta=20$

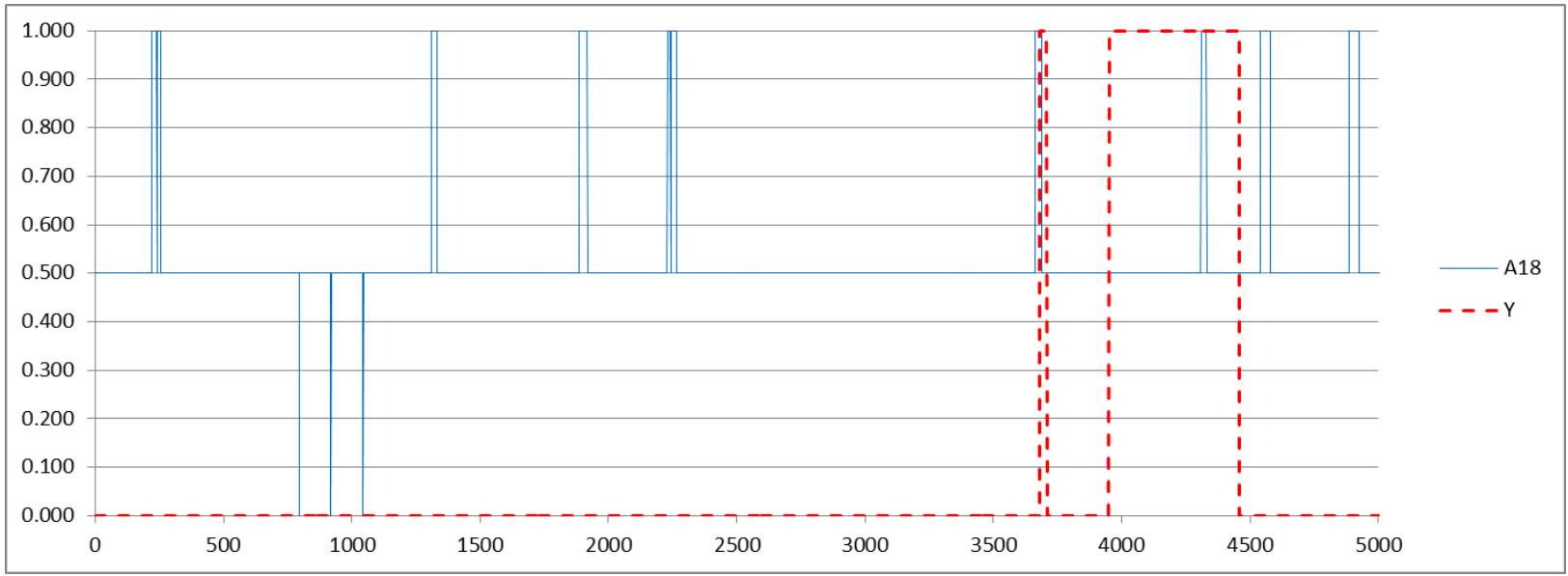

$\beta=50$

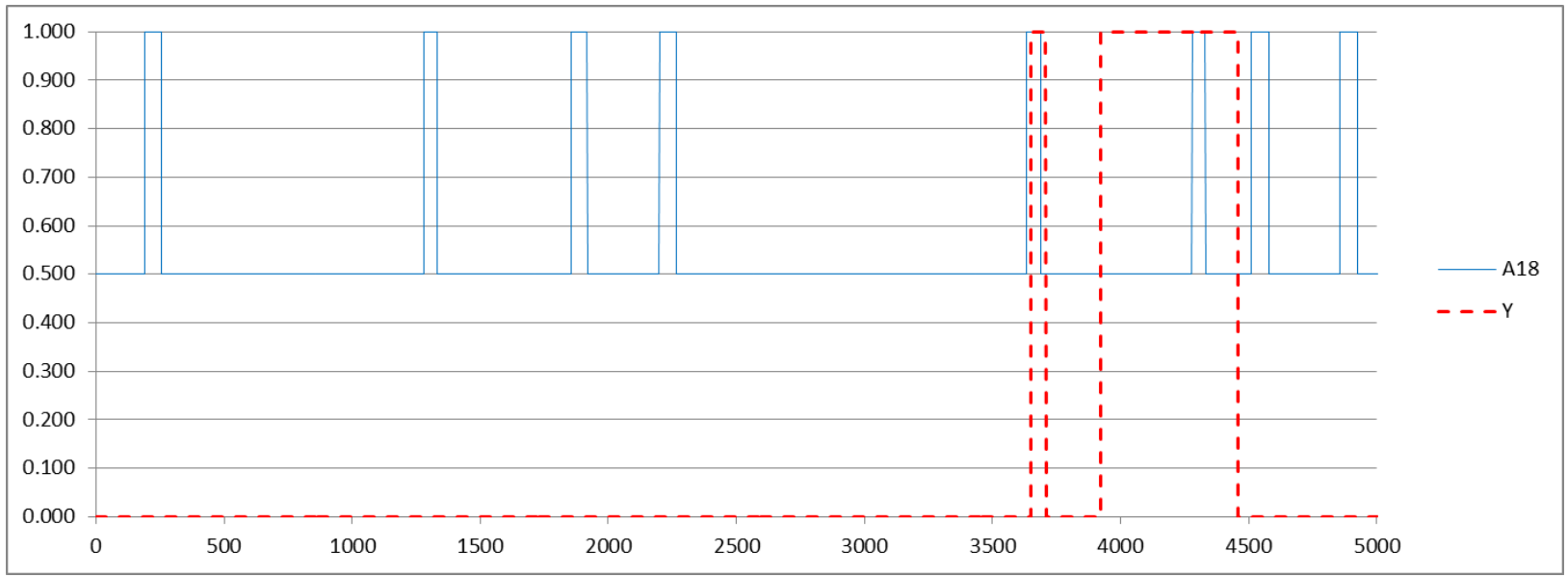

$\beta=100$

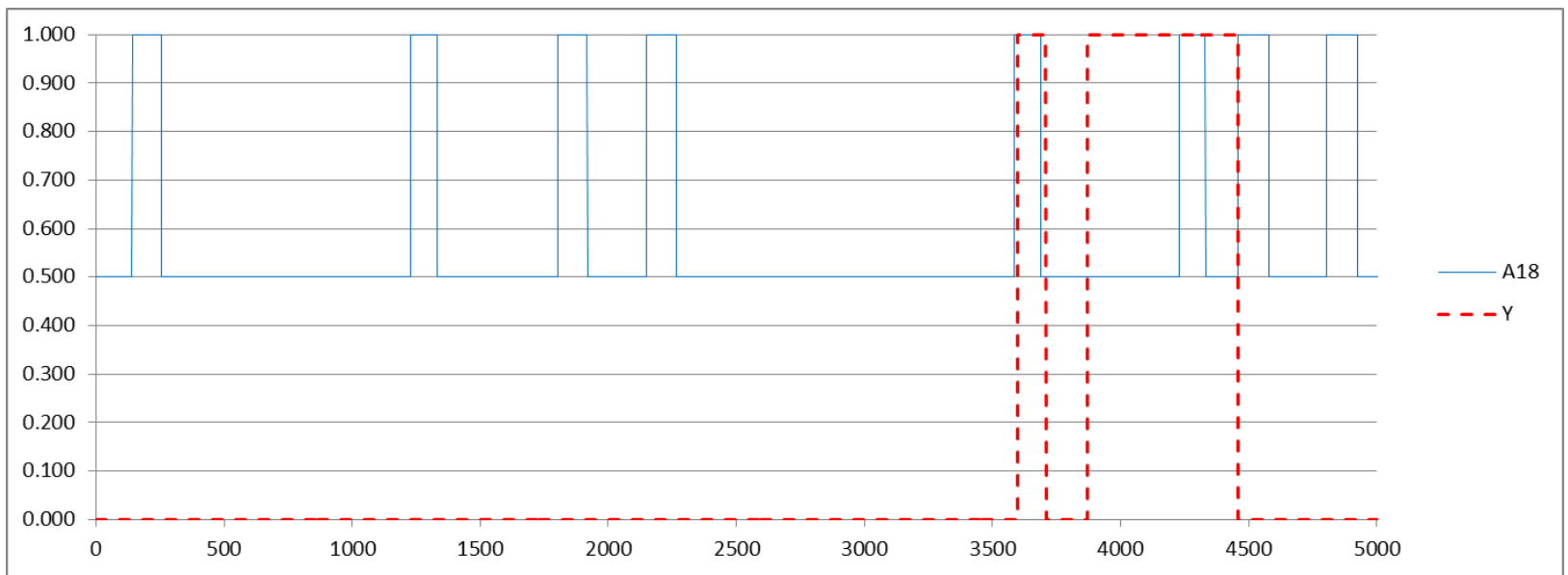

Cenário 04 - Atributo A18 
$\beta=20$

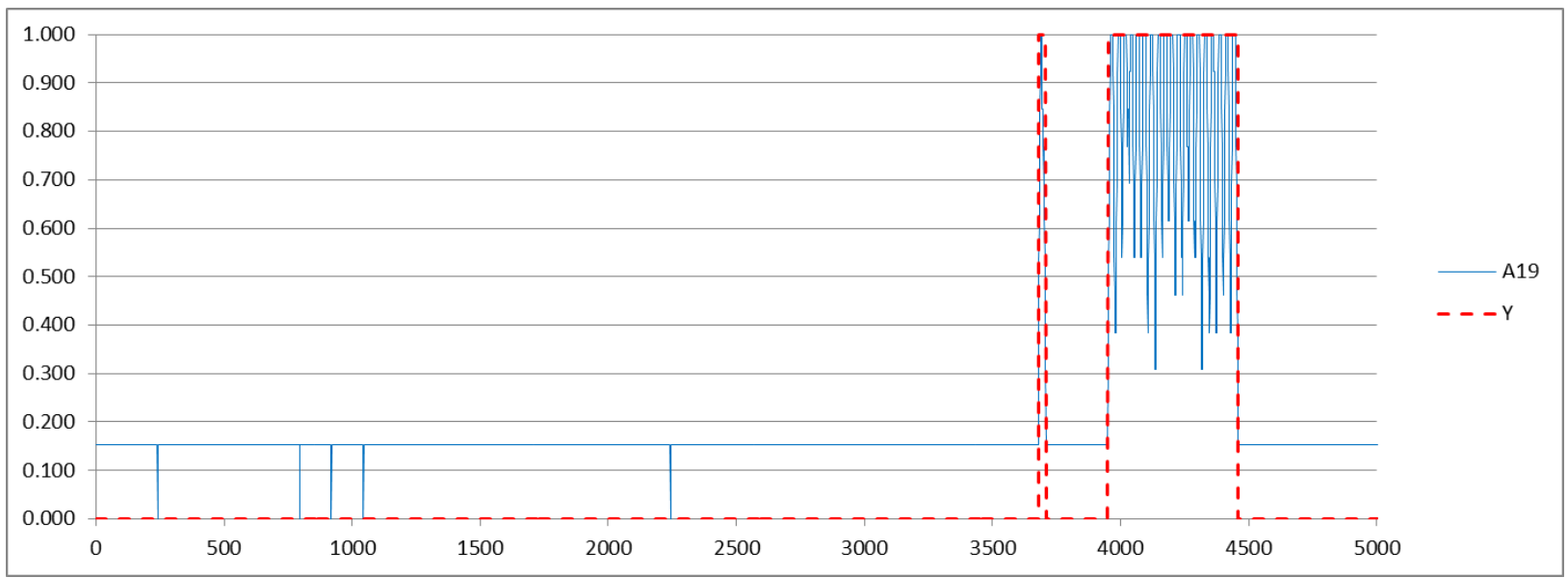

$\beta=50$

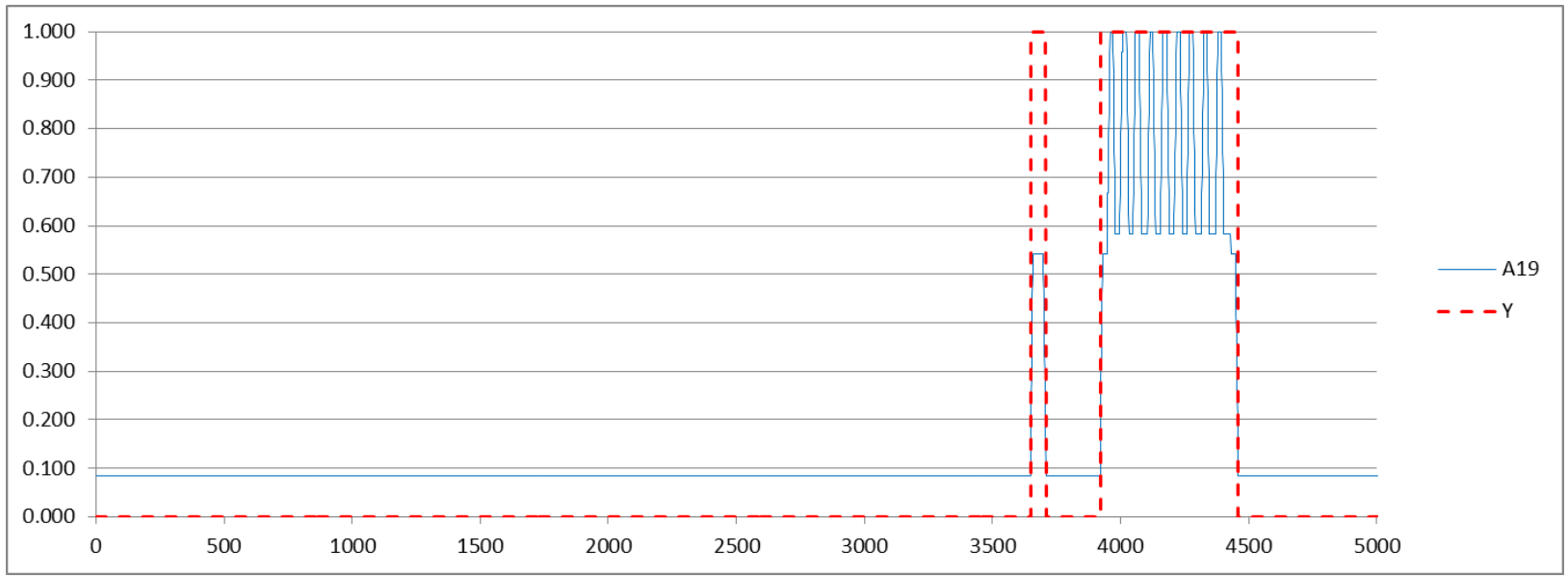

$\beta=100$

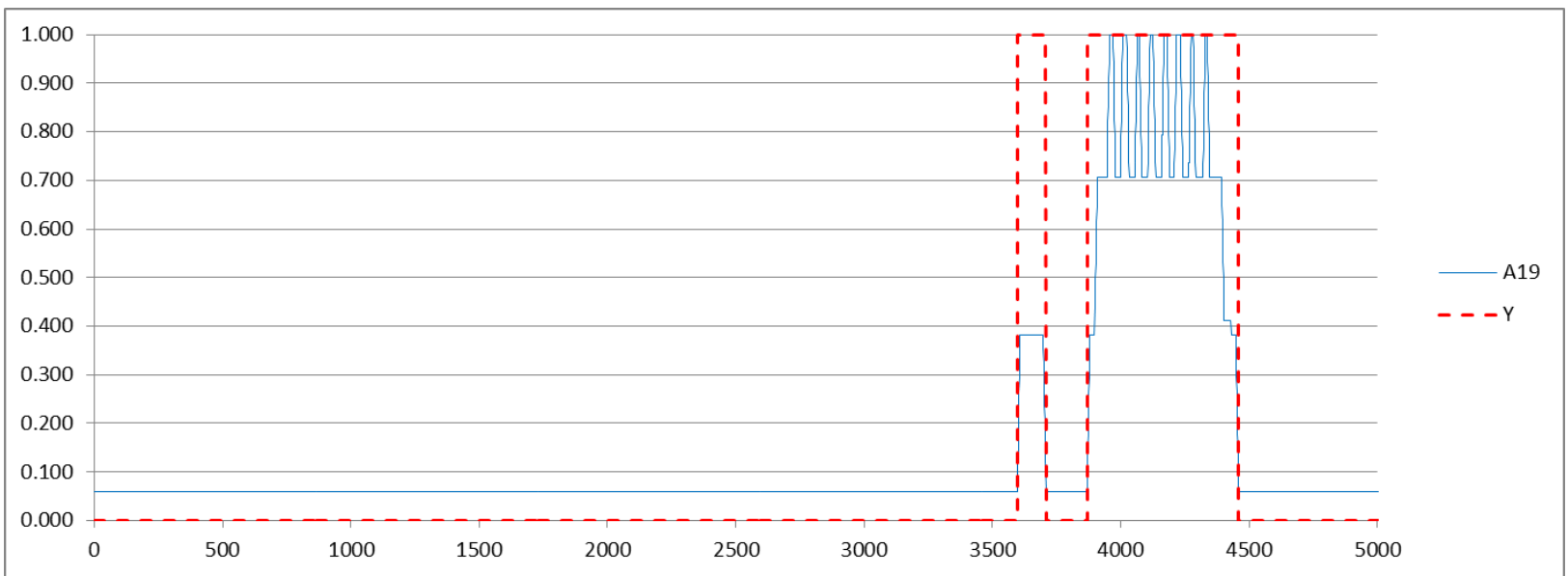

Cenário 04 - Atributo A19 
$\beta=20$

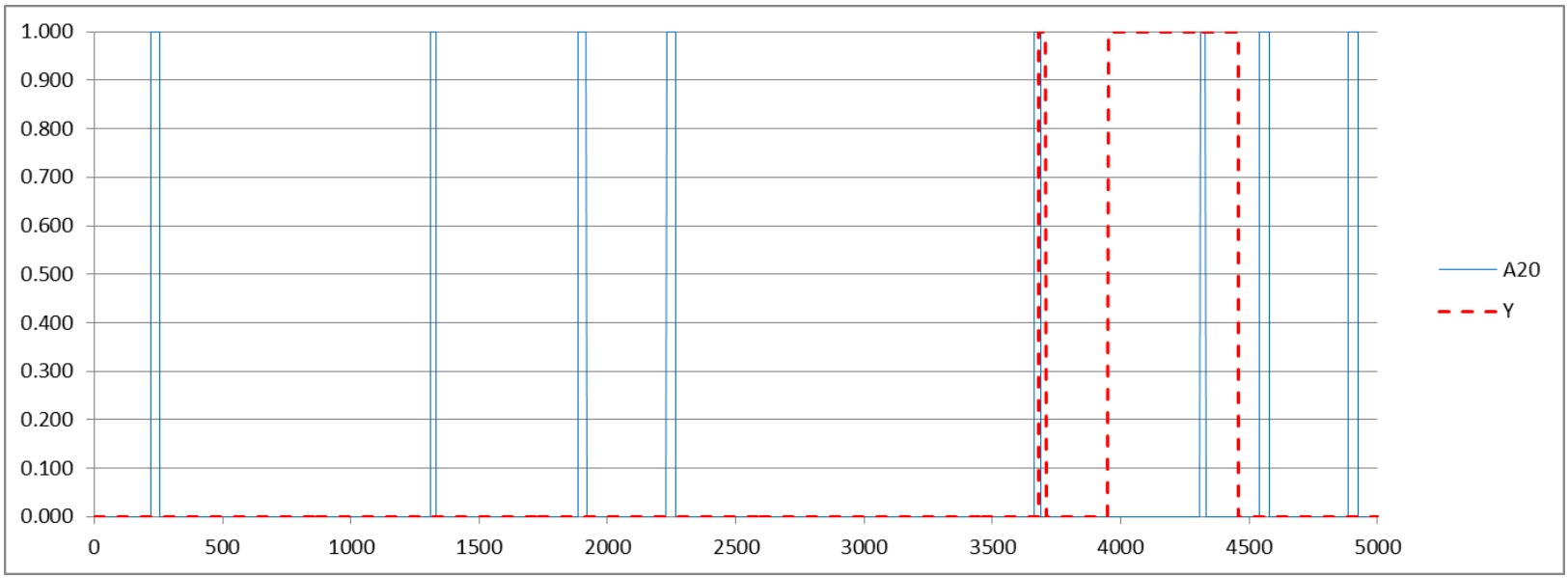

$\beta=50$

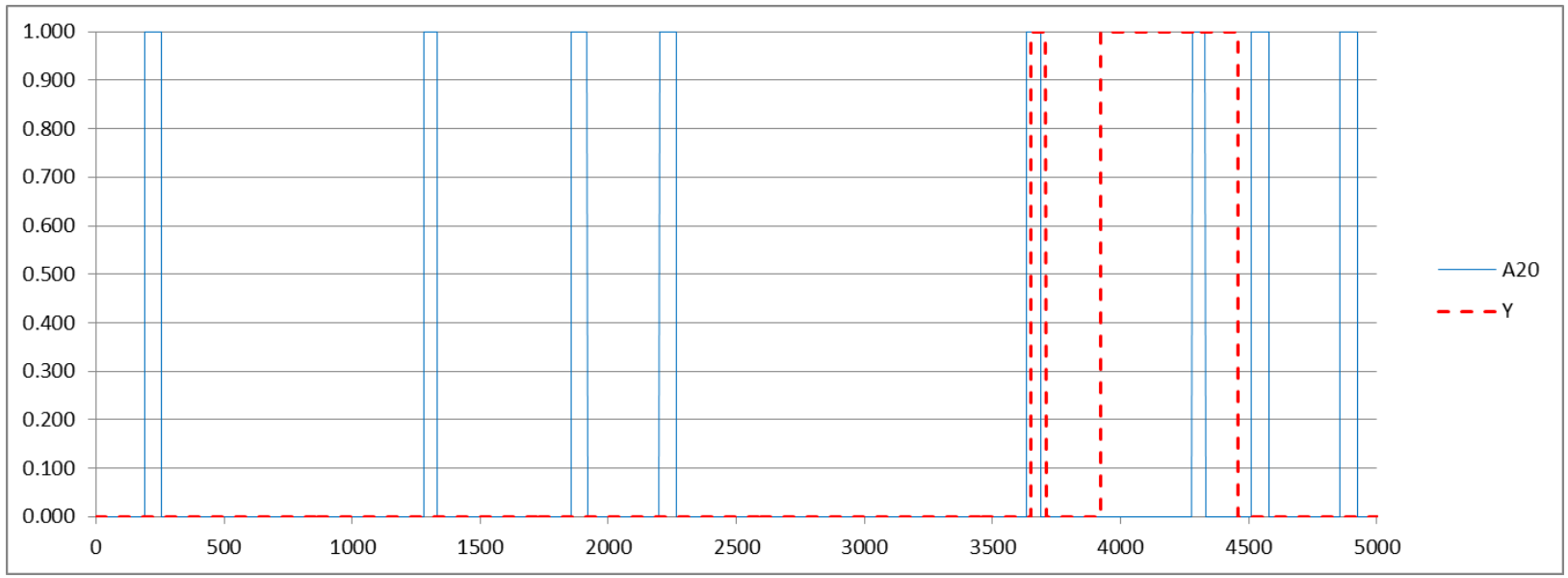

$\beta=100$

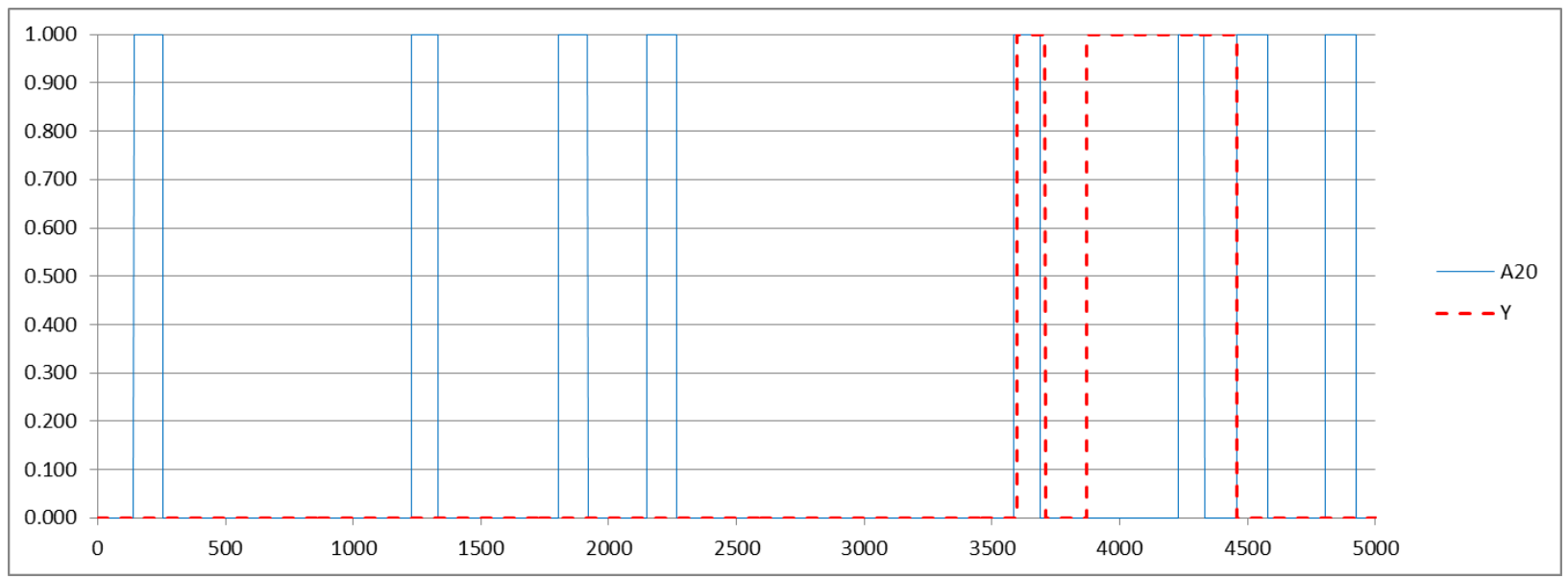

Cenário 04 - Atributo A20 